\title{
Walter Benjamin and Kitsch Politics in the Phantasmagorical Age
}

\author{
by
}

Ayşegül Ergül

A thesis submitted to the Faculty of Graduate and Postdoctoral Affairs in partial fulfillment of the requirements for the degree of Doctor of Philosophy

in

Political Science

Carleton University

Ottawa, Ontario

(C) 2016, Ayşegül Ergül 


\begin{abstract}
In this dissertation I explore the relationship between politics, aesthetics, culture and technology by (re)thinking and (re)conceptualizing the concept of kitsch as a theoretical construct in order to investigate the dream-worlds of Europe which sprang at the intersection of liberalism, social democracy and capitalism. I argue that the unexplored potentialities of kitsch, as a concept, reside in the analysis of the dream-worlds, which have been occupying the social and political imaginaries of Western individuals, communities and institutions since the disenchantment of the world. My methodological approach is built on Benjamin's notion of historical materialism. Thus, I engage with the historical object(s) (e.g., arcades, fashion, technological reproductions etc.) not as “object(s) of experience" but as a "participant(s) in historical experience" (Caygill 2004, 90). Challenging the progressive notion of history, I argue that within the objective impenetrability of commodity fetishism a "sur-real" world of fetishized images - that is, kitsch - emerges, alienated from the individual and the collective, yet constituting and shaping them. By mapping out the implications of this "sur-real" world on "the political," the collective (un)conscious and action, I conclude that alternative politics could arise from the unsettling interpretations of the reified and symbolic expressions of this same "sur-real" world, paving a path for new political imaginaries.
\end{abstract}


Dedicated to my dearest friend Hilal Özçetin 


\section{Acknowledgments}

Firstly, I would like to express my sincere gratitude to my supervisor Dr. Tom Darby. His agreement to take me on after the unexpected retirement of my previous supervisor was one of the greatest things that happened to me. His guidance made me find my way out of the dark and deep hole I had fallen into for a very long time. His unwavering support and belief in my intellectual abilities helped me to rediscover myself. I could not have imagined the completion of this dissertation without his supervision and mentorship. I also would like to thank Professor Peter Swan for his unending support and confidence in me, and Dr. Hans-Martin Jaeger for his insightful comments and questions on my chapters and sincere interest in my thesis.

I would like to thank my family for never losing their faith in me, and supporting me unconditionally. Last, but not least, I would like to thank my husband who never stopped believing in me even when I lost all belief in myself, who held me for hours when I was in distress, whose unwavering support and love guided me to the completion of my dissertation. I cannot thank you enough my dearest husband. I love you... 


\section{Table of Contents}

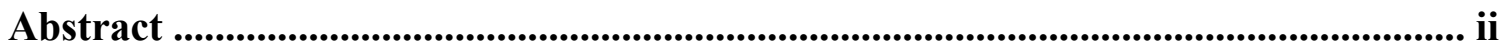

Acknowledgements ............................................................................................................ iv

Table of Contents ........................................................................................................................... v

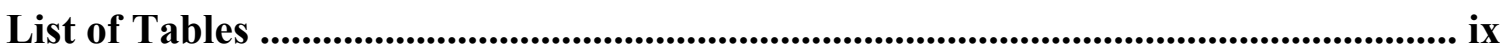

1 Chapter I: Introduction ...................................................................................................... 1

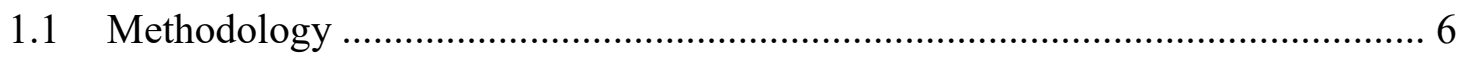

1.1.1 Dialectical Image ............................................................................... 10

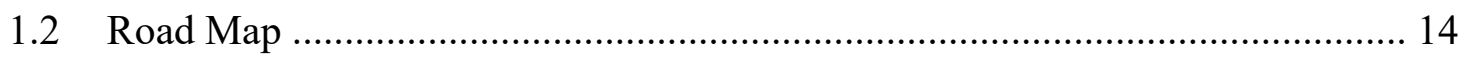

1.2.1 Chapter II: The Concept of Kitsch ......................................................... 14

1.2.2 Chapter III: Capitalism, Culture and Technology .................................. 16

1.2.3 Chapter IV: The Crisis of Experience ………………............................... 17

1.2.4 Chapter V: Politics of Phantasmagoria: Kitsch Politics ......................... 19

2 Chapter II: The Concept of Kitsch .............................................................................. 24

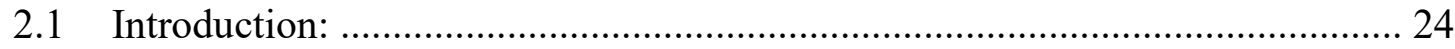

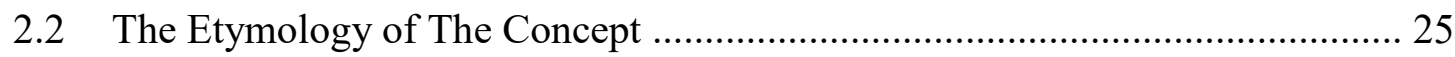

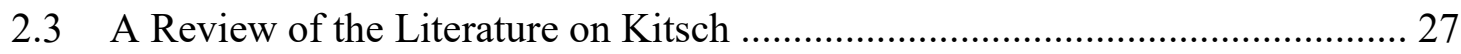

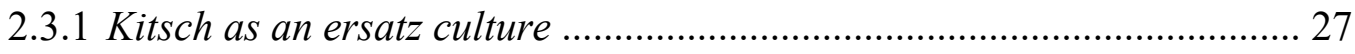

2.3.2 Kitsch as a philosophical and existential phenomenon ........................... 31

2.3.3 Kitsch as "travestied aesthetic consciousness" ....................................... 35

2.3.4 Kitsch as a technique of political manipulation ....................................... 41

2.3.5 Kitsch as an aesthetic category .............................................................. 43

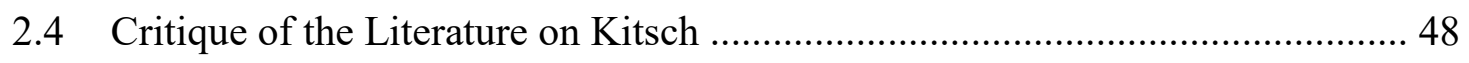




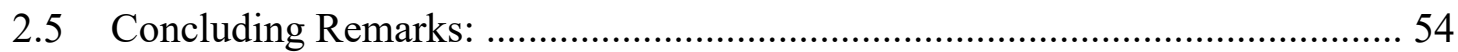

3 Chapter III: Capitalism, Culture and Technology ………….................................... 57

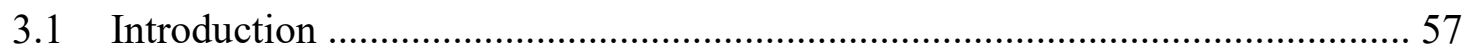

3.2 Commodity Form, Commodity Fetishism ……………………….................. 59

3.2.1 Commodity: Use-Value and Exchange Value ........................................... 61

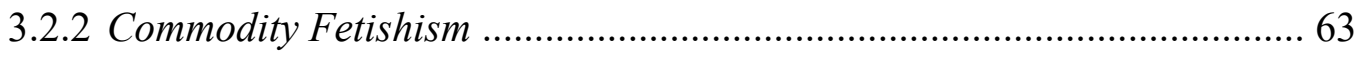

3.3 Reification and the Commodity Analysis of Art ……........................................ 65

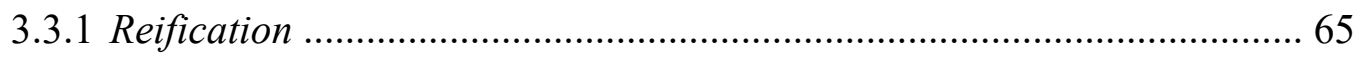

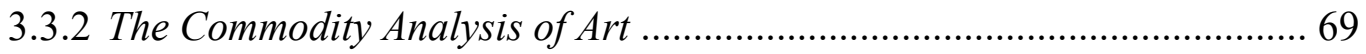

3.3.3 Walter Benjamin: Critique of Ideology-Critique ……………….............. 74

3.3.4 The Aura and the Demise of Auratic Art .............................................. 77

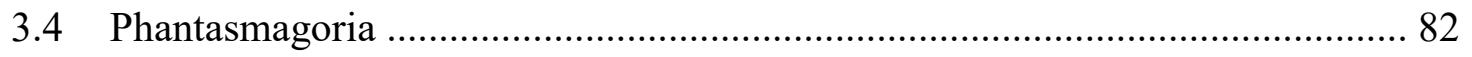

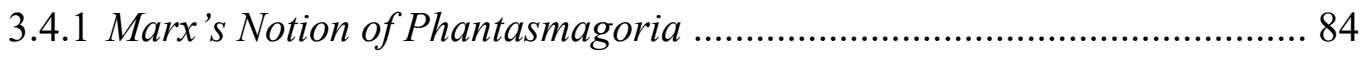

3.4.2 Benjamin's Notion of Phantasmagoria ................................................... 86

3.4.3 First and Second Order Phantasmagoria ............................................. 91

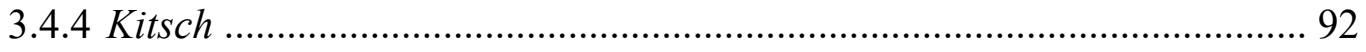

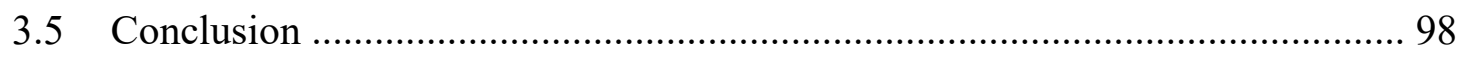

4 Chapter IV: The Crisis of Experience …………........................................................... 102

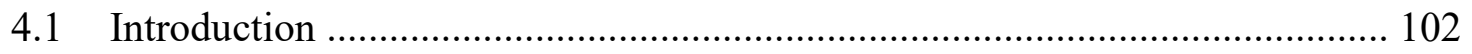

4.2 The Transformation of the Forms of Communication ................................... 107

4.2.1 From Storytelling to the Novel .............................................................. 107

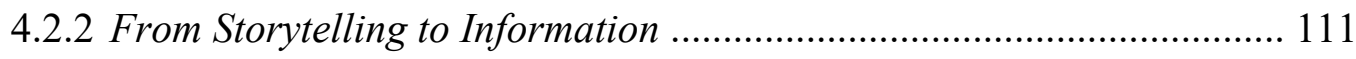

4.3 The Advent of Shock: Memory and Experience ………................................. 116 
4.3.1 Voluntary and Involuntary Memory …………………..................... 118

4.3.2 Memory as Gedächtnis and Memory as Erinnerung ............................ 122

4.3.3 The Transformation of the Mimetic Faculty ........................................ 127

4.4 Auratic Perception versus Kitsch Perception .................................................. 134

4.4.1 Spatial-Temporal Categories ............................................................ 138

4.4.2 The Object's Mode of Being in Relation to Others ................................ 140

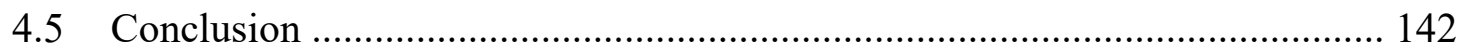

5 Chapter V: Politics of Phantasmagoria: Kitsch Politics ........................................ 145

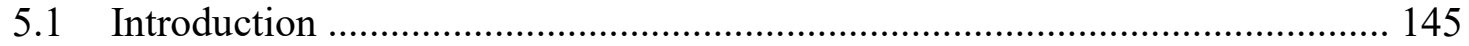

5.2 The Transformation of the Relationship between the Public and Private

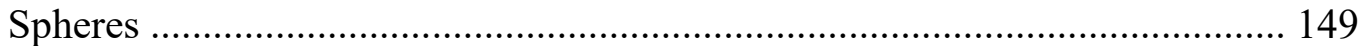

5.2.1 The Public and Private Spheres ......................................................... 149

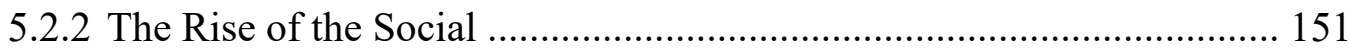

5.2.3 The Rise of the Interior as the Private Realm ....................................... 154

5.2.4 The Liquidation of the Domestic Interior ............................................... 162

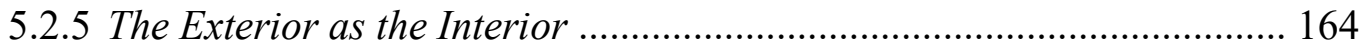

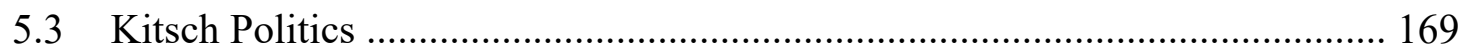

5.3.1 Surrealism \& Style: Metaphor \& Image ............................................... 169

5.3.2 Politics: Metaphor and Image ………………………........................ 172

5.3.3 Dream Agora: Metaphor and Image ................................................. 175

5.3.4 Phantasmagoria and the Public Sphere ………………........................ 177

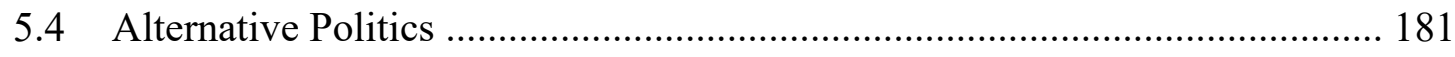

5.4.1 Now-Time [Jetztzeit]: Messianic Time and Non-Messianic Politics ..... 184 


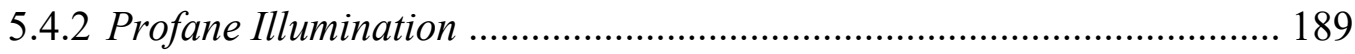

5.4.3 Image-Space and Body-Space ......................................................... 192

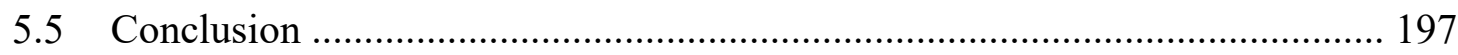

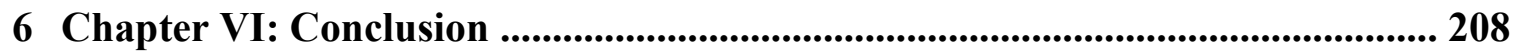

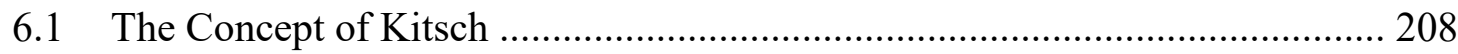

6.2 Capitalism, Culture and Technology ....................................................... 212

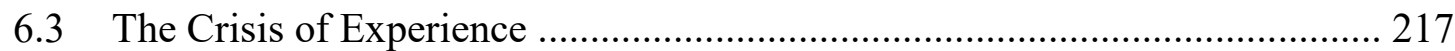

6.4 Politics of Phantasmagoria: Kitsch Politics .............................................. 225

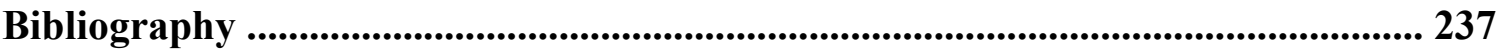




\section{List of Tables}

Table 1 First and Second Order Phantasmagoria.............................. 92 


\section{Chapter I: Introduction}

In the nineteenth century, the foundation of the technological age had been laid out; capitalism was solidified within the social relations of production by focusing its energies on the development of a system of mass production. Half a century later, the transformations that took place in the infrastructure started to find their cultural expression, leading to changes both in the mode of existence of human collectivities and the collective organization of human perception. The rise of the masses and their desire to get closer to things, coupled with the ability of technological reproduction to respond to such desire, prompted a shift in the medium of perception away from storytelling (and listening) towards a new form of communication - namely, information - which was based on "prompt verifiability" rather than narration (W. Benjamin 2002e; W. Benjamin 1968). The changes in the way in which human perception was organized signaled one of the characteristic paradoxes of modernity: the shattering of tradition and the potential renewal of humanity (W. Benjamin 2002e).

In reference to this paradox, Walter Benjamin diagnoses the crisis of experience, while emphasizing the opening of a new era with revolutionary potentialities in the 1930s. Although Benjamin relates the crisis of experience to the decline of the communicability of experience - specifically after the monstrous events of the First World War (W. Benjamin 2005b) $)^{1}$ - and to "the dream-filled sleep that fell over Europe"

\footnotetext{
${ }^{1}$ In his essay Experience and Poverty (1933), Benjamin argues that a sense of experience as tradition, wisdom, passing "like a ring from generation to generation" has been totally devalued in the experience of the generation of 1914-1918 who underwent the monstrous events of the First World War. For the experiences of the war generated the most contradictory experiences for this generation. Moreover, this was not an experience that could be passed on through tradition, since it destroyed all received wisdom. Benjamin states: "strategic experience has been contravened by positional warfare; economic experience, by inflation; physical experience, by hunger; moral experiences, by the ruling powers" (W. Benjamin 2005b).
} 
with capitalism (W. Benjamin 2002a, 391), he also associated the opening of a new era with the awakening potentialities of dream images produced by the same commodityproducing society. Has anything changed since the 1930s? We have witnessed the rise of the dissemination of information, the dissolution of the boundaries between time and space, the development of new media and technology, all of which intensifies the process of the extraction of "sameness even from what is unique" and in turn extends even further "the sense for sameness in the world" (W. Benjamin 2006c, 105). We have also continued to witness the atrocities of war - e.g., the Second World War, the Cold War, the Vietnam War, the Gulf War, the War on Drugs, the War on Terror - over and over again. The number and frequency of wars are in fact sufficient to make the claim that the monstrosities of war are a part of everyday life in the globalized world. Then, where do we stand now in relation to the aforementioned paradox of modernity? If the crisis of experience has been intensified, what has happened to the possibility of the renewal of humanity?

Giorgio Agamben (1993) argues in Infancy and History that the destruction of experience no longer requires a catastrophe, like World War I. Instead, the tediously repetitive daily life in the city is sufficient. Although modern man encounters a jumble of events (e.g., reading a newspaper, driving one's car for hours in traffic, lining up to grab a coffee) throughout the day, none of these events translate to experience. The "banality of the quotidian" (Agamben 1993,14) generates oppression rather than narratable and communicable experiences. In contrast, everyday life was once the raw material of experience. Agamben states:

Each event $\ldots$ became the speck of impurity around which experience accrued its authority, like a pearl. For experience has its necessary 
correlation not in knowledge but in authority - that is to say, the power of words and narration; and no one now seems to wield sufficient authority to guarantee the truth of experience and if they do, it does not in the least occur to them that their authority has its roots in an experience. On the contrary, it is the character of the present time that all authority is founded on what cannot be experienced (Agamben 1993, 14).

Then, can it be said that today there are no more experiences? Agamben suggests that rather than eradicated, experiences are "enacted outside of the individual" (Agamben 1993, 14). To put it differently, under the current conditions the individual becomes an observer of his experience. This occurs as a result of the increasing role of technology as a medium of perception in everyday life. For example, while visiting an ancient ruin or witnessing beautiful scenery, many of us grab our cameras or smartphones to photograph the scenery. Instead of experiencing the moment with our senses, we mediate our perception via the camera. Photographing the site or the scenery is followed by sharing this moment on various social media platforms, manifesting a second layer of mediation of experience via technology. Examples of this sort multiply easily. The point to be made here is not that we should be nostalgic for the past, but should rather try to understand the state of experience today, in order to glimpse upon how the possibilities of experience in the present can be realized.

Benjamin's diagnosis of 'the poverty of experience' (1933) and modernity's alienation - that is, the collective state of no longer being at home (Hanssen 2006) - have become even more crystalized in Western societies. His assumptions about cafés, movie theaters, or arcades becoming the new homes for urban dwellers, or rather, the new historical subjects - such as flâneur, surrealist artists and political crowds - who were to facilitate a 'new mode of seeing' seem to have failed. The dream images seem to have been frozen as ornamental archaic images adorning the parlor of modernity rather than 
transforming into dialectic images that could bring forth awakening. In this context, this dissertation explores the relationship between commodity form, technology, perception, experience, and politics in order to re-evaluate the aforementioned paradox of modernity. In this quest, I use the concept of kitsch as a theoretical tool to investigate the modern condition.

The term kitsch emerged in the second half of the nineteenth century, the century in which the transformations that took place in the material sphere started to manifest in the cultural sphere. In other words, kitsch came into existence when capitalism began to alter the structures of perception. Although there have been numerous attempts to define the term, it is used generally in relation to the judgments of taste, and has often been referred to as bad art, or as the aesthetic species of falsehood. As such, it is perceived as an imitation of imitation, a forgery, or a lie.

In this dissertation, I (re)think and (re)conceptualize the concept of kitsch in relation to the changes in the socio-political structures of perception under capitalism. Thus, rather than imprisoning the analysis of kitsch to disciplines that are defined in their own right (e.g., fine arts, philosophy, or sociology) or restricting the understanding of kitsch to the distinction between the works of art and the products of the culture industry, or delimiting its examination to the attributes of kitsch objects, attitudes, and kitsch-man [Kitschmensch], I (re)conceptualize kitsch as a theoretical construct to investigate the dream-worlds of Europe which sprang at the intersection of liberalism, social democracy and capitalism. I argue that the unexplored potentialities of kitsch, as a concept, reside in the analysis of the dreamworlds, which have been occupying the social and political imaginaries of Western individuals, communities and institutions since the 
disenchantment of the world, thereby brining forth the need for magic - through which the world was enchanted once again. Entré: Liberté, Eqalité, Fraternité!

As modernity calls for newness, change, and novelty, kitsch heralds repetition, familiarity, and banality. How is it possible then that kitsch emerged under modernity? Is kitsch against modernity, or is it a direct result of modernity? Is it the anti-modern, or is it the embodiment of the modern Zeitgeist? Rosenberg argues that "[i]n the present organization of society only kitsch can have a social reason for being" (H. Rosenberg 1994, 268). But, what about the political reason for the existence of kitsch? In other words, given that everything can become kitsch, the question that needs to be asked, is not whether something is kitsch or not?, or What qualifies a thing as kitsch?, but rather: Why, and how, has kitsch become so integral to the modern world?

In (re)conceptualizing kitsch in order to understand the ' $w h y$ ' of the seeming failure of the renewal of humanity, this dissertation has three main objectives that run through each of the four constitutive chapters. First, I aim to contribute to the theorizing of kitsch via its (re)conceptualization beyond the limits set on this concept within the existing literature. Second, I make a significant contribution to the Benjaminian literature by constructing kitsch as an historical object, a dialectical image by means of which a new perspective could be acquired in understanding modernity. Third, by closely examining the transformation of the public sphere and the concept of the political under the conditions of the commodity form and technological reproduction, I discuss the character of, and possible implications for, alternative politics. 


\subsection{Methodology}

"Telescoping of the past through the present"

Walter Benjamin

In this dissertation, I adopt Benjamin's historical materialism as a methodology where history becomes "the subject of a construction whose site is not homogenous, empty time, but time filled full by now-time [Jetztzeit]" (W. Benjamin 2006d, 395). ${ }^{2}$ As a critique of the continuous, linear understanding of historical time - in which the history of ideas are represented "as a 'development' of an earlier one" (Engels qt. in W. Benjamin 2006c, 261), “a new poetic school as a 'reaction' to one preceding, a new style as the 'overcoming' of an earlier one" (W. Benjamin 2006c, 261) and the historical object is experienced only through contemplation (W. Benjamin 2006c), Benjamin's historical materialism blasts out the past from the continuum of history by constructing a disruptive constellation of the past and the present. Therefore, by challenging the understanding of historical time as progress through stages of empty, homogeneous time (W. Benjamin 2006d), Benjamin's critique of chronological time stresses the shortcomings of a historically determined interpretation of Marx. ${ }^{3}$

In the Eduard Fuchs, Collector and Historian (1937) essay, Benjamin writes:

Historicism presents the eternal image of the past, whereas historical materialism presents a given experience with the past - an experience that is unique. The replacement of the epic with the constructive element proves to

\footnotetext{
${ }^{2}$ The 'now-time' [Jetztzeit] refers to a specific temporal constellation where the past and present are short-circuited, and the blasting out of the historical object from the continuum of history is actualized. This concept thus depicts the arresting of the linear, irreversible form of progressive history. I investigate this concept further in the fourth chapter.

${ }^{3}$ In the Thesis XIII (1940), Benjamin's critique of chronological time and the progressive notion of history was addressed specifically to the social democrats of his day who pictured progress first as "progress of humankind itself (and not just advances in human ability and knowledge)[,] [...] [s]econd, boundless[,] [...] [t]hird, inevitable - something that automatically pursued a straight or spiral course" (W. Benjamin 2006d, 394). Therefore, he argued that any critique of this linear historical progression requires a "criticism of the concept of progression itself" (W. Benjamin 2006d, 395).
} 
be the condition for this experience. The immense forces bound up in historicism's 'Once upon a time' are liberated in this experience. To put to work an experience with history - a history that is originary for every present - is the task of the historical materialist. The latter is directed toward a consciousness of the present which explodes the continuum of history (W. Benjamin 2006c, 262).

In this passage, Benjamin makes a distinction between historicism and historical materialism regarding the temporality and modality of experience (Caygill 2004). While the former is depicted as an "experience of the past" (Caygill 2004, 90) (emphasis in original) - where the past is regarded as an object that is present eternally - the latter is conceptualized as an "experience with the past" (Caygill 2004, 90) (emphasis in original) - which occurs when the constellation between the past and the present becomes recognizable (W. Benjamin 2006d). Benjamin identifies the replacement of the narrative with the constructive element of history as the condition of this experience (of the present with the past). For, the present recognizes itself in its past within and through this experience. In other words, this dialectical construction differentiates what concerns the historical materialist as originary ${ }^{4}$ in historical experience rather than the accumulated, put-together factualities of the past. Therefore, in this configuration, the historical object becomes a participant in the historical experience.

The perception of the historical object as a participant in the historical experience renders it possible for the dialectical materialist to leave "the contemplative attitude

\footnotetext{
${ }^{4}$ Benjamin writes in The Origin of German Tragic Drama (1928), "[t] hat which is original is never revealed in the naked and manifest existence of the factual; its rhythm is apparent only to a dual insight. On the one hand it needs to be recognized as a process of restoration and reestablishment, but, on the other hand, and precisely because of this, as something imperfect and incomplete. There takes place in every original phenomenon a determination of the form in which an idea will constantly confront the historical world, until it is revealed fulfilled, in the totality of its history. Origin is not, therefore, discovered by the examination of actual findings, but it is related to their history and their subsequent development. The category of origin is not therefore [...] a purely logical one, but a historical one (W. Benjamin 1998).
} 
toward his object in order to become conscious of the critical constellation in which precisely this fragment of the past finds itself with precisely this present" (W. Benjamin 2006c, 262). Thus, here, history is not seen as the history of facts, incidents, and developments, but "as an image that flashes up at the moment of its recognizibility" (W. Benjamin 2006d, 390). Herein resides Benjamin’s Copernican turn. He writes:

This [experience of the present with the past] is a wholly unique experience of dialectic [...] which refutes everything 'gradual' about becoming and shows all seeming 'development' to be dialectical reversal, eminently and thoroughly composed, is the awakening from dream. For the dialectical schematism at the core of this process, the Chinese have often found, in their fairy tales and novellas, a highly pregnant expression. The new, dialectical method of doing history presents itself as the art of experiencing the present as waking world, a world to which that dream we name the past refers in truth. To pass through and carry out what has been in remembering the dream! - Therefore: remembering and awaking are most intimately related. Awakening is namely the dialectical, Copernican turn of remembrance (W. Benjamin 2002d, 389, K1,3).

What Benjamin presents here is the "Copernican revolution in historical perception" (W. Benjamin 2002d, 388, K1,2). Challenging the historicist conception of history - which had found a "fixed point [...] in 'what has been"” (W. Benjamin 2002d, 388, K1,2), and engaged the present with the past on this fixed ground, the new historical perception overturns the relation of the present with the past from a 'fixed point' to a "dialectical fixation" (W. Benjamin 2002d, 388, K1,2) in which what-has-been and the present creates an illuminating constellation in every present. Yet, this image of the past "threatens to disappear in any present that does not recognize itself as intended in that image" (W. Benjamin 2006d, 391). Here, Benjamin emphasizes the fact that there is no definite past, and that "[h]istory is possible at the risk of not being history" (Hamacher 
$2005,46) .{ }^{5}$ That is to say, history is experienced only through the danger of being missed.

Benjamin writes in Thesis VI (1940):

Articulating the past historically does not mean recognizing it 'the way it really was.' It means appropriating a memory as it flashes up in a moment of danger. Historical materialism wishes to hold fast that image of the past which unexpectedly appears to the historical subject in a moment of danger. The danger threatens both the content of the tradition and those who inherit it. For both, it is one and the same thing: the danger of becoming a tool of the ruling classes. Every age must strive anew to wrest tradition away from conformism that is working to overpower it (W. Benjamin 2002d, 391).

Here, Benjamin combines historical cognition with action in and through his theory of thinking and acting in images. This theory is based on the understanding of history as a "form of mindful remembering [Eingedenken]" (Hamacher 2005, 46), which renders the re-interpretation of the past continuously from within and through the present in order to seize the missed possibilities of the past. ${ }^{6}$ That is to say, "[h]istorical materialism sees the work of the past as still uncompleted. It perceives no epoch in which that work could, even in part, drop conveniently, thing-like, into mankind's lap" (W. Benjamin 2006a, 267). According to Benjamin, the concept of culture - which is considered as the "embodiment of creations [...] independent, if not of the production process in which they originate, then of the production process in which they continue to survive - has a fetishistic quality" (W. Benjamin 2006a, 267). For, here, culture is treated as an

\footnotetext{
${ }^{5}$ As Hamacher (2005) argues, in this configuration, the dialectical materialist has to free himself from both the "traditional realism of the constancy of objects" and "the transcendentalism of the forms of perception of these objects" (46). If we look at Kant's notion of time, we find that, for him, the continuity of time is not historical. For, he establishes a form of perception a priori to any historical content. Therefore, Kant argues that "history moves in time, it does not constitute time and does not form specific historical times that are distinguishable from time's empty form" (Hamacher 2005, 46).

${ }^{6}$ In this configuration, "neither object nor subject and its forms of cognition [are] substantial. Because both can become effective as genuinely historical functions" (Hamacher 2005, 46).
} 
independent object of the present. Yet, the past is not an autonomous object of the present, but a reserve, a possibility for a political experience that is yet to be fulfilled.

The understanding of the past as a reserve comes along with the acknowledgement that "the past can unsettle and disrupt the present" (Caygill 2004, 93). This destructive element of the past does not mean the destruction of the past by the present; rather, it indicates the fact that there is a possibility that the index of the past explodes the aspects of the present by an encounter with the present, thereby generating an opening for new political imaginaries. ${ }^{7}$ In this configuration then, the historical happening is understood to be a 'flash' of synthesis between the 'what-has-been' and the 'now,' which manifests itself in and through the dialectical image.

\subsubsection{Dialectical Image}

Benjamin's use of the German word image $[$ Bild $]$ precedes the distinctions between mental, visual, and material images, the differentiation of scripture and pictures, and the separation of concept [Begriff] and metaphor (Weigel 2015). In fact, the term image $[$ Bild $]$ appears in various combinations in his writing, such as: graphic image [Schriftbild], dream image [Traumbild], the images of history [Bilder der Geschichte], mnemic images [Erinnerungsbild], thought-images [Denkbilder] and dialectical images [dialektische Bilder]. All of these conceptualizations of the image find their basis in the

\footnotetext{
${ }^{7}$ Benjamin's understanding of history as incomplete, unfinished derives from his treatment of history as a "form of remembrance" [Eingedenken]. He writes: "[H] istory is not simply a science but also and not least a form of remembrance. What science has 'determined,' remembrance can modify. Such mindfulness can make the incomplete (happiness) into something complete, and the complete (suffering) into something incomplete. That is theology; but in remembrance we have an experience that forbids us to conceive history as fundamentally atheological, little as it may be granted us to try to write it with immediately theological concepts" (W. Benjamin 2002d, 471, $\mathrm{N} 8,1)$. Here, Benjamin articulates the experience of the past in remembrance with the theological concept of incompleteness, which, according to him, pushes the present to confront its own fragmentation while demolishing the idea of completeness that attends the past (Caygill 2004).
} 
literal sense of the word, that is, "image as likeness, similitude, or resemblance [Ähnlichkeit] (Weigel 1996, 20).

He relates the image neither to representation [Darstellung] nor to reproduction [Abbild]. For, he attempts to rescue images from aesthetic discourses, and endow them with a politically charged power. "[T]he immediacy of images inherent in the graphic images contains the potential to interrupt, hence to counteract modes of perception and cognition that have become second nature" (Pensky 2004a, 179). Thus, he brings together his 'thinking' and 'writing' in, what he calls, a "third thing" [ein Drittes] (W. Benjamin 1968 , 205), that is, the image (W. Benjamin 2005d).

Benjamin's use of images, therefore, marks a specific form of thinking and writing that is based on simultaneity and constellation rather than continuity, similarity rather than representation, fragment rather than the whole (Weigel 1996). In this sense, Benjamin's images - such as the flâneur, the prostitute, the ragpicker - are not stereotypes, archetypes or ideal types, but constellations. That is to say, they are not recurring figures of speech that are immutable in time, rather, they are ever-changing "force field[s]" (W. Benjamin 2005d, 240) that are "saturated with tension" (W. Benjamin 2002d, 475, N10a,3). Thus, for Benjamin:

[I]mage is that wherein what-has-been comes together in a flash with the now to form a constellation. In other words, image is dialectics at a standstill. For while the relation of the present to the past is a purely temporal, continuous one, the relation of what-has-been to the now is dialectical: is not progression but image, suddenly emergent. - Only dialectical images are genuine images (that is, not archaic); and the place where one encounters them is language (W. Benjamin 2002d, 462, N2a,3) (emphasis is added).

In this passage, Benjamin depicts the dialectical image as a constellation of the "whathas-been" [das Gewesene] and the "now" which "come together in a flash" (W. Benjamin 
2002d, 462, N2a,3). ${ }^{8}$ In this fragment, the image emerges as a specific form of cognition [Erkenntnis] or insight [Einsicht]: a "simultaneous, instantaneous cognition [Erkenntnis]" (Weigel 2015, 8-9). Benjamin's use of the word "flash" is depictive. For it, on the one hand, qualifies the flashlike character of the image - whose coming-into-appearance is sudden, evanescent - and on the other hand, stresses the imagelike nature of cognition, which is bound to the 'now of a particular recognizibility' (W. Benjamin 2002d, 463, $\mathrm{N} 3,1)$.

Benjamin's notion of the 'now of recognizibility' is intimately related to his critique of the progressive notion of history and chronological time - which narrates the past as what has conditioned and made the present possible. In contrast, for Benjamin, "[t]he materialist presentation of history leads the past to bring the present into a critical stance" (W. Benjamin 2002d, 471, N7a,5) through the actualization of historical material, which then would shock what has been constructed as the present. In other words, in the dialectical image, linear time is suspended when what-has-been and now come together without the mediation of a distance in the 'now of recognizibility,' thereby interrupting the present.

In this configuration, as Weigel (1996) eloquently argues, the dialectical image emerges as an image that is read, "an image in language, even if the material of representation can here be very various" (18) - such as the world of objects (e.g., fashion, advertisement), architecture (e.g, Haussmannization, iron construction), cities (e.g., Moscow, Berlin), persons (e.g., Baudelaire, Proust). The arcades, for Benjamin, were the

\footnotetext{
${ }^{8}$ In another passage, Benjamin describes dialectical image as "an occurrence of ball lightening that runs across the whole horizon of the past" (W. Benjamin 2006d, 403). Ball lightning [Kugelblitz] is a rare form of lightning, which is an unknown atmospheric phenomenon. It has the form of a moving globe of light. It is frequently associated with thunderstorms, yet lasts considerably longer than a flash of light bolt, in some cases persisting for up to a minute.
} 
spaces where all of these components came together. Thus, they were the dialectical images where the organic and the inorganic world, basic needs and audacious luxury created the most contradictory constellations. On the basis of the correspondences he found between the outer world and the dream world, he read the world of objects as a dream world in which the opposition between the inner and the outer is sublated in a critical constellation. In other words, in his investigation, the outer world is read as the inward body of the collective (Weigel 1996). He writes:

[J]ust as the sleeper - in this respect like the madman - sets out on the macrocosmic journey through his own body, and the noises and feelings of his insides, such as blood pressure, intestinal churn, heartbeat, and muscle sensation (which for the waking and salubrious individual converge in a steady surge of health) generate, in the extravagantly heightened inner awareness of the sleeper, illusion or dream imagery which translates and accounts for them, so likewise for the dreaming collective, which, through the arcades, communes with its own insides. We must follow in its wake so as to expound the nineteenth century - in fashion and advertising, in buildings and politics - as the outcome of its dream visions (W. Benjamin 2002d, 389, $\mathrm{K} 1,4)$.

In this passage, it becomes clear that the production of dream images, for Benjamin, is the result of corporeal processes. This reading emerges out of Benjamin's adaptation of the Freudian notion of unconscious to the collective and the city, which, for Benjamin, is the body of the collective.

In this configuration, the world of the commodity is treated as the historical object, the dialectical image in which the what-has-been and the now come to a dialectical standstill, ${ }^{9}$ meaning that the dialectical oppositions between subject and object,

\footnotetext{
${ }^{9}$ Benjamin writes: To thinking belongs the movement as well as the arrest of thoughts. Where thinking comes to a standstill in a constellation saturated with tensions - there the dialectical image appears. It is the caesura in the movement of thought. Its position is naturally not an arbitrary one. It is to be found, in a word, where the tension between dialectical opposites is greatest. Hence, the object constructed in the materialist presentation of history is itself the
} 
progress and the eternally-the-same, corporeal immediacy and figural presentation are momentarily crystalized. Building on Benjamin's analysis of the world of the commodity, and his claim that "[h]istorical 'understanding' is to be grasped, in principle, as an afterlife of that which is understood" (W. Benjamin 2002d, 460, N2,3), in this dissertation, I construct kitsch as a historical object, along with the commodity, in which the dialectical oppositions - between closeness and distance, sameness and uniqueness, perceptibility and imperceptibility, reproducibility and novelty embodied in the commodity form and technological reproduction; discontinuity and continuity, fragmentation and unity, proximity and distance, individual and collective, ecstasy and sobriety materialized in the transformations taken place in human perception and experience - come to a standstill.

\subsection{Road-map}

\subsubsection{Chapter II: The Concept of Kitsch}

In the first chapter of this dissertation, firstly, I explore the etymology of kitsch; secondly, I review the broader literature on kitsch; and thirdly, I discuss the limitations of the existing literature. Thus, in the first section, by exploring the emergence of kitsch in the 1930s as an object of contemplation in relation to the rise of mass society and the commercialization of art, I discuss the ways in which the term kitsch was, at various points, associated with 'bad art' and 'taste, aesthetics and ethics' (Broch 1969b; Broch 2002; Giesz 1969; Kundera 1999) as well as depicted as 'a category of falsehood' (Greenberg 1961; Dorfles 1969; Ćelebonović 1969; Macdonald 1957; Macdonald 1983). Through this discussion, I identify three groups of criteria which serve to identify what 
qualifies a thing as kitsch. This discussion illuminates the fact that kitsch as a concept traverses disciplinary bounderies.

In order to effectively engage in a review of this interdisciplinary literature, therefore, in the second section of this chapter I employ a thematic approach. This, in turn, serves to reveal the analytical connections between, rather than within, the different disciplines. Thus, I develop five themes where kitsch is conceptualized either as: 1) an ersatz culture; 2) a philosophical and existential phenomenon; 3) a "travestied aesthetic consciousness"; 4) a technique of political manipulation; or 5) an aesthetic category. These thematic categories are reflective of the debates surrounding the implications of the emerging technological reproducibility on culture, in general, and art, in particular.

On the basis of this literature review, in the third, and final, section of this chapter I argue that the existing analyses of the concept of kitsch are restrictive, and therefore incomplete - often leading to underdeveloped theoretical conceptualizations, and on occasion, even to contradictory analytical conclusions. Despite this however, this thematic review of the literature points to a rather important observation. That is: collectively - and despite their individual deficiencies - the existing literature illuminates the fact that kitsch finds its expressions in the different spheres of life (social, political, economic, cultural, historical, etc.,). This, in turn, leads me to conclude that kitsch as a concept has considerable explanatory potential, one that significantly surpasses the sum of its - here to be analyzed - parts. Thus, in weaving a thread through the different areas of study, I argue that kitsch (re)produces particular: patterns of behavior; ways of engaging with reality; and forms of attitudes toward oneself, others, and the external world. In other words, I diagnose kitsch as a defining characteristic of modernity. 


\subsubsection{Chapter III: Capitalism, Culture and Technology}

In the second chapter of this dissertation I set the ground for the development of a new definition of kitsch as a defining characteristic of modernity. In order to do so, I decipher the nature and operation of the newly emerging reality - conditioned by the commodity form and technological reproduction, and their effects on the collective organization of human perception. Thus, in the first section of this chapter, I discuss Marx's concepts of use-value, exchange value, and commodity fetishism in order to explore the implications of commodity production and the commodity form on the transformation of human perception and the experience of reality.

This is particularly important as the originating debates regarding the state of art, and kitsch were a way to analyze the penetration of the commodity form into the cultural sphere and the alteration of cultural goods through technological reproduction. In the second section, therefore, in reference to Lukács' concept of reification and the review of the Marxist commodity analysis of art, I explore the ways in which the commodity form penetrates into the social and cultural spheres of life. As the commodity form penetrates all areas and aspects of life, the rise of technological reproducibility heralds a transformation in the materials and forms of life. As such, the interaction between the commodity form and technological reproduction affect the historically situated individual and collective in an immediate and sensuous way. Consequently, and in conjunction with the rise of the masses, the medium of human perception shifts from auratic perception towards a new form of perception - characterized by a dissolution of the "borders of objects by bringing them 'closer' spatially and humanly" and thus overcoming "the uniqueness of every reality" (Caygill 1998, 103). 
In this context, in the third, and final section, of this chapter I relate the concept of kitsch to the concept of phantasmagoria. To do so, I discuss the difference between Marx's and Benjamin's understandings of phantasmagoria, and argue that each is a distinct element of the same phenomenon. Thus, reading Marx's conceptualization of phantasmagoria against that of Benjamin leads me to two important conclusions: 1) there is an empathetic relation between the individual and the value of the object in the market; and 2) the collective organization of human perception is conditioned by the expression of the commodity form and exchange relation. This analysis, in turn, prompts me to distinguish between Marx's notion - as first order phantasmagoria - and Benjamin's conceptualization - as second order phantasmagoria. In doing so, I uncover the different levels of reality - which manifest the relationship between the commodity form and technological reproducibility - and the ways in which they interact with one another. Ultimately, I conclude that kitsch emerges as the defining condition of modernity at the point where the first and second order phantasmagorias converge. Thus, I define kitsch as the appropriation of a beautified ghostly reality.

\subsubsection{Chapter IV: The Crisis of Experience}

In the third chapter of this dissertation I deepen the exploration of the collective organization of human perception in relation to Benjamin's notion of the crisis of experience by analyzing the cultural forms and everyday practices that emerged in the nineteenth century as expressions of the economic structure. I argue that the changes in the mode of perception - resulting from the adaptation to the material and social conditions of capitalism - (re)constitutes the world of modernity as a sur-real world. In this world, the fabric of experience becomes characterized by discontinuity and 
fragmentation, the outcome of which Benjamin identifies as the crisis of experience. Here, the individual and collective consciousness is transformed by the mediating effects (on culture and tradition) of the newly emerging forms of communication. In the first section, therefore, I explore the transformation of the forms of communication from storytelling (oral narration) to the novel (textual narration), and from storytelling to information, thereby examining the implications of these transformations on the fabric of experience.

As the forms of communication shift towards information, the fabric of experience shifts from collective and continuous towards a "desultory and isolated, overwhelmingly private [in] character" (Wolin 1982, 22). Here, Benjamin distinguishes between experience as Erfahrung (connected through tradition) and experience as Erlebnis (immediate and singular). This leads him to conclude that as Erfahrung transitions into Erlebnis, the relationship between experience, memory and the mimetic faculty transforms. The crisis of experience, therefore, resides in the modern man's repetitive daily activities that are disconnected from those of the days before. As such, these activities are the exact repetition of the activities of previous days. For Benjamin, this repetitive, and in turn, novel character of the activities of each day is a sign of the decline of the mimetic faculty. In order to analyze the relationship between experience, memory and the mimetic faculty, in the second section of this chapter, I discuss Marcel Proust's notions of voluntary and involuntary memory, Freud's notion of memory trace, and Reik's theory of memory. In doing so, I demonstrate the relationship between memory and experience in reference to the transformations taken place in the human 
sensory organs as a result of the proliferation of shock sensations, technological reproduction and alienating division of labour.

In the third, and final section of this chapter, I explore the relationship between experience [Erfahrung] and Benjamin's concept of the aura, stressing its “anthropological, perceptual-mnenomic, and visionary dimensions" (Hansen 2012, 105). On the basis of this discussion, I conclude that as experience [Erfahrung] shifts towards immediate experience [Erlebnis] and as long-term memory [Gedächtnis] shifts into reminiscence/recollection [Erinnerung], the perceptual world [Merkwelt] is replaced by the semiotic, thereby leading the collective organization of human perception away from auratic perception. In this context, and in opposition to auratic perception, I introduce the concept of kitsch perception, which designates the new form of collective organization of human perception. Thus, as kitsch perception replaces auratic perception, the spatial and temporal categories of the auratic perception are liquidated, resulting in the subject being uprooted from a human range of perception, dissolving the distance of experience [Erfahrung] and crystalizing the closeness of immediate experience [Erlebnis].

\subsubsection{Chapter V: Politics of Phantasmagoria: Kitsch Politics}

In the fourth chapter of this dissertation, I explore the socio-political structure of perception and its effects on "the political" under the conditions of the capitalist social relations of production. For Benjamin, society's mode of representation, apprehension, and experience - that is human sense perception - are conditioned by the political and socio-economic configurations that mark the course of history. As such, the visual distractions of modernity are a response to the material environment and the perceptual challenges that arise in modern societies. This preoccupation with "looking" and "seeing" 
is in this sense a shield against the technological configurations of the urban environment, the acceleration of the speed of communication, and the overabundance of discontinuous stimuli on the streets, in the factory, in traffic, or in city centers. Therefore, this shield evokes aesthetic attitudes, which reinvent individual and collective identities against the grain of technological progress and institutional differentiation, thereby preserving the political community.

In this context, in the first section of this chapter, I explore the ways in which the transformations in the collective organization of human perception and experience express themselves in politics. In doing so, I discuss the ways in which the interior as the space where the individual "feel[s] at home, at ease, comfortable and comforted" (W. Benjamin 2005e, 621) emerged into the "light of the public space" (Arendt 1998, 38) that is, the exterior, where "looking" and "seeing" is visible by all, thereby blurring the distinctions between the public and private spheres. For Benjamin, this process is manifested in the arcades which - like the interior's "stimulus to intoxication and dream" (W. Benjamin 2002d, 216, I2,6) - become the source of "religious intoxication of great cities" (W. Benjamin 2002d, 61, A13). Thus, I argue that these privately owned and publicly accessible spaces of intoxication rapidly transgressed the boundaries of the arcades only to be replicated wherever the urban crowd congregated. This leads me to conclude that as the appropriation of a beautified ghostly reality traverses the confines of the dwelling and manifests within and through the spaces of the city, the political imaginary itself is affected by the interaction between the first-and second-order phantasmagoria and the consequent shift from auratic perception to the kitsch perception. 
This political community - where the interior and exterior are intertwined manifests the relationship between metaphor and image. In the second section of this chapter therefore, I explore the relationship between metaphor and image in order to diagnose the interaction between the capitalist social relations of production and liberal/social democratic politics. Drawing on the work of the Surrealists, Benjamin challenges us to witness the collision between the metaphor and the image. In the conventional metaphor, images are instrumentalized to designate something other than their immediate and temporal signification. Thus, in the metaphorical political language of liberal and/or social democracy, images are bounded by the practical language and existing reality, thereby losing their temporal and immediate mediacy. More importantly perhaps, these images materialize in "space, objects and practices" (Wohlfarth 1996, 199), and as a result, acquire an immediate perceptible presence in the capitalist everyday. On the basis of this, I argue that with the loss of the immediate mediacy and the acquisition of the immediate perceptible presence of images, the "dream agora" arises. Here, the collective desires, wishes and feelings are bound by the order of posited norms.

Collectively, the "dream agora" along with the "dream houses" render the interaction between the capitalist social relations of production and liberal/social democratic politics imperceptible by the senses while making the phantasmagoric reality of commonality, collectivity, and totality, perceptible. In turn, I define this configuration as "kitsch politics." Here, the phantasmagoric reality doubles through the interaction of the first- and second-order phantasmagorias, rendering it possible for the individual(s) to feel at home, comfortable and comforted while at the same time obscuring the 
relationship between the capitalist mode of production and liberal/social democratic politics. In this process, the shift from "whoness" to "whatness" of being - where fixed, static and exclusionary identities provide a sense of belonging through the demonization of the other(s) -is operationalized. Thus, I argue that kitsch politics is not only the expression of capitalism, but more importantly, as such, precludes the formation of new political imaginaries.

For Benjamin, the creation of new political imaginaries void of the conflation between metaphor and image are crucial for the development of an alternative politics beyond capitalism. In the third, and final, section of this chapter therefore, I articulate Benjamin's notion of alternative politics and discuss the ways in which this impacts the revolutionary potential of political action. I argue that Benjamin's alternative politics finds its origins in the "organization of pessimism" (W. Benjamin 2005d, 216), and therefore, is in direct opposition to kitsch politics. The "organization of pessimism" is reflective of a critique of the progressive notion of history and chronological, linear time. In direct contra-distinction to linear time, Benjamin proposes the configuration of 'nowtime' [Jetztzeit], which invokes the image(s) from the archive of historical memory, thereby embodying the dimension of the possible that claims to be actualized. Herein reside the seeds of Benjamin's notion of alternative politics: an interaction between profane illumination [profane Erleuchtung], "image-space" [Bildraum], and "bodyspace" [Leibraum], which collectively overcome the dualistic oppositions between the form and content, philosophy and literature, politics and art, theory and practice, sobriety and ecstasy, individuality and collectivity, corporeal immediacy and figurative representation. 
In this context, I argue that profane illumination produces experiences, which shatter the kitsch condition, disrupt the order of meanings, and thereby render synaesthetic experience possible. And as the image-space and body-space interpenetrate - or rather, as the body-space is "produced in an image-space" - the duality of kitsch perception and auratic perception is disrupted, thereby rendering the "corporeal materiality of the collective as its matrix" (Weigel 1996, 16). Thus, I conclude that only in this matrix, can the alarm-clock strike the 'now-time' [Jetztzeit], manifesting the revolutionary discharge, and actualizing the missed possibilities of the past. 


\section{Chapter II: The Concept of Kitsch}

\subsection{Introduction:}

The German word kitsch is an invention of the nineteenth century. Originating in 1870 s, it came in to use in the circles of painters and art dealers in Munich to describe types of paintings, which were made for English or American buyers who did not want to invest much for a painting, and thus, demanded a sketch (Menninghaus 2009). Therefore, at this time, the term kitsch was commonly used to designate "cheap artistic stuff," which were considered in bad taste because of their garishness or sentimentality. Although the term had been translated into French - as art de pacotille (junk art) or art tape-à-l'œil (garnish art) - and some other languages, it has now been firmly established internationally (Calinescu 1987).

The term kitsch did not become an object of academic reflection until the late 1930s. At this time, it was conceptualized by art critics (Greenberg 1961; Dorfles 1969; Macdonald 1957; Eco 1989; Broch 1969b; Kulka 1996) and critical theorists (T. W. Adorno 2001; T. W. Adorno and Horkheimer 2002b). The common goal was to demonstrate the derivitive nature of aesthetic objects that were the products of mass society, and the commercialization of art. Therefore, the concept of kitsch is generally used in relation to judgments of taste, and associated with aesthetic inadequacy. In certain contexts, this idea [of aesthetic inadequacy] resulted in the association of kitsch with bad art (Kulka 1996; Eco 1989); in others, it led to the interpretation of kitsch as a category of falsehood (Dorfles 1969; Calinescu 1987; T. W. Adorno 1941; T. W. Adorno 1997). But, most frequently, kitsch is understood as a category of taste, linked to both aesthetics and ethics (Broch 2002; Dorfles 1969; Calinescu 1987; Arendt 1993; Macdonald 1983). 
This chapter aims to present an overview of the literature on kitsch in order to reveal the limited nature of this literature. First, I present the etmology of kitsch, and three groups of criteria which are frequently used in the literature as the qualifying characteristics of kitsch. Second, I provide a literature review of the concept. Lastly, I discuss the limitations of the existing literature, and suggest to theorize kitsch through weaving a thread not within, but through the various areas of study.

\subsection{The Etymology of the Concept}

The etymology of kitsch is uncertain. Yet, the word is often traced back to three origins in the literature. Some authors argue that the German word kitsch is derived from the English word "sketch," - that is, the quality of being unrealized, merely hinted at (T. W. Adorno 1997) - which was mispronounced by artists in Munich and applied derogatorily to 'cheap' objects that are bought as souvenirs by tourists (Calinescu 1987). According to others, it originates from the German verb etwas verkitschen, meaning "to knock off cheaply" (Calinescu 1987). Lastly, it is viewed as derivative from the German word kitschen, in the sense of "collecting rubbish from the street" (Dorfles 1969).

Menninghaus (2009) suggests that the word kitsch shares two basic features with other monosyllabic German words that end in 'tsch', such as Qua-tsch, meaning nonsense or rubbish; Kla-tsch, menaing splash, smack, gossip; Ma-tsch, meaning mush, slush, sludge; or pi-tsch, pa-tsch (pitter-patter). He identifies two commonalities among the words ending in 'tsch.' First, they 'tend to describe 'lowly' objects or actions [...] representing rather a vulgar and/or childish mode of expression" (40) (Emphasis added). Second, they are "suggestive of blurred distinctions or the active suspension of distance or differentiation and tend to have an element of 'debasement' about them" (40). 
On the basis of these etymological roots, three groups of criteria, qualifying what kitsch is, are identified. The first set posits kitsch as having the features of "simple producibility" (e.g., bibelots), "simple re-producibility" (e.g., posters), and "stereotyping and clichés" (e.g., painting of a crying child) (Dorfles 1969; Ćelebonović 1969; Greenberg 1961; Macdonald 1983). All three of these features depict kitsch as a qualifier for a cultural and/or artistic object, which is thus seen as aesthetically inadequate. This aesthetic inadequacy is associated with the rise of mass society where the capacity of both production and consumption of cultural and artistic objects increased as a result of technological reproduction.

The second group of criteria describes kitsch as "error in space" (e.g., products of the music industry being presented as folk music), "error in time" (e.g., old styles being presented as fashionable), and "error in content" (e.g., the use of clichés, which produce ready feelings) (Calinescu 1987; Olalquiaga 2002; Dorfles 1969). In this group, the word "error" is used to demonstrate the centrality of the category of "falsehood" in understanding kitsch.

The third group of criteria is offered by Gillo Dorfles. He identifies seven features that could be used to identify whether an object, attitude, technique is kitsch or not: a) a mass production of works of art (e.g., re-prints of Dali's paintings); b) ascribing a ritual value to persons or events (e.g., 9/11); c) transferring of one medium to another (e.g., the conversion of novel into cinema); d) a transformation of appearance of something's original form in a completely different form (e.g., Bismarck as a beer-mug); e) a usable manipulation of dimension (e.g., an oversized glass); and f) an imitation of the past (e.g., new figures in the style of, for instance, the $19^{\text {th }}$ century) (Dorfles 1969). 
These three groups of criteria, developed by art critics, are the most common ways to qualify an object, attitude or idea, as kitsch. Yet, the discussion of kitsch is not limited to art criticism. In fact, since 1930 s, kitsch is widely problematized and questioned by philosophers, critical theorists, historians, artists, and essayists. In the following section, I present a thematic classification of the literature on the concept of kitsch. My preference for a thematic rather than a disciplinary classification is twofold. First, a disciplinary classification disguises rather than reveals the analytical connections between different disciplines. Second, most of the scholars who discuss the concept of kitsch cannot be classified under a single discipline.

\subsection{A Review of the Literature on Kitsch}

In the early 1930s a debate concerning the implications of technological reproducibility on culture in general, and on art in particular, developed among European and North American theorists. The literature on kitsch springs from this debate. I identify five thematic categories in this body of literature: 1) kitsch as an ersatz culture, 2) kitsch as a philosophical and existential phenomenon, 3) kitsch as "travestied aesthetic consciousness," 4) kitsch as a technique of political manipulation, and 5) kitsch as an aesthetic category. I devise this categorization in order to demonstrate which dimensions of the concept received more emphasis than others in each of the categories.

\subsubsection{Kitsch as an ersatz culture}

A quick glance at the writings of mass culture theorists (Greenberg 1961; Macdonald 1957; H. Rosenberg 1994; Ćelebonović 1969) will suffice to grasp the fact that their discussions on kitsch predominantly, even if unsurprisingly, focus on mass society and mass culture. Here, kitsch is depicted as a by-product of the Industrial 
Revolution. For, the Industrial Revolution entailed the urbanization of the masses, and in turn, unlocked the aristocratic privileges of reading and writing - i.e., cultivation [Bildung] - to everyone, without offering the leisure and comfort through which a genuine culture could be cultivated (Greenberg 1961, Ćelebonović 1969, Macdonald 1983).

The visible in-betweenness of the masses ${ }^{10}$ - proletariats and petty bourgeoisie generated a pressure on society for the creation of a new culture - that is, ersatz culture or kitsch - fitting "for those who are insensible for the values of a genuine culture" (Greenberg, 1961, p. 10). ${ }^{11}$ Accordingly, Greenberg described kitsch as "the debased and academicized simulacra of genuine culture, [which] welcomes and cultivates this insensibility" (Greenberg 1961, 10). ${ }^{12}$ This definition of kitsch brings forth the claim that there has to be a "fully matured cultural tradition" (Greenberg 1961, 10) at hand for kitsch to emerge and flourish. In Greenberg's terms, “[i]t draws its life blood, so to speak, from this reservoir of accumulated experience" (Greenberg 1961, 10).

\footnotetext{
${ }^{10}$ Prior to the rise of mass culture, a distinction was made between high culture and folk culture. It is claimed that the latter withered away with urbanization and industrialization (Greenberg 1961; Macdonald 1983). The main distinction between folk culture and mass culture is that the former mainly grew from below as a response to the needs of the people while the latter is fabricated by experts and technocrats, and imposed on the people from above in order to further the domination within society (Macdonald 1957; Macdonald 1983).

${ }^{11}$ Dwight Macdonald (1983) calls this new culture "masscult." According to him, the masscult produces not just unsuccessful art; but, more importantly, "non-art" or even "anti-art."

${ }^{12}$ Greenberg contrasted kitsch with the avant-garde in his famous essay Avant-garde and Kitsch (1939). Although both kitsch and the avant-garde, according to him, emerged as a result of the Industrial Revolution, and permanently destabilized the established aesthetic values, the avantgarde was able to "keep culture moving in the midst of ideological confusion and violence" (Greenberg 1961, 5). Although the avant-garde culture itself relies on imitation, this imitation is essentially different than the imitation inherent to kitsch culture - the former being the "imitation of imitating" (Greenberg 1961, 8). To put it more clearly, what is imitated here is the processes of art. For in the work of the avant-garde artist the content is dissolved completely into the form, and the work cannot be reduced to anything else, and thus, "creating something solely on its own terms" (Greenberg 1961, 6).
} 
Therefore, ersatz culture theorists depict kitsch as a "falsification of art," by means of which the works of art are decontextualized, sentimentalized, vulgarly reproduced, or by which ghastly objects are transformed and re-produced as aesthetically acceptable and effective (Dorfles, 1969). In this context, kitsch objects generally are depicted as cultural commodities, such as popular and commercial art and literature, advertisements, slick and pulp fiction, magazine covers, Hollywood movies (Greenberg 1961, Macdonald 1983), or as traditional kitsch (Ćelebonović , 1969), such as plastic knick-knacks, plaster buddhas, animal figurines, souvenirs, non-functional tumblers - all of which, according to the ersatz culture theorists, reflect vulgar taste in an attempt to imitate the life of a dominant class.

This however does not mean that kitsch has to be produced cheaply, as it can also be produced luxuriously. According to Greenberg, high-class kitsch serves to convert and water down the avant-garde material for its own uses. He illustrates high-class kitsch with some of the material published in The New Yorker (Greenberg 1961). However, Macdonald differentiates this high-class kitsch from the cheap mass-produced cultural products, and calls this high-class kitsch 'midcult,' and defines it as a form of culture that is a hybrid between masscult and high culture (Macdonald 1983).

Midcult has the essential qualities of masscult - such as the formulaic, standardized, mechanical, and standardless - but it pretends to respect the standards of high culture while vulgarizing it (Macdonald 1983, Dorfles 1969). The characteristics of midcult are identified as follows: a) it borrows the avant-garde procedures and distorts their form in order to popularize it; b) these procedures are borrowed only after they have been used for awhile so that they become familiar to the people; c) the message is 
constructed as a source of effect; d) it pretends to be art; and e) it satisfies its consumer by giving him/her the sense that he/she just experienced culture (Eco 1989, 192). Midcult is illustrated with magazines such as the Saturday Review, Harper's, the Atlantic, Horizon as well as Hemingway's The Old Man and The Sea, Thornton Wilder's Our Town, Archibald MacLeish's J.B. and Stephen Vincent Benét's John Brown's Body (Macdonald 1983, 37-40). Macdonald criticized mass culture "as the levelling imposition of the infantalistic and crude values of the masses upon the whole system of society, dragging down spiritual activities to the level of base material interests" (Markus 2011, $607)$.

In short, the theorists of ersatz culture depicted kitsch as "the culture of masses" or, a "debased form of high culture" that was to be found everywhere, from the totalitarian regimes of Italy, Russia and Germany to Western democracies (Greenberg 1961, Macdonald 1983). ${ }^{13}$ For both forms of regimes, the production of mass culture is a necessary cultural practice, either to project authority over the subjects through propaganda and pedagogy, or to promote the illusion that "masses actually rule!" (Greenberg, 1961).

Although Dorfles agrees with Greenberg, Ćelebonović and Macdonald about the lack of cultivation that the masses suffer and its implication for the relationship between the masses and art, he argues that the most important factor in the identification of kitsch resides not in the object, but in the "the attitude of the individual when confronted with artistic and natural phenomena, which are observed from that particular point of view [that] immediately transforms them into something inferior, false, sentimental and no

\footnotetext{
${ }^{13}$ Eco criticizes the conceptualization of ersatz culture as a surrogate for art. For more detail see (Eco 1989, 85-88).
} 
longer genuine" (Dorfles 1969, 29). The individual who adopts the aforementioned view is a Kitschmensch and only the examination of his view, according to Dorfles, can reveal the essence of kitsch.

\subsubsection{Kitsch as a philosophical and existential phenomenon}

Hermann Broch coined the concept of Kitschmensch. He was the first to claim that kitsch is not only a matter of capitalist production and/or bad taste; but more importantly, it is the sign of a particular historical sensibility which originates from the Romantic cult of beauty. Romanticism, Broch argued (1969b), substituted the transcendental aesthetic ideal - where beauty appeared as absolute and unattainable with the ideal in which beauty became the immediate and tangible goal for any work of art.

Therefore, in Romanticism, the artist became the "sublime priest" whose goal was to bring the eternal from its celestial heights to the level of mortal beings in every work of art (Broch 1969b). This process, according to Broch, is the process in which the system of art was transformed from an "open system" - namely, infinite - to a "closed system" - namely, finite (Broch 1969b). In the open system, the goal resides outside of the system. In other words, the goal - namely, beauty - always remains unattained, and thus, is endured as the standard of beauty. The system of art becomes closed when the immediacy and tangibility of beauty are identified as the goal of art, because such a goal is an attempt to bring the heavens on earth, which results in the relativization of the standards of taste (Broch 2002).

At this point, Broch draws a connection between academic art, which continually searches for rules of beauty and Romanticism while reminding the reader of the fact that 
neither academic art and Romanticism nor kitsch and academic art can be identified with each other. Yet, he emphasizes the fact that both academic art and Romanticism consist of a tendency to "render the system [of art] finite" (Broch 1969b, 62). He identifies this process - that is, raising the mundane to the level of the eternal - as "the precondition of every form of kitsch" (Broch 1969b, 62). Broch argued, Romanticism, "without [...] being kitsch itself, [has become] the mother of kitsch" (Broch 1969b, 62).

In this context, Broch claimed that kitsch is "certainly not 'bad art'; it forms its own closed system" $(1969 \mathrm{~b}, 62)$. But, what does this mean exactly? According to Broch, the relation of kitsch to art can be illustrated with the relation of the system of the AntiChrist to the system of Christ. He argued:

Every system of values, if attacked from the outside in its autonomy, can become distorted and corrupt... The enemy within, however, is more dangerous than these attacks from outside: every system is dialectically capable of developing its own anti-system and is indeed compelled to do so. The danger is all the greater when at first glance the system and antisystem appear to be identical and it is hard to see that the former is open and the latter closed. The Anti-Christ looks like Christ, acts and speaks like Christ, but is all the same Lucifer (Broch 1969b, 62-63).

In this context, kitsch plays the role of Anti-Christ, the enemy rising from within the value system of art, and thus, rendering itself invisible in becoming so much like what it rises against (Broch 1969b; Broch 2002). The sign that enables one to see the difference becomes manifest in the system in which it operates: the ethical or the aesthetic system.

Any system that operates on an aesthetic rather than on an ethical basis requires its followers to "work beautifully or live beautifully" rather than "work well and live well" (Broch 1969a; Broch 1969b; Broch 2002). Thus, the aesthetic system condemns its followers to the world of images, and in turn, blinds them to what is beyond. In other words, as a system of imitation, kitsch puts the spell of images over its followers. It 
should be noted here that the problem of kitsch, for Broch, does not lie so much in imitation itself. In agreement with Aristotle (1898), he argues that art imitates life. Thus, the problem with kitsch is not that it imitates, but in the fact that it imitates what is imitation itself, namely, art (Broch 1969b; Broch 2002). In choosing art as its reference, kitsch sacrifices the direct relationship between reality and art, and concentrates on the effects of beauty (Broch 1969a; Broch 2002; Broch 1969b). ${ }^{14}$

In doing so, kitsch, according to Broch, sacrifices the cornerstone of all artistic value: transcendence to worldliness, permanence to transitoriness, infinite to finite. By imposing mortal values on the transcendental, kitsch commits an unforgivable sin and becomes the "radical evil" of the value-system of aesthetics (Broch 2002, 27). Broch identifies two types of evil within a value-system: criminal and radical evil. As long as an externally located oppositional system can be found, to which responsibility for actions can be ascribed, the evil remains within the relativity of the value-system.

But, when such an outside force, aimed at the destruction of the system and abolition of its values, is no longer to be found, when the destruction becomes self-destruction, arising from and using the means of the system itself, a self-destruction that cannot be excused as "seduction" from without, then it is appropriate to speak of the effect of the 'radical evil' (Broch, 2002, 27).

The radical evil generates a "hypocritical exaltation" in its attempt to "unite heaven and earth in an absolutely false relationship" (Broch 1969b, 63). Therefore, for Broch, kitsch transforms human life into "a neurotic form of work of art, i.e., one which imposes a completely unreal convention on reality, thus imprisoning it in a false schema"(Broch 1969b, 64). While art reflects the image of a contemporary man in a broad sense, kitsch is

\footnotetext{
${ }^{14}$ The man of kitsch, therefore, "is the prisoner of a purely conventional system of symbols, and even if these symbols are copied from some sort of reality, the system is still a system of imitation" (Broch 1969b, 63).
} 
the aesthetic form of lying, which falls back on the contemporary man (Broch 1969a). This man, the Kitschmensch, always puts the beautiful as morally superior because it flatters a public sensitivity, which is always eager for its own heroic reflection.

In his analysis of Kitschmensch, Giesz contrasts the aesthetic distance in art with the sentimental self-enjoyment [Selbstgenuss] in experiencing kitsch. Accordingly, the Kitschmensch, he argues, enjoys himself while consuming the object, and is stimulated by the very fact of being moved by the object (Diaconu 2010). The attitude of the Kitschmensch is "idyllic and finds delight even in desperate situations by playing down their negativity or by converting them into sensational and melodramatic experiences" (Diaconu 2010, 104). That is to say, the lover of kitsch substitutes the 'real' with what is wished to be seen, felt, and/or experienced. ${ }^{15}$

Kundera's perspective on kitsch, like Broch and Giesz's, is a philosophical and existential one. He formulates the question of kitsch in relation to the ontology of being. For Kundera, kitsch is the weapon used against the discomforting dimensions of existence in a godless universe. He states:

Kitsch is something more than simply a work in poor taste. There is a kitsch attitude. Kitsch behavior. The kitsch-man's (Kitschmensch) need for kitsch: it is the need to gaze into the mirror of the beautifying lie and to be moved to tears of gratification at one's own reflection (Kundera 1988, 135).

To put it differently, kitsch holds up "a highly considerate mirror" that allows contemporary man to recognize himself in the counterfeit image it throws back at him, and to confess his own lies (Broch 1969a, 49); it glosses over harsh truths and

\footnotetext{
${ }^{15}$ The adoption of such attitude, according to Giesz, derives from the fundamental element of human existence, namely, "divertissement," a need to escape from the suffocating reality of everyday life, which manifests itself in different forms, such as anxiety, boredom or worry (Giesz 1969).
} 
anaesthetizes genuine pain. Thus, Kundera claims that kitsch is a "categorical agreement with being," for "[it] excludes everything from its purview which is essentially unacceptable in human existence" (Kundera 1999, 248). In other words, it is an 'aesthetic ideal' in a narrow, mundane sense - namely, an aesthetic ideal that is the projection of desires - that further culminates in a belief positing firmly the goodness of human existence, and therewith encouraging the ideal of humanity through speaking directly to the hearts and feelings of human beings.

Within the analyses of the Kitschmensch, the counter concept of kitsch is identified not as art but as reality. ${ }^{16}$ However, it is not only these analyses that examine the relationship between reality and kitsch. The depiction of kitsch as an ideology also derives from the examination of this relationship.

\subsubsection{Kitsch as "travestied aesthetic consciousness"}

While the analyses of Kitschmensch concentrate on the attitude of the observer toward the artwork and the world, Adorno and Horkheimer focus their analyses of kitsch on the capitalist socio-economic conditions under which the culture industry is produced. For Adorno, the culture industry "provides ersatz for the sensual immediacy of which it deprives people in a sphere where that is not its abode" (Adorno 1997, 13). In other words, through the colonization of the cultural sphere the (culture) industry imposes its (instrumental) rationality on the sphere of art. This is the sphere where the aesthetic truth manifests itself; it is the sphere where aesthetic experience is about the disappearance of the observer into the material, and not about the observer's enjoyment, or the fun of the art lover; it is the sphere in which the structure of the aesthetic object is the source of

\footnotetext{
${ }^{16}$ According to Rosenberg, kitsch does not have a counter concept. The only antagonist of kitsch is the reality itself (Rosenberg 1994).
} 
enjoyment rather than the feelings and emotions of the observer. The colonization of the cultural sphere thus leads to the reification ${ }^{17}$ of artworks and culture itself as well as the transformation of the relationship between the observer and the artwork, and in turn, the formulation of culture as a source of pleasure (T. W. Adorno 1997; T. W. Adorno 2001; Horkheimer 1982).

Kitsch, for Adorno, cannot only be traced back to the individual inadequacy of the artist; rather, it has its "own objective origin in the downfall of forms and material into history" (Adorno 1997, 501). He defines kitsch as "the precipitate of devalued forms and empty ornaments from a formal world that has become remote from its immediate context" (Adorno 1997, 501). That is to say, kitsch is able to offer objectively compelling and pre-established forms, and it is this objectivity that becomes the source of its justification. Adorno, however, was aware of the difficulties in differentiating true aesthetic fiction (art) from merely sentimental rubbish (kitsch). For, according to him, kitsch has a poisonous substance that is mixed with art. This poisonous substance is found in the ways in which kitsch makes use of the art of former times, and in turn, "sustains the memory, distorted and as mere illusion, of a formal objectivity that has passed away" (Adorno 1997, 501). Kitsch-objects, then, are "up-to-date" works of art whose objectivity provides a fertile source for kitsch production.

According to Adorno, kitsch cannot be understood only in aesthetic terms. Rather, it should be understood within the context of "the social," because it has a social function - that is, "to deceive people about their true situation, to transfigure their existence, to allow intentions that suit some powers or other to appear to them in a fairy-tale glow"

\footnotetext{
${ }^{17}$ The concept of reification is developed by Georg Lukács in his book History and Class
} Consciousness (1971). This concept will be examined in the second chapter in detail. 
(Adorno 1997, 502). In short, kitsch, for Adorno, is an ideology through which the intrinsic contradictions of the socio-economic system are concealed and transfigured, and in turn, the tormented individuals of the modern liberal democratic societies are mystified. This is done through the production of kitsch objects, by means of which the masses can escape from the boredom and toil of their lives. By the consumption of these objects manipulated pleasures are produced through masking of the frenzy of reality and the substitution of it [reality] with happy countenance (T. W. Adorno 1997; T. W. Adorno 2001; Horkheimer 1982). ${ }^{18}$

In contrast to Adorno and Horkheimer, Benjamin sees an emancipatory effect in technological reproducibility, especially its ability to free artworks from their "parasitic subservience to ritual" (W. Benjamin 2006c, 106), on the basis of which the authenticity of the artwork was defined. When the work of art is designed for its reproducibility, and not for its originality, authenticity ceases to be the criterion of artistic production. It is this transformation that, according to Benjamin, revolutionizes the whole social function of art. Art ceases to be the carrier of the cult value - i.e., the cult of beauty - through which human beings were to make sense of their experiences. Instead, it [art] becomes a vehicle to overcome the alienation created by the capitalist mode of production (W. Benjamin 2006c).

Although Benjamin expresses his belief in the revolutionary potential of the mass production of art, he emphasizes the need for art to be liberated from the "fetters of

\footnotetext{
${ }^{18}$ Under the conditions of the capitalist socio-economic structure, the only way to emancipation is through art, Adorno and Horkheimer claim. For it is only art, which can bring forth what is repressed on the empirical world by reality's compulsion to identity. That is to say, by detaching themselves from empirical reality, artworks free reality from the reified external experience (T. W. Adorno 1997; T. W. Adorno 2001; Horkheimer 1982).
} 
capitalist exploitation” (W. Benjamin 2006c, 113). If not, he argues, art turns into kitsch, thereby reconstructing the cult value (W. Benjamin 2002e). ${ }^{19}$ Benjamin writes:

The very last, the topmost face on the totem pole, is that of kitsch. It is the last mask of the banal, the one with which we adorn ourselves, in dream and in conversation, so as to take the energies of an outlived world of things. What we used to call art begins at a distance of two meters from the body. But, now, in kitsch, the world of things advances on the human beings; it yields to his uncertain grasp and ultimately fashions its figures in his interior (W. Benjamin 2005d, 4).

To put it differently, kitsch is the means through which we beautify ourselves within the disenchanted world of things. It is "the topmost face on the totem pole" because kitsch recreates cult values when there is nothing left beyond the images to look forward to. Such recreation is done by the elimination of the distance between things, ideas, fantasies and human beings through the utilization of human beings' interior needs. Thus, for Benjamin, kitsch undercuts the distinction between art and useful object. Moreover, it provokes a kind of intimacy which is heart-warming and conducive to heart's ease (Menninghaus 2009; W. Benjamin 2002d). It is these qualities of kitsch - i.e., its usefulness, and ultimately its heartening, namely, its sentimental character - that bring it closer to the masses, and it is these qualities which should be integrated into the expressions of social dream energies only to be dialectically overcome (W. Benjamin 2002a).

Conversely, Calinescu depicts kitsch as an expression of a bourgeoisie life style, which has become desirable for the rest of society with the rise of affluence. He thus associates kitsch within the 'hedonistic' character of the mentality of the middle class. Calinescu argues that "[t]he middle-of-the-road hedonism" finds its perfect illustration in

\footnotetext{
${ }^{19}$ For example, film-capital fosters the cult of a movie star, which preserves the magic of the personality. But, the cult value of the movie star originates in nothing other than its mysterious commodity character (W. Benjamin 2002e).
} 
the "principle of mediocrity" (Calinescu 1987, 248). This hedonism of the middle class, he argues, is confined to the use of spare time since the bourgeoisie became an active class. Therefore, according to Calinescu, "a systemic attempt to flee from daily reality" (Calinescu 1987, 248) manifests itself in kitsch. For, it "appears as an easy way of 'killing time,' a pleasurable escape from the banality of both work and leisure" (Calinescu 1987, 248). ${ }^{20}$ In this context, kitsch is depicted as an "ideologically manipulated illusion of taste" or "false aesthetic consciousness" (Calinescu 1987, 240).

Although Calinescu formulates kitsch as a form of ideology, similar to Adorno and Horkheimer, he does not agree with them in their claim that kitsch is deliberately produced by the dominant class to divert the working class from its revolutionary goals. On the contrary, kitsch, according to Calinescu (1987) emerges spontaneously. He argues:

Kitsch is the direct artistic result of an important ethical mutation for which the peculiar time awareness of the middle classes has been responsible. By and large, kitsch may be viewed as a reaction against the 'terror' of change and meaninglessness of chronological time flowing from an unreal past into an equally unreal future. Under such conditions, spare time is felt as a strange burden, the burden of emptiness. [...] The fun of kitsch is just the other side of a terrible and incomprehensible boredom (Calinescu 1987, 248).

To put it differently, for Calinescu, kitsch results from the time consciousness of the hedonistic middle class(es) who react to the flux of time and the boredom of modern life.

Like Calinescu, Arendt starts her analysis of kitsch in reference to the middle classes. She posits the origin of mass society (and mass culture) in the 'good society' of the eighteenth and nineteenth centuries where the European middle classes found

\footnotetext{
${ }^{20}$ According to Calinescu, at a practical level, this idea of relaxation leads to the rise of gadgets for the household in order to perform the household activities with as little effort as possible. Therefore, these gadgets are categorized as kitsch objects (Calinescu 1987, 245).
} 
themselves in "an uphill fight against aristocracy and its contempt for the vulgarity of sheer moneymaking" (Arendt 1993, 203). ${ }^{21}$ In this fight for social position, the educated philistine utilized culture to elevate himself "out of the lower regions, where supposedly reality was located, up into the higher, non-real regions, where beauty and spirits were at home" (Arendt 1993, 202).

In other words, the educated philistine escaped into pure poetry in order to see reality through a "veil of sweetness and light" (Arendt 1993, 203). Consequently, culture manifested itself in objects of social and individual refinement and tools of selfperfection or self-education while losing its principal quality to "grasp and move the reader or the spectator over the centuries" (Arendt 1993, 203). It is in this attitude of the philistine that Arendt finds an inspiration for the rise of kitsch products in the nineteenth century. In other words, for Arendt, it is not the spread of culture to the masses, ${ }^{22}$ but the rise of the entertainment industry as a response to the needs of the cultural philistine that is the source of kitsch. Therefore, her attack is directed not at the consumers of the entertainment industry, but, at the "special kind of intellectuals" (Arendt 1993, 203) who are the promoters and producers of this industry. ${ }^{23}$

\footnotetext{
${ }^{21}$ According to Arendt, mass society emerged when the mass of the population was incorporated into society in the sense that the masses were liberated from the burden of labour which then gave them the leisure time for 'culture' (Arendt 1993).

${ }^{22}$ Although Benjamin agrees with Arendt about the loss of breadth in writing and the debasement of the word - especially through the expansion of journalistic style, he also sees the possibility of awakening under the conditions of the "literarization of living" (W. Benjamin 2007, 225). According to him, the literarization eliminates the distinction between author and public, thereby making it possible for the reader to become a writer, "that is, a describer, but also a prescriber" (W. Benjamin 2007).

${ }^{23}$ Rosenberg was the first person to problematize the intellectualization of kitsch. He criticizes intellectuals who write about what is right or wrong about kitsch in claiming that in doing so, these intellectuals produce "kitsch critics of kitsch." For such critiques (whether they are positive or negative) serve to increase in the production of kitsch (H. Rosenberg 1994).
} 
Like Arendt, Eco does not disclaim the cultural democratization carried out by mass reproduction. He argues that as long as mass culture does not pretend to be original, in the sense of being capable of novel experiences, there is no problem. The problem arises when mass culture claims to be original. For such claim reduces it [mass culture] to kitsch (Eco 1989). According to Eco, what is required then is a well-balanced cultural context in which mass culture products could be kept under control, dosed, and seen to that "they are not sold and consumed as art" (Eco 1989, 194).

\subsubsection{Kitsch as a technique of political manipulation}

Friedländer argues that kitsch speaks to a specific type of sensibility of people concerning the need to reconcile with the social environment that surrounds them, a common sensibility "for the order of things - for the established order and for things as they are" (Friedländer, 1984, 26). In this regard, kitsch is formulated as a means by which submission and consensus are continually fabricated, and maintained within societies. In this process, culture is instrumentalized for the purposes of propaganda. It is at this point where the relationship between (political) kitsch and mass sentiment becomes manifest (Montgomery 1991; Kundera 1999).

In his analysis, Friedländer makes a distinction between 'common kitsch' and 'uplifting kitsch.' According to him, the former tends toward universality and emotional communion of the whole while the latter is rooted, symbol-centered and emotionally linked to the values of a specific group. He describes the function of uplifting kitsch as symbol reinforcing while the function of common kitsch as symbol demeaning. Thus, he claims, it is the uplifting kitsch that is dangerous and ethically problematic. For it is the 
manifestation of kitsch "as a principle of evil, much beyond the value system of art" (Friedländer 1984; Friedländer 1990).

Friedländer illustrates 'uplifting kitsch' with Nazism. The hypnotic power of Nazism, he argues, originates in the amalgamation of the contradictory elements of a kitsch representation of death: on the one hand, "an appeal to harmony, to emotional communion at the simplest and most immediate level" (Friedländer 1984, 27) - that is, universal sentimentality - and on the other hand, "solitude and terror" (Friedländer 1984, 27) - that is, the attraction to nothingness. It is this juxtaposition of two contradictory elements that constitutes the foundation of a specific 'religious aesthetic' because here death takes on an essential religious and/or mythical dimension. Such amalgamation results in the justification of the annihilation of a people through the insertion of extermination into the stable values of society. Thus, taking part in the extermination is made into a universally accepted behaviour, and thus, is emptied of its horror.

[...] blowing up of synagogues, the extermination of the Jews, the bombing of London [...] He [Hitler] shows first of all that such deeds are thinkable and possible, destroys the safeguards and gives the masses an opportunity for agreement. The frantic applause that accompanied his appearance was the agreement of self-destruction, a highly nihilistic act (Ernst Jünger qt. in Friedländer 1984, 71).

In this context, the aesthetic hold of kitsch serves to formulate unacceptable, unforgivable, terrifying actions, and attitudes into a familiar, identifiable, bearable and universally acceptable course of things, and in turn, casts a lasting and convincing spell on the people (Friedländer 1984).

Friedländer argues that fascist and communist regimes utilize kitsch as a technique of political manipulation, mainly at the times of total war. Yet, he distinguishes between fascist and communist kitsch. According to him, the former creates an 
apocalyptic imagination while the latter utilizes kitsch to celebrate life. He also notes that kitsch is used during election campaigns, or when mobilization is necessary in democratic regimes. Yet, to him, this common or commercial kitsch is neither dangerous nor politically significant (Friedländer 1990; Friedländer 1984).

\subsubsection{Kitsch as an aesthetic category}

Tomas Kulka (1996) argues that the socio-historical conception of kitsch results in the categorization of certain objects under kitsch, not because of their inherent structural similarities or their immanent structures, but because they fulfill a specific social function in a given society. However, there are aesthetic and artistic reasons independent from the socio-historical function of kitsch - for the categorization of certain objects under kitsch (Kulka 1996). Thus, the analysis of kitsch as an aesthetic category concentrates on the demonstration of what is aesthetically deficient and artistically inferior in kitsch.

One of the most important aesthetic deficiencies of kitsch is identified as its mass appeal, or popularity. Such appeal is achieved through the use of images, objects and themes that are instantly and effortlessly discernable, and are highly charged with "stock emotions that spontaneously trigger an unreflective emotional response" (Kukla 1996, 26). Kulka (1996) illustrates these objects with pictures of kittens and puppies, children in tears, beaches with palms and colourful sunsets, mountain panorama from Swiss villages, etc.

Umberto Eco criticizes this focus on the "effects" in identifying the characteristics

of kitsch. He argues that in certain societies art is integrated into daily life to such a 
degree that its primary function is to provoke particular effects - i.e., religious, erotic, and ludic. But, he argues:

The production of an effect becomes Kitsch in a cultural context in which art is seen not as a technical ability (as was the case in the ancient Greece and in the Middle Ages) but rather as something produced for art's sake (Eco 1989, 184).

Here, Eco makes a distinction between art and artisticity (Eco 1989). Accordingly, the former is seen as autonomous, and is appreciated for its form while the latter is related to any process, which uses artistic means to achieve a heteronomous end, such as (the art of) cooking, living, conversation, etc. Although artistic means might be utilized in these processes, they all serve a standard that is external to themselves. Yet, for a work to be art, "it would have to be appreciated for its style rather than desired for its [desired effect]" (Eco 1989, 184) Eco thus categorizes kitsch under artisticity since kitsch both utilizes artistic means and aims at achieving a desired effect(s).

Secondly, Eco (1989) argues that although kitsch does not, in any substantial way, enrich one's association with the depicted object, image or theme, it pretends to be art. And this, according to Eco, is the most definitive quality of kitsch, and it is this quality that creates the dialectical relationship between art and kitsch. At this point, Eco (1989) criticizes the conceptualization of kitsch as ersatz culture (Greenberg 1961; Macdonald 1957; Dorfles 1969; Ćelebonović 1969), and as culture industry (T. W. Adorno 2001; Horkheimer 1982; T. W. Adorno 1997). He argues that if kitsch were only a series of messages communicated by the culture industry in order to satisfy certain cultural demands, there would have been no dialectical relationship between kitsch and avantgarde. Thus, he makes a distinction between mass products that aim at the production of effects without pretending to be art, and the ones that pretend to be art (Eco 1989). 
According to him, the cultural product is meant only for consumption. Therefore, it has nothing to do with an aesthetic experience. Eco develops this distinction in reference to Macdonald's conceptualization of "masscult" and "midcult" (Macdonald 1983). It is argued that while the former is neither concerned with itself nor with its audience, the latter wishes to pass for the real thing itself (Macdonald 1983). Despite adopting Macdonald's conceptual distinction, Eco criticizes him for his disregard towards the dialectical relationship between the avant-garde and kitsch (Eco 1989).

According to Macdonald (1989), the avant-garde is the only manifestation of high art, and thus, any attempt to mediate it results in bad taste. Working under the assumption that the man of industrial society is beyond recovery, Macdonald formulates a view of (aesthetic) value which is based on the non-diffusion and the non-diffusibility of the artwork (Macdonald 1957; Macdonald 1983). Accordingly, in Macdonald's view, if a cultural product, which is appreciated and desired by the few, comes to be desired by the many, this product loses not only its (aesthetic) value but also its authority.

Eco finds Macdonald's approach to mass society totalizing and reductive. For mass culture with its "immensely elaborate network of mediations and reactions" can neither be reduced to kitsch nor to bad taste in its totality (Eco 1989, 187-194). Therefore, he finds the attributes of kitsch in the object(s), which "appears already consumed; reaches the masses, or the average customer, because it is already consumed; [and] will quickly be re-consumed because the use to which it has already been put by a large number of customers has hastened its erosion (Eco 1989, 197). Therefore, for Eco (1989), despite its aesthetic and artistic worthlessness kitsch is capable of creating a dialectical tension within art, thereby leading to the creativity of the avant-garde. On the contrary, 
for Kulka, kitsch is "an enemy of art, camouflaged as art, that ... puts on the disguise of art in order to infiltrate and destroy art" (Kukla 1996, 44),

Eco also argues that the kitsch object - which (re)produces an artwork, such as reprints of Van Gogh's Withered Sunflowers - cannot eliminate the arousal of a genuine communication between this (reproduced) artwork and the consumer. For "the consumption of a form is not always total and irreversible," which means that "the unachieved promise of a potentially fuller appreciation" remains intact in the background of the reproduced artworks (Eco 1989, 199). Accordingly, it is possible that one day the consumer of this print version of Van Gogh's painting might "bump into an aspect of [the] work - one of the infinite aspects of its structural complexity - that will unexpectedly offer him a tenuous glimpse of a much richer sort of communication, therefore rescuing the work from the basest form of consumption" (Eco 1989, 198).

Like Eco, Gumpert emphasizes the potency of kitsch. But, not in reference to the dialectical tension created within art by kitsch; rather, in stressing the creation of revival and confirmation by mocking of the "original" in duplication, and in turn, the degeneration of the original. Each replica, Gumbert (1999) argues, ridicules the ritual power of "the original," and thus, it is "a story about desecration and resurrection" (176). Thus, his view of kitsch is built on his criticism of the "Western faith in and fear of representation" (Gumpert 1999, 157). Thus, according to him, the debate over kitsch is nothing more than a playing out of the "Platonic logic of supplementarity" (mimesis to truth) or the "Augustinian logic of referentiality" (sign to God) ${ }^{24}$ all over again. Thus,

\footnotetext{
${ }^{24}$ According to Augustine, only God is referred to by all signs; it is God alone who is to be
} enjoyed and the rest are only objects of utility (Augustine 1997). 
these debates recall the combat of idolatry (the worship of image) against iconoclasm (the desecration of image) in the Western tradition (Gumpert 1999, 158-159).

With this claim, Gumpert also suggests that kitsch is not a modern phenomenon; but rather, it has existed throughout the Western tradition of representation. ${ }^{25} \mathrm{He}$ argues: "Kitsch is the $\sin$ of representation; it is the representation as sin; in other words: idolatry. To condemn kitsch is to return to the Hebrew tradition of the rejection of graven image, and Plato's prosecution of imitation" (Gumpert 1999, 157). In other words, it is to say: "the true god (art) is real; the idol (kitsch) is an imitation of and surrogate for the real"'(Gumpert 1999, 158) (emphasis in original).

In defining "kitsch as idol," Gumpert reaches the following conclusions: 1) "god is singular; the idol is plural;" the kitsch-idol is a reproduction; 2) "god is original; the idol is secondhand;" the kitsch-idol is a product which is designed to be bought and sold; 3) "god is natural; the idol is artificial;" the kitsch-idol is an imitation, not the "real" object; 4) "god is immaterial, abstract; the idol is fetishistic;" the kitsch-idol is anthropomorphized; 5) "god is absolutely distant; the idol is intimately close;" the kitschidol is attainable (Gumpert 1999, 158).

$\mathrm{He}$, therefore, rejects both the modern and the postmodern arguments in claiming that they both remain nostalgic prophets in disclosing the relationship between the real and the copy, the original and the reproduction, art and kitsch. Their difference resides in their attitudes toward the condition that came about as a result of the collapse of the distinction between the original and the double; the former bans while the latter celebrates it (Gumpert 1999). In short, Gumpert criticizes the condemnation of kitsch as falsehood or, as a lie. According to him, such an approach nostalgically re-invites the

${ }^{25}$ For more detail on early kitsch see (Gumpert 1999, 158-160). 
(arbitrary) distinction between the true and false god. Thus, he suggests that the hierarchical distinction between the copy and the original should be set aside, and both the copy and the original should be recognized as simulations.

\subsection{Critique of the Literature on Kitsch}

It is not a coincidence that the concept of kitsch emerged in the nineteenth century, the century in which both the commodity form and technological reproduction expanded beyond the sphere of production, penetrating into the other spheres of life such as the social, the political, and the cultural. The birth of kitsch objects and their unceasing proliferation are a testimony that kitsch is one of the stamps of modernity. This is why it is almost impossible to decide whether the elusiveness of the meaning of this concept derives from its own qualities or, from the paradoxes of modernity, which find their expressions in and through kitsch.

In this dissertation, I develop a comprehensive study of kitsch, a study that goes beyond the scope of the existing literature, which, in general, has been preoccupied with identifying what qualifies a thing as kitsch. In the above section, I demonstrated that the existing literature consists of the discussions of the various expressions of kitsch (e.g., kitsch as an objet, an idea, an attitude) as well as the discussions of why kitsch emerged. All of these analyses however, focus on one of the spheres of life (e.g., the social, the aesthetic, the economic, the cultural), thereby failing to reveal the interaction and connectedness among the various aspects of life.

The examination of kitsch as "ersatz culture" presents a sociological and cultural reading of the concept (Greenberg 1961; Macdonald 1983; Dorfles 1969; Ćelebonović 1969; H. Rosenberg 1994). Here, kitsch is depicted as a by-product of the Industrial 
Revolution, and the masses are depicted as the precondition of kitsch. Thus, the ersatz culture theorists examine kitsch in its relation to high culture - that is, a "genuine," "authentic" and "true" culture whose autonomy is being threatened by the debased culture, that is, kitsch.

In their analysis, the ersatz culture theorists limit the analysis of kitsch to the spheres of the social and the cultural, and depict kitsch as a form of 'demagogy' striving to erect an 'official culture' on behalf of authority under the rule of totalitarian regimes (Greenberg 1961) or, a form of debased art responding to the insensibilities of the new dwellers of urban cities in Western liberal democracies (Greenberg 1961; Ćelebonović 1969; Macdonald 1957; Dorfles 1969). The reliance of the ersatz culture theorists on the distinction between high and low culture leads them to disregard, or be blind to, the fact that the tradition within which this distinction was valid was breaking down under the conditions of the commodity form and technological reproduction (W. Benjamin 2006c) - both of which irreversibly altered the fabric of everyday life and the forms of communication as well as human perception and experience.

The theorists of Kitschmensch identify kitsch as a philosophical and existential phenomenon (Broch 1969b; Giesz 1969; Kundera 1999). In this context, kitsch is seen as the mark of a particular historical sensibility, which originates in the Romantic cult of beauty - in which the transcendental aesthetic ideal was substituted with the immediate and tangible notion of beauty (Broch 1969b; Broch 2002). This shift, it is argued, resulted in the transformation of the system of art from an 'open' to a 'closed' system. That is to say, the system of art ceased to operate on the basis of ethical values, and started to operate on the grounds of aesthetic values (Broch 1969b; Broch 2002). As a result, it has 
become possible for the observer to adopt an aesthetic form of lying as an attitude in her/his relation to the external world, by means of which $\mathrm{s} /$ he could affirm her/his existence (Broch 1969b; Giesz 1969; Kundera 1999).

The idea of the newly emerging historical sensibility and its function on the modern individual's affirmation of oneself is an important one. Yet, the association of this sensibility with an 'aesthetic ideal' that is portrayed as an aesthetic form of lying for it is understood to be merely the projection of desires and thus, a devaluation of transcendental notion of beauty - results in the distinction of 'true' and 'false' aesthetic ideal, thereby reproducing the distinction between high and low culture, and/or ethical and unethical existence. Moreover, the emphasis on the role of the transformation of aesthetic values in the emergence of this new sensibility results in the disregard of the effects of economic, social, political and technological transformations.

Adorno (2001) and Horkheimer (1982) conceptualize kitsch as "false aesthetic consciousness." The penetration of exchange relations into the cultural sphere, they argue, leads to the reification of culture and art, resulting in the reconstruction of culture as a source of pleasure. In short, kitsch, for Adorno and Horkheimer, is an ideology through which the intrinsic contradictions of the capitalist social relations of production are concealed and transfigured, and in turn, the tormented individuals of the modern liberal democratic societies are mystified. This analysis, however, reproduces the Marxist assumption that the superstructure is the reflection of the infrastructure. On the contrary, Benjamin convincingly argues that the relationship between the infrastructure and superstructure is considerably more nuanced, and as such it is better characterized as 
expressive (allowing for mutual conditioning) rather than reflective (limited to unidirectional hierarchy). ${ }^{26}$

Similar to Adorno and Horkheimer, Calinescu conceptualizes kitsch as false aesthetic consciousness or, an "ideologically manipulated illusion of taste," which emerged spontaneously with the rise of bourgeois society. Although he associates the growth of kitsch with the "capitalist technology and business interest" (Calinescu 1987, 8), Calinescu does not find the problem of kitsch in the processes of commodification and reification - like Adorno and Horkheimer - but in a peculiar time-consciousness, in which time is understood in reference to efficiency. In this "extremely time-conscious civilization" (Calinescu 1987, 8), he argues, kitsch functions to 'save time' through achieving enjoyment via effortless and instantaneous activities, and to 'kill time' by temporarily freeing oneself from the disturbed time consciousness, thereby "making bearable [the] otherwise empty, meaningless present" (Calinescu 1987, 9).

Although Calinescu's work The Five Faces of Modernity (1987) is one of the most elaborate studies on kitsch, his reading of kitsch falls prey to the problem of restricting the understanding of kitsch to cultural and social contexts. Moreover, he makes a number of contradictory claims. For instance, although he conceptualizes kitsch as an "ideologically manipulated illusion of taste" (Calinescu 1987, 240), he then suggests that it [kitsch] has risen spontaneously. These two arguments are contradictory. For, if kitsch is an ideologically manipulated illusion of taste, the manipulation of taste as such must serve certain political, social and economic purposes. What is interesting is the fact that Calinescu acknowledges that taste is manipulated by the market. He states:

\footnotetext{
${ }^{26}$ Benjamin's argument regarding the relationship between the infrastructure and superstructure will be examined in more detail in Chapter II.
} 
" $[\mathrm{N}]$ early everything directly or indirectly associated with artistic culture can be turned into something fit for immediate consumption" (Calinescu, 1987, p. 247). Yet, he then proceeds to disregard the significance of the relationship between kitsch and the capitalist mode of production by associating the existence and endurance of kitsch to the "peculiar time awareness of the middle classes" (Calinescu 1987, 248). As such, he contradicts his own claim which states that "consumption [has become] a sort of regulating social ideal" (Calinescu, 1987, p. 245).

These contradictions in Calinescu's argument originate from two sources. Firstly, the restriction of his examination of kitsch to the cultural and social spheres has resulted in the exclusion of the political and the material from his analysis. Secondly, Calinescu has attempted to prioritize the peculiar time-consciousness and the hedonistic character of the middle class mentality as the fundamental dimensions of understanding kitsch; however, he has not provided a political economic assessment of the middle class(es) which are at the center of his analysis.

Arendt has related the rise of kitsch to the educated philistine of the eighteenth and nineteenth centuries' "good society" whose engagement with culture was fundamentally instrumental. The habituation into the instrumental engagement with culture along with the commodification of cultural objects, according to Arendt, has resulted in the transformation of the role of culture in Western societies. As a result, she argues, mass society has started to seize upon cultural objects, the danger of which is their consumption and destruction by the life process of society.

In his examination of kitsch as a technique of political manipulation, Friedländer brings forth the political dimensions of kitsch, by discussing the ways in which 
submission and consensus are created. In his analysis, he turns his attention to Nazism, and illustrates the ways in which (political) kitsch is utilized in order to generate a mass sentiment. At this point, he specifies the role played by kitsch representations of death, which is one of the most important points of his analysis. However, Friedländer fails to explain and justify the reason why kitsch representations of death are associated with, and restricted to, fascist and communist regimes. For the examination and deciphering of kitsch representations of death within liberal democratic societies will shed light not only on the operation and function of kitsch within the political sphere in these societies but also expand our understanding of the concept. Therefore, in this dissertation, I further examine the relationship between politics and kitsch in Western liberal and/or social democratic societies.

The conceptualization of kitsch as an aesthetic category is the most problematic among all because it confines the analysis of kitsch merely to the aesthetic sphere. The isolation of the aesthetic sphere in this way results in attempts to find a fitting place for kitsch within the value system of aesthetics. However, such attempts become vain in a context in which the influence of technological reproducibility on both the aesthetic sphere and human perception is irreversible. Besides, in a world in which "the uppermost values [have] devalue[d] themselves", in a world in which "all goals are annihilated" and “all estimates of value collide against one another" (Heidegger 1991, 157), it becomes rather meaningless to hold onto and re-impose the values that have lost their place in time and space. 


\subsection{Concluding Remarks:}

Each of the five categories identified explore the rise, expansion, and predomination of kitsch in modern societies. These discussions were initiated by the concerns regarding the effects of technological reproduction on culture in general, and on art in particular, in the 1930s. As demonstrated above, in each category one (or two) dimension(s) of the concept of kitsch is emphasized more than others. For instance, ersatz culture theorists focused their analysis on the social aspect while the theorists of Kitschmensch concentrated their analysis more on the aesthetic and existential aspects in explaining the emergence and expansion of kitsch.

Yet, all these conceptualizations have one common denominator: that is, the assumption of the unity of art as a discipline and its objects and practices. Therefore, in the literature kitsch is conceptualized in its relation to, or perhaps more precisely, in comparison to, 'authentic' or 'autonomous' work(s) of art, and genuine artistic activity, thereby reproducing a dichotomy between 'true' and 'false' art. In contrast to these conceptualizations, in this dissertation, I propose to theorize kitsch by weaving a thread through the different spheres of everyday life within which kitsch finds its expression. Weaving such a thread, as Benjamin argues, requires a questioning of "the closed unity of disciplines and their products" (W. Benjamin 2006c, 261).

In his Eduard Fuchs, Collector and Historian (1937) essay, Benjamin quotes Engels:

It is above all this semblance of an independent history of state constitutions, of legal systems and of ideological conceptions in each specialized field of study, which deceives most people. [...] And ever since the bourgeois illusion of the eternity and finality of capitalist production entered the picture, even the overcoming of the mercantilists by the physiocrats and Adam Smith is seen as a mere victory of thought - not as the reflection in thought of changed 
economic facts, but as the finally achieved correct insight into actual relations existing always and everywhere (Engels qt. in W. Benjamin 2006c, 261).

Drawing on Engels' critique of the separation of the specialized fields of history, Benjamin challenges the unity of any discipline in itself, and the object(s) and practices of that discipline. Benjamin illustrates this idea in reference to the unity of art history and its object, namely, 'art.' Here, he questions both the unity of art itself and the works that come under the rubric of art. Thus, he puts into question not only what constitutes the artwork as an object of art but also the discipline of art that study these objects and practices. In doing so, he disperses the unity of the object (e.g., art) into the world which contains, and which is contained, in these objects (e.g., artworks) and practices (e.g., creativity). As such, he disperses the disciplines into the world spatially, and into history temporally. ${ }^{27}$

Benjamin also emphasizes the fact that the historical object, for a historical materialist, is not

a tangle of mere factualities but out of the numbered group of threads representing a woof of a past fed into the warp of the present. [...] [T] his woof is thoroughly dialectical. For centuries, threads can be lost, only to be picked up again by the present course of history in a disjointed and inconspicuous way. The historical object removed from pure facticity does not need any "appreciation." It does not offer vague analogies to actuality, but constitutes itself in the precise dialectical problem [Aufgabe] which actuality is obliged to resolve (W. Benjamin 2006c, 269).

Following Benjamin, in my analysis, I remove the concept of kitsch from pure facticity. In doing so, I eliminate the need to respond to the questions regarding the dichotomy of 'true' and 'false' art, or to put it differently, the need to investigate the reasons of

\footnotetext{
${ }^{27}$ Benjamin writes: "For the dialectical historian concerned with works of art, these works integrate their fore-history as well as their after-history; and it is by virtue of their after-history that their fore-history is recognizable as involved in a continuous process of change" (W. Benjamin 2006c, 261).
} 
'appreciation' or 'condemnation' of kitsch within the unity of art and culture. For, I view the order of values that had previously determined the consideration of art has lost its influence under the conditions of the commodity form and technological reproduction.

Adapting Benjamin's critique "the closed unity of disciplines and their products" (W. Benjamin 2006c, 261), in this dissertation, I aim to pick up the threads that have been lost "by the present course of history in a disjointed and inconspicuous way" (W. Benjamin 2006c, 269). Thus, I propose a radical re-appropriation of the concept of kitsch - beyond its restrictive conceptualization that references culture in general, and art in particular. Thus, I construct the concept of kitsch theoretically in order to explore the relationship between commodity form, technology, aesthetics, perception, experience, and politics, and in turn, develop a nuanced understanding of the modern condition. 


\section{Chapter III: Capitalism, Culture and Technology}

\subsection{Introduction}

In the nineteenth century the foundation of the technological age was laid out, and capitalism solidified itself within the social relations of production by focusing its energies on the development of a system of mass production. Half a century later, the transformations that had taken place in the economic structure - commodity production and exchange relations - started to manifest themselves in all areas of life giving culture a crucial role in the reproduction and expansion of the capitalist mode of production. The significance of culture within the production and social reproduction processes has become even more pronounced after World War II, leading to increasing interest in the examination of the cultural sphere. Such examinations were often concerned with the 'state' of the artworks in the age of technological reproduction (Lukács 1971a; T. W. Adorno 1997; Horkheimer 1982; T. Adorno and Horkheimer 2002; T. W. Adorno and Horkheimer 2002b; W. Benjamin 2005d; W. Benjamin 2005e; W. Benjamin 2006c; W. Benjamin 2006d), ${ }^{28}$ raising questions about the experience of reality since "reality is a phenomenon, a putative object of experience" (Germain 2009, xi).

Lukács discussed the question of reality through his theory of reification. On the basis of a Marx's analysis of the commodity, he argued that the commodity form is the "universal structuring principle" of capitalism which "penetrate[s] society in its all aspects and remold[s] it in its own image" (Lukács 1971, 85), and called this process reification. Adorno and Horkheimer, on the other hand, problematized the transformation

\footnotetext{
${ }^{28}$ The interest in the cultural sphere in this period was not limited to Marxist theorists; in fact, interest was expressed by theorists and philosophers with different political orientations. For example, The Revolt of the Masses (Gasset 1994) (originally published in 1931) and The Origin of the Work of Art (Heidegger 2001) (originally published in 1936) also raised concerns about the issue of the state of art in modern society.
} 
of cultural objects into standardized, mass-produced commodities through their concept of the culture industry, and questioned the implications of this process on society in general, and individuality in particular. They argued that the striking unity of the macrocosm and microcosm created by the massive administrative complexes of capitalism and the culture industry produces docile, subservient, and content producers and consumers (T. Adorno and Horkheimer 2002). In contrast to Adorno and Horkheimer, Benjamin argued that cultural goods are not entirely determined by exchange systems. To explain the effects of the commodity form and technological reproduction on the human perception of reality, he turned to the exploration of Marx's notion of phantasmagoria.

In this chapter, I will examine the effects of the commodity form and technological reproduction on the collective organization of human perception, by deciphering the nature of the newly emergent reality and the ways in which this reality operates. In doing so, I set the ground on the basis of which I develop a new definition of kitsch, a definition that reflects kitsch as one of the defining characteristics of modernity. In this chapter, therefore, I first present an examination of commodity production and the commodity form within which, use-value, exchange value and commodity fetishism are explained. In the second section, I turn to the concept of reification in order to demonstrate the ways in which the exchange relations penetrate into other areas of life. I illustrate the implications of this process of reification through a discussion of the commodity analysis of art.

In the third section, I examine Marx's and Benjamin's understandings of phantasmagoria, and demonstrate how Benjamin builds on Marx by expanding the 
content of the term to depict the transformation of the collective organization of human perception under the conditions of technological reproduction. In this section, I introduce an analytical distinction between what I identify as 'first-order' phantasmagoria and 'second-order' phantasmagoria in order to show: 1) the apparition of different dimensions of reality under the conditions of commodity form and technological reproduction, 2) the type of relationship that exists between these two dimensions of reality, and 3) the ways in which these dimensions of reality intersect and what the effects of this intersection on the collective organization of human perception. This analysis thus, demonstrates the different layers of reality at play under the commodity form and technological reproducibility, and the ways in which they interact with one another.

\subsection{Commodity Form, Commodity Fetishism}

"The wealth of societies," Marx argues, "in which the capitalist mode of production prevails, presents itself as 'an immense accumulation of commodities,' its unit being a single commodity" (Marx 1887, 26). In other words, commodity production is peculiar to the capitalist mode of production just as capital is a form specific to commodity production (Uno 1980). ${ }^{29}$ For Marx, capital presupposes money, and money arises from commodity exchange. Not all products however, are commodities; rather,

29 Does this mean that there was no commodity produced prior to the capitalist mode of production? For Marx, there had been markets throughout history and in these markets people exchanged products. These products however were part of a 'petty commodity production' process in which the relationship between people was characterized as: Commodity-MoneyCommodity [C-M-C ${ }^{1}$. In this form of production, people entered into the market in order to sell their product, which then provided them the means (money) to buy a product that they needed. In other words, what was happening in the petty commodity production was: "selling in order to buy" (Marx 1887, 71). "The exchange becomes an accomplished fact by two metamorphoses of opposite yet supplementary character - the conversion of the commodity into money, and the reconversion of money into a commodity" (Marx 1887, 71). The product bought then withdraws from the market to be consumed. For more detail see (Marx 1887; Harvey 2010). For Marx, commodity production and capital coincide with each other. To put it more precisely, they are specific to each other. 
they adopt the commodity form when they are mutually exchanged. As commodities, they generate money which then brings capital into being. ${ }^{30}$ In capitalist production, capital takes possession of the production process. ${ }^{31}$ That is to say, in order to extract value from the consumption of a commodity, capital requires locating a commodity in the market "whose use-value possesses the peculiar property of being a source of value whose actual consumption, therefore, is itself an embodiment of labour, and, consequently, a creation of value" (Marx 1887, 117). ${ }^{32}$ By integrating labour-power ${ }^{33}$ (as

${ }^{30}$ Capital is value in motion, which appears in different forms, such as commodity and money (Harvey 2010, 90). Marx states: "Because it is value, it [capital] has acquired the occult quality of being able to add value to itself. It brings forth living offspring, or, at the least, lays golden eggs" (Marx 1887, 105). The existence of capital however does not mean production by the means of capital. Although in pre-capitalist societies there had been commodity exchanges that had then given rise to money and capital, production in those societies was independent from capital. For example, even though merchants and moneylenders used their money as capital, they did not undertake capitalist production. That is to say, neither the merchants nor the moneylenders were able to secure a firm foundation for the value-augmentation activity of capital since neither of them was able to step forward from the circulation form of capital to create value. The operation of merchant capital can be formulated as: $\mathrm{M}-\mathrm{C}-\mathrm{M}^{1} \quad\left[\mathrm{M}^{1}=\mathrm{M}+\mathrm{m}\right.$ (surplus) $]$. Merchants accumulated wealth through buying cheap and selling dearly. Moneylenders, on the other hand, accumulated wealth through interest charged as the cost of borrowing. Thus, in the operation of moneylenders' capital can be formulated as: $\mathrm{M} \ldots . . \mathrm{M}^{1}\left[\mathrm{M}^{1}=\mathrm{M}+\right.$ interest $]$. Therefore, in those societies products assumed the form of a commodity only by chance, whereas when capital started to rule over the entirety of the production process, the commodity form became the only way of existence for the products. It is industrial capital that steps forward and integrates the production process into itself. In doing so, it "produces a surplus value inside the process of its own motion, instead of obtaining a surplus value from the outside of its motion, either by 'buying cheap and selling dear' or by collecting interest on loaned money" (Uno 1980, 15-28).

${ }^{31}$ In the formula of industrial capital the commodities purchased in $\mathrm{M}-\mathrm{C}$ must include not only the material means necessary for the production of $\mathrm{C}^{1}$, but also the labour-power of workers as a commodity. In the market, the capitalist needs to find a commodity "whose use-value possesses the peculiar property of being a source of value [...] labour-power" (Marx 1887, 117). The formula of the industrial capital thus is: M-C = MMP [material means of production - constant capital] $+\mathrm{L}$ [labour - variable capital] ....P [Production] ....C ${ }^{1} \mathrm{M}^{1}$. The value of the commodity is made up of constant capital, variable capital and surplus value (Marx 1887, 139-151). Constant capital is accumulated labour. In other words, it is past labour which is already congealed in commodities that are used as means of production in the present production process. "All the accumulated past values are brought into a new production process in the form of dead labour" (Harvey, 2010, 128). For they are simply used and preserved, they cannot create value. It is only through living labour (labour-power) that they can be reanimated.

${ }^{32}$ Variable capital is value that is given in hiring labourers, whose labour power reincarnates dead labour and in turn passes their value into new commodities (Harvey 2010, 128). The surplus 
a commodity) into the production process, capital expands itself. To put it differently, in the capitalist mode of production, by becoming thoroughly endogenous to the production process itself, the commodity form in turn entrenches commodity production.

\subsubsection{Commodity: Use-Value and Exchange Value}

Marx defines the commodity, in the broadest sense, as an external object that satisfies human wants, desires or needs by its properties (Marx 1887). More specifically, the commodity, he argues, manifests itself as a twofold thing - that is, use-value and (exchange) value - as soon as it is placed in an exchange relation with another commodity. Before going into the discussion of commodity in more depth, let us explore the concept of use-value by abstracting the commodity from the object. To do so, let's take a simple wooden table as an example.

The wooden table is an object, which has utilities such as being a place to study, eat, write, or sleep, among others. All of these utilities reflect the fundamental nature of the table as an object - an object alien to human beings, an object that in its production reflects the necessity to satisfy human needs or wants. This function of the table, its "usability," or more precisely, its actual use, is what constitutes, for Marx, its use-value (1887). Therefore, the use-value of the table is created through the tangible alteration of one product, namely, wood (with a manifestly different use-value) into another, namely, the table. The transformation of the wood into the form and shape of a table, coupled with

value is extracted from the labourer by making him produce "value over and above that which would be required to reproduce the labourer at a given standard of living. This surplus-value produces and reproduces the capitalist" (Harvey, 2010, 129). Surplus value demonstrates the fact that capital not only produces new use value, but produces value that has greater value $[\mathrm{M}-\mathrm{C}<$ $\mathrm{C}^{1} \mathrm{M}^{1}$. For more detail on the production of surplus value see (Marx 1887, 128-139).

${ }^{33}$ Labour-power is understood as "the aggregate of those mental and physical capacities existing in a human being, which he exercises whenever he produces use-value of any description" (Marx 1887, 117). 
the table's consumption as a table, establishes its use-value as a property, which is not separable from the physical properties of the object (Marx 1887). It is this relationship between the physical property of the object and the tangible utility of the same object that establishes the use-value of the object. The most important aspect of this relationship is the alteration of one product into another, which results from the application of human labour. Therefore, labour is the constitutive element of the object's use-value.

In conflating the object and the commodity, now we can turn to a discussion of its exchange-value. Marx argues that while objects are simply use-values, ${ }^{34}$ commodities are “social use-values" (Marx 1887, 40), or simply put, they are useful objects produced for others. In the exchange relation, value assumes an independent form, i.e., the exchange value, which "presents itself as a quantitative relation, as the proportion in which values in use of one sort are exchanged for those of another sort" (Marx 1887, 26). ${ }^{35}$ In other words, the relation of equivalence is established between different sorts of commodities in the value form.

The establishment of such equivalence requires finding a common element in all commodities. This common element could be found only through a total abstraction from

${ }^{34}$ Commodities are heterogeneous use-values. To put it differently, they are qualitatively different from each other because they serve different purposes in their consumption (Marx 1887).

${ }^{35}$ Labour-power is neither a product nor is it intrinsically a commodity. It becomes a commodity when direct producers are stripped of their means of production and freed from their feudal bondages, and in turn, confront the capitalist in the market to sell their labour-power for their own subsistence. The conversion of labour-power into a commodity makes it possible for capital to take hold of the production process. Marx argues: "Every product of labour is, in all states of society, a use value; but it is only at a definite historical epoch in a society's development that such a product becomes a commodity, viz., at the epoch when the labour spent on the production of a useful article becomes expressed as one of the objective qualities of that article, i.e., as its value. It therefore follows that the elementary value form is also the primitive form under which a product of labour appears historically as a commodity, and that the gradual transformation of such products into commodities, proceeds pari passu with the development of the value form" (Marx 1887, 40-41). 
the heterogeneous use-values of commodities, which means the reduction of varieties of labour embodied in different commodities to their common quality: that is, human labour in the abstract. To put it differently, the object in the commodity form strips the object from the concrete labour of its production and adorns it with the abstract human labour (Marx, 1887). A commodity, Marx states, "consists of [...] a mere congelation of homogeneous human labour, of labour power expended without regard to the mode of its expenditure. [...] When looked at as crystals of this social substance, common to them all, they are - Values" (Marx 1887, 28). Simply put, (exchange) value is abstract human labour that is objectified and materialized in the commodity. ${ }^{36}$

\subsubsection{Commodity Fetishism}

The stripping of the commodity from the concrete labour of its production has some serious consequences. In Marx's powerful words: “[The] value [of a commodity] can only manifest itself in the social relations of commodity to commodity" (Marx 1887, 32). This, in turn, makes it possible for both the producers and consumers of commodities to view their relationship to the fruits of their labour as a "social relation, existing not between themselves, but between the products of their labour" (Marx 1887, 47). Thus, the existence of objects qua commodities, and the exchange relation between the products of labour, which stamps them as commodities, are a definite social relation between men, which assumes, in the eyes of men, "the fantastic form of a relation between things" (Marx 1887, 47).

\footnotetext{
${ }^{36}$ According to Marx, the magnitude of the value of any product is determined by the socially necessary labour time for its production. "The labour time socially necessary is that required to produce an article under the normal conditions of production, and with the average degree of skill and intensity prevalent at the time" (Marx 1887, 28).
} 
Let's return briefly to our example of the wooden table. The table as an object is, but a table. That is to say, it is a creation of man's labour with a given use-value. In other words, the table is the manifestation of the value of the object, which is realized "by means of a direct relation between the object and man" (Marx 1887, 52) - the alteration, and consumption of the object by man. The table however, as a commodity is something far more than a mere table. In Marx's words:

A commodity is therefore a mysterious thing, simply because in it the social character of men's labour appears to them as an objective character stamped upon the product of that labour; because the relation of the producers to the sum total of their own labour is presented to them as a social relation, existing not between themselves, but between the products of their labour. This is the reason why the products of labour become commodities, social things whose qualities are at the same time perceptible and imperceptible by the senses (Marx 1887, 46-47).

The table as a commodity is the reflection of a relationship that is manifested in the abstraction of the process of production (of the object through labour) from the relations that exist between the various commodities. This is what Marx calls "commodity fetishism" (Marx 1887). This abstraction serves to alter the very nature of social relations by establishing the fetishized commodity as the source of social relations.

In his analysis, Marx demonstrated the fact that under capitalism the patterns of economic life increasingly dominate the whole society. This is, in fact, the main reason why he attempted to show the ways in which: a) the mode of production - the economic structure - operates; and b) the state functions as a means of the bourgeoisie class. Marx however, did not provide a general cultural analysis of the capitalist forms of life in which commodity fetishism becomes exemplary for society as a whole.

Therefore, in the next section, I turn to the concept of reification, which is used by Frankfurt School theorists - such as Adorno, Horkheimer, and Marcuse - to criticize 
“capitalism's systemically induced social pathologies of the life-world that distort the relation between actors and the world, the others and the self and bring the dialectics between agency and structure to a standstill" (Vandenberghe 2013). I then illustrate the process of reification through an examination of the commodity analysis of art within the Marxist framework. For, the transformations in the content and the form of art as well as its perception are seen as the symptoms of the process of reification. ${ }^{37}$

\subsection{Reification and the Commodity Analysis of Art}

\subsubsection{Reification}

The term reification literally means the transformation of human properties, relations, processes, actions, concepts, etc. into things. Figuratively, it refers to the transformation of human properties, relations, processes, actions and concepts into things that act as pseudo-persons, endowed with a life of their own. Marx used the term reification in the context of commodity fetishism to criticize the transformation of social relations (Marx 1887). In the History and Class Consciousness (originally published in 1923), Georg Lukács generalized Marx’s concept of commodity fetishism and fused it with Weber's concept of rationalization (Lukács 1971a). Accordingly, Lukács' theory of reification presented a depiction of the ways in which human activity is reorganized and analytically fragmented according to various rational models of efficiency.

The essence of the commodity form, Lukács argues, is "a relation between people [which] takes on the character of a thing and thus acquires a 'phantom objectivity,' an autonomy that seems so strictly rational and all-embracing as to conceal every trace of its fundamental nature: the relation between people" (Lukács 1971, 83). For instance, when

\footnotetext{
${ }^{37}$ For more detail see (T. W. Adorno 2001; Horkheimer 1982; T. W. Adorno and Horkheimer 2002a; Lukács 1971a; Lukács 1971b; W. Benjamin 2006c).
} 
we say that a cup of coffee costs $\$ 2.50$, this statement expresses a network of human and historically variable relationships - e.g., the farmer who grows the coffee, the retailer who sells the coffee, the barista who brews and serves the coffee, and the consumer who buys and consumes the coffee. But the relationships among all of these people involved in the production and consumption of a cup of coffee are not visible. Instead, these relationships are expressed by the price of a cup of coffee. This is the principal character of the capitalist society, that is, the appearance of the relationships between people as relationships between commodities. In other words, in the commodity-producing society, while the social relations between men are expressed in the exchange of commodities, they are at the same time disguised by the commodity form.

In his analysis, Lukács explained the ways in which the commodity form has transformed one's relationship to oneself, to others, and to the material world. Thus, taking Marx's argument further, he argued that the commodity form must be recognized not only as the "elementary and universal form of social wealth under capitalist conditions" (Markus 2011, 555), but as "the central, structural problem of capitalist society in all its aspects," since "[o]nly in this case can the structure of commodityrelations be made to yield a model of all the objective forms of bourgeois society together with all the subjective forms corresponding to them" (Lukács 1971, 83) (emphasis added). The society that Lukács discusses here is a society in which the commodity form is not one form among many, regulating the metabolism of human society, but rather, is the "universal structuring principle" that "penetrate[s] society in its all aspects and remold[s] it in its own image" (Lukács 1971, 85). Thus, Lukács asks: "[H]ow far is commodity exchange together with its structural consequences able to influence the total 
outer and inner life of society" (Lukács 1971, 84)? Then, he answers:

Objectively a world of objects and relations between things spring into being (the world of commodities and their movements on the market) [...] Subjectively $[\ldots]$ a man's activity becomes estranged from himself, it turns into a commodity which, subject to the non-human objectivity of natural laws of society, must go its own way independent of man just like any consumer article (Lukács 1971, 87).

This process, the process in which capitalist production and consumption have farreaching implications for society - from the sphere of economy to that of culture - is called the process of reification [Verdinglichung] (Lukács 1971, 86).

There are, according to Lukács, two dimensions to this process: an objective and a subjective dimension. The former is explained through Marx's concept of commodity fetishism. The latter is related to the individual's position in relation to the production process within which he is divided into "an agent and a thing," that is, "the duality of man as subject and object" (Connerton 1974, 168). Therefore, reification, which characterizes the fundamental experience of bourgeois life, is defined as "the petrification of living processes into dead things, which appear as an alien second nature" (Jay 1986, 109).

If we unpack this argument further, we find that the capitalist division of labour which is both the presupposition and the product of capitalist production - manifests itself in a "continuous trend towards greater rationalization, [and] the progressive elimination of the qualitative, human and individual attributes of the worker" (Lukács 1971, 88). While the labour process is "progressively broken down into abstract, rational, specialized operations," as a result of which the worker loses contact with the finished product and his labour is reduced to a mechanical repetition, the necessary labour time is "converted, as mechanization and rationalization are intensified, from a merely empirical figure to an objectively calculable work-stint that confronts the worker as a fixed and 
established reality" (Lukács 1971, 88). Consequently, the object of the labour process "turns into the objective synthesis of rationalized special systems whose unity is determined by pure calculation" and which "seem[s] to be arbitrarily connected with each other" (Lukács 1971, 88). This fragmentation of the object of production simultaneously leads to the fragmentation of its subject. For the labourer becomes a "mechanical part incorporated into a mechanical system" (Lukács 1971, 89). In other words, "neither objectively nor in relation to his work does man appear as the authentic master of the process" (Lukács 1971, 89).

This is a process that perpetuates itself independently of the labourer and requires the labourer to conform to the self-regulatory, natural and fixed laws of the market that are impervious to human intervention. This "perfectly closed system" thus transforms the basic categories of man's attitude toward the world: "[I]t reduces space and time to a common denominator and degrades time to the dimension of space" (Lukács 1971, 89). As a result, time crystallizes into an "exactly delimited, quantifiable continuum filled with quantifiable "things"” (Lukács 1971, 90). This is the crystallization of the reified performance of the labourer, separated from his "total personality." To put it differently, the process of reification produces a split in the individual; "a split in which the [individual] perceives himself partly as a human being with a personality, partly as an object of commodity exchange" (Connerton 1974, 170). This split becomes a conditioning factor in the subject's immediate relation to the material world. ${ }^{38}$

\footnotetext{
${ }^{38}$ Benjamin read Lukács' essay "Reification and the Consciousness of the Proletariat" together with Asja Lacis and Ernst Bloch while vacating in Capri in 1924 (Cohen 2006). In a letter to Scholem, dated September 16, 1924, Benjamin writes: "While proceeding from political considerations, Lukács arrives at principles that are, at least in part, epistemological and perpaps not entirely as far-reaching as I first assumed. The book astonished me because these principles resonate for me or validate my own thinking" (Scholem and Adorno 1994, 248).
} 


\subsubsection{The Commodity Analysis of Art}

In the 1930s the rapid penetration of the commodity form into the cultural sphere and the alteration of cultural goods through technological reproduction initiated a debate among Marxist theorists, concerning the state of art (Benjamin 2002a; Adorno 1997; Horkheimer 1982; Adorno et al. 2007; Adorno 2008). For, art was one of the areas in which the implications of the commodity form and technological reproduction manifested themselves rather distinctly. Therefore, turning to the question of the state of art was a way to examine and explain the transformation of human perception and the experience of reality.

According to Marx, the commodification of all products of human activities including mental labour - was a constitutive aspect of the capitalist mode of production. It was, Marx argued, this commodification process that made capitalist production "hostile to art and poetry" in general (Marx cited in Markus 2011, 554). With respect to aesthetic productivity proper, however, "the commodity form of [art's] products appeared to [the artist] as an externally imposed, aggravating-restricting condition that necessarily remains alien to their own logic and norms" (Markus 2011, 554).

Markus (2011) claims that this argument is, in fact, implied in Marx's notion of "socially necessary labour," which determines the objective value of the commodity. ${ }^{39}$ The notion of "socially necessary labour" however, is applicable only to products that are socially reproducible. Since, for Marx, genuine works of art were "strictly individual and irreplaceable objectivations of human creativity" (Markus 2011), this notion cannot be applied them. To put it differently, "[t]he artwork as universal human value can thus have no economic value in the proper sense, only an irrational, both economically and

${ }^{39}$ For more detail on Marx's notion of "socially necessary labour time" see (Marx 1887, 26-42). 
aesthetically accidental, price" (Markus 2011, 554) (emphasis in the original). Genuinely artistic activities, as an "active affirmation of [one's] own nature" (Marx qt. in Markus 2011, 554), therefore, Marx argued, cannot be truly subsumed under capitalism.

Following Marx, Lukács suggested that 'authentic' art is exempt from the universal process of reification, and thus, it is the manifestation of the possibility of a non-reified relation to reality. Although this possibility of non-reified relation to reality makes it possible for art to impose a form upon the antinomies of reification, it does not mean that art can provide a practical solution to the problem of reification. Lukács writes:

[I]n the aesthetic mode, conceived as broadly possible, they may be salvaged from the deadening effects of the mechanization of reification. But only in so far as these contents become aesthetic. That is to say, either the world must be aestheticized, which is an evasion of the real problem and is just another way in which to make the subject contemplative and to annihilate 'action.' Or else, the aesthetic principle must be elevated into the principle by which objective reality is shaped: but that would be to mythologize the discovery of intuitive understanding (Lukács 1971, 139140).

To put it differently, the aesthetic attitude remains derivative and contemplative, in the sense that it is only the ideal relation of the isolated subject to reality. If this is not the case, then the aesthetic is translated into the constitutive principle of reality through a mythologizing ontology (Markus 2011, 556).

While Marx and Lukács claimed that authentic art is prone to reification, Adorno formulated the relationship between art and commodification in a more nuanced manner. According to him, the process of commodification is a precondition not only for art's subsumption under capital but also, paradoxically, art's autonomy. In turn, the commodification of art, according to Adorno and Horkheimer, leads to the rise of the 
'culture industry,' an industry which transforms not only the form and the content, but also the perception of artworks through the adaptation of principles of efficiency, profitability, and the instrumental rationality of the market to the cultural sphere. ${ }^{40}$ Consequently, artworks are fragmented into a mere sequence of recurring effects and sensuous stimulants, which are then connected via the most familiar stereotypical formulae in order to respond to the predispositions of the consumers (Adorno 2001).$^{41}$ It is this process, according to Adorno, that dissolves the inner consistency and coherence of artworks. Thus, he argues, all products of the culture industry, are:

tailored for consumption by masses [...] [and] are manufactured more or less according to plan $[\ldots]$ The culture industry intentionally integrates its consumers from above [...] Although the culture industry undeniably speculates on the conscious and unconscious state of the millions towards which it is directed, the masses are not primary, but secondary, they are an object of calculation; appendage of the machinery [...] The masses are not the measure but the ideology of the culture industry (T. W. Adorno 2001, 98-99).

${ }^{40}$ It should be noted here that although the members of the Frankfurt School - Marcuse, Horkheimer, and particularly Adorno - adopted Lukács' theory of reification, they however, radicalized, universalized and totalized this theory. For, in the face of the rise of fascism in Europe, they progressively lost their faith in a proletarian revolution.

${ }^{41}$ Adorno and Horkheimer are generally categorized as mass culture theorists, because of their use of the distinction between high and low culture and their condemnation of mass culture. Their critique however does not simply target mass culture but the culture industry, which encompasses mass culture but cannot be reduced to it. Three reasons can be identified in this regard: First, the culture industry extends the scope of mass culture through transforming the performances and reception of works of traditional high culture - concerts, theater, radio, records - by means of the technological reproducibility of artworks. Second, all artistic performances, as a result, start to target the predispositions of the audience. Third, in the fully administered world of culture industry, the distinction between high and low culture has become a mere ideology. Accordingly, they argue that all mass culture is identical under monopoly. To put it more clearly, although the heterogeneity of tastes is recognized and satisfied by means of different types of consumer goods, such diversity is only an appearance. For, it conceals the homogeneity of subject-attitudes, which is an effect of the products of the culture industry (Adorno and Horkheimer 2002; Adorno 2001; Horkheimer 1982). Adorno and Horkheimer write: "Everyone is supposed to behave spontaneously according to a 'level' determined by indices and to select the category of mass product manufactured for their type" (Adorno and Horkheimer 2002, 97). 
In other words, the culture industry administers, integrates and qualitatively reshapes art and/or entertainment in order to expand and reproduce the interests of capital. ${ }^{42}$

The commodity form, despite its reifying implications, Adorno suggests, is also the precondition of art's autonomy. For, through commodification, art is freed from its cultic function and become valuable in its own terms. Artworks, he suggests, also acquire independence in terms of their end and value because the ultimate (individual) buyer of the artwork is not determined. On this basis, Adorno claims that the artwork is a contradiction created by capitalism. And it is at the locus of this contradiction where the possibility of "autonomous art" resides in (Adorno 1997). Autonomous art, Adorno (1997) argues, immerses itself in society's imagerie in order to subversively create the "mimesis of the hardened and alienated" $(21) \cdot{ }^{43}$ In other words, autonomous art expresses the alienation and reification of the powerful subject through the transgression of the conventional boundaries of artistic activity by the artist and the imposition of the artist's own form upon the historically transmitted material of artistic activity. Adorno however, does not find the materialization of such art in the avant-garde, but in solitary figures such as Proust, Joyce, Kafka and Beckett in literature, Kandinsky and Klee in painting, and Schönberg and the Second Vienna School in music (Markus 2011, 611).

\footnotetext{
${ }^{42}$ In contrast to the liberal defenders and the conservative critics of mass culture, who justify or reject mass culture on the basis of its satisfaction of the desires of the masses, Adorno considers the disposition of the masses who favor the culture industry as part of the system rather than the reason for its existence (Adorno 2001).

43 "Commodification is a condition of the possibility of autonomous art as well as a condition of its impossibility [...] Just like the autonomous artwork is defined by its independence from any use or purpose outside of itself, so is the commodity defined by the independence of its exchange value from its use-value" (Martin 2007, 18). In other words, the stripping of modern art from any use or purpose coincides with the destruction of use-values by exchange value, and thus increasing consumption of exchange value disguises art as "object of enjoyment" (Adorno 2008, 39; Adorno 1997, 17) (emphasis added).
} 
Brecht, on the other hand, challenges Adorno's claim about the possibility of autonomous art under the conditions of the capitalist mode of production. His challenge was grounded in his own experiences accumulated during the filming of the Threepenny Opera. In making this film, Brecht aimed at demonstrating the power of the commodity form in reshaping the work of art and testing the claims about the independence of the author and the autonomy of art (Markus 2011, 556).

Brecht wrote, "[i]n reality, of course, it is the whole art which without exception found itself in the new situation, ... art as a whole becomes commodity or it does not become it at all" (Brecht qt. in Markus 2001, 6). In other words, Brecht viewed the arguments claiming the possibility of the autonomous art under the conditions of the commodity form as illusionary. To him, the autonomy of art in the commodity form is not possible. Brecht's critique however did not lead him to a pessimistic or cynical notion of art. Rather, "[b]y destroying the aesthetic ideology of authorial self-expression and empathetic reception in the individual artwork, it [the commodity form] at least negatively makes way for a new conception and practice of art as a collective 'pedagogical discipline"” (Markus 2001, 6). In other words, Brecht defends nonautonomous, political-educative and operative art. ${ }^{44}$

Benjamin challenges both Adorno's claim about the possible autonomy of artworks and Brecht's argument that the autonomy of art is an ideological illusion, hiding the subservience of art under the interests of capital. According to him, cultural objects are neither entirely autonomous from the material conditions nor are such products entirely determined by exchange value. Instead, he approaches cultural objects as the

${ }^{44}$ Brecht writes: "The technique, which is victorious here and which seems unable to deliver anything else but profit for some reptiles and thereby to promote barbarism, in the right hands will be able to do something completely different" (Brecht qt. in Markus 2011, 558). 
collective expressions conditioned by technological reproduction and the social relations of production. Therefore, before going into Benjamin's analysis of the implications of the commodity form on the cultural sphere in general, and the state of art in particular, it is important to outline how his view differ from the general Marxist theory of ideology and the ways in which the relationship between the economic structure and the superstructure is formulated within this theoretical framework.

\subsubsection{Walter Benjamin: Critique of Ideology-Critique}

Marx uses the analogy of camera obscura ${ }^{45}$ in explaining the ways in which ideology operates. Accordingly, he claims, ideology functions like an optical inversion as in a camera obscura. That is to say, the reality - namely, the reality created by the capitalist mode of production - is reflected upside-down in the superstructure (the state, culture, religion, education, etc.), disguising the reality with appearances, and in turn, leading to false consciousness (Marx and Engels 1998b).

Such an understanding however, Benjamin argues, assumes a stable and fixed relation between the economic structure and the superstructure, a relation that requires the reflection of the objects to be unchanging and constant. In the face of technological changes and their implications, Benjamin grows even more doubtful of the inversed mirroring function of the superstructure. He writes:

It seems, at first sight, that Marx wanted to establish here only a causal relation between superstructure and infrastructure. But already the observation that ideologies of the superstructure reflect conditions falsely and invidiously goes beyond this. The question, in effect, is the following: if the infrastructure in a certain way (in the materials of thought and experience) determines the superstructure, but if such determination is not

\footnotetext{
${ }^{45}$ Camera obscura is an optical device, which projects an image of its surroundings on the screen. This device includes a box or a room with a hole from which light from an external scene can pass through and strike a surface inside where the image is reproduced. This reproduction requires the image to be rotated 180 degrees; in other words, the image is turned upside-down.
} 
reducible to simple reflection, how is it then - entirely apart from any question about the originating cause - to be characterized? As its expression. The superstructure is the expression of the infrastructure. The economic conditions under which society exists are expressed in the superstructure - precisely as, with the sleeper, an overfull stomach finds not its reflection but its expression in the contents of dreams, which, from a causal point of view, it may be said to "condition." The collective, from the first, expresses the conditions of its life. These find their expression in the dream and their interpretation in the awakening (Benjamin 1999, 392, $\mathrm{K} 2,5)$ (emphasis added).

This, rather important, fragment from the Arcades Project (2002d) sheds light on Benjamin's understanding of the relationship between the economic- and super-structure.

Let's have a closer look at this passage.

In this fragment, Benjamin writes:

[I]f the infrastructure in a certain way (in the materials of thought and experience) determines the superstructure, but if such determination is not reducible to simple reflection, how is it then - entirely apart from any question about the originating cause - to be characterized? As its expression (Benjamin 1999, 392, K2,5) (emphasis added).

Here, Benjamin suggests interpreting the relationship between the economic structure and superstructure in reference to the relationship between the conscious and the unconscious rather than the simplistic notions of mimesis and causality. Thus, he re-formulates the issue concerning the relation between the economic structure and superstructure as the issue of expression rather than reflection.

By stressing that the superstructure is expressive rather than reflective (of the economic structure), Benjamin first underlines the fact that the relation between the economic structure and superstructure is not one-dimensional (from the economic structure to the superstructure). Second, he draws attention to the fact that the relationship between the infrastructure and superstructure concerns the ways in which the "materials of thought and experience" are conditioned, meaning that, the economic conditions find 
their expressions in the materials of thought and experience. In other words, the new materials and forms of life that are conditioned by the commodity form and technological reproduction enter the world of historically situated individuals not through ideological transposition but in their immediate presence in a sensuous way. Therefore, the role of the superstructure cannot be reduced to the inversed mirroring image of the economic structure; rather, the superstructure is where the economic conditions find their expression.

To illustrate the difference between the expression and reflection, Benjamin refers to the sleeper with an overfull stomach and the contents of his dreams. In the dream, the overfull stomach is not represented with the image of the sleeper having heart burn or sitting in front of a table full of empty plates - this would be the case if the dream was to reflect the state of an overfull sleeper - rather, the overfull stomach finds its expression in the dream through various images - unpleasant images, nightmares (being stuck in an uneasy situation), or pleasing images (strolling through a meadow of chocolate), etc. Similarly, the conditions brought forth by the commodity form and technological developments find their expressions in cultural forms, which are the expressions of a collective unconscious that are mostly inadvertent, overlooked or worthless; for instance, advertising, fashion, popular literature, commercial ventures, journalism, new building forms and designs, etc. ${ }^{46}$ This expressive relationship between the economic structure and

\footnotetext{
${ }^{46}$ Under the conditions of the neoliberal economy, one of the ways the conditions of life find their expression in the superstructure is the restructuring of the public and private spaces in the cities. The increasing privatization in the economic structure translates into the superstructure through the restructuring of the public and private spaces. In this process, public spaces - such as parks, community centers, city-streets, etc. - shrink while hybrid spaces - namely, privately owned and publicly accessible spaces such as shopping malls, gyms, etc. - expand. Such restructuring of public and private spaces gives rise to the emergence of new social categories - e.g., desirables and undesirables - as well as alters our perception of public space - e.g., perception of the public
} 
the superstructure is what Benjamin calls the "dream." He argues, "capitalism [is] a natural phenomenon with which a new, dream-filled sleep came over Europe, and with it a reactivation of mythic forces" (Benjamin 1999, 391, K1a,8). To illuminate the forms and ways in which the conditions of life find their expression in the superstructure, Benjamin turns to the question of the state of the art in the age of technological reproduction.

\subsubsection{The Aura and the Demise of Auratic Art}

In the period of classical capitalism, Benjamin argues, artworks had an autonomous existence that found their expression and substance in the "aura." But, the aura is not a consciously created ideological façade; rather, it is "the historically-socially imposed relation of the recipient to the work of art" (Markus 2011, 561). The aura is then, for Benjamin, an objective aspect of the collective experience of art, which guides the production of artworks while regulating the ways in which the works of the remote past are perceived. ${ }^{47}$ Since the collective experience of art is about the historically changing ways of the production and the reception of artworks, ${ }^{48}$ Benjamin's analysis of the demise of auratic art should be considered within the context of the wide range of changes taking place in the collective perception of reality, which occur as results of the

space a space of consumption rather than a space of socialization, plurality and political participation. For more detail on the implications of the neoliberal restructuring of the city see (Harvey 2008; Coleman 2005; Volker 2006; Peck and Tickell 2002; Purcell 2013).

47 "The era of the migration of peoples, an era which saw the rise of the late Roman art industry and the Vienna Genesis, developed not only an art different from that of antiquity but also a different perception" (W. Benjamin 2006c, 104).

${ }^{48}$ Benjamin writes: "For the dialectical historian concerned with works of art, these works integrate their fore-history as well as their after-history; and it is by virtue of their after-history that their fore-history is recognizable as involved in a continuous process of change. Works of art teach him how their function outlives their creator and how the artist's intentions are left behind. They demonstrate how the reception of a work by its contemporaries is part of the effect that the work of art has on us today. They further show that this effect depends on an encounter not just with the work of art alone but with the history which has allowed the work to come down to our own age" (W. Benjamin 2006c, 262). 
penetration of commodity relations into the cultural sphere and technological reproduction of cultural objects. ${ }^{49}$ Thus, for Benjamin, the question of what constitutes an artwork is symptomatic of broader questions concerning the changes in the character of experience and the collective apperception of reality. ${ }^{50}$

In his Artwork (1936) essay, in order to explain the implications of technological reproduction, Benjamin identifies the particular qualities of traditional art that are waning in modernity and relates these qualities to the "aura" of artworks. In this essay, the concept of aura is associated with the singular existence and authenticity, historical testimony and authority, of the work of art. The singularity of the art-object or "the here and now of the work of art" concerns the unique existence of the artwork in a particular place, which bears "the mark of history to which the work has been subjected to" (W. Benjamin 2006c, 103).

It is this "here and now of the original" that Benjamin relates to the authenticity of the artwork. He writes: "[The] here and now of the artwork is the quintessence of all that is transmissible in it from [...] its physical duration to the historical testimony relating to it" (W. Benjamin 2006c, 103). ${ }^{51}$ Thus, "[t]he uniqueness of the work of art is identical to

\footnotetext{
${ }^{49}$ Benjamin acknowledges the fact that the different techniques of reproduction - woodcuting, engraving and etching, print, and lithography - had impacts on the spatio-temporal uniqueness of the work of art, however, technological reproduction differs significantly in its effects and the scope of these effects from the reproduction by hand. For technologies of mass (re)production do not only alter the nature of the work of art qualitatively but also simultaneously establish " a place of its own among the artistic production (W. Benjamin 2002e).

${ }^{50}$ In this context, technology could be used in different ways: to "resist the change in experience, to monumentalize the present closing it off to any other future than the repetition of the present, or it can be used to promote the transformation of experience itself' (Caygill, 1998, 94). I discuss the transformations taken place in the structure of experience, the character of the collective organization of human perception and the implications of these changes in more detail in the following chapter..

${ }^{51}$ To put it differently, with the proliferation of replicas, the authentic experience of art, based on the ownership of, or direct contact with, a unique work of art, is dismantled.
} 
its embeddedness in the context of tradition" (W. Benjamin 2006c, 105), a tradition that is thoroughly alive and changeable. Therefore, "while the significance of an object changes with tradition, its uniqueness is preserved" (Caygill 1998, 104).

Technological reproduction, Benjamin argues, has decisively surpassed this "here and now of the work of art" and its attempts to mimetically replicate reality. According to him, technological reproducibility does not only replace the unique existence of the artwork with its mass existence via its replications, ${ }^{52}$ but also makes it possible for the recipient to meet the reproduced object in one's own situation (W. Benjamin 2006c). Such permeability does not only destroy the established identity of the work of art but also opens it to numerous possible uses and identities, by means of which the possible futures of the work of art are increased and the reproduced object is reactivated (Caygill 1998).

These changes brought forth by technological reproduction, Benjamin argues, lead to a cataclysm in the domain of objects that are transposed from the past. This cataclysm is in fact a manifestation of two processes that take place simultaneously: "a shattering of tradition" and the (possible) "renewal of humanity" (Benjamin 2002, 104). Technological reproduction leads to the "shattering of tradition" by: 1) "detach[ing] the reproduced object from the sphere of tradition," and in turn, "substitute[ing] a mass existence for a unique existence;" and 2) the emancipation of artistic production "from its parasitic subservience to ritual" (W. Benjamin 2002e). ${ }^{53}$ Benjamin writes: "It is the

\footnotetext{
${ }^{52}$ Benjamin states: "For its part, photography greatly extends the sphere of commodity exchange, from mid-century onwards, by flooding the market with countless images of figures, landscapes, and events which had previously been available either not at all or only as pictures for individual customers" (W. Benjamin 2002c, 6).

${ }^{53}$ The contextual integration of art in tradition, according to Benjamin, finds its expression in cult. Therefore, he argues, the work of art originated in ritual, which was first magical, then
} 
peculiarity of technological forms of production (as opposed to art forms) that their progress and their success are proportionate to the transparency of their social content. (Hence glass architecture)" (Benjamin 1999, 465, N4,6) (emphasis in the original).

The shattering of tradition symptomatically manifests itself in the "decay of aura." For the medium in which sense perception occurs is subjected to the changes brought forth by the technological reproducibility and the rise of the masses. Benjamin acknowledges the fact that there is a difference between the copy and its original. ${ }^{54} \mathrm{But}$, he argues that the decisive question concerning the fate of art, at this point, is not about the accuracy of reproduction; rather, it is about how the nature of this reproducibility alters the way the recipient perceives these objects.

Reproduction as a mechanical process is indefinitely repeatable and improvable, which renders the copy (of the original) to be produced independently of the subjective intentions and the individual skills (of the artist) and makes the copy available to a wide range of people by delivering it into the hand of the recipient. This process, according to Benjamin, retroactively changes the recipient's attitude towards the original and the status of art, in the sense that the artwork ceases to be the unattainable object of contemplation. In other words, the art object is stripped off of its protective shell, that is,

religious. The aura thus is inseparable from ritual; in fact, it is preserved in it (W. Benjamin 2006c). The decline of ritual and the decay of the aura however generated consequences for the reception and validation of the works of art, materializing in the polarization between "cult value" and "exhibition value." In the cult value, "what is important is that they [artworks] are present, not that they are seen" (W. Benjamin 2006c, 106), such as the prehistoric paintings on cave walls which were meant to be seen by the spirits. Here, the work of art is "first and foremost an instrument of magic" and only after can they be recognized as artworks. The increase in the scope of exhibition of artworks - as a result of the numerous methods of technological reproduction led to a qualitative shift between two poles - from the cult value to exhibition value - resulting in a qualitative transformation in its nature.

54 "Everyday the urge [of the masses] grows stronger to get a hold of an object at a close range in an image [Bild], or better, in a facsimile [Abbild], a reproduction [...] Uniqueness and permanence are as closely entwined in the former as are transitoriness and repeatability in the latter" (W. Benjamin 2006c, 105). 
"the aura of its enduring uniqueness and inapproachability" (Markus 2007, 361).

The decline of auratic perception heralds the rise of a new form of sense perception. This new form of sense perception has two distinctive features: a) "it dissolves the borders of objects by bringing them 'closer' spatially and humanly," and in turn, b) "overcomes the uniqueness of every reality" (Caygill 1998, 103). These characteristics differ significantly from the auratic perception, which Benjamin defines as "the unique apparition of a distance, however near it may be" (W. Benjamin 2006c, 104105). What is witnessed then under the conditions of technological reproduction and the rise of the masses is the disruption of both the spatial and temporal definitions of distance, which points out the fundamental feature of human perception in the age of technological reproduction; that is, the desire to extract "sameness even from what is unique" (W. Benjamin 2006c, 105). This is the point where the immeasurable impact of the "alignment of reality with the masses and of the masses with reality" resides in (W. Benjamin 2006c, 105). ${ }^{55}$

In order to explain the nature of this new reality Benjamin turns to the term phantasmagoria in his analysis. The concept of phantasmagoria was used by Marx to depict the reality that comes forth under the conditions of commodity fetishism (Marx 1887). Instead of adopting Marx's concept as is, Benjamin expands the word to depict the collective organization of human perception in the modern world. Thus, in the following section, I investigate both Marx's and Benjamin's understandings of phantasmagoria. Then, I introduce an analytical distinction between first and second order phantasmagoria in order to demonstrate the nuanced and intriguing nature of reality that emerged under

${ }^{55}$ I explore this shift from the auratic perception to the new form of perception, and the implications of this shift on the structure of experience in more detail in the following chapter. 
the conditions of the commodity form and technological reproduction. On the basis of, and as an extension of these two notions of phantasmagoria, I then present a new definition of kitsch as one of the defining characteristics of modernity.

\subsection{Phantasmagoria}

But certainly for the present age, which prefers sign to the thing signified, the copy to the original, fancy to reality, the appearance to the essence... illusion only is sacred, truth profane. Nay, sacredness is held to be enhanced in proportion as truth decreases and illusion increases, so that the highest degree of illusion comes to be the highest degree of sacredness. Ludwig Feuerbach

The term phantasmagoria emerged in the late eighteenth and early nineteenth centuries in Europe. It was coined by Etienne-Gaspard Robertson - a Belgian physicist and student of optics - when he performed his first ghost show in Paris in 1798 and later in London in $1802 .{ }^{56}$ As illusionist exhibitions, these ghost shows were a type of public entertainment where ghostly images were produced by the use of a magic lantern (Kang 2011, 83; Castle 1988, 27-29). The magic lantern is "a simple optical device using slides to display a magnified image on a white screen, wall, etc., in a darkened room" (The Oxford English Dictionary 2005). ${ }^{57}$ Though the invention of the magic lantern is traced

${ }^{56}$ Castle (1988) suggests that the term phantasmagoria is most likely derived from the Greek phantasma (phantom) and agoreuein (to speak in public) on the model of allegory. Margeret Cohen (2006) also stresses the similarity between the allegory and phantasmagoria, in arguing that, "both allegory and phantasmagoria traffic in enchantment, the supernatural, and the dead" (209). The nature of enchantment at issue in allegory and phantasmagoria, however, she claims, is different and this difference becomes apparent in the etymology of allegory and phantasmagoria. While the former derives from allos agoreuein, "to speak other than in the public place or the marketplace, the latter originates from phantasma agoreuein, meaning the ghosts of the public place or marketplace" (209). Thus, she suggests "the supernatural conjured up in the allegory is indeed an other to the marketplace; allegory is the mask taken by the divine when it appears in fallen history" while the supernatural in the phantasmagoria is "the specter of the marketplace in the senses both of firmly located there and generated by it" (209).

${ }^{57}$ A concaved mirror is used at the back of a light source to direct the light through a small rectangular sheet of glass, which is called a 'lantern slide,' onto which the painted or photographic image was to be projected, and then onward into a lens that was adjusted to optically focus the slide at the distance of the projection screen. 
back to the fifteenth century, this device reached its maturation in the late $18^{\text {th }}$ century. Throughout the nineteenth century, it was used in the illusionist shows where the audience were tricked by the technical manipulations in thinking that spirits and ghosts ranging from the collective heroes and villains of the French Revolution to lost loved ones - were summoned. The projected images created the feeling of real dreams, visions or apparitions, prompting the audience to react to the projections with bewilderment. The phantasmagoria intensified the effects of these ghostly images by the use of music, smoke, projection of voices and other illusionist theatrical techniques.

According to the Oxford English Dictionary (2005), the meaning of the word phantasmagoria expanded later in the nineteenth century to include "([a] vision of a rapidly transforming collection or series of imaginary (and usually fantastic) forms, such as may be experienced in a dream or fevered state, or evoked by literary description." To put it differently, the word phantasmagoria depicted "hallucinatory mental processes that were deluded yet that had an undeniable reality of their own" (Cohen 2006, 207). According to Castle, later Romantic and symbolist writers, such as Edgar Allan Poe, Arthur Rimbaud and Charles Baudelaire, used phantasmagoria frequently in their writings. For these writers, phantasmagoria was a preferred representation for "the heightened sensitivities and often tormented awareness of the Romantic visionary: delirium, loss of control, [and] the terrifying yet sublime overthrow of ordinary experience" (Castle 1988, 48).

Marx and Benjamin use the word phantasmagoria in order to describe the nature of reality that emerged under the conditions of the commodity form. In what follows, I make an analytical distinction between Marx's notion of phantasmagoria (first order 
phantasmagoria) and Benjamin's notion of phantasmagoria (second order phantasmagoria) to illuminate the multi-layered character of reality in the modern age.

\subsubsection{Marx's Notion of Phantasmagoria}

Marx uses the term phantasmagoria to describe the character of the social relations produced by the commodity form and exchange value. The commodity form, according to Marx, is the only form that expresses a social relation without antagonism within the capitalist mode of production. That is to say, there is no other human relation behind the relations of things in capitalism. Therefore, in Marx's analysis, commodity fetishism does not refer to an "epistemic illusion of the subject of cognition," but rather, it emphasizes the "split nature of the capitalist reality itself" (Khatib 2013a, 3). In this context, commodities appear as the necessary phenomenal form of a social relation - that is, (exchange) value.

The existence of things qua commodities and the exchange relation between the products of labour, which stamps them as commodities, Marx argues, are a definite social relation between men; however, in the eyes of men, they assume "the phantasmagorical form of a relation between things" (Marx 1967, 76-77). These social relations of production create a ghostly reality in which "the qualities of social things are at the same time perceptible and imperceptible by the senses" (Marx 1887, 47) (emphasis added). They [the qualities of social things] are imperceptible by the senses because of the mysterious character of [the] commodity and the occult character of capital, ${ }^{58}$ which is a

\footnotetext{
${ }^{58}$ According to Marx, "[capital] is value, it has acquired the occult quality of being able to add value to itself. It brings forth living offspring, or, at the least, lays golden eggs" (Marx 1887, 105). In this quote, Marx points to the imperceptible (supra-sensuous) aspect of the qualities of social things. Capital, Marx argued, is both money and commodity. More precisely, it is value in process. In the exchange relation, capital goes through two metamorphoses: "the conversion of the commodity into money, and the re-conversion of the money into a commodity" (71). Perhaps
} 
purely social (supra-sensuous) relation, and perceptible by the senses because this purely social (supra-sensuous) relation is expressed by (sensuous) things as commodities. In this context, the appearance of things as commodities - which is other than what they 'are' and in turn, the passing of the relationship between men as relations between things is what Marx identifies as "spectral." ${ }^{9}$

Let us return to our example of the simple wooden table. The wooden table was, before entering into the exchange relation, an object with use-value, which has the utility of being a place for working, eating, and meeting, among other things. But, when the wooden table enters into an exchange relation, in other words, when it becomes a commodity - that is, a useful object produced for others, an object commodified - it becomes something more than a mere table. This means that the exchange value of the wooden table appears as an objective quality of the table, which is supposedly determined on the basis of the relationship between things as commodities. According to Marx, this is where the ghost makes its appearance on the stage. For, in this process, the function of human labour in the production of the wooden table and the role that human labour-time plays in the determination of the price of this table become imperceptible by the senses while the commodity as the specter, as a sensuous thing, becomes the means through

more importantly, within this unceasing movement, capital expands spontaneously. "For the movement, in the course of which it adds surplus value, is its own movement, its expansion, therefore, is automatic expansion" (105).

${ }^{59}$ To summarize Marx's use of phantasmagoria, Benjamin cites Otto Rühle in The Arcades Project: "Once escaped form the hand of the producer and divested of its real particularity, it [the thing as a commodity] ceases to be a product and to be ruled over by human beings. It has acquired a 'ghostly objectivity' and leads a life of its own. [...] Cut off from the will of man, it aligns itself in a mysterious hierarchy, develops and declines exchangeability, and, in accordance with its own peculiar laws, performs as an actor on a phantom stage. In the language of the commodities exchange, cotton 'soars,' copper 'slumps,' corn 'is active,' coal 'is sluggish,' wheat 'is on the road to recovery,' and petroleum 'displays a healthy trend.' Things have gained autonomy, and they take on human features... The commodity is transformed into an idol, that, although the product of human hands, disposes over the human" (W. Benjamin 2002d, 181, G5,1). 
which the social relations of production between men are expressed. This is what I call the first order phantasmagoria

\subsubsection{Benjamin's Notion of Phantasmagoria}

In his analysis, Marx examines the why of the "phantasmagorical form of a relation between things." Benjamin writes in the Exposé of 1939: “The world dominated by its phantasmagorias [...] is "modernity"' $(2002 b, 26)$. Therefore, he turns to the investigation of how the phantasmagorical reality of a relation between things is perceived and how the distorted traces of the social relation, performed by commodities, are immediately imprinted in the process of human perception. Thus, he states:

Our investigation proposes to show how, as a consequence of this reifying representation of civilization, the new forms of behavior and the new economically and technologically based creations that we owe to the nineteenth century enter the universe of a phantasmagoria. These creations undergo this "illumination" not only in a theoretical manner, by ideological transposition, but also in the immediacy of their perceptible presence. They are manifest as phantasmagorias. Thus appear the arcades - first entry into the field of iron construction; thus appear the world exhibitions, whose link to the entertainment industry is significant. Also included in this order of phenomena is the experience of the flâneur, who abandons himself to the phantasmagoria of the market place. Corresponding to these phantasmagorias of the market, where people appear only as social types, are the phantasmagorias of the interior, which are constituted by man's imperious need to leave the imprint of his private individual existence on the rooms he inhabits. As for the phantasmagoria of civilization itself, it found its champion in Haussmann and its manifest expression in his transformation of Paris (W. Benjamin 2002b, 14-15).

As indicated in this passage, Benjamin traces the material, sensuous, immediate presence of the phantasmagorias and the ways in which they are imprinted in human perception. For, according to him, the phantasmagoric nature of reality can be comprehended only through the demonstration of "how things are in fact the expression of processes" (Cohen 2006, 209). Thus, he catalogues the new cultural forms (e.g., utopian social theory, literature and art, ranging from Fourier to Baudelaire's Les Fleurs and Hugo's Les 
Misérables, from the caricatures of Grandville to panoramas and dioramas; commercial practices such as advertising, fashion and world exhibitions; new forms of architecture such as the arcades, department stores, railway stations, the interior and the Haussmanization; technological innovations like gas lighting, the wax museum, and photography; social types like the flâneur, the sandwich man, the rag-picker and the prostitute; social and political events such as street revolts of the July Revolution and the barricade fighting of 1848) (W. Benjamin 2002d). In this context, the arcades emerge as the immersion of the industrial and commercial aspects of capitalism. On the one hand, they were a manifestation of a new form of architecture that was dependent on iron and glass, and on the other hand, they were spaces in which the powerful fascination, the pleasure and desire of the commodity was inspired through the exhibition of luxury goods.

As such, radicalizing Marx's concept of phantasmagoria, Benjamin writes:

It is only as commodity that the thing has the effect of alienating human beings from one another. It produces this effect through its price. What is decisive is the empathy with the exchange value of the commodity, with its equalizing substrate. (The absolute qualitative invariance of the time in which labour that generates exchange value runs its course - such absolute equality is the grayish background against which the gaudy colors of sensation stand out (W. Benjamin 2002d, 387, J92,4)

The equivalence constructed between the product and its price not only leads to the receding of the use-value into the background ${ }^{60}$ but also elicits "empathy" with the

\footnotetext{
${ }^{60}$ In the market, the use-value recedes into the background. But, this does not mean that the usevalue is replaced by the exchange value - for the use-value of the object is intrinsic to it (Marx, 1887). According to Uno, the use-value of an object reflects its manifest difference from other objects; conversely, the exchange value of an object reflects the object's similarity to all other objects in the commodity form (Uno, 1980). Thus, the intrinsic nature of the use-value of an object is a "passive factor" while the relative aspect of the exchange value of the object as a commodity is the "active agent" (Uno 1980, 5). This dichotomy between the passive factor and the active agent highlights another aspect of the relationship between use-value and exchange
} 
exchange value. Benjamin's description of the relationship between the consumer and the exchange value of the commodity as empathetic is crucial to understanding the implications of the commodity form on the collective organization of human perception. ${ }^{61}$

The term empathy is a standard translation of the German term "Einfühlung" (“feeling into") into English. ${ }^{62}$ The Oxford English Dictionary (2014) defines empathy (a

value, an aspect which characterizes the very act of consumption, for the act of consumption embodies this very duality. This is of particular importance because the object in its commodity form has as its main objective of existence its consumption. Thus, the consumption of the object in its commodity form, from the perspective of the consumer must: a) satisfy a want or a need, and b) be expressed in terms relative to other objects in the commodity form - thus the consumer is at once concerned with both the use-value and the exchange value of the object. There is however, according to Marxist thought, a marked difference between the two types of concerns, for where the concern with the use-value of the object in its commodity form is a concern that is introspective - i.e., it has an inner-directionality, or rather, is concerned with the consumer herself, the exchange value of the object reflects an outer-directionality - that is, it is concerned with establishing the relationship between the consumer herself and other consumers in the exchange system.

${ }^{61}$ The term empathy plays a significant role in Benjamin's discussion of epic theater - What is Epic Theater" (1939) - and it is also scattered throughout The Arcades Project (2002). Benjamin also uses the term in his description of what the historical materialist must not do. His use of the term as antithesis of historical materialism could be found in The Arcades Project (2002) as well as in On the Concept of History (1940) especially in Thesis VII. Benjamin neither defines nor specifies the sources of his understanding of the term empathy [Einfühlung]. This is partially because of his fragmentary writing style and his desire to eliminate the authority of the author on the reader as much as possible, and partially because of the fact that the term at the time was in frequent use, and thus, its meaning could be taken as given.

${ }^{62}$ The term "empathy" was introduced into the English language by the psychologist Edward Titchener in 1909 as the translation of the German term "Einfühlung" ("feeling into"). The philosophical interest in the term Einfühlung originates in the thought of the German Romantics. For instance, Herder endowed nature with a consciousness, which could be penetrated by man through Einfühlung. According to him, our ability to "feel into" nature was a vital corrective against the modern scientific attitude and a means for a mystical union between the subject and object. Herder's theory is echoed in the writings of philosophers such as Schelling, Novalis and the Schlegel brothers. Empathy however, did not become a subject of significant debate until the second half of the nineteenth century. This debate was triggered by the growing interest in the psychology of perception. Robert Vischer was the first to introduce the term "Einfühlung" to this debate in his essay On the Optical Sense of Form (1873). In this essay, he discussed the psychology of aesthetics and form perception. According to Vischer, the psychology of aesthetic appreciation involved a projection of the self into an object of beauty (Wind 1963). Karl Gross, building on Vischer's psychology of aesthetics, described aesthetic satisfaction as "inner imitation" (Eisenberg and Strayer 1987). It was however Theodor Lipps (1851-1914) who 
term of psychology and aesthetics) as "[t]he quality or power of projecting one's personality into or mentally identifying oneself with an object of contemplation, and so fully understanding and appreciating it." On the basis of this definition, how could we interpret Benjamin's description of the relationship between the consumer and the exchange value of the commodity as empathetic? If the exchange value of the commodity represents "the mysterious character of commodities" (Marx 1887, 46) as well as the occult character of capital, which is a purely social (supra-sensuous) relation, what does the consumer empathize with?

There are two important points to be made here. First, since the exchange value of the commodity generates an apparition of a specter, the consumer does not enter into an empathetic relation with the producer(s) of the commodity. Rather, s/he empathizes with an inorganic matter: the commodity or the medium of the measurement of the value of the commodities in the market, namely, money. ${ }^{63}$ Second, the commodity form and

scrutinized empathy in the most thorough manner. Lipps did not only argue that empathy is a concept that is central to the philosophical and psychological analysis of aesthetic experiences, but, perhaps more importantly, his work transformed empathy from a concept of philosophical aesthetics into a central category of the philosophy of the social and human sciences. According to Lipps, empathy plays a role not only in our aesthetic appreciation of objects, but also in human being's recognition of each other as minded creatures. The term was later on adopted, modified and questioned by, among others, Edmund Husserl, Max Scheler and Edith Stein. In the contemporary world, the term empathy remains central to philosophical and psychological discussions in two respects: a) "our capacity to gain grasp of the content of other people's minds and to predict and explain what they will think, feel, and do," and b) "our capacity to respond to others ethically" (Coplan and Goldie 2011, ix). In the former, empathy is examined in relation to simulation, which is depicted as one of the ways in which we engage with other's minds. In the latter, empathy is associated with the revival of moral sentimentalism, and its importance in the ethics of caring. For more detail on the current philosophical and psychological perspectives on empathy see (Coplan and Goldie 2011).

${ }^{63}$ Benjamin writes: "Empathy with the commodity is fundamentally empathy with exchange value" (W. Benjamin 2002d, 448, M17a,2). Again, in a letter to Adorno dated December 9, 1938, Benjamin writes: "Fundamentally, however, empathy with the commodity may be empathy with the exchange value itself" (Scholem and Adorno 1994, 291). In this letter, he associates his depiction of the empathy with the commodity and/or the exchange value of the commodity with Adorno's understanding of the "consumption" of the exchange value," citing Adorno - "The 
exchange relation "expresses" itself on the collective organization of human perception as the empathetic relation between the consumer and the commodity and/or the exchange value of the commodity. This empathetic relation generates a form of identification between the object and the subject of empathy, similar to the equivalence relation constructed between the commodity and its price - "absolute equality," in Benjamin's terms. This relation of identification leads to the transposition of the consumer's wishes, desires and feelings onto the commodity and/or the exchange value of the commodity. Thus, Benjamin writes: "Such absolute equality [the equivalence created between the product and its price] is the grayish background against which the gaudy colors of sensation stand out" (W. Benjamin 2002d, 386, J96,4).

Simply put, in the exchange relation, the exchange value of the commodity appears as the objective quality stamped on the commodity where the specter makes its first appearance. The empathic relation to which the consumer enters into with the commodity and/or the exchange value of the commodity, the wishes, desires and feelings of the consumer are given a corporeal form - the apparition of the specter once again. This is what I call the second order phantasmagoria. While the first order phantasmagoria is about the mysterious character of commodity, which gives rise to a "sensuous-supra-sensuous" relation, a relation that is "perceptible and imperceptible by the senses," the second order phantasmagoria is about the implications of the phantasmagorical reality between things on the collective organization of human perception.

consumer actually venerates the money he himself spent on the ticket for a Toscanini concert" (Adorno qt. in Scholem and Adorno 1994, 591). For more detail on Adorno's understanding of the consumption of exchange value see (T. W. Adorno 2001). 


\subsubsection{First and Second Order Phantasmagorias}

The first order phantasmagoria creates a form of a 'real-abstract' reality in which things as commodities act out social relations. In this constellation, the object's use-value constitutes the 'real,' and the object in the commodity form - the object commodified constitutes the 'abstract' dimension of reality. This form of a 'real-abstract' reality is to be read as the reality in which "[t]hings as commodities are not "what they reallyconcretely are' because their social properties are not derived from their physical shape or practical use. Rather, they are 'what they really-abstractly are,' that is, the material and/or symbolic screen of abstract social relations" (Khatib 2014, 4). Here, things as commodities become the sensuous medium of social relations while at the same time being non-sensuous - as they are the expression of a purely social relation.

The second order phantasmagoria, on the other hand, creates a form of 'abstractreal' reality in which things as commodities and the exchange value of the commodity (money) act out human wishes, desires, and feelings. Despite the fact that what becomes concrete in commodities is a reified and symbolic expression of human wishes, desires and feelings, the consumption of the commodity and/or the exchange value of the commodity generates a sense of realization and fulfillment. Thus, commodities and/or money become the means through which individuals define, represent and express themselves. In this constellation, human wishes, desires and feelings constitute the 'abstract' dimension of reality. Despite the fact that these wishes, desires, and feelings appear to be personal and subjective, they are conditioned by the socio-economic, political, and cultural relations among people. Simply put, they are socially constructed. Therefore, they are the manifestations of the supra-sensuous (social). On the other hand, 
the sense of realization and fulfillment through the consumption of the commodity and/or the exchange value of the commodity constitute the 'real' dimension of reality; for, the act of consumption presupposes the use of the commodity, thereby giving a corporeal form to the wishes, desires and feelings of human beings.

\begin{tabular}{|l|l|}
\hline \multicolumn{2}{|l|}{ Table 1: First and Second Order Phantasmagoria } \\
\hline First Order Phantasmagoria & Second Order Phantasmagoria \\
\hline $\begin{array}{l}\text { "mysterious character of the commodity" } \\
\text { "occult character of capital" }\end{array}$ & $\begin{array}{l}\text { empathy with the commodity and/or the } \\
\text { exchange value of the commodity (i.e., } \\
\text { money) }\end{array}$ \\
\hline "sensuous-supra-sensuous" & "supra-sensuous-sensuous" \\
\hline 'real-abstract" reality & 'abstract-real' reality \\
\hline
\end{tabular}

It is at the point of convergence between the first and second order phantasmagorias that kitsch emerges as the defining characteristic of modernity.

\subsubsection{Kitsch}

I conceptualize kitsch neither as an "ersatz culture" (Greenberg 1961) nor as a "technique of political manipulation" (Friedländer 1984; Montgomery 1991; Kundera 1999) neither as a "travestied aesthetic consciousness" (T. W. Adorno and Horkheimer 2002b) nor as a simple aesthetic category (Eco 1989; Kulka 1996); rather, I (re)conceptualize kitsch as a defining characteristic of modernity, a condition that is unavoidable. Thus, I define kitsch as the apparition of a beautified ghostly ('realabstract' / 'abstract-real' or 'abstract-real' / 'real-abstract') reality. ${ }^{64}$ The conditions for the apparition of this reality are created, on the one hand, by the increasing accessibility of the world of objects through the commodity form and technological reproduction, and

${ }^{64}$ The relationship between aura and kitsch will be discussed in more detial in the third chapter where I examine the implications of the transformations taken place in the collective organization of human perception under the commodity form and the conditions of technological reproduction. 
on the other hand, by the rise of the masses and their "desire to get closer to things" (W. Benjamin 2006c, 105). The closer the world of objects (as commodities) comes to the masses, the more attainable the dreams of the masses appear to them.

In his Surrealism (1929) essay, Benjamin writes:

Any serious exploration of occult, surrealistic, phantasmagoric gifts and phenomena presupposes a dialectical intertwinement to which romantic turn of mind is impervious. For histrionic or fanatical stress on the mysterious side of the mysterious takes us no further; we penetrate the mystery only to the degree that we recognize it in the everyday world, by virtue of a dialectical optic that perceives the everyday as impenetrable, the impenetrable as everyday (W. Benjamin 2005d, 216).

Benjamin's "dialectical optic" "perceives everyday as impenetrable." Thus, when we read Marx ${ }^{65}$ through Benjamin's “dialectical optic," we discover that the most trivial occurrences and facts of the capitalist everyday are also perceived as "sur-real," in Marx's terms, as "sensuous-supra-sensuous." Benjamin describes this sur-real world as a world of fetishized images alienated from the people, yet constituting and shaping them. This sur-real world is composed by the material graphicness that these images acquire in the capitalist everyday life. It is this sur-real character of the capitalist world where I identify kitsch as one of the defining characteristics of modernity. To explore this sur-real world of kitsch, I turn to the relation between the first- and second-order phantasmagoria, the relation between the 'real-abstract' and 'abstract-real' reality. In doing so, I put Benjamin's dialectical optic to work and reveal the occult and phantasmagoric phenomena as an integral part of reality rather than depicting it as a cover up behind which the actual reality resides in.

${ }^{65}$ Marx finds the objective impenetrability of the everyday in commodity fetishism where a purely social (supra-sensuous) relation is expressed by (sensuous) things (as commodities). 
Kitsch manifests itself in two ways in the age of technological reproduction. When the consumer enters into an empathetic relation with the commodity and/or the exchange value of the commodity, s/he transposes her/his wishes, desires and feelings on to the commodity and/or money since the empathetic relation requires the identification of the subject of empathy with its object. In this context, the commodity and/or the exchange value of the commodity - the object(s) of empathy - turns into the expression(s) (as well as limitation(s)) of the dreams, the imagination, and the identities of the subject of empathy. Here, kitsch manifests itself as the appropriation of the 'realabstract'-'abstract-real' reality. Let me unpack this further.

Above I argued that under the conditions of the commodity form, the specter first appears in the commodity relation in which a purely social (supra-sensuous) relation is expressed by (sensuous) things as commodities. The expression of a purely social relation by things as commodities constitutes the 'real-abstract' dimension of reality while the transposition of human wishes, desires and feelings that are socially constructed onto the commodity, and the generation of a sense of fulfillment and realization through the consumption of the commodity and/or exchange value of the commodity constitutes the 'abstract-real' dimension of reality - where the specter appears once again. What is important to note here is that there is a movement from the 'real-abstract' to the 'abstractreal' dimension of reality, meaning that there is a doubling of the phantasmagoria, which strengthens the conditioning function of phantasmagorias on the perceptual habituation of the individual and the collective. I therefore argue that it is this intertwinement of the first- and second-order phantasmagoria or the doubling of phantasmagoria that brings forth kitsch as a defining characteristic of modernity. 
As such, kitsch also manifests itself in the "commodification of non-objects." 66 The process of commodification and the acts of production and consumption are vividly illustrated through objects that have a tangible physical form, such as the example of the wooden table. This process however, becomes harder to explain when it comes to nonobjects, which I here identify with intangible, pseudo-rational feelings - such as feelings of fear or desire to belong. The non-object is a rather abstract idea. Yet, it more accurately represents the processes of the transformation of intangible, pseudo-rational feelings into a tangible, physical commodity form. The non-object is immaterial, subjective and pseudo-rational. To illustrate this rather abstract idea of the non-object, let's consider the example of security.

According to Spitzer, security is a feeling, an intangible assurance and confidence in one's safety (Spitzer 1995). Neocleous depicts security and its corollary insecurity as an ideology (Neocleous 2007). Both of these depictions of security reflect its primary feature, that is, the lack of a manifest physical form. Thus, security cannot be understood through the same parameters as the tangible object in the commodity form. Security is something fundamentally different than a simple wooden table. In fact, security as a feeling is both a derivative of objects (Spitzer 1995) and an impetus for their production. The production of security in the commodity form obscures the fact that the security object in the commodity form represents not a physical property; but rather, the immaterial non-object. This is the reason for identifying security as a non-object and

\footnotetext{
${ }^{66}$ I am indebted to Martin V. Manolov for the concept of the "non-object." He presented this concept at the Canadian Law and Society Association, which took place in June 3-5, 2015 in Ottawa. The paper was titled "Security - from use, exchange and the symbolic, to simulation, hyperreality and the beyond."
} 
depicting the security commodity as one of the means through which kitsch manifests itself.

The security object in the commodity form shares the attributes of other commodities: physical use-value as well as exchange value, and thus, is subject to the same process of fetishization. More importantly however, in obscuring the immaterial nature of the non-object, the security object in the commodity form is able to transform the non-object into a tangible commodity whereby it becomes "fetishistically inscribed in commodified social relations" (Neocleous 2007, 350). Thus, security becomes a commodity (Neocleous 2007, Rigakos 1999, Spitzer 1995).

In this configuration, a feeling of fear or desire for security is transformed into a commodity. Here, a pseudo-rational, immaterial feeling whose meanings are socially constructed and whose satisfaction through the consumption of the security commodity generates a sense of security constitutes the 'abstract-real' dimension of reality while its commodified form - namely, the security commodity - constitutes the 'real-abstract' dimension of reality. Thus, what is witnessed here is the movement from the 'abstractreal' reality - namely, feeling of fear, desire to be safe and its fulfillment - to the 'realabstract' reality. This is the second form in which kitsch manifests itself.

In both manifestations of kitsch, the first and second order phantasmagorias are intertwined. In other words, the relation between them is not a one-directional deterministic relation; rather, it is a complex, nuanced and reciprocal conditioning relation. It should be however emphasized that the first order phantasmagoria - the commodity form and the exchange relations - was the one that paved the way for the rise of the second order phantasmagoria. Benjamin writes: "The world exhibitions were 
training schools in which the masses, barred from consuming, learned empathy with exchange value. 'Look at everything; touch nothing”' (W. Benjamin 2002d, 201, G16,6). He also writes: "The game of chance in the guise of stock-market speculation paved the way for empathy with exchange value, much as world fairs did" (Scholem and Adorno 1994, 591). When the training of the masses was completed, the world of commodities have become closer to them and "everyday [their] urge [have grown] stronger to get a hold of an object at close range as an image [Bild]" (W. Benjamin 2006c, 105).

In these peculiar constellations, the commodity - with all the socially imposed and sensuously evoked meanings - becomes a "highly considerate mirror" (Broch 1969a, 49) which allows the modern man to recognize himself in a "beautifying" image. To put it more clearly, a commodity and/or the exchange value of the commodity to which the consumer's desires, wishes and feelings are transferred onto throws back a reflection onto the consumer, and thus, generates feelings of security, comfort and contentment. The reflection that is thrown back at the consumer is beautified; it is a reflection that reassures the familiarity of the consumer with the world in which s/he lives in. These beautifying, and intoxicating properties of the image are the distinctive characteristic of the sur-real which qualifies it as kitsch. For, kitsch renders it possible to transform a merely functional object into an object of narcissistic adoration. Thus, when the consumer identifies with the commodity and/or the exchange value of the commodity, $\mathrm{s} /$ he adopts, or more precisely, becomes the embodiment of the image reflected back on her/him. 


\subsection{Conclusion}

I began this chapter with a discussion of Marx's analysis of the commodity form and the commodity-relations, which arise therefrom. The development of technology as well as the effects of technological reproducibility are intimately related to the emergence and perpetuation of the capitalist mode of production, and the resulting alteration of the "whole relations of society" (Marx and Engels 1998a, 6). As the commodity-relations penetrated into all aspects of life, the role of culture has become central to the discussions concerning the reproduction and expansion of capitalism. In these discussions the state of art was a prominent feature, as the form and content of art as well as its perception by the recipient were transformed by the developments in technology. Reproductions were replacing original works of art, and as a result, the previously unwavering boundaries of the sphere of art were being demolished.

For some, art manifested a contradiction within capitalism because the commodity form, on the one hand, created the conditions for the creation of autonomous art by freeing art from its cultic function and making it valuable in its own terms, and on the other hand, contaminated art by inserting into its fabric the interests of capital (T. W. Adorno 2001; T. W. Adorno and Horkheimer 2002b). For others, art - its production and function - was fundamentally reshaped by the commodity form, thereby making its

autonomy illusory, yet also engendering the possibility of political-educative, and operative art (Brecht 2007). Yet, these conceptualizations implicitly limit the exploration of the relationship between the aesthetic, culture, and society by narrowly depicting the issue as an issue of the possibility/impossibility of autonomous art under the conditions of capitalism. But, as Benjamin argues, cultural objects are neither entirely autonomous 
from the material conditions nor are such products entirely determined by exchange value. Rather, they are collective expressions conditioned by technological reproduction and the social relations of production.

Benjamin develops this interpretation on the basis of the way in which he reads the relationship between the economic structure and the superstructure: one of expression rather than reflection (W. Benjamin 2002d). Viewed thusly, the alterations brought forth by the proliferation of technological reproduction meant that art is neither a manifestation of a capitalist paradox, nor an ideological illusion, concealing the subservience of art under the interests of capital. Rather, the state of art in the age of technological reproduction is an expression of an objective aspect of the 'collective experience' of art, which was a symptom of a broader issue: that is, the issue of the atrophy of experience (W. Benjamin 2006c). In order to examine this atrophy of experience Benjamin radicalizes Marx's notion of phantasmagoria by shifting the question of why the existence of things qua commodities manifests a "phantasmagorical form of a relation between things" (Marx 1967, 76-77) to a question of how the phantasmagorical reality of a relation between things is perceived and how the distorted traces of the social relations, performed by commodities, are immediately imprinted on the process of perception (W. Benjamin 2002d).

Yet, Benjamin's diagnosis of the atrophy of experience is inextricable from Marx's diagnosis concerning the transformation of social relations of production. In other words, there is a reciprocal, unavoidable, unceasing interaction between the phantasmagoria of social relations and the ways in which they are imprinted on the processes of perception. This relationship, in turn, illuminates the ways in which the 
relationship between infrastructure and superstructure unfolds. Thus, in order to clarify the difference between Marx's and Benjamin's concepts of phantasmagoria and to reveal the intricate and nuanced nature of reality that emerged under the conditions of technological reproduction, in this chapter, I introduced a analytical distinction between first and second order phantasmagoria. Here the first order refers to Marx's notion of phantasmagoria and illuminates the ways in which the 'real-abstract' dimension of reality - the phantasmagorical nature of things (as commodities) - operates. In contrast, the second order refers to Benjamin's notion of phantasmagoria, and shows the ways in which the 'abstract-real' dimension of reality - the perception of the phantasmagorical relationship between things (as commodities) - operates.

On the basis of the distinction between the first and second order phantasmagorias and their intricate and complex relationship, I proposed a new definition of kitsch as "the apparition of a beautified ghostly reality." I argued that the apparition of this beautified ghostly reality occurs through a movement from the 'real-abstract' to 'abstract-real' or 'abstract-real' to 'real-abstract' dimensions of reality. In turn, I suggested that within these constellations of reality, the commodity - with all the socially imposed and sensuously evoked meanings - becomes a "highly considerate mirror" (Broch 1969a, 49) which allows the modern man to recognize himself in a "beautifying" image, an image which throws back a reflection onto the consumer by means of which feelings of security, comfort, and contentment are generated. These beautifying, and intoxicating properties of the image are the distinctive characteristic of the sur-real, which characterize kitsch. For, kitsch - the apparition of a beautified ghostly reality - renders it possible to transform a merely functional object into an object of narcissistic adoration. 
In short, by exploring the ways in which - under the conditions of the commodity form and technological reproduction - reality emerges and operates on the objective and subjective forms of bourgeois life, I conclude that kitsch, as a concept, is not limited to the aesthetic sphere, rather kitsch is the defining characteristic of modernity. Reformulating kitsch thusly allows us to comprehend how the collective organization of human perception and experience are altered, and what such transformations mean for the individual and the collective. Building on this definition of kitsch, in the next chapter, I explore the ways in which the apparition of a beautified ghostly reality finds its expression in human perception and experience. 


\section{Chapter IV: The Crisis of Experience}

\subsection{Introduction:}

"Modern man can no longer work at what cannot be abbreviated."

Paul Valéry

"Just as the entire mode of human collectives changes over long historical periods, so too does their mode of perception," writes Benjamin in the Artwork essay (W. Benjamin 2006c, 104). It is in the changes to the mode of perception that Benjamin finds the most telling sign of modernity. According to him, the adaptation of human perception to the material and social conditions of capitalism - such as commodification, urbanization, transportation and technological reproduction as well as the alienating division of labour and the proliferated shock sensations - results in a radical restructuring of human perception both spatially and temporally. Thus, human perception starts to manifest itself in spatial and temporal registers, such as proximity and distance, permanence and transitoriness. The modality of an object in relation to others also begins to be apprehended by the register of singularity versus multiplicity, similarity versus sameness (Hansen 1987). In this context, discontinuity and fragmentation of experience replaces continuity and unity of experience - wisdom that is passed on from generation to generation - leading to its incommunicability.

Benjamin's interest in the concept of experience started early on. When he was part of the German Youth Movement, he published an article called "Erfahrung" (Experience) (1913) in the movement's journal Der Anfang. ${ }^{67}$ In this article, he enthusiastically criticized the concept of experience, claiming that experience is the mask

\footnotetext{
${ }^{67}$ It should be noted here that Benjamin does not make an explicit distinction between Erfahrung (experience) and Erlebnis (immediate experience) in this essay. The distinction between Erfahrung and Erlebnis will be examined in detail in the following sections.
} 
of the adult, which "is expressionless, impenetrable, ever the same. The adult has always already experienced [erlebt] everything: youth, ideas, hopes, woman. It was all an illusion" (W. Benjamin 1996, 3). Against "expressive vitality, transparent openness and defiance of the status quo" (Jay 2005, 315), the adult insists that the rapturous youth is a brief moment which "will be followed by grand 'experience,' the years of compromise, impoverishment of ideas, and lack of energy" (W. Benjamin 1996, 3). The experience of the adult thus, for Benjamin, is "the meaninglessness of life"; it is the experience of the philistine who "has taken experience as his gospel," resulting in the cancellation of anything "great, or new or forward-looking” (W. Benjamin 1996, 3).

In contrast to the "defeatist cynicism of the philistine adult" (Jay 2005, 315), Benjamin advocated for an alternative notion of experience where the value of the mistakes made by youth is acknowledged in the search for truth and where rapture and fearlessness are preferred to conformity and comfort (W. Benjamin 1996). Even in this early essay, one can see that Benjamin's notion of experience had little to do with the scientific notion of experience, which saw the mistakes occurred in the past as mere illusions which were irrelevant to experience, ${ }^{68}$ or David Hume's conservative reading of

\footnotetext{
${ }^{68}$ Francis Bacon and René Descartes developed the scientific method in order to overcome the untrustworthy effects of raw sensations, and in turn formulated the scientific notion of experience. They desired scientific truth and absolute certainty based on designed rather than random encounters with the external world, and rule governed explanations of those encounters. Thus, Bacon argued that experience in the traditional sense "is blind and silly, so that while men roam and wander along without any definitive course, merely taking counsel of such things as happen to come before them, they range widely, yet move little further forward... [But] the right order for experience is to kindle a light, then with that light to show the way, beginning with experience ordered and arranged, not irregular and erratic, and from that deriving axioms, and from the axioms thus established deriving again new experiments" (Francis Bacon qt. in Jay $2005,31)$. In other words, Bacon and Descartes argued that experience can be taken seriously only if it is replicable and verifiable by objective instruments (Jay 2005, 28-39).
} 
experience, and his trust in the wisdom of the past. ${ }^{69}$ Instead, Benjamin's understanding of experience, from early on, demonstrated sympathy for "the meanderings of experience" and "a valorization of the experimental moment in the concept" (Jay 2005, $316) .^{70}$

Twenty years later, in his essay Experience and Poverty (1933), Benjamin diagnoses the rise of "a completely new [kind of] poverty," originating in the "tremendous development of technology" (W. Benjamin 2005a, 732). This poverty, he argues, "is not merely poverty on the personal level, but poverty of human experience in general" (W. Benjamin 2005a, 732). The first signs of this crisis of experience, according to Benjamin, became apparent with the First World War, where the unparalleled scale of technological warfare and the capacity of the weapons of mass destruction became manifest. ${ }^{71}$ Benjamin writes:

Experience has fallen in value, amid a generation which from 1914 to 1918 had to experience some of the most monstrous events in history of the world... [A]t the time how many people returned from the front in silence? Not richer but poorer in communicable experience? [...] [T] here was nothing remarkable about that. For never has experience been contradicted more thoroughly: strategic experience has been contravened by positional warfare; economic experience, by inflation; physical experience, by hunger; moral experiences, by the ruling powers. A

\footnotetext{
${ }^{69}$ David Hume rejected the idea of the conscious subject, advocated by Cartesian rationalism, whose existence was claimed to precede the sense experiences of the subject. On the basis of his distrust of abstract reason, Hume attempted to ground thinking in the matter of the body, on which impressions were imprinted. Thus, experience is understood as "accumulated learning," which took place by the repetition of discrete experiences over time. In this sense, Hume saw custom, habit and repetition as part of experience (Jay 2005, 56-66). For a through analysis of the concept of experience in Western political thought see (Jay 2005).

${ }^{70}$ In a note written probably in 1929 , Benjamin recognizes the militant idealism of his youth in assessing his critique of the concept of Erfahrung in 1913. However, he states that he has remained true to himself in the sense that his attack on the concept of experience in 1913 broke through the word without destroying it (W. Benjamin 2011).

${ }^{71}$ The onset of the First World War resulted in Benjamin's disillusionment with the Youth Movement. For, by embracing German nationalism and the war effort the Movement lost its bearings (Jay 2005).
} 
generation that had gone to school in horse-drawn streetcars now stood in the open air, amid a landscape in which nothing was the same except the clouds, and at its center, in a force field of destructive torrents and explosions, the tiny, fragile human body (W. Benjamin 2005e).

In this passage, Benjamin elaborates on the reasons why experience had become incommunicable after the First World War. According to him, the incommunicability of experience was conditioned not only by the catastrophic events that the War had caused but also by the contradictions generated within experience by the War, which rendered any type of meaningful explanation about what had happened impossible. For, every explanation that fit into neat little boxes within tradition had been contravened. To put it differently, the War had resulted in the creation of an abyss in which an entire array of meanings originating in tradition "have become unrecognizable, if not patently unserviceable, to us in the present" (Wolin 1982, 19).

Although the process of the crisis of experience had become apparent with the First World War, the war was definitely not the end of this crisis. In fact, Benjamin states, "it looks as if it is continuing to fall into bottomlessness" (W. Benjamin 1968, 84) within the tediously repetitive daily life in the metropolis. For the "banality of the quotidian" (Agamben 1993, 14) does not only reproduce but also intensifies the conditions of the incommunicability of experience. To illustrate, a quick gaze into the everyday life of a city-dweller would suffice. Although contemporary man encounters a jumble of events (e.g., reading a newspaper, driving one's car for hours in traffic or lining up to grab a coffee) throughout the day, none of these events are translated into experience, no matter what their nature - i.e., entertaining or tedious, unusual or common, disturbing or pleasurable. The untranslatability of everyday events and occurrences into experience, according to Benjamin, is intimately connected to the restructuring of the human sensory 
apparatus and the historical shifts that occurred within the forms of communication namely, a shift from unmediated to mediated communication, storytelling to information.

In the first section of this chapter, I examine the transformations that had taken place in the forms of communication, specifically the shift from storytelling (oral narration) to the novel (textual narration), and from storytelling to information. The significance of this transformation resides in the fact that the different forms of communication are the means through which experience [Erfahrung] is stored. In the second section, I examine the distinction Benjamin introduces between experience [Erfahrung] and immediate experience [Erlebnis]. In order to explain this distinction, first, I discuss the concepts of voluntary and involuntary memory, developed by Marcel Proust in the first volume of the Remembering of Things Past (1913). Then, I discuss memory as Gedächnis (long-term memory) and memory as Erinnerung (reminiscence or recollection) in order to demonstrate the relationship between memory and experience. In doing so, I examine the ways in which the radical restructuring of the human sensory organs - through the effects of, for instance, the proliferation of shock sensations, technological reproduction and the alienating division of labour - affect the fabric of experience. Secondly, I investigate the implications of the transformation of human perception on the mimetic faculty.

Benjamin's analysis of the transformation of the forms of communication and his diagnosis of the crisis of experience are not a yearning for the "good old days." Rather, these investigations aim at revealing the disintegration of the aura in: 1) a narrow sense as the ground upon which the illusion of bourgeois art's autonomy is created; and 2) a broader sense as a modality for the collective organization of human perception. As such, 
Benjamin does not impose an "ideal" on the cultural forms and everyday practices of bourgeois society. As Habermas (1988) puts it, "he does not raise critical demands against a culture still unshaken in its substance[;] [rather], [h]e proceeds descriptively" (96). As such, he treats cultural forms themselves as "suggestive of critique" (Habermas 1988, 96).

In the final section, I turn to Benjamin's concept of aura, which he relates to experience [Erfahrung]. In contrast to the common restrictive understanding of Benjamin's notion of the aura - as an aesthetic category - here, I treat the aura in a broader sense to stress its "anthropological, perceptual-mnenomic, and visionary dimensions" (Hansen 2012, 105). On this basis, I introduce the notion of "kitsch perception" in relation to immediate experience [Erlebnis] and in opposition to auratic perception in order to mark the distinction between experience [Erfahrung] and immediate experience [Erlebnis].

\subsection{The Transformation of the Forms of Communication ${ }^{72}$}

\subsubsection{From Storytelling to the Novel}

Benjamin treats the form of communication as a prism to depict the immense transformations that took place in the collective organization of human perception and the fabric of experience. It is for this reason that the examination of the nature of storytelling as a form of narrative and its decline occupies a central position in his writings. In this section, I examine the decline of storytelling in relation to the rise of the novel, and then, in relation to the predominance of information in order to demonstrate what the shift from

\footnotetext{
${ }^{72}$ For Benjamin's writings particularly on the transformation of the forms of communication see Journalism (1927), The Crisis of the Novel (1930), A Critique of the Publishing Industry (1930), The Newspaper (1934), The Storyteller: Observations on the Works of Nikolai Leskov (1936), On Some Motifs in Baudelaire (1940) in (W. Benjamin 2005d; W. Benjamin 2005e; W. Benjamin 1968).
} 
storytelling to novel to information tell us about the collective organization of human perception and the fabric of experience.

Benjamin describes storytelling as "the epic form at its purest" (W. Benjamin $2005 \mathrm{~d}, 299),{ }^{73}$ and argues that "[w]hat can be handed on orally, the wealth of the epic" is different from what can be expressed and communicated through the textual narrative of the novel (W. Benjamin 1968, 87). In the Crisis of Novel (1930), he portrays the difference between the epic and the novel as follows:

From the point of view of epic, existence is an ocean... One can of course react to the sea in different ways - for example, lie on the beach, listen to the surf, collect shells that it washes up on the shore. This is what the epic writer does. You can also sail on the sea... You can embark on a voyage and then, when you are far out, you can cruise with no land in sight, nothing but sea and sky. This is what the novelist does. He is truly solitary, silent person. Epic man is simply resting. In epics, people rest after their day's work; they listen, dream and collect. The novelist secluded himself from people and their activities. The birthplace of the novel is the individual in isolation, the individual who can no longer speak of his concerns in exemplary fashion, who himself lacks counsel and can give none (W. Benjamin 2005d, 299).

In this passage, Benjamin depicts not only the ways in which existence is perceived differently by the bard and the novelist, but also the ways in which such perception relates to the collective in general. In both cases, a relationship between the sea - namely, existence - and the author is crucial. The bard's relation to the sea is based on him staying on the shore, highlighting the necessity of a close contact between the bard and the community. During this stay, he performs activities - lying on the beach, listening to the surf, collecting shells - that render it possible to dream and re-collect. This illustration underlies the fact that as stories are handed down from generation to

${ }^{73}$ For more detail see The Crisis of Novel (1930), The Storyteller: Observations on the Works of Nikolai Leskov (1936), On Some Motifs in Baudelaire (1940) in (W. Benjamin 2005d; W. Benjamin 1968; W. Benjamin 2006d). 
generation orally, they belong to the community, in the sense that "they are the primary means of recording experience" (Wolin 1982, 23). In this context, "tradition functions as the medium, rendering the transmissibility of a story possible" (Kang 2014, 29). In the Storyteller (1936), Benjamin writes, "the storyteller takes what he tells from experience his own or that reported by others. And he in turn makes it the experience of those who are listening to his tale" (W. Benjamin 1968, 87), meaning that both the production and the reception of storytelling is a collective process.

On the contrary, the novelist's relation to the sea requires him to embark on a voyage where he travels until there are "no land(s) on sight," isolating himself from any human relation and activity. In other words, the novelist's relation to existence is conditioned by isolation and individuation. The isolation of the novelist from the collective during the production of the novel is an expression of the fact that the relationship between experience [Erfahrung] and the collective is not the same any longer. That is to say, with the rise of the novel the shared collective experience, passed on through storytelling, in which experience was assimilated into life, is substituted with privatized and individualized experiences $[$ Erlebnisse $] .{ }^{74}$ Consequently, experience lost its ability to sink into life, or its capacity to be absorbed by the collective. Thus, Benjamin writes in The Storyteller (1936), the novel differs from the epic because it "neither comes from oral tradition nor goes into it" (W. Benjamin 1968, 87). In other words, not only the production but also the reception of the novel necessitates isolation. ${ }^{75}$

\footnotetext{
${ }^{74}$ It should be noted here that the rise of novel as a literary-cultural form is one of the ways in which the transformations that took place in the economic structure find their expression in the superstructure.

${ }^{75}$ In this context, a similarity between Benjamin's portrayal of the novel and Lukács' depiction of the modern novel - in contradistinction to the Homeric epic - can be found. In The Theory of the Novel (1971b), Lukács compares the bourgeois world of "transcendental homelessness" to the
} 
The diminishing of the communal aspect of the storytelling and its connection to everyday life also signals the withering away of wisdom. In The Storyteller (1936), Benjamin defines wisdom as "[c]ounsel woven into the fabric of real life" (W. Benjamin 1968, 86-87). That is to say, wisdom is extracted from experiences [Erfahrungen], which then are passed on from generation to generation. Thus, while the rootedness of storytelling in tradition rendered it possible to provide counsel to its listeners, today "we have no counsel either for ourselves or for others"; instead, "[i]n the midst of life's fullness, and through the representation of this fullness, the novel gives evidence of the profound perplexity of the living" (W. Benjamin 1968, 86-87). Yet, when Benjamin points out the end of the art of storytelling and wisdom, this is not a yearning for the past; rather, he aims to understand the ways in which everyday life has changed in the modern society, and what these changes mean for the individual and the collective as well as what kinds of possibilities reside in them. ${ }^{76}$

While Benjamin found the earliest symptom of a process that ended with the decline of storytelling in the rise of the novel, in the crisis of the novel, he recognized the emergence of a new form of communication, that is, information. Whereas he associated the rise of the novel with the emergence of the new middle class in early industrial capitalism, he saw the rapid growth of the newspaper as indicative of "the full control of

\footnotetext{
"integrated civilizations" of the Homeric epic. Paralleling Benjamin's analysis of the decline of storytelling, he suggests that "[t]he novel is the epic in an age in which the extensive totality of life is no longer directly given, in which the immanence of meaning to life has become a problem, yet which still thinks in terms of totality" (Lukács 1971b, 56). Like Benjamin, Lukács also stresses the dissociation between experience [Erfahrung] and the collective in reference to the form of narrative, namely, the novel.

${ }^{76}$ In The Storyteller (1936), he writes: "Nothing would be more fatuous than to want to see in it [the decline of storytelling] merely a "symptom of decay" [...] It is rather a concomitant symptom of the secular productive forces of history, a concomitant that has quite gradually removed narrative from the realm of living speech and at the same time is making it possible to see a new beauty in what is vanishing" (W. Benjamin 1968, 87).
} 
the middle class, which has the press as one of its most important instruments in fully developed capitalism" (W. Benjamin 1968, 88). The rise of information, Benjamin argues, affected the epic form in an unprecedented way that is "more menacing" than any form that came before it (W. Benjamin 1968, 88).

\subsubsection{From Storytelling to Information}

Benjamin identifies the proliferation of information - as the dominant form in which experience is stored - as a primary symptom of the crisis of experience. For "the vast stockpiling of information indicates the degree to which the parameters of society have been qualitatively extended at the expense of its former integral unity (Wolin 1982, 23). In this context, Benjamin (1968) defines information as a type of report that "convey[s] a happening per se" (159), or "the pure essence of the thing" (91). Accordingly, unlike a story which "sinks the thing into the life of the storyteller in order to pass it on as experience to those listening" (91), information is not assimilated into everyday life. Thus, Benjamin claims that the replacement of "older narration with information, of information with sensation, reflects the increasing atrophy of experience" (159).

In his examination of the transformation of the forms of communication, Benjamin detects three major differences between the storytelling and information. The first difference concerns the changes occurring in the spatial and temporal organization of human perception. Storytelling passes on experience from mouth to mouth. That is to say, the source of the storyteller's stories is experience. In this context, Benjamin identifies two groups as the nameless, archaic representatives of storytelling: "the resident tiller of the soil" and "trading seaman" (W. Benjamin 1968, 84-85). Both of these men are the 
men of wisdom. While the former is a man "who knows the local tales and traditions," the latter is a man "who has come from afar," and thus, "has something to tell about" (84-85). Here, Benjamin makes it clear that the spatial and temporal distance - the mysteries of tradition and far away places respectively - is crucial to the storytelling. Distance as a spatial and temporal category however, erodes with the predominance of information. For, "it is no longer intelligence coming from afar, but the information which supplies a handle for what is nearest that gets the readiest hearing" (89). The word "nearest" here means both spatial and temporal nearness, signaling the erosion of distance as the correlate of authority. ${ }^{77}$

The second difference concerns the shift from the authority of the story to the verifiability of information. In The Storyteller (1936), Benjamin writes:

The intelligence that came from afar [...] possessed an authority which gave it validity, even when it was not subject to verification. Information, however, lays claim to prompt verifiability. The prime requirement is that it appears "understandable in itself." Often it is not more exact than the intelligence of earlier centuries was. But while the latter was inclined to borrow from the miraculous, it is indispensible for information to sound plausible (W. Benjamin 1968, 89).

To put it more simply, while the necessary correlation of experience resided in authority, information lays a claim to verifiability. Benjamin characterizes storytelling with its

77 The transformations in the organization of human perception are closely related to technological developments. For instance, Wolfgang Schivelbusch demonstrates how the invention of the railroad train in the early nineteenth century restructures the modern perception of time and space. The train not only makes travelling faster, but also restructures the relationship between the traveler, vision and space. As Schivelbusch suggests, vision becomes 'panaromic' while the "velocity of train dissolves the foreground, the pre-industrial relation between traveler and landscape. While the traveler previously saw himself/herself as a part of the foreground, joined to the landscape, the speed of the train radically displaces that traveler [...] The traveler is 'removed from that 'total space' which combines proximity and distance' and is separated from the space of perception by an 'almost immaterial barrier"' (Doane 1985, 43-44). Thus, Schivelbusch argues, "[p]anoramic perception, in contrast to traditional perception, no longer belongs to the same space as the perceived objects: the traveler sees the objects, landscapes, etc. through the apparatus which moves him through the world" (Schivelbusch qt. in Doane 1985, 44) (emphasis in the original). 
orientation and ability to overtly or covertly communicate practical interests, ${ }^{78}$ and its ability to communicate the intelligence of what is distant - either as spatial distance (coming from foreign countries) or as temporal distance (deriving from tradition) (W. Benjamin 1968, 86). In this context, the subject of experience is commonsense and the source of commonsense is everyday life. This is why, Agamben (1993) argues, "[e]ach event $[\ldots]$ became the speck of impurity around which experience accrued its authority, like a pearl. For experience has its necessary correlation not in knowledge but in authority - that is to say, the power of words and narration" (14). Consequently, experience [Erfahrung] by carrying on the wisdom of tradition ${ }^{79}$ creates a "continuity and flow [in] the continuum of experience" (Wolin 1982, 22).

As a result of the transformation within the forms of communication, "the 'existential moment' of the subject and its temporality transformed from totality to singularity and towards privacy of knowledge and experience" (Lindroos 2001, 24). To put it differently, in modern life a totally different structure of experience has emerged, a structure in which "events take on desultory and isolated, overwhelmingly private character" (Wolin 1982, 22) (emphasis in original), meaning that the collective and continuous aspects of experience [Erfahrung] are forfeited.

To clarify this point, Benjamin turns to the journalistic style. Press, he argues, aims at "isolat[ing] what happens from the realm in which it could affect the experience of the reader" (W. Benjamin 1968, 158). Such isolation is achieved through an unceasing production of fresh news, consisting of verifiable facts. These news pieces are presented

\footnotetext{
${ }^{78}$ These practical interests might be communicated through moral or practical advice, or a proverb or a maxim.

${ }^{79}$ That is to say, experience is not compatible with certainty. In fact, Agamben states, "[o]nce an experience has become measurable and certain, it immediately loses its authority. There is no formulating a maxim nor telling a story where scientific law holds sway" (Agamben 1993, 18).
} 
in a brief fashion to make them understandable in themselves, so that there will be neither space nor need for their interpretation. The isolation of the information from both the journalist herself and the readers - because of its claim to verifiability - and the "lack of connection between individual news" as well as "the make-up of the pages and the paper's style" (W. Benjamin 1968, 159) thwart the absorption of information into everyday life.

Benjamin also argues that there is a decline in the depth of knowledge despite the increase in the breadth of information. He suggests that "[e]very morning brings us the news of the globe, and yet we are poor in noteworthy stories. This is because no event any longer comes to us without being shot through with an explanation" (W. Benjamin 1968, 89). Such an explanation narrows, if not completely eliminates, the space for interpretation, and in turn, any possibility of providing counsel to the readers. In contrast, storytelling provides counsel to its listeners. Such counsel though is "less an answer to a question than a proposal concerning the continuation of a story which is just unfolding" (W. Benjamin 1968, 86). Thus, storytelling keeps a story free from explanation, giving space to the listener to interpret it himself. Such independence of the story from explanation is the reason why the story retains its authority and why it is inexhaustible and lasting (W. Benjamin 1968, 89). ${ }^{80}$

This point brings us to the third difference between the storytelling and information: the temporality of information versus timelessness of story. Benjamin argues, "[t]he value of information does not survive the moment in which it was new. It

${ }^{80}$ Referring to the story of the Egyptian king Psammenitus who was captured and beaten by the Persian king Cambyses, Benjamin suggests, this story "resembles the seeds of grain which have laid for centuries in the chambers of the pyramids shut up air-tight and have retained their germinative power to this day" (W. Benjamin 1968, 90). 
lives only at that moment" (W. Benjamin 1968, 90). That is to say, information is only an item of momentary interest, which shortly after ceases to be topical, and in turn, is discarded. On the contrary, storytelling "does not expend itself. It preserves and concentrates its strength and is capable of releasing it after a long time" (W. Benjamin 1968, 90). This aspect is related to the "chaste compactness" of storytelling, which, according to Benjamin, makes it easier for the story to "claim a place in the memory of the listener," rendering it possible for the story to become integrated into the listener's experience, increasing the inclination to repeat it (W. Benjamin 1968, 91). Such process of integration, Benjamin argues, requires relaxation, a state in which the listener can forget oneself. For " $[\mathrm{t}] \mathrm{he}$ more self-forgetful the listener is, the more deeply is what he listens to impressed upon his memory" (W. Benjamin 1968, 91).

The relaxation Benjamin refers to here is rendered possible via the "activities intimately associated with boredom," such as spinning and weaving that have a certain rhythm, which seizes the listener when he listens to the tales "in such a way that the gift of retelling them comes to him all by itself (W. Benjamin 1968, 91). However, with modernity, the relationship between experience and memory is transformed. Benjamin associates this transformation with the advent of shock, which is portrayed by him not only as the very fundamental feature of the modern experience but also as a primary sign of the crisis of experience. Thus, in the following section, I will examine Benjamin's notion of shock in its relation to the collective organization of human perception, memory and the mimetic faculty in order to demonstrate the implications of the advent of shock on the fabric of experience. To do so, I will start by introducing the distinction Benjamin makes between experience [Erfahrung] and immediate experience [Erlebnis]. 


\subsection{The Advent of Shock: Memory and Experience}

Benjamin's diagnosis of the crisis of experience intimately relates to the transformation of the relationship between experience [Erfahrung] and memory as well as experience [Erfahrung] and the mimetic faculty. Therefore, Benjamin identifies two different temporalities of experience: experience [Erfahrung] and immediate experience [Erlebnis]. Before going into the examination of these concepts within Benjamin's writing, it is necessary to look at the meaning of Erfahrung and Erlebnis in German. For their English translations are somewhat limiting.

The origin of the English word experience is traced back to the Latin experientia, which denotes "trial, proof, or experiment" (Jay 2005, 10). In contrast to this empiricist connotation of experience in English, the root of Erfahrung, Hansen argues, originates in "fahren," meaning to ride, to travel, and "Fahrt," meaning journey. Erfahrung is also associated to the German word "Gefahr," meaning danger (Hansen 1993; Jay 2005). These origins of the word Erfahrung convey a "sense of mobility, of journeying, wandering, or cruising, implying both a temporal dimension, that is, duration, habit, repetition, and return, and a degree of risk to the experiencing subject" (Hansen 1993, xvi). ${ }^{81}$ These connotations distinguish Erfahrung from the immediate, singular occurrence of Erlebnis. The root of Erlebnis is "Leben," meaning life. Jay (2005) suggests that "[a]lthough Leben can suggest the entirety of a life, Erlebnis generally

${ }^{81}$ Hansen (1993) acknowledges that the dimension of danger, or peril is present in the root of the Latin word - periri, despite the fact that it is quite submerged (Hansen 1993). Jay (2005) also points out that "to try" - experiri - contains the same root as periculum, indicating a covert association between experience and peril. 
connotes a more immediate, pre-reflective and personal variant of experience than Erfahrung" (11). ${ }^{82}$

${ }^{82}$ Beginning in his early writings, Benjamin demonstrated sympathy toward the "meanderings of experience" and a "valorization of experimental moment" in the concept of experience (Jay 2005, 316). His desire was to overcome not only the modalization of experience into its component parts but also the split between the subject and the object of experience (Jay 2005, 316). This desire led Benjamin to criticize Kant's conception of experience, and in turn, the Enlightenment which Kant sought to foster. According to Kant, "experience involves the imposition of categories and forms by the transcendental mind on the multiplicity of sensations" (Jay 2005, $319)$. Here, the subject of experience is separated from the noumenal objects, and the experience is limited to what can be known by synthetic a priori judgments. In his critique, Benjamin argues that Kant's conception of experience - which is based on the perceptual empiricism of the physical sciences - is a historically contingent rather than a universally necessary element of transcendental philosophy. In other words, Kant's conception of experience, Benjamin argues, was "unique and temporally limited," which in fact stands for "a worldview [...] that of the Enlightenment" (W. Benjamin 1996, 101). In On the Program of the Coming Philosophy (1918), Benjamin writes: "We know of primitive peoples of the so-called pre-animalistic stage who identify themselves with sacred animals and plants and name themselves after them; we know of insane people who likewise identify themselves in part with objects of their perception, which are thus no longer objecta, 'placed before' them; we know of sick people who relate the sensations of their bodies not to themselves but rather to other creatures, and clairvoyants who at least claim to be able to feel the sensations of others as their own. The commonly shared notion of sensuous (and intellectual) knowledge in our epoch, as well as in the Kantian and the pre-Kantian epochs, is very much a mythology like those mentioned. In this respect, so far as the naïve concept of the receipt of perceptions concerned, Kantian 'experience' is metaphysics or mythology, and indeed only a modern and religious infertile one" (W. Benjamin 1996, 103). On this basis, Benjamin challenges Kant's distinction between intuition and understanding, and questions both the structure of Kant's conception of experience and its basic assumptions: namely, the distinction between the subject and object of experience, and the rejection of the possibility of experiencing the absolute. According to Caygill (1998), "[Benjamin's] extension of the bounds of experience to include 'sooth-saying from coffee grounds' threatened to dissolve the bounds of sense that were so carefully demarcated by Kant and policed by his philosophical heirs" (2). In his attempt at developing a speculative concept of experience, Benjamin recasts "the distinction between intuition/understanding and reason into an avowed metaphysics of experience in which the absolute manifests itself in spatio-temporal experience, but in complex, tortuous and even violent forms" (Caygill 1998, 2). Benjamin's speculative recasting of the distinction between intuition, understanding and reason was aimed at showing that the totality expressed by ideas of reason appear not only in concepts but also in intuitions, which means that spatio-temporal categories include elements of categorical universality and rational totality. This claim, as Caygill argues, puts into question the assumption of critical philosophy, which makes a distinction between the activity of reason and understanding and the passivity of intuition. For a detailed analysis of Benjamin's understanding of the "coming philosophy" see (Caygill 1998). For Benjamin's writings concerning radical transformation of the concept of experience see On Language as Such and on the Language of Man (1916), Painting and Graphic Arts (1917), On Perception (1917), Painting, or Signs and Marks (1917), On the Program of the Coming Philosophy (1918), Doctrine of the Similar (1933), On the Mimetic Faculty (1933) in (W. Benjamin 1996; W. Benjamin 2005e). 


\subsubsection{Voluntary and Involuntary Memory}

"For an experienced event is finiteat any rate, confined to one sphere of experience; a remembered event is infinite, because it is merely a key to everything that happened before it and after it."

Walter Benjamin

Understanding Benjamin's notions of experience [Erfahrung] and immediate experience [Erlebnis] requires a close reading of his notion of memory and a deciphering of the relationship between memory and experience. Building on Henri Bergson's argument in Matter and Memory (1896), Benjamin highlights the fact that:

[T] he structure of memory [Gedächtnis] [is] decisive for the philosophical structure of experience [Erfahrung]. Experience is indeed a matter of tradition, in collective existence as well as private life. It is the product less of facts that are firmly anchored in memory [Erinnerung] than of accumulated and frequently unconscious data that flow together in memory [Gedächtnis] (W. Benjamin 2006d, 314).

This quotation recalls Proust's notion of involuntary memory [mémoire involuntaire], developed in the Remembrance of the Things Past (1913). Here, Proust makes a distinction between involuntary memory [mémoire involuntaire] and voluntary memory [mémoire voluntaire], associating the former with the unconscious and the latter with the conscious. To illustrate the difference, he tells the story of how one afternoon a taste of a type of pastry called madeleine brought back the memory of the town of Combray where he spent most of his childhood, and how until then all his attempts to remember that past had failed. For "he had been limited to the promptings of a memory [Erinnerung] which obeyed the call of conscious attention" (W. Benjamin 2006a). In this example, it becomes clear that involuntary memory is a "sensorily and synesthetically triggered embodied memory that can be retrieved only through 'actualization, not reflection'" (Hansen 2012, 109). Thus, for Proust, the past is situated 
"somewhere beyond the reach of the intellect and its field of operations, in some material object [...], though we have no idea which one it is. And whether we come upon this object before we die, or whether we never encounter it, depends entirely on chance" (Proust qt. in W. Benjamin 2006d, 315).

In other words, for Proust, "it is a matter of chance whether an individual forms an image of himself, whether he can take hold of his experience" (W. Benjamin 2006a, 315).

Challenging Proust's claim in this matter, Benjamin suggests that a person's inner concerns do not by nature have an inescapably private character. Rather, "[t]hey attain this character only after the likelihood decreases that one's external concerns will be assimilated to one's experience" (W. Benjamin 2006a, 315). In other words, one's inner concerns attain a private character under the conditions where it becomes increasingly impossible for the person to assimilate the knowledge of the world around him by way of experience. ${ }^{83}$ Here, Benjamin stresses the atrophy of experience once again, and delves into the examination of the relationship between the involuntary memory [mémoire involuntaire] and the conditions that have engendered it. To do so, Benjamin associates Proust's notion of the involuntary memory [mémoire involuntaire] to Freud's assumption, which hypothesizes a correlation between memory and consciousness.

Freud treats the mental apparatus "as a compound instrument" whose components, he calls, "systems" (Freud 2010, 539). In his analysis, Freud attaches psychical processes to these systems. Accordingly, he suggests that in the sensory end of the mental apparatus resides a system that receives perceptions. When a perception occurs, "a trace is left in our psychical apparatus of the perception which impinges upon

${ }^{83}$ This relates back to Benjamin's arguments concerning the decline of storytelling and the predominance of information. For more detail see (W. Benjamin 1968). 
it" (Freud 2010, 540). He calls this a "memory-trace" and the function relating to it "memory."

Memory traces, according to Freud, generate permanent modifications in the elements of the systems. If this is the case, then one and the same system cannot accurately retain modifications of its elements and "yet remain open to the reception of fresh occasions for modification" (Freud 2010, 540). For, "[t]he mirror of a reflecting telescope cannot at the same time be a photographic plate" (Freud 2010, 540). Thus, Freud distributes these two functions on to different systems: first is a system that resides in the very front of the apparatus and receives the stimuli but does not retain any trace of them, and second is a system "which transforms the momentary excitations of the first system into permanent traces" (Freud 2010, 540). The former is the "perceptual system" which has no memory while the second system is the "mnemic system" which retains associative traces (Freud 2010, 541) ${ }^{84}$ Freud associates consciousness with the former and memory with the latter system. For, "becoming conscious and leaving behind a memory trace are processes incompatible with each other within one and the same system" (W. Benjamin 2006a). In fact, memory fragments are "often most powerful and most enduring when the incident which left them behind was one that never entered consciousness" (W. Benjamin 2006a). ${ }^{85}$

\footnotetext{
${ }^{84}$ To put it differently, for Freud, "what consciousness yields consists essentially of perceptions of excitations coming from external world and feelings of pleasure and unpleasure which can only arise from within the mental apparatus" (Freud 1961, 18). Consciousness thus resides at the borderline between inside and outside. Accordingly, although the excitatory process becomes conscious in the conscious system, it leaves no permanent trace there. Instead, the memory traces are left in the system that lies behind the conscious system after they are transmitted there (Freud 1961).

${ }^{85}$ In other words, the perceptual system - which lies in the very front of the apparatus - has no memory, meaning that it cannot retain any associative traces. This conclusion leads Freud to claim that "the basis of association lies in the mnemic system" (Freud 2010, 541). Accordingly, it
} 
In Proustian terms, this means that only "what has not been experienced explicitly or consciously, what has not happened to the subject as an isolated experience [Erlebnis] can become a component of the mémoire involuntaire" (W. Benjamin 2006a). To put it in Freud's terms, "consciousness arises instead of a memory trace" $" 86$ (Freud 1961, 19) (emphasis in the original). Then, what is the role of consciousness in this process? For Freud, it is the protection against stimuli, which is "an almost more important function for the living organism than reception of stimuli" (Freud 1961, 21) (emphasis in the original). Freud suggests:

The protective shield is supplied with its own store of energy and must above all endeavor to preserve the special modes of transformation of energy operating in it against the effects threatened by the enormous energies at work in the external world - effects which tend towards a leveling out of them and hence towards destruction (Freud 1961, 21).

To put it differently, consciousness provides a shield against shocks, "exposure to [which] has become a norm" (W. Benjamin 2006a, 318) in urban life. Accordingly, the particular function of the psychic mechanism under the present conditions, Benjamin

is suggested that the perceptual system provides the consciousness with variety of sensory qualities while memories are in themselves unconscious (Freud 2010, 541). Freud identifies a new category in addition to consciousness and unconsciousness at this point, and calls it "preconscious." According to Freud, the preconscious "stands like a screen between the [unconscious] and consciousness" (Freud 2010, 542). It is the space where functions of censorship take place. While the preconscious stands in a closer relation to consciousness, the unconscious has no access to consciousness except through the preconscious (Freud 2010, 543). Moreover, according to Freud, the preconscious "directs our waking life and determines our voluntary, conscious actions" (Freud 2010, 542). Making an analogy between a suite of rooms and the structure of unconscious, Freud writes: "Let us [...] compare the system of the unconscious to a large entrance hall, in which the mental impulses jostle one another like separate individuals. Adjoining this entrance hall is a separate, narrower, room - a kind of drawing room in which consciousness, too, resides. But on the threshold between these two rooms a watchman performs his function: he examines the different mental impulses, acts as a censor, and will not admit them into the drawing-room if they displease him" (Freud qt. in Rice 2004, 278). In other words, the preconscious is a threshold between the unconscious and conscious, acting as a watchman, and policing the division between these states.

${ }^{86}$ Freud writes: "Excitatory processes do not leave behind any permanent change in its elements but expire, as it were, in the phenomenon of becoming conscious" (Freud 1961, 19), 
argues, is its ability to endure daily shocks. Such reception of shocks "is facilitated by training in coping with stimuli” (W. Benjamin 2006a, 318).

To illustrate the situation, Benjamin refers to a man Baudelaire speaks of, a man "who plunges into the crowd as into a reservoir of electric energy. Circumscribing the experience of the shock, he calls this man “"a kaleidoscope endowed with consciousness"” (Baudelaire qt. in W. Benjamin 2006d, 318). Although dreams and recollection are also enlisted as means of coping with the stimuli, ${ }^{87}$ this training "devolves upon the wakeful consciousness, located in a part of the cortex which is 'so frayed by the effect of the stimulus' that it offers the most favorable situation for the reception of stimuli" (W. Benjamin 2006a, 318). The shock that is "cushioned, parried by consciousness" thus "would lend the incident that occasions it the character of the isolated experience [Erlebnis], in the strict sense" (W. Benjamin 2006a, 318).

\subsubsection{Memory as Gedächtnis and Memory as Erinnerung}

The distinction Benjamin makes between experience [Erfahrung] and immediate experience [Erlebnis] in their relation to memory is complicated further with the distinction he introduces between memory [Gedächtnis] and reminiscence/recollection [Erinnerung] in reference to Reik's theory of memory - which, Benjamin argues, is also in line with Proust's distinction between involuntary and voluntary memory. Building on Freud's argument regarding shock, Reik suggests that "the majority of impressions $[\ldots]$ come to people too intensely or too immediately to be assimilated at first" (Reik 1936, 130). This idea leads Reik to assume that "we live to a large extent unconsciously" (Reik

${ }^{87}$ For more detail see (Freud 1961). 
1936, 130). ${ }^{88}$ It is at this point that Reik identifies a difference between memory [Gedächtnis] and reminiscence [Erinnerung]. He asserts: "The function of memory [Gedächtnis] is to protect our impressions; reminiscence [Erinnerung] aims at their dissolution. Essentially memory is conservative, reminiscence destructive" (Reik 1936, 131). In other words, while memory "as a covered or hidden reservoir, has primarily the power to maintain and conserve" impressions (Reik 1936, 129), "reminiscences involve a perforation of our unconscious memory as a whole, an incipient process of dissolution in becoming conscious" (Reik 1936, 131).

Benjamin integrates the distinction presented by Reik into his analysis of experience. In the Storyteller (1968), he identifies memory [Gedächtnis] as "the epic faculty par excellence" (97). Accordingly, it is argued that memory [Gedächtnis] "retains by absorbing 'the course of events' and in repeating and hence in the continual possibility of repetition" (A. Benjamin 1991, 124). The epic element of the storytelling brings both aspects of the memory together. For the epic is understood in relation to its muse, Mnemosyne. This muse of the epic is the rememberer. In this context, memory as Gedächtnis - namely, a long-term memory - marks the specific character of the tradition of experiences [Erfahrungen]. That is to say, it plays a significant role in the creation of the community of listeners since memory [Gedächtnis] is intimately bound to the ability to repeat narration. ${ }^{89}$ On the other hand, reminiscence [Erinnerung] leads to the disintegration of impressions (W. Benjamin 1968). Here, "disintegration" refers to the creative element of the storytelling, which indicates the fact that in storytelling the

\footnotetext{
${ }^{88}$ It should be noted here that through the process of shock defense the impressions are not cancelled out; rather, they are laid aside to be brought out later.

89 "As Benjamin understands Gedächtnis as an example of the epic ability, the epic itself produces 'perpetuating remembrance' that also makes the continuity of tradition possible" (Lindroos 2001, 26).
} 
stories are not only repeated; but rather, each time they are told, they are created afresh. It is this characteristic of storytelling that renders it possible to reform any specific tradition.

This interplay between retention and repetition is called "epic remembrance," which endures the "Muse-inspired element of the narrative" (W. Benjamin 1968a, 98). Benjamin writes: "[The story] bears the trace of the storyteller, much the way an earthen vessel bears the trace of the potter's hand" (W. Benjamin 2006a, 316). In other words, the repetition inherent to storytelling does not imply the repetition of 'the same'; rather, "[t]he same was never the same because it was supplemented by its own repetition" (A. Benjamin 1991, 130). That is to say, it is memory as Gedächtnis that mediates an event from generation to generation, and thus renders the creation of the chain of tradition. ${ }^{90}$ Benjamin writes:

All great storytellers have in common the freedom with which they move up and down the rungs of their experience as on a ladder. A ladder extending downward to the interior of the earth and disappearing into the clouds is the image for a collective experience to which even the deepest shock of every individual experience, death, constitutes no impediment or barrier (W. Benjamin 1968, 102).

In this passage, the ladder represents the totality of tradition, whose past does not "exist as a series of discrete events in themselves," but "endures a ritual" (A. Benjamin 1991, 127). In other words, "[t]radition and repetition do not unfold into an empty space";

\footnotetext{
${ }^{90}$ In this context, the difference of the novel resides in the fact that "it is not lodged within the process of taking over, retaining and repeating" (A. Benjamin 1991, 125). In other words, the novel neither articulates nor continues a tradition. Despite the fact that it takes place within tradition, it does not function to continue this tradition. "The novel opens an enclosed world closed off from the world of repetition. The world it opens is self-enclosing and within it the novel preoccupies with a unique happening... The impossibility of repetition is therefore inscribed within the actual identity of the novel itself" (A. Benjamin 1991, 126). Benjamin calls this "perpetuating remembrance" (W. Benjamin 1968), it is remembrance that "perpetuates within the self-enclosed world of the novel" (A. Benjamin 1991, 126).
} 
rather, they unfold into a space of a community of listeners where the storyteller must repeat and must be repeated (A. Benjamin 1991, 127). ${ }^{91}$ However, the present has become fragmentary and discontinuous, meaning that the site of retention - namely, the community of listeners - has become fragmented while the site of repetition - namely, the destructive, and in turn, creative aspect - has been lost to the re-production of the same, thereby leading to immediate, privatized and isolated experiences [Erlebnisse], that are unrepeatable.

To exemplify the fragmentation of the present, Benjamin provides a description of an unskilled worker in On Some Motifs in Baudelaire (1940):

The unskilled worker is the one most deeply degraded by machine training. His work has been sealed off from experience [Erfahrung]; practice counts for nothing in the factory [...] The hand movement of the worker at the machine has no connection with the proceeding gesture for the very reason that it repeats that gesture exactly (W. Benjamin 2006d, 329-330) [emphasis added].

According to Benjamin, the continuity of work does not construct the continuity of action that establishes itself as experience [Erfahrung] because the repetition at play here is different than the repetition integral to storytelling. The latter requires the retention, and passing over, of experience through the narration of the storyteller. Here, the repetition of a story - each telling of a story - is unique, which means that the repetition of the same is never the same, which serves the continuity of tradition.

The worker at the machine, however, does not repeat by taking over, and thus, is "sealed off from experience [Erfahrung]" (W. Benjamin 2006d, 330). It is this newness -

${ }^{91}$ That is to say, "the erosion of spatial relations crucial to epic tradition - the proximity of the collective of listeners, the mystery of faraway places - [relate] to that of the temporal conditions of experience, the dissociation of collective memory and individual recollection, the latter surviving only in the privatized subjectivity of the novel writing and reading" (M. Hansen 1987, 189). 
in the sense of being disconnected from what-has-been - that is created by the modern day repetition that breaks the continuity of tradition. To put it more clearly, at the machine, each moment, each repetition is the same, and thus new (novel) ${ }^{92}$ It is because of this repetition of the same in each moment that the experience [Erlebnis] at the machine is perceived as the reception of shocks, meaning that these experiences [Erlebnisse] do not become part of long-memory [Gedächtnis]. Benjamin writes:

The greater the shock factor in particular impressions, the more vigilant consciousness has to be screening stimuli; the more efficiently it does so, the less these impressions enter long experience [Erfahrung] and the more they correspond to the concept of isolated experience [Erlebnis]. Perhaps the special achievement of shock defense is the way it assigns an incident a precise point in time in consciousness, at the cost of integrity of the incident's contents. This would be a peak achievement of the intellect; it would turn the incident into an isolated experience (W. Benjamin 2006a, 319).

The fragmentary nature of the memory and the experience of the unskilled worker, according to Benjamin, mirror the structure of the memory and experience of the modern individual. Just like the worker at a conveyer belt, the activities and events that take place within the everyday life of the modern individual are particularized and isolated. To put it more clearly, the modern conditions, Benjamin argues, do not result in the absorption of the course of events and their repetition in narration. For, although there appears to be a chain of events and activities in the modern everyday life, which should result in a continuity and unity of experience [Erfahrung], they are neither connected to the previous events or activities nor to the ones of the previous day/week/month/year. More precisely, these events, activities, or occurrences - such as driving to work, getting

${ }^{92}$ This is the point where Benjamin identifies a similarity between work and gambling. He argues, "each operation at the machine is just as screened off from the preceding operation as a coup in a game of chance is from the one that preceded it, the drudgery of labourer is, in its own way, a counterpart to a drudgery of the gambler" (W. Benjamin 2006a). 
a cup of coffee, being stuck in traffic, etc. - are, in fact, the exact repetition of the previous ones. None of these repetitions serve to take over and pass on a tradition; rather, they generate isolated, individualized experiences [Erlebnisse], which mark the fractures in the memory of the individual and the fragmentation of the community of listeners. It is this fragmentary, unrepeatable, individualized and isolated nature of the experiences of modern man that characterizes the crisis of experience. These observations are not a call for the restoration of the experience [Erfahrung]; rather, they are a call for an understanding of the state of experience [Erfahrung] so that a way for new beginnings could be paved. In On the Concept of History (1940), Benjamin writes: "Every age must strive anew to wrest tradition away from the conformism that is working to overpower it" (W. Benjamin 2006d, 391).

\subsubsection{The Transformation of the Mimetic Faculty}

The crisis of experience also marks the decline of the mimetic faculty, which, for Benjamin, is "one of the quintessential modes of human cultural production" (Hanssen 2004, 56). In a fragment from 1931/1932, Benjamin suggests that "[e]xperiences are lived similarities. [...] What is decisive here is not the causal connections established over time, but the similarities that have been lived" (W. Benjamin 2005d, 553). Therefore, it is necessary to explore Benjamin's interpretation of the relationship between experience and the mimetic faculty.

In the Doctrine of the Similar (1933), Benjamin argues that "[n]ature produces similarities; one need only think of mimicry. The highest capacity for producing similarities, however, is man's. This gift for seeing similarity is nothing but a rudiment of the once powerful compulsion to become similar and to behave mimetically" (W. 
Benjamin 2005e, 694). Here, Benjamin depicts a reciprocal relationship between nature and man, suggesting that "the natural correspondences are given their true importance only if we see that they, one and all, are stimulants and awakeners of the mimetic faculty which answers them in man” (W. Benjamin 2005e, 695).

In a fragment from 1917 On Perception in Itself, Benjamin writes:

Perception is reading;

Only that appearing in the surface is readable...

Surface that is configuration - absolute continuity.

In this passage, Benjamin identifies the condition of a possible experience as appearance on the surface that is readable. Here, experience is defined not as what is received as impressions but the reading of appearances within a configuration. This understanding of experience eliminates the distinction between the subject and the object of experience, because, here, what is read is not just a "passive datum" (Caygill 1998, 4) but makes an active contribution to the reader's accomplishment of perception. ${ }^{93}$

In On the Mimetic Faculty (1933), Benjamin expresses his idea of "perception as reading" in the following way: "'To read what was never written.' Such reading is the most ancient: reading prior to all languages, from entrails, the stars, or dance" (W. Benjamin 2005e, 722). In this passage, configuration is identified once again as the condition of legibility. That is to say, it is portrayed as both the condition of a possible experience and as the discovery of "non-sensuous similarity" between configured patterns. ${ }^{94}$ Thus, for Benjamin, the mimetic faculty concerns the configurations of

\footnotetext{
93 According to Scholem, Benjamin conceptualizes "perception as a reading in the configurations of the surface - which is the way prehistoric man perceived the world around him, particularly the sky" (Scholem qt. in Caygill 1998, 5).

${ }^{94}$ According to Caygill, space and time, which were forms of intuition in Kant's philosophy, are to be regarded as "modes of configuration whose plasticity, or openness to other forms of patterning, can 'decay' or be otherwise 'transformed' in Benjamin's argument (Caygill 1998, 5).
} 
similarities or correspondences in nature. It is thus the capacity to not only recognize but also produce such similarities and correspondences.

According to Benjamin, the mimetic faculty has a history in both the phylogenetic and ontogenetic sense. ${ }^{95}$ In the ontogenetic sense, it manifests itself in the everydayness of children's play. Benjamin writes: "Children's play is everywhere permeated by mimetic modes of behavior. [...] The child plays at being not only a shopkeeper or a teacher, but also a windmill and a train" (W. Benjamin 2005e, 694). The phylogenetic, on the other hand, refers to the transformations that have taken place within the mimetic capacity. Benjamin writes:

$[N]$ either mimetic powers nor mimetic objects remain the same in the course of thousands of years. Rather, we must suppose that this gift for producing similarities (for example, in dances, whose oldest function is this), and therefore also the gift of recognizing them, have changed in the course of history (W. Benjamin 2005e, 694).

This change, Benjamin argues, "lie[s] solely in the increasing fragility of this mimetic faculty. For clearly the perceptual world [Merkwelt $]$ of modern human beings seems to contain far fewer of those magical correspondences than did that of ancient or even that of primitive peoples"96 (W. Benjamin 2005f, 695). Does this mean that human beings' mimetic faculty is totally diminished? Not quite. ${ }^{97}$

${ }^{95}$ In the Oxford English Dictionary (2005), phylogenesis is defined as "the evolutionary development of a species or other group of organisms through a succession of forms" while ontogenesis is defined as "the development of the individual organism from the earliest embryonic stage to maturity."

${ }^{96}$ For example, in the fragment On Astrology (1932) Benjamin suggests, "there can be no doubt that people in Antiquity had a much sharper mimetic sense for physiognomic resemblance than does modern man, who really only recognizes facial similarities, and no longer has much ability to recognize bodily similarities" (W. Benjamin 2005e, 684-685).

${ }^{97}$ A quote from Benjamin should suffice: "Overcoming the concept of 'progress' and overcoming the concept of 'period of decline' are two sides of one and the same thing" (W. Benjamin 2002d, $460, \mathrm{~N} 2,5)$. This quote highlights the fact that Benjamin finds both the concept of "progress" and the "concept of period of decline" as obstacles for a historical materialist. The survival of these 
Understanding this transformation of the mimetic faculty requires an explanation of Benjamin's notion of "non-sensuous similarity" ["unsinnliche Ähnlichkeit"]. To illustrate this notion, Benjamin refers to astrology. He suggests that in an archaic past, there was a mimetic correspondence between a person's moment of birth and the constellation of the stars at that moment. This mimetic knowledge was perceived by the ancients and passed on to the newborn (W. Benjamin 2005e).${ }^{98} \mathrm{He}$ argues,

the perception of similarities is bound to a flashing up. It flits past, can possibly be won again, but cannot readily be held fast as can other perceptions. It offers itself to the eye as fleetingly and transitorily as a constellation of stars. The perception of similarities thus seems to be bound to a moment in time. It is like the addition of a third element - the astrologer - to the conjunction of two stars; it must be grasped in an instant (W. Benjamin 2005e, 695) (emphasis added).

To put it differently, the correspondences actualized by the mimetic faculty are not concerned with an iconic relationship - "a perceptual likeness between sign and reality" - in semiotic terms. Rather, they pertain to "the realm of the indexical, which involves a relationship of material contiguity hinging upon a particular moment in time and thus brings into play the disjunctive temporality of all reading" (M. Hansen 1987, 195). However, Benjamin argues, this capacity to perceive similarities has diminished in the modern world. Here, he draws attention to the dulling of the perceptual apparatus, which has increasingly become unable to perceive and reproduce similarities under the conditions of the commodity form and technological reproduction - as a result of, for

concepts are rendered possible through feeding each other as its opposite while connoting to the same notion of history, that is, continuous, linear, progressive.

98 "The perception of this correspondence was bound to a moment in time, a fleeting instant" that is, the moment of the birth and the particular constellation of the stars at that moment - "and depended upon the presence of a reader, individual or collective, for an interpretation" (M. Hansen 1987, 196). 
instance, commodification, urbanization, alienation, the proliferation of shock sensation, mediation of perception through technology. ${ }^{99}$

Although our capacity to perceive similarities is diminished, "it can still be claimed of our contemporaries that the cases in which they consciously perceive similarities in everyday life make up a tiny portion of those numberless cases unconsciously determined by similarity" (W. Benjamin 2005e, 694) (emphasis added). For instance, what is this that we call "gut feeling" if not a sensuous judgment which derives from an unintentional recognition of unconscious similarities and correspondences that we have - at one point or another - cultivated? Moreover, despite the fact that "our existence no longer includes what once made it possible to speak of this kind of [non-sensuous] similarity [...] we, too, possess a canon according to which the meaning of non-sensuous similarity can be clarified. And this canon is language" (W. Benjamin 2005e, 721). ${ }^{100}$ Although the influence of the mimetic faculty on language has been recognized, such recognitions, Benjamin argues, have been closely related to the "sensuous realm of similarity." 101

\footnotetext{
${ }_{99}$ Accordingly, Benjamin suggests, "the sphere of life that formerly seemed to be governed by the law of similarity was much larger" (W. Benjamin 2005a, 694).

${ }^{100}$ The transition from reading 'what was never written' to writing affects the complexity of the configuration. While in the former the configurations were read against each other in a space where there was neither foreground nor background, in the latter configurations are read "according to their relative position on a given uniform extended surface. Configuration thus transformed into inscription, reducing speculative reading of the similarity between patterns into the transcendental reading of graphically inscribed marks upon an infinite but bounded surface" (Caygill 1998, 5).

${ }^{101}$ In his essay The Problems of Sociology of Language (1935), Benjamin provides an overview of the sociology of language, with a specific focus on the discussions on the origin of language. Here, he draws attention to theories of language that emphasize the primitive people's irresistible tendency to imitate all they hear, all they see, and in general all they perceive, including gestures and movements, in order to demonstrate the fact that the reproduction of the similarities perceived create the magical qualities attributed to language by primitive people. The significance of the "magical" correspondences resides in the absence of the divide between object and subject, brought forth by the objectifying view of scientific methodology and reason. It should also be
} 
Benjamin acknowledges the role of onomatopoeia ${ }^{102}$ in the transformation of language, but he expands the scope of similarity to include the "non-sensuous similarity" by treating the phonetic element of language as the "mimic-expressive movement of the body” (W. Benjamin 2006c, 84). In citing Mallarmé, Benjamin states:

The dancer is not a woman but a metaphor that may give expression to one aspect of the elementary forms of our existence: sword, goblet, flower, and others. With such a perception - namely, that linguistic expression and choreographic expression are rooted in one and the same mimetic faculty - we cross the threshold of a physiognomics of language, which takes us far beyond the primitive attempts of onomatopoetic theory (W. Benjamin 2006c, 84-85).

He also expresses the need to add "non-sensuous similarity at the level of writing" to "similarity at the level of sound" (Hanssen 2004, 67). To illuminate this point, he turns to the issue of translation where the relationship between the words of different languages denoting the same meaning becomes manifest. Benjamin writes:

If words meaning the same thing in different languages are arranged about that signified at their center, we have to inquire how they all - while often possessing not the slightest similarity to one another - are similar to the signified at the center. Yet this kind of relationships between words meaning the same thing cannot be restricted to the spoken word. They are equally concerned with the written word. And here it is noteworthy that the latter [...] illuminates, by the relation of its written form [Schriftbild] to the signified, the nature of non-sensuous similarity. In brief, it is the non-sensuous similarity that establishes the ties not only between what is said and what is meant but also between what is written and what is meant, and equally between the spoken and the written (W. Benjamin 2005e, 696).

In both of the passages quoted above, Benjamin emphasizes the significance of the expressive character and physiognomic powers of language, which is overlooked in

noted here that in this overview, Benjamin discusses the relationship between the transformation of language and socio-economic processes as well as the relationship between class struggle and language.

102 The Oxford English Dictionary (2004) defines onomatopoeia as "[t]he formation of a word from a sound associated with the thing or action being named; the formation of words imitative of sounds." 
comparison to its semantic function. ${ }^{103}$ To further illustrate his point, he turns to graphology, which, he argues, "taught us to recognize in handwriting images $[\ldots]$ the unconscious of the writer" (W. Benjamin 2005e, 697). The mimetic faculty expressing itself in this way in the activity of the writer - namely, handwriting - has become "an archive of non-sensuous similarities, of non-sensuous correspondences"(W. Benjamin 2005e, 697). This, according to Benjamin, is one of the ways in which the "magic" dimension of language manifests itself. The dimension of language, which becomes manifest in handwriting, however,

does not develop in isolation from [...its] semiotic aspect. Rather, the mimetic element in language can, like a flame, manifest itself only through a kind of bearer. This bearer is the semiotic element. Thus, the nexus of meaning of words or sentences is the bearer through which, like a flash, similarity appears. For its production by man - like its perception by him - is in many cases, and particularly the most important, tied to its flashing up (W. Benjamin 2005e, 722).

The growing speed of writing and reading has enhanced "the fusion of the semiotic and the mimetic in the sphere of language" (W. Benjamin 2005e, 722). ${ }^{104}$ In this process, the semiotic aspect has become predominant while the mimetic aspect has been rendered indiscernible. Benjamin writes:

Am I the one who is called W.B., or am I simply called W.B.? These are two sides of a medallion, but the second side is worn and effaced, while the first is freshly minted. This initial take on the question makes it evident that the name is object of a mimesis. Of course, it is in the nature of the latter to show itself not in what is about to happen, but always only

\footnotetext{
${ }^{103}$ It should be noted here that this point is directly related to Benjamin's critique of the treatment of language merely as an instrument. "As soon as human beings use language to establish a living relationship to themselves and others, language is no longer an instrument, no longer a means, but a manifestation, a revelation of our innermost being and of the psychic bond linking us to ourselves and to our fellow human beings" (W. Benjamin 2006b, 85).

${ }^{104}$ It should also be noted here that Benjamin's notion of reading is not limited to written material, but it ranges from the reading of constellations on the sky to a critical reading of the 'natural' phenomenon of the nineteenth century capitalism. For more detail see (W. Benjamin 2002b; W. Benjamin 2005a).
} 
in what has been - that is, in what has been lived. The habitus of a lived life: this is what the name preserves, but also marks out in advance. With the concept of mimesis, it is further asserted that the realm of the name is the realm of the similar. And since similarity is the organon of experience [Erfahrung], it may be said that the name can be recognized only in the contexts of experience, only in them is its essence - that is, linguistic essence - recognizable (W. Benjamin 2002d, 868, Qo,24).

In this passage, Benjamin illustrates the relationship between the mimetic faculty and language in order to demonstrate the implication of the treatment of language only as a medium of communication, which detaches it [language] from its task in configuring the relationship between experience and mimesis. Such treatment of language turns language into a medium, "into which earlier powers of mimetic production and comprehension have passed without residue, to the point where they have liquidated those of magic" (W. Benjamin 2005c, 722). This process has been accompanied by the withdrawal of similarity into the non-sensuous correspondences, which have originated in both the decline of "the subjective and intersubjective capability of perceiving similarity" and the compromising of the status of the sensuous irrevocably - as a result of "the effects of universal commodity production and a concomitant standardization of social identity and subjectivity" (Hansen 1987, 199).

\subsection{Auratic Perception versus Kitsch Perception}

The distinction Benjamin makes between experience [Erfahrung] and immediate experience [Erlebnis] originates in the transformation of the collective organization of human perception. This transformation manifests itself in a shift from auratic perception to, what I call here, kitsch perception. The conceptualization of the latter allows us not

only to expand our understanding of the significance of the radical restructuring of 
human perception, but also, and perhaps more importantly, to interrogate the ways in which the crisis of experience can be overcome.

At the beginning of March 1930, in an unpublished report on one of his hashish experiences, Benjamin writes:

Everything I said on the subject [the nature of the aura] was directed polemically against the theosophists, whose inexperience and ignorance I find highly repugnant... genuine aura appears in all things, not just in certain kinds of things, as people imagine (W. Benjamin 2005d, 327) (emphasis added).

Here, Benjamin's conceptualization of the aura goes beyond the common understanding of his concept of the aura as an aesthetic category, which is examined in its relation to the "here and now" of the work of art, its authority, and unattainability, epitomized by the idea of a beautiful semblance as well as its decline in the context of modernity (W. Benjamin 2006c). Conversely, in this section, I treat Benjamin's concept of the aura in a broader sense to stress its "anthropological, perceptual-mnenomic, and visionary dimensions" (Hansen 2012, 105).

In the Artwork (1936) essay, Benjamin defines the aura as "a strange tissue of space and time: the unique apparition of a distance, however near it may be" (W. Benjamin 2006c, 104-105). In On Some Motifs on Baudelaire (1940), he depicts the aura as a form of perception that "invests" a phenomenon with "the ability to look at us in return" (W. Benjamin 1968, 188). ${ }^{105}$ He writes:

'Perceptibility,' Novalis puts it, 'is a kind of attentiveness.' The perceptibility he has in mind is none other than that of the aura. Experience of the aura thus rests on the transposition of a response common in human relationships to the relationship between the inanimate or natural object and man. The person we look at, or who feels he is being

\footnotetext{
${ }^{105}$ In the Arcades Project, conjoining the two definitions presented earlier, he states: "definition of the aura as the aura of distance opened up with the look that awakens in an object perceived" (W. Benjamin 2002a, 361).
} 
looked at, looks at us in turn. To perceive the aura of an object we look at means to invest it with the ability to look at us in return (W. Benjamin $1968,188)$.

In this passage, the aura is presented not as an essential property of persons or objects; rather, it is depicted as the medium of perception, which indicates a particular mode of vision. But, under the conditions of the commodity form and technological reproduction as well as sensory alienation and increased shock sensations, the aura - just like experience [Erfahrung] - has begun to decline. Thus, Benjamin argues:

If we think of the associations which, at home in the mémoire involontaire, seek to cluster around an object of perception, and if we call those associations the aura of that object, then the aura attaching to the object of a perception corresponds precisely to the experience [Erfahrung] which, in the case of an object of use, inscribes itself as a long practice. The techniques inscribed by the camera and subsequent analogous types of apparatus extend the range of the mémoire volontaire; these techniques make it possible at any time to retain an event - as image and sound through the apparatus. They represent important achievements of a society in which long practice is in decline (W. Benjamin 2006d, 337) (emphasis added).

In this passage, Benjamin describes the camera's indifference to the human gaze as a manifestation of the transformation of the relations of looking in modern society, which signals the rise of a new mode of perception. If the aura renders it possible for the object to return the gaze of the beholder, kitsch perception tears apart this "strange tissue of space and time" (W. Benjamin 2006c, 104), thereby dislodging the possibility of returning of the gaze.

According to Benjamin, the data of involuntary memory are "incidentally, unique: they are lost to the memory that seeks to retain them" (W. Benjamin 2006d, 338). Thus, they share the definitive aspect of the aura as "a unique apparition of a distance," which indicates unapproachability and unattainability. The connection 
between the aura and involuntary memory signifies not only the fact that the "unique apparition of a distance" (that appears to the beholder) has a temporal dimension, but also the intertwinement of distance with the unconscious.

In contrast to auratic perception and its relationship to involuntary memory and experience [Erfahrung], what materializes in kitsch perception is the "perpetual readiness of voluntary, discursive memory, encouraged by technological reproduction" (W. Benjamin 2006d, 337). To put it more clearly, the associations or correspondences are substituted by techniques that render it possible to retain an event through the apparatus. "[A] touch of a finger," Benjamin writes, "sufficed to fix an event for an unlimited period of time" (W. Benjamin 2006d, 328). This process in turn generates the conditions under which experience [Erlebnis] is isolated and particularized, signaling a fracture in collective memory. Thus, in the modern era, kitsch perception and immediate experience [Erlebnis] replace auratic perception and experience [Erfahrung].

According to Benjamin, haptic experiences of the kind exemplified above are not the only examples of the impact of technology on human perception. According to him, they "were joined by optic ones, such as are supplied by the advertising pages of a newspaper or the traffic of a big city. Moving through this traffic involves the individual in a series of shocks and collisions" (W. Benjamin 2006d, 328). Therefore, kitsch perception is conditioned by the subjection of the "human sensorium to a complex kind of training" (W. Benjamin 2006d, 328) by technology. Within this configuration, kitsch perception manifests itself in a vision in which the subject and object are disassociated, and the linear notions of time and space as well as the hierarchy between the subject and object are materialized. 
Kitsch (perception) cannot be conceptualized without the demonstration of its relation to the masses, considering that in the Artwork essay (1936), Benjamin treats aura and masses as though they were parallel yet opposed categories, embodying mutually exclusive forms of perception. In the Artwork (1936) essay, Benjamin writes:

Everyday the urge grows stronger to get hold of an object at close range in an image $[$ Bild $]$, or better, in a facsimile $[$ Abbild $]$, a reproduction. And the reproduction [Reproduktion], as offered by illustrated magazines and newsreels, differs unmistakably from the image. Uniqueness and permanence are as closely entwined in the latter as are transitoriness and repeatability in the former. The stripping of the veil from the object, the destruction of the aura, is the signature of a perception whose 'sense for sameness in the world' has so increased that, by means of reproduction, it extracts sameness even from what is unique (W. Benjamin 2006c, 105). ${ }^{106}$

In this passage, Benjamin elaborates the transformation of perception along with two distinct axes: the first one is concerned with spatial and temporal categories such as closeness versus distance, transitoriness versus permanence while the second one concerns itself with the object's mode of being in relation to others such as sameness versus uniqueness, multiplicity versus singularity (Hansen 2012).

\subsubsection{Spatial-Temporal Categories}

Under the conditions where the spatial and temporal categories of auratic perception - such as the proximity of the collective of listeners and the dissociation of collective memory and individual recollection respectively - are liquidated, despatialization and de-temporalization become possible by means of which the subject is uprooted from a human range of perception. Thus, in kitsch perception, the distance is dissolved while closeness is crystalized. If "perception is reading" as Benjamin argues,

\footnotetext{
${ }^{106}$ It should be noted here that Benjamin uses the word Bild (image) in German. This word does not distinguish between image and picture. His use of the word "refers to a meaning of Bild that precedes the distinctions among mental, visual, and material images as well as the differentiation of scripture and pictures and the separation of concept [Begriff] and metaphor" (Weigel 2015, 344). For a detailed analysis of the genealogy of the image see (Mitchell 1986).
} 
the effect of closeness on "reading" needs to be articulated. Benjamin suggests that if one looks at a bunch of rocks from afar, she might perceive different shapes, images, figures, on this surface, which itself is a configuration (W. Benjamin 2006d). Such reading does not reflect an intended meaning, but rather, "a discovery of a 'non-sensuous similarity' between configured patterns" (Caygill 1998, 5). Yet, the closer the observer comes to these rocks, the possibility to perceive similarities and configured patterns reduces. For, the spatial and temporal closeness diminishes the horizon of looking; to put it differently, it limits perception (as reading) to a particular configuration, which restricts the possible imaginaries.

The rise of closeness - as the definitive aspect of kitsch (perception) - by means of which the "unique apparition of a distance" is jettisoned, is itself conditioned by a growing urge of the masses to get closer to things both in time and space. The more the desire of masses to get closer to things increases, and concomitantly, the more things get closer to the masses by means of commodity production and technological reproduction, the perceptivity of the masses decreases. For, the closeness between the masses and the things reduces the possibility of a discovery of non-sensuous similarities. Instead, it creates the conditions that are favorable to the absorption of the intended meaning (created through re-temporalization and re-spatialization) that is inscribed in a particular configuration. This could be further explained by looking at what happens to perception in the modern metropolises.

Benjamin makes an analogy between the factory workers and the masses. In $\mathrm{On}$ Some Motifs on Baudelaire (1940), he writes: "What determines the rhythm of production on a conveyor belt is the same thing that underlines the rhythm of reception" 
(W. Benjamin 2006d, 328) in a metropolitan city. Like the factory workers who learn to coordinate "their own movements with the uniformly constant movements of an automaton" (W. Benjamin 2006d, 328), the masses learn to coordinate their attire and behavior as well as facial expressions in accordance to the tempo, density and shocks of everyday life. While the workers' sensory organs are trained in the assembly line, the sensory organs of the masses are trained by shocks and collisions of the everyday life in the industrial-capitalist city. It is through such training that the masses learn how to "express themselves only automatically" (W. Benjamin 2006d, 329).

Such training in the factory - which produces and re-produces the alienating division of labour and the separation of the means of production from the producers themselves - and in the city - which is rendered possible by the rise of the masses as well as the movement of the masses towards the things and the things towards the masses - lead to the thickening of the protective shield, which in turn exacerbates sensory alienation. As a result, the mimetic faculties of human beings turn into "mimetic shock absorber[s]" (W. Benjamin 2006d, 328). Just think of a smile appearing on the face of a passerby or, an immediate apology given both by the jostler to the jostled on the street. These examples illustrate the fact that the connection between cognition and the mimetic faculty is short-circuited in the modern individual's attempt to protect him/her-self. Thus, I argue, kitsch perception is a quasi-perception. For it is concerned more about deflecting rather than perceiving.

\subsubsection{The Object's Mode of Being in relation to Others}

While the possibility of the discovery of non-sensuous similarity decreases with the move of the masses toward the things and the things towards the masses, a different 
form of perceptual mode of similitude emerges, that is, sameness qua identity. "Sameness qua identity stands in implicit distinction from similitude or similarity [Ähnlichkeit]" (Hansen 2012, 94). Benjamin illustrates the distinction of the perceptual mode of similitude from sameness qua identity in reference to dreaming and the hashish experience. In the process of dreaming, he argues, "everything that happens appears not in identical but in similar guise, opaquely similar to itself" (W. Benjamin 2005d, 239) while in the hashish experience, everything appears to be, or in Benjamin's words, "everything is face: each thing has the degree of bodily presence that allows it to be searched - as one searches a face" (W. Benjamin 2002c, 418, M1a,1).

Here, Benjamin draws attention to the symbolic in the dream process while emphasizing the ability to perceive nuances among the same in the hashish experience. Despite the fact that both the dreaming process and the hashish experience are processes in which similitudes appear in a 'distorted' form, perhaps more importantly, such distortions also become a medium of cognition. For instance, in the dreaming process, anything that happens or appears is in fact an expression of the unconscious. To put it differently, in the dream, these expressions appear in a similar but not identical form to what they symbolize. That is to say, the expressions appearing in the dream - or say, the ‘distorted similarity’ [entstellte Ähnlichkeit] - could become a medium of cognition if these expressions are investigated attentively. ${ }^{107}$

${ }^{107}$ In The Arcades Project (2002), this is exactly what Benjamin attempted to do. In this work, he constructed the materials (e.g., architecture, arcades, barricades, commodities) of the nineteenth century as dream images of the collective. As the distorted images of the "dream-filled sleep that fell over Europe" (W. Benjamin 2002d, 391, K1a,8), they were the expressions of the collective unconscious, which therefore needed to be attentively investigated to understand the modern condition. 
In the hashish experience, Benjamin argues, "even a sentence (to say nothing of the single word) puts on a face, and this face resembles that of the sentence standing opposed to it" (W. Benjamin 2002c, 418, M1a,1). What is important here is the recognition of the nuance despite the acknowledgement of the similarity. Benjamin

writes: "When we say that one face is similar to another, we mean that certain features of this second face appear to us in the first, without the latter's ceasing to be what it has been" (W. Benjamin 2002d, 418, M1a,1). Thus, the 'distorted similarity' in the hashish experience, like in the dreaming process, becomes a medium of cognition.

In contrast, the sameness qua identity results in a transferring of a quality of perception, which is integral to technological reproduction (e.g., seriality and repeatability) to the masses. As a result, the non-sensuous similarity that is the perceptual condition for the mimetic faculty in modernity submerge[s] into the "iconicity of photographic representation" (Hansen 2012, 94). Therefore, by divorcing the nonsensuous similarity from its mnemic and historical dimensions, kitsch perception leads to the identification of 'what appears on the surface' - and thus should be read - with 'what is.' This is exemplified with the phantasmagorias in which dream images are materialized as being experienced [Erlebnis] as wish fulfillments rather than read as distorted similarities by means of which the collective unconscious could be discovered.

\subsection{Conclusion}

In this chapter, I examined Benjamin's notion of the crisis of experience in order to demonstrate the ways in which the dream consciousness emerges in the modern age through the restructuring of the human perception by means of the development of technology and commodity production. Benjamin traces the beginning of this crisis back 
to the World War I, where the conditions in which experiences had become incommunicable were created. The emergence of the incommunicability of experience, in this context, is related to the destruction of the possibility of any meaningful explanation concerning the monstrous events that had taken place during the War. For, every explanation that fit into neat little boxes within tradition had been contravened. In other words, the War had resulted in the creation of an abyss through which an entire array of meanings originating in tradition "have become unrecognizable, if not patently unserviceable, to us in the present" (Wolin 1982, 19). The end of the War however, was not the end of the crisis of experience. In fact, the abyss created by the War has become even deeper by the restructuring of the collective organization of human perception in accordance with the material and social conditions of capitalism and technological reproduction. The penetration of the tediously repetitive daily life in the metropolis has resulted in the reproduction and intensification of the conditions of the incommunicability of experience, leading to the substitution of the continuity and unity of experience with its fragmentation and discontinuity.

Benjamin thus introduces two temporalities of experience: experience [Erfahrung] and immediate experience [Erlebnis]. Accordingly, he argues that in the modern age, experiences [Erlebnisse], which are assigned to an individual at an exact point in time, have become the raw data of lived moments deprived of their transmittable meaning. Thus, with this distinction, Benjamin stresses not only the dissociation of the collective and the individual as well as collective memory and individual recollection but also the transformation in the mimetic faculty of human beings. In this chapter, I analyzed the distinction between experience [Erfahrung] and immediate experience 
[Erlebnis] through the transformation of the relations of looking in modern society, which I argued, reflects a shift from auratic perception to kitsch perception. Defining the aura as the medium of perception inherent in experience [Erfahrung], I have identified kitsch as the new medium of perception in the immediate experience [Erlebnis]. The introduction of this shift in the collective organization of human perception renders it possible to clarify the implications of the subjection of the human sensory organs to training by technology, which leads to the liquidation of the spatial and temporal categories of auratic perception, and in turn, paves the way for the interrogation of the possibilities of new modes of production of meaning.

Despite his lament of the crisis of experience, Benjamin has not called for the revival of the experience [Erfahrung] of the past. Instead, his main concern was the thinking/imagining of a new medium in which individual experiences could be embedded and shared collectively in a world where "[a]ll that is solid melts into air" (Marx and Engels 1998a, 6). Therefore, according to Benjamin, this new medium of experience [Erfahrung] has to start from scratch - that is, the world of fragmented experience [Erlebnisse], the world whose most significant sign is the poverty of experience [Erfahrungsarmut]. In the following chapter, I will first discuss the implications of the crisis of experience on "the political" through a new conceptualization, that is, kitsch politics, and examine the relationship between kitsch perception, kitsch politics and the new medium of experience [Erfahrung]. 


\section{Chapter V: Politics of Phantasmagoria: Kitsch Politics}

\subsection{Introduction}

Benjamin did not present a single, comprehensive notion of politics. Yet, throughout his writings, he unwaveringly discussed "the gradual insinuation of a deeply oppressive form of cultural life in conformity with the economic and political imperatives of a nascent capitalist system" (Pensky 2004b, 182). Accordingly, he argued that the injustice that is in operation in this particular society is harder to grasp because of its infiltration of both the largest and smallest vessels of consciousness - from the highest forms of cultural expression to everyday practices. Therefore, he repeatedly expressed the importance of the examination of the socio-political structure of perception and implicitly called for an analysis of the implications of the transformation of human perception and the fabric of experience on "the political" under the conditions of the commodity form and technological reproduction.

Human sense perception, Benjamin argues, is deeply engrained in the course of history and technological advancement, whose development bears witness to crucial social changes. That is to say, the socio-economic and political conditions under which we live shape our patterns of representation, apprehension and experience. For instance, the predominance of visual distractions in modernity, according to Benjamin, is not a quasi-automatic corollary of modern secular life; rather, it is a response to the material environment and the perceptual challenges that arise in modern societies. Modernity's preoccupation with "looking" and "seeing" 108 allows a peculiar form of protection

\footnotetext{
108 The centrality of "looking" and "seeing" as a concern of (post)modern society has become manifest in the works of many social and political theorists; for instance, Guy Debord's diagnosis of the "society of spectacle" (Debord 2005), Michel Foucault's problematization of the institutionalization of the "gaze" (Foucault 1995; Foucault 1988), Jean Baudrillard's concepts of
} 
against the technological configurations of the urban environment, the acceleration of the speed of communication and the overabundance of discontinuous stimuli on the streets, in the factory, in traffic, or in city centers. Such transformations in the sphere of everyday life have evoked aesthetic attitudes, such as "scopophilic exhilaration and distraction" (Koepnick 1999, 142), which function to preserve the political community, and reinvent individuality and collectivity against the grain of technological development, alienation and isolation. ${ }^{109}$

"simulacra and simulation" (Baudrillard 1994; Baudrillard 1993); Gianni Vattimo's questioning of the "transparent society" (Vattimo 1988; Vattimo 1992) Friedrich Jameson's examination of the "visible" (Jameson 1979; Jameson 2007).

${ }^{109}$ According to Benjamin, fascism, and liberal and social democratic regimes were the responses to the changing relationships between nature, technology and the collective organization of human perception. In this dissertation, I solely concentrate on the examination of the latter. Therefore, I will provide only a glance of Benjamin's analysis of fascism in this footnote. Benjamin depicts fascism as an aestheticization of politics, that is, "the consummation of l'art pour l'art'" (W. Benjamin 2006c, 122). The principle of l'art pour l'art was based on the idea of the differentiation of a realm of art from all the other human activities, and functioned on a claim to the absolute autonomy of art and its autotelic self-referentiality (Jay 1992, 43). Therefore, an aestheticized politics which makes a claim to absolute autonomy of politics and its autotelic selfreferentiality adopts the criterion of value as "aesthetic worth" (Jay 1992, 43), which is determined on the basis of formal considerations rather than content. In other words, in appropriating the principle of indifference toward all other human pursuits, politics aestheticized beautifies destruction for the sake of creation. "Fiat ars - pereat mundus" [create art - destroy the world] (W. Benjamin 2006c, 122), as Benjamin puts it. It is such a victory of form over matter, or say, "disinterestedness," that makes humanity capable of experiencing its own annihilation as a supreme aesthetic pleasure" (W. Benjamin 2006c, 122). This is best exemplified both in the creation of the cult of warfare, and, perhaps more importantly, in self-experience and self-liberation materialized in the "heroic stance," by means of which the proletarianized masses could express themselves. In war, the individual's action becomes an expression of a life force; thus, action becomes representational, and in turn aestheticized" (Hillach 1979, 104). The people's "mystical surrender to the spirit of war", or to the "will to destruction," and "heroic distancing of oneself from individuality" (Hillach 1979, 106) as a result of defining one's self only in relation to, or as part of, a totality are the reflections of aestheticized politics through which the "subjectivist presuppositions of heroic thought is transformed into the objectivist affirmation of metaphysical-vitalistic strength shaped by fate" (Hillach 1979, 106). In doing so, not only is the aestheticization of action is achieved but also violence is legitimated. As the artist shapes matter, the political leader gives form - as well as norm - to the formless masses in an aestheticized politics. Like the avant-garde artist who turns art into the expression of an absolute "in which all relativities and contradictions would either be solved or beside the point" and creates an artwork that is valid in its own terms, the political leader of an aestheticized politics creates a political form that is in itself treated as an artwork. This work of art is created through 
In this chapter, I explore the implications of the transformation of the collective organization of human perception and experience on the "political," and discuss the possibilities for an alternative politics. To do so, I first examine the relationship between the public and the private spheres, and the consequent blurring of the distinction between the two with the rise of the social. In order to explore the relationship between the rise of the social, perception and experience, I engage with Benjamin's analysis of the 'interior' - as a space separated from work, a space of the dreaming subject - and its emulation by the 'exterior,' which lead to the rise of the 'exterior as interior,' that is, the expression of the dreaming collective.

In the second section of this chapter, I relate this transformation to "the political," and explore the relationship between metaphor and image. Here I argue that in the metaphorical political language of liberal and/or social democracy, images: a) lose their temporal and immediate mediacy, and b) become materialized in "space, objects and practices" (Wohlfarth 1996, 199), thereby acquiring an immediate perceptible presence. While Benjamin associates the former process with the "dream house," I develop the concept of the "dream agora" in order to reflect the latter process. On this basis, I explore the relationship of the loss of immediate mediacy of images and their acquisition of an immediate perceptible presence in everyday life to "the political." I conceptualize the

the re-enchantment of the disenchanted world of capitalism through mythical-nationalist objectives by means of which the form itself is deified. The deification of the form through "manipulatively instated symbols" (Hillach 1979, 112) goes hand in hand with the transformation of action into a representation. The conversion of political action into an expression through the "emotive-symbolic relation to reality" (Hillach 1979, 112) makes it possible for the masses to identify themselves with the image of the leader. What we see in a purely aestheticized politics is then the intertwined relationship between the image and action, myth and reality, masses and demagogues, form and content, technology and organic, representation and political inactivity. For more detail see Benjamin's essay on Theories of German Fascism (1930), and also (Hillach 1979; Jay 1992). 
intertwinement of metaphorical political language with the immediate perceptible presence of images as "kitsch politics." In turn, kitsch politics finds its expression in the re-arrangement of the public sphere as a result of which the operational principle of the public sphere becomes sameness (as opposed to distinctiveness). That is to say, "the political" finds its articulation not in distinctiveness but in fixed, static and exclusionary identities. Kitsch politics therefore precludes the emergence of new political imaginaries.

Yet, this is not to say that the "dream-filled sleep that came over Europe" (W. Benjamin 2002d, 391, K1a,8) with capitalism - that is, kitsch - is the immutable, unavoidable, and therefore, permanent characteristic of modernity; for, every sleep is followed by a waking hour. In the third section of this chapter, I therefore explore Benjamin's understanding of alternative politics. Benjamin's alternative politics rises against the optimistic metaphorical political language of kitsch politics. Here, I discuss the ways in which the "organization of pessimism" prompts us "to discover in the space of political action the one hundred percent image space [Bildraum]" (W. Benjamin 2005d, 217). The sudden, evanescent - flash-like - coming together of the image at the intersection of "what-has-been" [das Gewesene] and the "now" brings forth a mode of cognition, which is bound to the 'now of a particular recognizibility' (W. Benjamin 2002d, 463, N3,1).

In configuring 'now-time' [Jetztzeit] - which invokes image(s) from the archive of historical memory - beyond the continuum of history, Benjamin criticizes linear time and progressive notion of history. This critique prompts Benjamin to articulate his vision for an alternative politics through three new conceptualizations (i.e., profane illumination [profane Erleuchtung], “image-space" [Bildraum], and "body-space" [Leibraum]) 
designed to overcome the dualistic oppositions, which characterize kitsch politics. On the basis of this discussion, I conclude that the explosive, unintentional and unmitigated beginnings of alternative politics have two rather distinct possible outcomes.

\subsection{The Transformation of the Relationship Between the Public and Private Spheres}

\subsubsection{The Public and Private Spheres}

In the fully formed Greek city-state the sphere of the polis consisted of the free citizens and was strictly separated from the sphere of the oikos (household), which was a space of necessity. The bios politikos (public life) took place in the agora (market) and was founded on lexis (discussion) and praxis (common action). In this configuration, the private sphere was concerned with the processes and activities of economic (re)production while the public sphere was concerned with freedom and permanence (Habermas 1991; Arendt 1998). ${ }^{110}$ As the sphere in which the few equals - namely, peers - act, the public realm was the sphere where "everybody had constantly to distinguish himself from all others, to show through unique deeds or achievements that he was the best of all" (Arendt 1998, 41).

According to Arendt, the 'public' indicates two closely interconnected but not altogether identical phenomena. ${ }^{111}$ She thus describes the public realm as: 1) a "space of appearance," and 2) a "world we hold in common" (Arendt 1998). Accordingly, the

\footnotetext{
${ }^{110}$ Despite the fact that these two spheres might at first glance appear to be relatively autonomous, they were mutually dependent. In the Greek city-states, political order rested on the slave economy, which set the citizens free from productive labour. "It was, however, their private autonomy as masters of the households on which their participation in public life depended" (Habermas 1991, 3). In other words, "status in the polis was [...] based upon states as unlimited master of an oikos" (Habermas 1991, 3).

${ }^{111}$ Habermas describes the "critical bourgeois public sphere" as "the sphere [in which] private people come together as a public," claiming that this sphere is "regulated from above against the public authorities themselves, to engage them in a debate over the general rules governing relations in the basically privatized but publicly relevant sphere of commodity exchange and social labour" (Habermas 1991, 27).
} 
public realm is the space in which everything can be seen and heard by everybody, and in this respect, has the broadest possible publicity. Thus, according to Arendt, "our feeling for reality depends utterly upon appearance and therefore upon the existence of a public realm into which things can appear out of [the] darkness of sheltered existence" (Arendt 1998, 51). Similarly, Habermas (1991) claims that "[o]nly in the light of the public sphere did that which existed become revealed, did everything become visible to all" (4). To put it differently, the public realm as a "space of appearance" is the space in which and through which reality is constituted - since "the presence of others who see what we see and hear what we hear" (Arendt 1998,50) assures us of the reality of the world and of ourselves, by means of shared words and deeds, the evaluation of actions and the revealing of our identities. More succinctly, the public realm provides the light and the publicity which are necessary for the formation of identities and the recognition of a common world.

Appearance in the public realm becomes possible through action (praxis) and speech (lexis). "To act," in its broadest sense, Arendt (1998) argues, means to "take an initiative, to begin, to set something into motion" (179). In this context, action and speech are seen as "coeval and coequal, of the same rank and the same kind" (Arendt 1998, 26). Briefly, by calling something into being "which did not exist before, which was not given, not even as an object of cognition or imagination," action demonstrates creativity and unpredictability (Arendt 1998, 151). On the other hand, action as a specific form of speech, whose distinctive features are debate and deliberation, argument and persuasion, provides a form of being and acting together. 
The "space of appearance" emerges whenever individuals gather together in the "manner of speech and action," and "therefore predates and precedes all formal constitution of the public realm and the various forms of government, that is, the various forms in which the public realm can be organized" (Arendt 1998, 199). That is to say, the public realm is not restricted to a set of institutions or to a specific location; rather, it may arise suddenly, as in the case of revolution, or it may arise gradually out of the efforts to change specific government policies. For instance, preventing the establishment of a nuclear energy station, legalizing gay marriage, or extending public education. Town hall meetings of workers' councils, demonstration and sit-ins, and struggles for justice and equal rights are only some of the historical examples of the public realm as the "space of appearance."

\subsubsection{The Rise of the Social}

The rise of the capitalist mode of production and the formation of the nation-state created the conditions in which the relationship between the public and the private spheres is transformed. ${ }^{112}$ In this new configuration, the economic activity, which had

\footnotetext{
112 Here, I adopt a particular Arendtian-Habermasian account of the rise of the social, which associates this phenomenon to the shifting of the activities, problems and organizational devices of the household into the public sphere, thereby blurring the distinction between the public and the private spheres, and consequently unsettles the content and matters of this sphere. In adopting this particular account of the rise of the social, I: 1) demonstrate the transformation of the arrangement and operation of the public sphere; and 2) articulate a Benjaminian notion of "the political." Thus, this particular account of the rise of the social and the blurring of the distinction between the public and the private sets the stage not only for my discussion of Benjamin's investigation of the interior and exterior, the emulation of the interior by the exterior but also for my analysis of Benjamin's investigation of the interior and exterior in relation to "the political" and the public sphere. It should also be noted here however that Foucauldian theorists associate the rise of the social to the rise and implementation of the political rationality of social welfarism (Miller and Rose 2008; O'Malley 1996; Donzelot 1991). It is argued that the political rationalities - namely, "social liberalism," "social democracy" and "socialism," which played a great part in the twentieth century - despite their differences agreed on one particular point: that is, "the nation must be governed in the interests of social protection, social justice, social rights and social solidarity" (Miller and Rose 2008, 86). It should also be noted here that some Foucauldian
} 
taken place in the household where each person was in their own realm "had to be oriented toward a commodity market that had expanded under public direction and supervision; the economic conditions under which this activity now took place lay outside the confines of the single household" (Habermas 1991, 19). To put it more clearly, the sphere of the social arose with the growth of market economy, in which the market becomes a self-regulating and self-generating phenomenon and the prime mover of society, heralding the separation of the state from society. The shift of the economic reproduction processes and activities from the private to the public sphere, or rather, the private sphere of society becoming publicly relevant is portrayed as the rise of the social (Arendt 1998; Habermas 1991). ${ }^{113}$

The rise of the social marks the fact that the activities, problems and organizational devices of housekeeping become public matters (Arendt 1998). ${ }^{114}$ "Society," according to Arendt, "is the form in which the fact of mutual dependence for the sake of life and nothing else assumes public significance and where the activities

scholars argue that the particular concerns, methods and interventions of the police state of the eighteenth century - namely, the "welfare of the community" - were carried into the liberal state of the nineteenth century. In other words, these scholars trace the concept of "the social" back to the rise of "police science" in the eighteenth century and claim that rather than being displaced the police science is merged into the social interventions of the nineteenth century (Pasquino 1991; Donzelot 1979; McMullan 1998; Donzelot 1991). Yet, others claim that there was rapture between the police state and the liberal state. For, it is argued, the liberal state abandoned the fantasy of a totally administered society and confronted the realities of the market, civil society and citizen, all of which have their own internal logics and mechanisms of self-regulation, thereby setting limits to the state's capacity to know and act by introducing social economy into the art of governing (Osborne 1996; Miller and Rose 2008).

113 According to Adam Smith, the common-interest of society derives from the pursuit of private interest in the market. For, while an individual pursues one's own interest, s/he will also serve the interests of the others. In other words, "an individual's interest, without him knowing it, wishing it, or being able to control it, is linked to a series of positive effects which mean that everything which is to his advantage will turn out to be to the advantage of others" (Foucault 2008, 277).

${ }^{114}$ Habermas (1991) states that, "[i]n the measure in which it [the sphere of the social] was linked to the market exchange, production was disengaged from its connection with functions of public authority; conversely, political administration was released from production tasks" (141). 
connected with sheer survival are permitted to appear in the public sphere" (Arendt 1998, 46). The rise of the social from the interior of the household into the "light of the public space" (Arendt 1998, 38) not only blurs the frontier between the public and the private spheres, but it also changes the meaning and function of the public and private spheres for the life of the individual, the citizen and the collective. The imposition of "innumerable and various rules, all of which tend to 'normalize' its members, to make them behave, to exclude spontaneous action" (Arendt 1998, 40) by society results in pushing issues of distinction and difference, which were the matters of the public realm, to the private sphere.

The private sphere, according to the Ancients, was a sphere which was marked as a "state of being deprived of something" (Arendt 1998, 38). In the modern age, on the contrary, the private sphere is enriched with the increasing emphasis on individualism, leading to the identification of the private sphere as the sphere of intimacy. At the beginning of the liberal era, the two realms - namely, the realm of commodity exchange and social labour (the social) and the household, which was relived from any direct economic function - were structured in concordance. But, in the second half of the nineteenth century, they started to develop into different directions. As Habermas puts it, "[t]he intimate sphere, which was once the center of the private sphere, moved to its periphery to the extent that the private sphere itself became deprivatized" (Habermas 1991, 152). To put it differently, "the family became ever more private and the world of work and organization ever more "public" (Habermas 1991, 152). That is to say, the occupational sphere "gained independence as a quasi-public realm in relation to a private sphere" (Habermas 1991, 154) and the private sphere was reduced to the realm of 
intimacy. In this context, time that is not spent at work represents the preserve of the private sphere while work begins with stepping into occupational activity. ${ }^{115}$

Thus, in contemporary society, the sphere of the intimate emerges as a domain of leisure, a domain of the purely personal, where all the socially controlled roles are left behind. This domain "take[s] the place of public sphere in the world of letter that at one time was the point of reference for a subjectivity shaped in the bourgeois family's intimate sphere" (Habermas 1991, 159). Moreover, in the sphere of the intimate, private autonomy is sustained not as much in the functions of control but in functions of consumption, resulting in "the illusion of an intensified privacy in an interior domain whose scope had shrunk to comprise the conjugal family only insofar as it constituted a community of consumers" (Habermas 1991, 156).

\subsubsection{The Rise of the Interior as the Private Realm}

"A room just like a daydream, a truly spiritual room, in which the air is tinged with rosiness and blue"

Charles Baudelaire

Benjamin discusses public and private life within bourgeois society in reference to the built space, namely, the 'interior.' He depicts the modern city as "a site of disambiguation and rationalization of social space through either the privatization and atomization" (e.g., Berlin and Paris) or the collectivization (e.g., Moscow) of built space and "hence also [the] atomization or [the] collectivization of the subjects who dwelt

\footnotetext{
${ }^{115}$ It is important to note that " $[\mathrm{t}]$ his process presented itself, however, as deprivatization of the occupational sphere only in the historical perspective of the property owning private person. Conversely, it appeared as a privatization to the workers and employees and did so to the extent that they were no longer subject exclusively and without regulation to a patriarchal regiment but instead to a psychological arrangement promoting the human relations on the job that create pseudo-private well-being" (Habermas 1991, 154).
} 
within these spaces" (Schmiedgen 2009, 147). ${ }^{116}$ His exploration thus is developed in reference to two primary conceptions of the subject in modernity: liberal individualism and (Marxist and/or anarcho-socialist) collective subjectivity. Since Benjamin views the interior as a "space of subjectification" (Schmiedgen 2009, 147), he is concerned with the following questions: Who does occupy the interior? In what ways is the interior occupied? What do the occupiers of the interior and their ways of inhabitation tell us about the relationship between the public and private spheres as well as the social, economic, cultural and political practices in bourgeois society? And, what is the significance of the division between interior and exterior?

The word 'interior' came into use in the English language in the late fifteenth century. At this time, it was used to mark the basic division between the inside and outside, and to describe the spiritual and inner nature of the soul. In the early eighteenth century, the meaning of the word shifted to designate the inner character and a sense of subjectivity. In the middle of the eighteenth century, the meaning shifted again to designate the domestic affairs of the state and the territory that belongs to a country (The Oxford English Dictionary 2005; Rice 2007; Rice 2004).

In the aftermath of the industrial revolution in the nineteenth century, the word 'interior' started to be used in relation to bourgeois domesticity. At this time, it [the interior] was defined as: "The inside of a building or room, especially in reference to the artistic effect; also, a picture or representation of the inside of a building or room. Also, in a theatre, a 'set' consisting of the inside of a building or room" (The Oxford English Dictionary 2005). Thus, in the context of the nineteenth century, the interior was

116 This dissertation is limited to the examination of the private and public spheres within bourgeois society. Therefore, Benjamin's analysis of Moscow is not within the scope of this dissertation. 
articulated in reference to decoration, namely, the literal covering of the inside of an architectural space with upholstery and plush material. This interior was inhabited and experienced in a double sense: in and through both material and immaterial registers (Rice 2007).

The material, social and political conditions of life in the nineteenth century transformed the relationship between the public and the private spheres as well as their functions. Benjamin argues that, "[u]nder the reign of Louis Philippe, the private individual makes his entry into history" (W. Benjamin 2002b, 19). Here, he draws a connection between the apotheosis of bourgeois individuality and a site, namely, the interior. He argues:

the flâneur $[\ldots]$ abandons himself to the phantasmagoria of the market place. Corresponding to these phantasmagorias of the market, where people appear only as social types, are the phantasmagorias of the interior, which are constituted by man's imperious need to leave the imprint of his private individual existence on the rooms he inhabits (W. Benjamin 2002b, $14)$.

To put it more simply, the built space of the interior, according to Benjamin, exists for the sake of the private individual.

The place of dwelling and the office then emerged as two sides of the new social and urban fabric of the nineteenth century. Benjamin argues:

For the private individual, places of dwelling are for the first time opposed to places of work. The former come to constitute the interior. Its complement is the office. The private individual, who in the office has to deal with reality, needs the domestic interior to sustain him in his illusions. This necessity is all the more pressing since he has no intention of allowing his commercial considerations to impinge on social ones. In the formation of his private environment, both [commercial and social considerations] are kept out. From this arise the phantasmagorias of the interior - which, for the private man, represents the universe. In the interior, he brings together the far away and the long ago. His living room is a box in the theater of the world (W. Benjamin 2002c, 8-9) (emphasis added). 
That is to say, the interior demarcated a space - namely, the dwelling - that was separated from work. This demarcation rendered it possible for the domestic interior to emerge. That is to say, the interior arose as a response to the alienating processes of the capitalist social relations of production ${ }^{117}$ as well as the unfamiliar city, and its shockridden, momentary and instantaneous experiences [Erlebnisse]. "Ever since the time of Louis Philippe," Benjamin writes, "the bourgeois has shown a tendency to compensate for the absence of any trace of private life in the big city. He tries to do this within the four walls of his apartment” (W. Benjamin 2002b, 20).

In this context, the interior became a place of refuge, thereby providing a shield to the private individual. According to Benjamin, the living space of the nineteenth century therefore was a closeted dream-space, or more precisely, a space characterized by the "phantasmagoria of the interior." The bourgeois interior, he argues, created a mood which was a "stimulus to intoxication and dream" (W. Benjamin 2002d, 216, I2,6). "To live in these interiors," he writes, "was to have woven a dense fabric about oneself, to have secluded oneself within a spider's web, in whose toils world events hang loosely suspended like so many insect bodies sucked dry. From this cavern, one does not like to stir" (W. Benjamin 2002d, 216, I2,6). That is to say, the phantasmagoria of the interior was the desirable and welcoming universe of the private individual, the universe from which both the social and commercial considerations of the everyday were "kept out,"

117 Benjamin writes: "The residential character of the rooms in the early factories, though disconcerting and inexpedient, adds this homely touch: that within these spaces one can imagine the factory owner as a quaint figurine in a landscape of machines, dreaming not only of his own but of their future greatness. With the disassociation of the proprietor from the workplace, this characteristic of the factory buildings disappears. Capital alienates the employer, too, from his means of production, and the dream of their future greatness is finished. This alienation process culminates in the emergence of the private home" (W. Benjamin 2002d, 226 I7a,1). 
the universe which was removed from the everyday traumas of the world.

To dwell, or the experience of dwelling in the nineteenth century, therefore, "has to do with fashioning a shell for [one's self]" (W. Benjamin 2002d, 221, I4,5), a shell which serves as an inverted mold of the self into which the individual neatly fits, encased like a compass in violet folds of velvet. ${ }^{118}$ Benjamin describes the bourgeois interior and its inhabitation as follows:

It is as if he [the bourgeois] had made it a point of honor not to allow the traces of his everyday objects and accessories to get lost. Indefatigably, he takes the impression of a host of objects; for his slippers and his watches, his blankets and his umbrellas, he devises coverlets and cases. He has a marked preference for velour and plush, which preserve the imprint of all contact. In the style characteristic of the Second Empire, the apartment becomes a sort of cockpit. The traces of its inhabitant are molded into the interior (W. Benjamin 2002b, 20).

In this passage, the production of the interior is depicted as an 'infolding' through a surface that is soft and impressionable. Instead of creating an airtight seal against the external world, the surface of the interior is activated through the inhabitant's relation to the city and its social world, engendering a subjectivity and social identity that is marked as 'bourgeois' (Rice 2007). ${ }^{119}$ According to Benjamin, this interior is the "étui of the

118 According to Benjamin, the idea of dwelling as a "shell" is not an eternal or a timeless phenomenon; rather, it is a historically specific cultural form of the nineteenth century. He writes: "The difficulty in reflecting on dwelling: on the one hand, there is something age-old - perhaps eternal - to be recognized here, the image of that adobe of the human being in the maternal womb; on the other hand, this motif of primal history notwithstanding, we must understand dwelling in its most extreme form as a condition of nineteenth century existence. The original form of all dwelling is existence not in the house but in the shell. The shell bears the impression of its occupant. In the most extreme instance, the dwelling becomes a shell. The nineteenth century, like no other century, was addicted to dwelling. It conceived the residence as a receptacle for the person, and it encased him with all his appurtenances [...] what didn't the nineteenth century invent some sort of casing for! Pocket watches, slippers, eggcups, thermometers, playing cards - and, in lieu of cases, there were jackets, carpets, wrappers, and covers" (W. Benjamin 2002b, 220, I4,4).

${ }^{119}$ It should be noted here that furniture and its arrangements as well as domestic habits and mores existed prior to the nineteenth century. But, what is specific to the nineteenth century in 
private individual" (W. Benjamin 2002c, 9), ${ }^{120}$ and thus bears the impressions of its occupant. "To dwell," Benjamin argues, "means to leave traces" (W. Benjamin 2002c, 9). ${ }^{121}$ The interior of the bourgeois dwelling thus is portrayed as the place where the occupant stamps his mark, transforming it into a frozen museum of prosperity. It is only in this place that the bourgeois individual was surrounded by his own traces, among the marks of his property, and thus, was 'at home.'122

"The contents of the interior are mere decorations, alienated from the purposes they represent, deprived of their own use value, engendered solely by the isolated dwelling space. Their semblance-character is historically-economically produced by the

terms of the interior is the conceptualization of a "particular emerging and developing consciousness of and comportment to the material realities of domesticity" (Rice 2007, 3).

120 Oxford English Dictionary (2014) defines étui as "a small case, typically ornamental, for holding needles, cosmetic instruments, and other personal articles. Formerly also: a case for surgical instruments."

${ }^{121}$ Benjamin uses the term trace [Spur] to describe the mark left by the commodity or the individual on the plush of bourgeois interior. This is where history turns into a detective story and the historical trace emerges as a clue. Benjamin writes: "Trace and aura. The trace is the appearance of a nearness, however far removed the thing that left it behind may be. The aura is the appearance of a distance, however close the thing that calls it forth. In the trace, we gain possession of the thing; in the aura, it takes possession of us" (W. Benjamin 2002d, 447, M16a,4). It is then no coincidence that the rise of the detective novel coincides with the emergence of the domestic interior. The traces left behind in the interior become incriminating clues for the investigating detective. The methods of Émile Gaboriau's Monsieur LeCoq and Sir Arthur Conan Doyle's Sherlock Holmes are based on the examination of the impressions of personality and deeds that are absorbed by the animate objects of the interior, which are to be deciphered and read as the hieroglyphic of crime.

122 Benjamin writes: "Against the armature of glass and iron. Upholstery offers resistance with its textiles (W. Benjamin 2002d, 218, I3,1). He also states: "Plush - the material in which traces are left especially easily" (W. Benjamin 2002d, 222, I5,2). In another fragment, he states: "The étuis, dust covers, sheaths with which the bourgeois household of the preceding century encased its utensils were so many measures taken to capture and preserve traces" (W. Benjamin 2002c, 226, I7,6). Contrary to the arcades that expressed the wedded advance of technology and commerce in their iron and glass construction, the bourgeois interior resisted the new and alienating forms of experience through its upholstery and textiles within the domestic interior (Rice 2007). Benjamin describes the collector as the "true resident" of the interior since he bestowed a "connoisseur's value" rather than a "use value" on objects. Benjamin explores the notion of "the collector" particularly in in his essays: Unpacking My Library (1931), Eduard Fuchs: The Collector and Historian (1937), and Exposé of 1935. For a through and insightful analysis of Benjamin's notion of the collector see (Wohlfarth 2006). 
alienation of thing from use value" (Adorno qt. in W. Benjamin 2002d, 220, I3,a). In Chapter II, I identified the deprivation of things from their use-value within the exchange relation - the thing commodified - as the first order phantasmagoria, which creates a form of a 'real-abstract' reality in which things as commodities act out social relations. In this constellation, the object with a use-value constitutes the 'real,' and the thing in a commodity form constitutes the 'abstract' dimension of reality. Here, things as commodities become the sensuous medium of social relations while at the same time being non-sensuous - as they are the expression of a purely social relation.

"[I]n the interior," however, "the things do not remain alien... Foreignness transforms itself from alienated things into expression; mute things speaks as "symbols", (Adorno qt. in W. Benjamin 2002d, 220, I3a) (emphasis added). The ability of mute things to speak as 'symbols' is where we find the second order phantasmagoria, which creates a form of 'abstract-real' reality in which things as commodities act out human wishes, desires and feelings. I suggest reading the following quote in this light:

The ordering of things in the dwelling space is called arrangement. Historically illusory [Geschichtlich scheinhafte] objects are arranged in it as the semblance of unchangeable nature. In the interior, archaic images unfold: the image of the flower as that of organic life; the image of the orient as specifically the homeland of yearning; the image of the sea as that of eternity itself. For the semblance to which historical hour condemns things is eternal (Adorno qt. in W. Benjamin 2002d, 220, I3,a).

In other words, the arrangement of things in the interior transforms the foreignness of the alienated things into expressions, and in turn, these things create the "semblance of the spatial in the image of the interior" (Adorno qt. in W. Benjamin 2002d, 220, I3,a). Thus, the 'far away' and 'long ago' become sensible, perceivable through the arrangement of things in the domestic interior. Thus, in this space, the bourgeois individual aims at 
seizing from things experience [Erfahrung]. For instance, the mantelpiece might play the role of the fireside where stories are told.

The concern of establishing the interior as a sphere of private life is to sustain experience [Erfahrung]. Yet, "[t]he illusions constructed in the interior suggest that the sense of [experience] [is] itself illusionary, the story of stories told by the fireside [are rendered] mythical precisely in the substitution of campfire with the domestic hearth" (Rice 2007, 18). The sense of experience [Erfahrung] created in the bourgeois domestic interior is thus the manifestation of kitsch - the apparition of a beautified ghostly ('realabstract'/'abstract-real') reality. This "real-abstract"-"abstract-real" reality is constructed through a movement from a thing as commodity (exchange value) - in this context, the interior furnishings, decoration materials, etc. - to a thing that acts out human wishes, desires and feelings, thereby manifesting as a force, generating a sense of experience [Erfahrung].

The attempt to create the sense of experience is related to a desire/longing for permanence and continuity in the world of transience and discontinuity. Therefore, the domestic interior, just like the monuments of the city, is established as 'timeless' and impervious to the changing socio-economic and political conditions. ${ }^{123}$ In this image of the domestic interior, the bourgeois recognizes the permanence and endurance of his own comfort and privileges. Thus, it does not come as a surprise that neither poverty nor death have any place in the rooms of bourgeois apartments. Benjamin writes:

In the course of the nineteenth century bourgeois society has, by means of hygienic and social, private and public institutions, realized a secondary

\footnotetext{
${ }^{123}$ In the domestic interior, "reigned a species of things that was, no matter how compliantly it bowed to the minor whims of fashion, in the main so wholly convinced of itself and its permanence that it took no account of wear, inheritance, or moves, remaining forever equally near to and far from its ending (W. Benjamin 2005e, 621).
} 
effect which may have been its secondary purpose: to make it possible for people to avoid the sight of the dying. Dying has been pushed further and further out of the perceptual world of the living. There used to be no house, hardly a room, in which someone had not once died. [...] Today people live in rooms that have never been touched by death, dry dwellers of eternity, and when their end approaches they are stowed away in a sanatoria or hospitals by their heirs (W. Benjamin 1968, 93-94).

Thus, the bourgeois individual's perceptual world in the bourgeois interior is a vivid reflection of kitsch perception: the apparition of a beautified ghostly reality in order to dissolve a distance however far that distance may be. For, in the domestic interior, we not only witness the generation of a sense of experience [Erfahrung] through the material presence of things, which are liberated from their commodity character by their presence and arrangement in the interior, but also the collection of things bringing the distance in space and time close to hand while removing death from the perceptual world of the living. In doing so, within the domestic interior the bourgeois individual "feel[s] at home, at ease, comfortable and comforted" (W. Benjamin 2005e, 621).

\subsubsection{The Liquidation of the Domestic Interior}

Yet, the unceasing growth of the social led to the liquidation of the interior. By the early twentieth century, new building materials and construction methods - namely, concrete and glass - along with the development of technological reproduction began to transform not only the interiors but also the way they were inhabited. Benjamin writes:

The twentieth century, with its porosity and transparency, its tendency toward the well lit and airy, has put an end to dwelling in the old sense. Set off against the dollhouse in the residence of the master builder Solness are the "homes for human beings." Jugendstil unsettled the world of the shell in a radical way. Today this world has disappeared entirely, and dwelling has diminished: for the living, through hotel rooms, for the dead, through crematoriums (W. Benjamin 2002d, 221, I4,4).

The use of glass in the domestic interior blurred the conventional distinction between 
inside and outside, exposing what had been private to the outside world. That is to say, "the visually permeable qualities of glass suggested a concomitant social transparency, with the potential to abolish the conventional bourgeois preoccupation with personal discreetness and physical comfort as manifest in domestic interior" (Winton 2013, 43). Moreover, the nature of glass rendered it impossible to leave one's trace within an interior, as "neither dust nor the impressions of everyday life imprint themselves on this material" (Winton 2013, 44). Thus, transparency "put an end to dwelling in the old sense" (W. Benjamin 2002d, 221, I4,4).

By the mid-nineteenth century the blurring of conventional boundaries between inside space and the outside world became a commonplace. The Jugendstil [Art Nouveau $]^{124}$ amplified the idea of the interior as nature to the extreme, confusing the distinctions between the animate and the inanimate, the living and the dead. In an attempt to mobilize "all reserves of inwardness" (W. Benjamin 2002c, 9), the Jugendstil "began to assume the role of a total designer, taking up the tectonic elements of the new constructional forms, and naturalizing them with a distinctly animated and vegetal stylistic line" (Rice 2007, 17). This tendency exposed the interior upon the exterior, which led to the shattering of its casing. ${ }^{125}$

Around this time, Benjamin argues that, "the real gravitational center of living space shifts to the office. The irreal center makes its place in the home" (W. Benjamin

\footnotetext{
${ }^{124}$ The Jugendstil was an artistic style that arose in mid-1890s in Germany, and lasted through the first decade of the twentieth century.

${ }^{125}$ According to Benjamin, the Jugendstil created new possibilities for the unification of the public and private under the conditions of technological reproduction. Yet, this attempt to fuse an idyllic image of nature with new construction materials failed to go beyond ornament. For, as Caygill (1998) argues, while the forms of art nouveau [Jugendstil] exposed the individuality of the inhabitant of the interior, they were not sufficiently strong to reorganize the distinction between public and private space into a new conception of dwelling" (145).
} 
2002c, 9). Therefore, "the true framework for the life of the private citizen must be sought increasingly in offices and commercial centers. The fictional framework for the individual's life is constituted in the private home" (W. Benjamin 2002b, 20). In other words, the social takes the central place in the constellation of the individual's everyday life while the recently established sphere of intimacy is pushed further into the periphery.

The phantasmagoria of the interior in the nineteenth century was created through taking possession of things and arranging furniture to create a private world. In the twentieth century, on the other hand, the domestic interior as a dwelling is lost not only because its creation is handed over to the designer but also because the distinction between the inside and outside is liquidated. As a result, the individuality of the inhabitant expressed within the domestic interior through the collection of things has shifted to the expression of the vision of the "architect-turned-artist" (Rice 2007, 17), limiting the space of the inhabitant, and in turn, his/her individuality. To put it differently, both the tectonic shift that is witnessed in the new materials of construction and the emergence of the notion of domestic interior as a blank canvas for the "architect-turnedartist" in the twentieth century has unsettled the bourgeois individual's cozy, encased existence, thus, constricting, if not liquidating, his/her individuality.

\subsubsection{The Exterior as the Interior}

Benjamin's analysis of the domestic interior is accompanied by his analysis of the exterior. Here, he articulates "the relation between the private dreaming self and the public space of production and history" (Gunning 2003, 112). As discussed above, the experience [Erlebnis] of the bourgeois society is founded on the creation of the domestic interior and its separation from the exterior as a place of refuge - a refuge from the 
masses in general, and the process of production in particular. The domestic interior is the space where the bourgeois finds solace, without disruption by the external stimulus or threat of the streets; it is the space where the private individual is divorced from the collective. Despite this assumed divide of the private from the public, of the interior from the exterior, Benjamin demonstrates the ways in which the private/public, the interior/exterior interpenetrate one another in the capitalist society. He writes:

Streets are the dwelling place of the collective. The collective is an eternally unquiet, eternally agitated being that - in the space between the building fronts - experiences, learns, understands, and invents as much as individuals do within the privacy of their own four walls. For this collective, glossy enameled shop signs are a wall decoration as good as, if not better than, an oil painting in the drawing room of a bourgeois; walls with their "Post No Bills" are its writing desk, newspaper stands its libraries, mailboxes its bronze busts, benches its bedroom furniture, and the cafe terrace is the balcony from which it looks down on its household. The section of railing where road workers hang their jackets is the vestibule, and the gateway which leads from the row of courtyards out into the open is the long corridor that daunts the bourgeois, being for the courtyards the entry to the chambers of the city (W. Benjamin 2002d, 423, M3a,4).

The interior, according to Benjamin, is imprinted on the exterior. To put it differently, the ideal of dwelling embodied by the living room permeates the public spaces, resulting in the replication of some of the characteristics of the interior on a grand scale in the city. Yet, the interior/exterior relationship is not unidirectional. As the exterior replicates some of the characteristics of the domestic interior, the forms, gestures, textures, and technologies of public spaces also seep into the design and décor of the bourgeois living room. Therefore, "[a]s living quarters and public spaces began to emulate one another, leaving one's dwelling only mean[s] substituting the coziness of the private for the diversion of urban topographies, all the more mesmerizing in view of their marble backdrops and stylish promenades" (Solibakke 2009, 158). This emulation between the 
interior and the exterior, the private and the public, serves not only to stimulate economic aspirations but also illustrates the tendency to transform the city into "prosceniums for collective representation" (Solibakke 2009, 158).

In his analysis of the exterior, Benjamin concentrates on the arcades, the earliest forms of shopping malls, which were erected in the nineteenth century as spaces of aggressive merchandising, heralding contemporary consumer society. The arcades were constructed in the shape of a cross in order to make it possible for the pedestrians to cut through a city block in four directions. They also offered respite to the city-dwellers from the busting traffic. The very nature of the arcades required an enclosing of an alleyway, or forcing a passage through a block of buildings. "Arcades," Benjamin argues, "are houses or passages having no outside - like the dream" (W. Benjamin 2002d, 406, L1a,1). It is this very nature that presents a contradictory and an ambiguous space, allowing an interpenetration of spaces (interior and exterior) as well as the ways of inhabiting and using these spaces. This "utter ambiguity" of the arcades made them both "street and house" (W. Benjamin 2002c, 861, $\left.\mathrm{O}^{\circ}, 40\right)$.

It is for this reason that Benjamin found the most spectacular manifestation of the encounter between the individual of the domestic interior and the public - the private individual and the collective, the interior and the exterior - in the form of the arcades. He writes: "[T]he arcade was the drawing room. More than anywhere else, the street reveals itself in the arcade as the furnished and familiar interior of the masses" (W. Benjamin 2002d, 423, M3a,4) (emphases added). These privately owned and publicly accessible spaces hosted luxury goods and elegant shops that tantalized the eye, stimulated consumer appetite, and aroused a desire to acquire. While the domestic interior created 
"stimulus to intoxication and dream" (W. Benjamin 2002d, 216, I2,6) for the private individual, the arcades became the source of "religious intoxication of great cities" (W. Benjamin 2002d, 61, A13), where the promise of happiness for the masses was materialized.

Since the early nineteenth century however, the dream houses of the collective have burst out of the narrow confines of the arcades. In fact, wherever the urban crowd has congregated, dream houses have arisen. The technological developments and their use in urban design - especially iron and glass - have led to an emergence of a multitude of dream houses, such as "winter gardens, panoramas, factories, wax museums, casinos, railroad stations" (W. Benjamin 2002d, 405, L1,3), cafés, exhibition halls, department stores, etc. ${ }^{126}$ The explosion of these mass culture forms has transformed the faces of cities, turning them into "landscape[s] of techno-aesthetics, dazzling, crowd-pleasing dreamworld[s] that provided total environments to envelop the crowd" (Buck-Morss 1995, 6). In this constellation, the "exterior as interior" becomes the expression of the dreaming collective, similar to the arrangement, décor and furnishing of the domestic interior being the expressions of the dreaming subject. ${ }^{127}$

\footnotetext{
126 "Museums unquestionably belong to the dream houses of the collective. In considering them, one would want to emphasize the dialectic by which they come into contact, on the one hand, with scientific research and, on the other hand, with 'the dreamy tide of bad taste.' 'Nearly every epoch would appear, by virtue of its inner disposition, to be chiefly engaged in unfolding a specific architectural problem: for the Gothic age, this is the cathedrals; for the Baroque, the palace; and for the early nineteenth century, with its regressive tendency to allow itself to be saturated with the past: the museum.' Sigried Giedion, Bauen in Frankreich, p. 36. This thirst for the past forms something like the principal object of my analysis - in light of which the inside of a museum appears as an interior magnified on a giant scale. In the years 1850-1890, exhibitions take the place of museums" (W. Benjamin 2002d, 407, L1a,2).

${ }^{127}$ The concept of dream plays a significant part in Benjamin's writing. This concept emphasizes the multiplicity of themes and motifs, the multilayered character of what is seen, heard or sensed, the oscillation between the literal and figurative meanings that arise out of, and from within, social reality. Therefore, for Benjamin, it is necessary to examine and interpret the dream images of the private individual and the collective.
} 
To put it more precisely, within and through the dream houses, what is understood as "common among men" becomes the possible realization of the personalized, immediate, temporal fantasy world of the individuals. In this constellation, the reality of commodities exceeds the binary of either concrete materiality or merely illusionary abstractions, saturating capitalist reality with kitsch - the appropriation of a beautified ghostly reality. This recognition vividly demonstrates the fact that capitalism is not only about the disenchantment of the world; rather, and perhaps more importantly, it is about the re-enchantment of the world via its disenchantment: an enchanting (phantasmagorical) reality of relentless disenchantment - that is, the way in which a ghostly reality is "beautified."

In this context, "the individual consciousness more and more secures itself in reflecting, while the collective consciousness sinks into deeper sleep" (Benjamin 1999, $389, \mathrm{~K} 1,4)$. Such sinking into deeper sleep of the collective is driven, on the one hand, by the distracted dreaming state, and on the other hand, by the fact that the collective is "unconscious of itself, composed of atomized individuals, consumers who imagined their commodity dream world to be uniquely personal $[\ldots]$, and who experienced their membership in the collectivity only in an isolated, alienating sense" (Buck-Morss 1991, 260). This, in turn, raises some important questions regarding the function of "the political." For if the collective organization of human perception is broadly characterized as a dream, and if the individual inhabitant of this dream is simultaneously alien from the collective, and yet, perceives himself as part of the collective in his uniquely personal reality, then does this not mean that "the political" is an expression of this dream? And if, 
so, then how does this manifest in politics? But perhaps more importantly, is there a possibility to awaken from this dream?

\subsection{Kitsch Politics}

\subsubsection{Surrealism \& Style: Metaphor \& Image}

"I have discarded clarity as worthless. Working in darkness, I have discovered lightening."

André Breton

In his Surrealism (1929) essay, Benjamin draws a parallel between style ${ }^{128}$ and politics. Here, he argues that just like style, politics requires a distinction between metaphor and image (W. Benjamin 2005d). Benjamin's claim concerning the distinction between metaphor and image is inspired by Surrealism ${ }^{129}-$ the artistic, cultural and political movement, which officially started in Paris with the publication of the Manifesto of Surrealism by André Breton (1924).

In their visual and written works, the Surrealists - Hans Bellmer, Salvador Dali, Max Ernst, Alberto Giacometti, Paul Klee, Pablo Picasso, among others - explored Sigmund Freud's notion of dream and stressed the relation of the unconscious to lived reality. They used the techniques of free association and psychic automatism as means of detaching themselves from habitual and rational thought processes in order to release the unbridled imagination of the unconscious. These techniques transgressed traditional boundaries, including both generic and disciplinary conventions. For instance, the

\footnotetext{
${ }^{128}$ In the study of arts, style is associated with certain characteristics that are "more or less stable, in the sense that they appear in other products of the same artist(s), era or locale," and also "flexible, in the sense that they change according to a definable pattern when observed in instances chosen from sufficiently extensive spans of time[,] of geographical distance" (Ackerman 1962, 227). The concept of style thus refers to a distinguishable ensemble of characteristics, which permit the grouping of artworks in related categories.

${ }^{129}$ Surrealism, Anna Balakian (1986) argues, is based on an integrated vision. This vision "derives from a metaphor, which translated into art, means the possibilities of association between objects" (144).
} 
Surrealists refused to distinguish poetry from art. While Surrealist poets appropriated the various techniques of the painters, adapting them to their own needs, Surrealist painters appropriated some of the techniques of the poets (Bohn 2002). ${ }^{130}$ In other words, the Surrealists manipulated words as if they were objects, and objects as if they were words, for the purpose of rendering it possible for language to transcend itself, so that what is incommunicable could become communicable, and what is unimaginable could be portrayed through the image's ability to surpass (physical) reality.

Thus, Surrealist images are produced by the intersection of two mutually exclusive planes. "The image," Pierre Reverdy claims, "[...] results not from a comparison but from a juxtaposition of two realities that are more or less distant. The more the relations between the two juxtaposed realities are distant and true, the stronger the image will be" (Reverdy qt. in Rattray 2001, 166). Here, the dynamic between the two intersecting planes is identified as "intensity," which is "a function of distance or, more precisely, of dissimilarity" (Bohn 2002, 143).

This Surrealist conceptualization of the image differs significantly from the conventional model, which we see examined in the Philosophy of Rhetoric (Richards 1965). Richards identifies two components of the metaphor, the tenor ("the idea") and the vehicle ("the image"). Simply put, the former is the subject to which attributes are ascribed, and the latter is the object whose attributes are borrowed (Richards 1965, 96). In the conventional model of mimesis, the distance to be crossed (between the tenor and the vehicle) is deliberately kept to a decorous proximity. For, as Aristotle expressed in The Poetics, "to make good metaphors implies an eye for resemblances" (Aristotle 1898,

\footnotetext{
130 The pictorial bias of the Surrealist poetry as well as the role of verbal models in the works of the Surrealist painters is an instance of this practice (Bohn 2002).
} 
87). Yet, when the metaphor is used so cautiously, the potential force of language is curtailed, thereby denying the creative drive of words. Moreover, the Aristotelian rules of mimesis, which regard ambiguity as the vice, and clarity as the virtue of language, suspends the generative function of language, which - in contrast - is rendered possible through the exploitation of polysemy (Rattray 2001). In this context, the demand for resemblance between the components of the metaphor results in the envisioned image being bound by reason, thereby restricting it to being a "copy" or "duplicate." Thus, here, words play a purely referential role in which they are understood as transparent truths, which portray an external reality.

Conversely, the Surrealists expand the distance between the tenor and the vehicle to the point where it exceeds the bounds of ordinary logic. Breton (1969) writes:

For me, their [of the Surrealist images] greatest virtue, I must confess, is the one that is arbitrary to the highest degree, the one that takes the longest time to translate into practical language, either because it contains an immense amount of seeming contradiction or because one of its terms is strangely concealed; or because, presenting itself as something sensational, it seems to end weakly (because it suddenly closes the angle of its compass), or because it derives from itself a ridiculous formal justification, or because it is of a hallucinatory kind, or because it very naturally gives to the abstract the mask of the concrete, or the opposite, or because it implies the negation of some elementary physical property, or because it provokes laughter (Breton 1969, 38).

To put it more clearly, in Surrealism, the distance between the components of the metaphor is stretched to a point where the logical resemblances are transgressed for the purpose of igniting the emotive power of the image, by means of which a "re-vision" of the world as habitually depicted by the conventional language could be provoked. When the reader makes the necessary switch between diverse concepts in order to visualize the surrealist image, an illuminating effect occurs. Here, what the viewer/reader experiences 
is stimulated by rapidly shifting perspectives whose goal is to constantly evade any singular and fixed form. In this context, the metaphor is not used in a conventional sense where it functions to "explain and reconcile" (Salzani 2008, 24); rather, by tending to erase the relationship between the tenor and the vehicle, and in turn, floating both of them far away from an object that is single or composite, the Surrealists destroy the fixed imagery of the metaphor by bringing forth the image, which becomes legible within the text while simultaneously dissolving it. Thus, the prevention of the collision between metaphor and image is one of the most important stylistic characteristics of Surrealism. But, how could this Surrealist distinction between metaphor and image and the Surrealist attempt to avoid the collision between metaphor and image serve for the understanding of politics?

\subsubsection{Politics: Metaphor and Image}

In his Surrealism (1929) essay, Benjamin unequivocally states that, "nowhere do these two - metaphor and image - collide so drastically and so irreconcilably as in politics" (W. Benjamin 2005d, 217). While in the conventional metaphor, images are instrumentalized to designate something else other than their immediate and temporal signification, it is precisely this instrumentalization of images in the service of a single or composite object and/or a fixed meaning that the Surrealists resist. This resistance was fuelled by their desire to transgress the boundaries that were imposed on the imagery by the conventional model of mimesis, which operates through the established, given and fixed resemblances. ${ }^{131}$

131 The Surrealist rediscovery of myth and dream in the metropolis was an inspiration to Benjamin. Yet, in The Arcades Project, he wrote: "Aragon persists within the realm of dream, here the concern is to find the constellation of awakening. While in Aragon there remains an impressionistic element, namely the 'mythology' [...], here it is the question of the dissolution of 
Thus, in adopting the Surrealist analysis of the conventional metaphor to politics, Benjamin challenges us to witness the collision of the metaphor and the image. Consequently, in the metaphorical political language of liberal and/or social democratic politics, images become means to a fixed and predetermined end(s), which are represented by the metaphor, losing their temporal and immediate mediacy, and in turn, turning into a stock of imagery, whose boundaries are carefully and strictly marked by the practical language and existing reality. For instance, the metaphor of the invisible hand is used to describe a self-regulating and self-generating market (A. Smith 1958). Since what the "invisible hand" ("vehicle" - "image") signifies is already determined, this image creates a stock of imagery, which includes, for example, the rational, self-interested, isolated individuals pursuing their interests in complete blindness to the interests of others while the market appears to regulate itself (magically) through the adjustment of prices on the basis of supply and demand. Another example is manifested in the imagery of "the rule of law." In this metaphor, "the rule of law" represents a system, which is governed by transcendental truths (i.e., justice, fairness, objectivity, and equality) rather than the arbitrary decisions of individuals. Thus, "the rule of law" creates a stock of imagery - including, but not limited to: rights, freedoms, individuality, etc. - all of which, independently and collectively affirm the existing political structures.

Benjamin's critique of the loss of immediate mediacy of the image(s) originates in his critique of the politics of means-ends (W. Benjamin 2005d). According to him, despite the claim that ends are removed from the sphere of means, or even superior to it,

'mythology' into the space of history. That, of course, can happen only through the awakening of not-yet-conscious knowledge of what has been" (W. Benjamin 2002d, 458, N1,9). In this passage, Benjamin criticizes Surrealism for staying within the dream and mythology rather than "[binding] revolt to revolution" (W. Benjamin 2005d, 215). Thus, for Benjamin, the Surrealist movement proved to be politically "inadequate and undialectical" (W. Benjamin 2005d, 216). 
they [the ends] are nothing more than historical positings whose mediacy is masked by the metaphorical political language. ${ }^{132}$ This form of politics, Benjamin argues, serves to preserve and mandate certain ways of life, tainted by positive forms of law.

In his Surrealism (1929) essay, he writes:

"To win the energies of intoxication for the revolution" - in other words, poetic politics? "We've tried that beverage. Anything, rather than that!" Well, it will interest you all the more to see how much an excursion into poetry clarifies things. For what is the program of the bourgeois parties? A bad poem on springtime, filled to bursting with metaphors. The socialist sees that "finer future of our children and grandchildren" in a society in which all act "as if they were angels" and everyone has as much "as if he were rich" and everyone lives "as if he were free." Of angels, wealth, freedom, not a trace - these are mere images. And the stock imagery of these poets of the social-democratic associations? Their gradus ad parnassum? Optimism (W. Benjamin 2005d, 216).

In this passage, Benjamin criticizes the sacrifice of the immediate mediacy of the image at the altar of the moral and/or political program of liberal and/or social democratic politics. He calls this form of politics: poetic politics, which utilizes poetic devices, rhetorical figures and political imagery. In doing so, both liberal and social democratic politics create political imaginaries which consist of optimistic images of the future such as the "liberal moral-humanistic ideal of freedom" (W. Benjamin 2005d, 215) or the social democratic idea of a future society in which "everyone lives 'as if they were free", (W. Benjamin 2005d, 216). ${ }^{133}$ These images of the future seek to create a "reconciliation"

\footnotetext{
${ }^{132}$ As an alternative to means-ends politics, Benjamin calls for a "politics of pure mediacy" (Hamacher 1994, 110) where "the political" becomes the sphere of mediacy in which the imagespace and body-space interpenetrate. Benjamin's notion of alternative politics and his notions of image- and body-space will be discussed in detail in the third section of this chapter.

${ }^{133}$ Benjamin criticizes the common Marxist understanding of the future as a utopia or the concept of the future being temporally and spatially distinguished from the present, and set as an 'end.' This critique has two dimensions: On the one hand, Benjamin sees the future as "part of the extended present" where utopias are understood as "stories of the present conditions, which legitimize its inclusion in the present topos" (Lindroos 1998, 38); on the other hand, he criticizes utopian politics which impose predetermined ends on politics.
} 
[Verständigung] "between classes, between nations, [and] between individuals" (W. Benjamin 2005d, 217), which serves to perpetuate the "homogeneous, empty time" (W. Benjamin 2006d, 395) of the history of the victors.

In this context, images become the bearers of liberal and/or social democratic values, ${ }^{134}$ which claim to be eternal, universal and timeless. Thus, when one thinks of the metaphors of liberal and/or social democratic politics, the following quickly comes to mind: the invisible hand, the rule of law, the balance between liberty and security, humanity, pluralism, equality of opportunity, negative freedom, and the public/private divide. Yet, all these notions have a specific meaning within the established order of meanings. As such, their use in political language cancels out the immediate, temporal mediacy of these images, thereby creating political imaginaries that are delimited by the order of posited norms.

\subsubsection{Dream Agora: Metaphor and Image}

The effectiveness and efficiency of liberal and/or social democratic politics however, does not only derive from the use of metaphors; more importantly perhaps, is the materialization of these images in "space, objects and practices" (Wohlfarth 1996, 199), thereby acquiring an immediate perceptible presence ${ }^{135}$ - that is, the phantasmagoric character of reality - in the capitalist everyday. For instance, the ideal of equality is materialized in court buildings, welfare offices and their associated practices;

\footnotetext{
${ }^{134}$ Similar processes could be found in communist politics - namely, the Soviet propaganda machine and the metaphorical images of the collective happiness. Yet, this is beyond the scope of this dissertation.

${ }^{135}$ In the Exposé of 1939, Benjamin writes, “[o]ur investigation proposes to show how, as a consequence of this reifying representation of civilization, the new forms of behavior and the new economically and technologically based creations that we owe to the nineteenth century enter the universe of phantasmagoria. These creations undergo this 'illumination' not only in theoretical manner, by an ideological transposition, but also in the immediacy of their perceptible presence" (W. Benjamin 2002b, 14).
} 
democracy, in parliament buildings as well as legislative and executive practices; security, in the institution of the police and policing practices; diversity in the coexistence of different ethnic, religious, and racial groups and their cultural practices; freedom in the daily practices of movement, association, religion, etc., and the coexistence of temples, churches, synagogues, and mosques.

Within this immediate perceptible presence of images - informed by posited norms, which are the source and boundary-setters of collective desires, wishes and feelings - arises the "dream agora," which constitutes the space of commonality, collectivity and totality in a world of individualized, alienated and isolated individuals. This "dream agora" along with the "dream houses" render the relationship between the capitalist social relations of production and liberal and/or social democratic politics imperceptible by the senses while making the phantasmagoric reality of commonality, collectivity and totality perceptible. It is precisely this politics - within which metaphorical political language intertwines with the immediate perceptible presence of images - that I identify as "kitsch politics."

In the second chapter, I associated the first order phantasmagoria with the acting out of social relations by commodities, which renders the qualities of social things "at the same time perceptible and imperceptible by the senses" (Marx 1887, 47). In this constellation, things as commodities constitute the abstract screen of social relations. For, they are the sensuous mediums of social relations while simultaneously being the nonsensuous expressions of a purely social relation. In turn, the second order phantasmagoria reflected the acting out of human desires, wishes and feelings by the consumption of commodities, which then generates a sense of fulfillment and realization. I argued that the 
first- and second-order of phantasmagoria are in a continuous interaction, leading from one to the other. In this context, kitsch politics functions through the doubling of phantasmagoric reality within and through the interaction of the first- and second-order phantasmagoria.

If the public sphere is the "space of appearance" and a "world we hold in common" (Arendt 1998), then, the matter of concern in the public sphere is the collective desires, wishes, and feelings as well as their realization. Yet, in the doubling of phantasmagoric reality these collective desires, wishes and feelings - such as equality, freedom, security, human rights, etc., - are acted out through the sensory consumption of images, thereby giving rise to a sense of collectivity, commonality and wholeness. For instance, the collective desire for security is transposed onto the immediate perceptible presence of security images, which are materialized in "space, objects and practices" (Wohlfarth 1996, 199) - such as the increased presence of police officers, CCTV cameras, private security, terror threat alerts, and "clean" - both literally and figuratively - city-spaces, etc. These perceptible images of security render it possible for the individual(s) to feel at home, to identify with the collective and to develop a sense of belonging and rootedness while at the same time making the relationship between the capitalist mode of production and liberal and/or social democratic politics imperceptible to the senses.

\subsubsection{Phantasmagoria and the Public Sphere}

Arendt depicts the public sphere as a table, which both relates and separates the people around it (Arendt 1998), thereby creating a realm in which the distinctiveness of human beings is expressed and communicated through action and speech. However, the 
"dream agora" and "dream houses" transform both the arrangement and operation of the public sphere by creating the conditions of kitsch perception. In the previous chapter, I defined kitsch perception as the unique apparition of a beautified ghostly reality that dissolves a distance (both in space and time) however far that distance may be. The distance (the image of "the table") - which makes the perception of difference and commonality possible - is dissolved through: a) the material presence and closeness of things (as commodities) - which promise happiness and prosperity ${ }^{136}$ to the masses, and b) the immediate perceptible presence of the images in which the metaphors of liberal and/or social democratic politics are materialized. In this constellation, the assembly of things creates the phantasmagoria of tradition in which "the far away and the long ago" (W. Benjamin 2002c, 8-9) becomes attainable while the spaces, objects, and practices whose immediate perceptible presence establishes the "dream agora" - renders political collectivity sensible.

In other words, the phantasmagoria of tradition gives rise to a sense of continuity in a world of discontinuity and fragmentation through the appropriation and assimilation of the various components of it [tradition] by the commodity form, and the material graphicness of liberal and/or social democratic metaphors - which are supposedly liberated from their commodity character by the divide between the public (the state and civil society) and the private (market and the household) spheres. As a result, the distance

\footnotetext{
136 "The domestic interior moves outside. It is as though the bourgeois were so sure of his prosperity that he is careless of façade, and can exclaim: My house, no matter where you choose to cut into it, is façade. Such façades, especially, on the Berlin houses dating back to the middle of the previous century: an alcove does not jut out, but - as niche - tucks in. The street becomes room and the room becomes street. The passerby who stops to look at the house stands, as it were, in the alcove" (W. Benjamin 2002d, 406, L1,5).
} 
in space and time is brought close to hand, making the people "feel at home, at ease, comfortable and comforted" (W. Benjamin 2005e, 621).

As the distance in the public sphere is liquidated, Arendt's allegorical table magically vanishes, signaling the rearrangement of the public sphere on the basis of sameness rather than human distinctiveness. In this constellation, the sameness - whether it is identified in reference to a shared essence or a shared experience - operates as a "highly considerate mirror" (Broch 1969a, 49), a mirror which throws back an image at the individual in which s/he recognizes her/himself as part of a collective (e.g., a nation, race, ethnic, religious or political group) in a society which is organized on the basis of individuality, which, in turn, functions on the basis of the ever increasing social division of labour and in which the lived, immediate, and in turn, quickly forgotten experience [Erlebnis] has replaced experience [Erfahrung].

Under this re-arrangement, the operational principle of the public sphere shifts from "whoness" to "whatness" of being. Arendt describes the "what" of someone as one's "qualities, gifts, talents, and shortcomings" (Arendt 1998, 179) while the "who" of someone as the "intangible yet distinguishable persona[,] true only of that one person" (Hull 2002, 55). To put it differently, the "whatness" concerns the common qualities that are used to describe anyone while the "whoness" is found "in everything somebody says and does" (Arendt 1998, 179). Accordingly, the public sphere as the sphere in which the distinctiveness of human beings is expressed and communicated operates through the "whoness" of being, which celebrates human distinctiveness.

However, the transformation of the public sphere as a result of the liquidation of distance leads to the operationalization of the "whatness," which operates through fixed, 
static and exclusionary identities, identities that provide a sense of belonging through the demonization of the other(s). Here, acting is reduced to being, and difference is effaced for the sake of sameness. Therefore, in a world where capitalism has become the material and social formation that defines the horizon of the thinkable, the communicable and the imaginable, identities become the sensuous mediums of social relations while simultaneously being the non-sensuous expressions of a social relation - the commodity form. To put it more clearly, just like commodities - onto which human desires, wishes and feelings are transposed, and whose consumption produce a sense of fulfillment and realization - identities become the mediums onto which human desires, wishes and feelings are transposed, and by means of which a sense of collectivity and totality is created.

In this constellation, what is witnessed is the channeling of social tensions inherent in the capitalist relations of production into political identities, and in turn, the limitation of political imaginaries. For the manufactured identities that are to be worn as a mask in the public sphere permeate through the body, and soon, become a part of the human physiognomy. Social, legal, and political identities, are constituted by 'othering' e.g., labourer versus bourgeois, citizen versus non-citizen, criminal versus non-criminal, liberal versus conservative, modern versus barbaric, developed versus underdeveloped, Christian versus Muslim, patriot versus terrorist, etc. - all the while venerating the ideal of humanity and human rights. This realization leads us to two rather important questions: Does this mean that we are at a structural, political and imaginary deadlock? Is there a way to wake up from the "dream-filled sleep that came over Europe" (Benjamin 2002d, 391, K1a,8) with capitalism? 


\subsection{Alternative Politics}

"The reform of consciousness consist solely in ... the awakening of the world from its dream about itself"

Karl Marx

In The Arcades Project, Benjamin wrote, "[c]apitalism was a natural phenomenon with which a new dream-filled sleep came over Europe, and, through it, a reactivation of mythical forces" (W. Benjamin 2002d, 391, K1a,8). In this configuration, Benjamin transfers a phenomenon that is associated with the individual to the collective. As I discussed in the first section of this chapter, here he identifies the fact that what is internal to the former - such as "the sensoria organs, the feeling of sickness or health" is external to the latter, and what is internal to the latter - such as "architecture, fashion" is external to the former. Yet, sleep is a natural process like "digestion, breathing, and the like," for both the individual and the collective. Therefore, if the collective "preserve this unconscious, amorphous dream configuration, $[\ldots]$ they stand in the cycle of the eternally selfsame" (W. Benjamin 2002d, 389-390, K1,5). Every sleep however, is followed by a waking hour. Even if the sleep is the result of an induced or natural coma, there still is a chance of waking. This conceptualization prompts us to ask: Where does the "constellation of awakening" (W. Benjamin 2002d, 458, N1,9) originate from in modernity? According to Benjamin:

[a]wakening [i]s a graduated process that goes on in the life of the individual as in the life of generations. Sleep is its initial stage. A generation's experience of youth has much in common with dreams. Its historical configuration is a dream configuration. Every epoch has such a side turned toward dreams, the child's side. [...] But whereas the education of earlier generations explained these dreams for them in terms of tradition, of religious doctrine, present-day education simply amounts to the distraction of children. Proust could emerge as an unprecedented phenomenon only in a generation that had lost all bodily and natural aids to remembrance [Eingedenken] and that, poorer than before, was left to itself 
to take a possession of the worlds of childhood in merely an isolated, scattered, and pathological way. What follows here is an experiment in the technique of awakening. An attempt to become aware of the dialectical the Copernican - turn of remembrance (W. Benjamin 2002d, 388, K1,1) (emphasis added).

Therefore: remembering and awakening are most intimately related. Awakening is namely the dialectical, Copernican turn of remembrance" (W. Benjamin 2002d, 389, K1,3).

Within a world where tradition was shattering and secularization was taking place, the sur-real world of fetishized images - that is, kitsch - arose. In this world, the explanation of dreams is substituted by distraction, which while eliminating "all bodily and natural aids to remembrance" (W. Benjamin 2002d, 388, K1,1) also paved a path for a new mode of remembering. This “Copernican Revolution in historical perception” (Benjamin 2002, $388, \mathrm{~K} 1,2)$ overturns the former perception - in which "what has been" [Gewesenes] was thought of as a fixed point - to its "dialectical reversal - the flash of awakened consciousness" (Benjamin 2002, 388, K1,2). Here, "politics attains primacy over history" (W. Benjamin 2002d, 389, K1,2) in the sense that "what-has-been" is seen as "something that just first happened to us" (W. Benjamin 2002d, 389, K1,2). In this configuration, the act of remembrance is no longer about the gaze from the present into the past; rather, it is about the gaze of the past at the present. Benjamin writes:

In regard to such a perception, one could speak of the increasing concentration (integration) of reality, such that everything past (in its time) can acquire a higher grade of actuality than it had in the moment of its existing. How it marks itself as a higher actuality is determined by the image as which and in which it is comprehended. And this dialectical penetration and actualization of former contexts puts the truth of all present action to the test. Or rather, it serves to ignite the explosive materials that are latent in what has been... To approach, in this way, "what has been," means to treat it not historiographically, as heretofore, but politically, in political categories (W. Benjamin 2002d, 392, K2,3).

In the structure of this perception, Benjamin finds the 'hailing to the surface' 
[Förderung] of "not-yet-conscious knowledge of what has been" (W. Benjamin 2002d, $389, \mathrm{~K} 1,2)$.

In this configuration, Benjamin establishes a "relation of immediacy to the material of the social" (Weigel 1996, 3) ) $^{137}$ and develops a re-reading of the material (e.g., things, writing, gestures, sociological types). In and through this re-reading, he reconfigures "the political" in relation to the image. ${ }^{138}$ The goal of his alternative politics therefore, is the "organization of pessimism" 139 against, what I call, kitsch politics, in which the optimistic metaphorical political language intertwines with the immediate perceptible presence of images. In his Surrealism (1929) essay, Benjamin writes:

Mistrust the fate of literature, mistrust in the fate of freedom, mistrust in the Fate of European humanity, but three times mistrust in all reconciliation: between classes, between nations, between individuals. And unlimited trust only in IG Farben and the peaceful perfecting of the air force $(\mathrm{W}$. Benjamin 2005d, 216-217).

This ironic statement at the end demonstrates Benjamin's awareness of the "progressive logic" of modern technology. The air force played a crucial role in both the WWI (e.g., colonial bombing campaigns) and WWII (e.g., strategic bombing). In the contemporary society, for instance, the use of drones for the purposes of both social control and policing

${ }^{137}$ In this dissertation, I expand the relation he established between immediacy and the social to the political.

${ }^{138}$ In his Surrealism (1929) essay, he writes: "The trick by which this world of things is mastered [...] consists in the substitution of a political for a historical view of the past" (W. Benjamin 2005d, 210).

${ }^{139}$ The notion of "revolutionary pessimism" was developed by Pierre Naville - in his book The Revolution and the Intellectuals (1928) - who was a member of the Surrealist movement from 1924 and the Communist Left from 1927. Naville was expelled from the French Communist Party in 1928 because of his Trotskyism. Benjamin's argument concerning the "organization of pessimism" was developed in reference to the closeness between the Surrealist and the communist movement at the time. According to him, "the hostility of the bourgeoisie toward every manifestation of radical intellectual freedom played a leading part" (W. Benjamin 2005d, 213 ) in the Surrealists' move toward the left and toward the revolution. Many members of the Surrealist movement were also the members of the communist party at the time, and for Benjamin, this engagement between the Surrealist and the communist movements created the conditions to organize pessimism for a revolutionary change. 
(at times of war and peace) nationally and internationally is telling in terms of Benjamin's call to "organization of pessimism". ${ }^{140}$ Thus, it is through the "organization of pessimism," by means of which the moral metaphors could be expelled from politics and doubt would be cast on the present and the future of art, freedom and European humanity, and in turn, "the one hundred percent image space [Bildraum]" could be "discover[ed] in the space of political action" (W. Benjamin 2005a, 217).

This image-space is not about a metaphor - where an image takes the place of a concept, thought or idea. Rather, it originates in the "distinction between metaphor and image" (W. Benjamin 2005d, 217). Thus, the matter of concern here, as Weigel most effectively puts it, "is not, then, the 'encoding' of meanings in images, but the insight that memory and action find articulation in images, that ideas are structured as images, and that what is at stake is therefore a praxis that can operate with images" (Weigel 1996, 8).

\subsubsection{Now-Time [Jetztzeit]: Messianic Time and Non-Messianic Politics}

The truly historical concept of history, Benjamin argues, cannot be based on a linear, successive time, but rather, on a non-linear time. ${ }^{141}$ In the fourteenth thesis of $O n$ the Concept of History (1940), he writes:

History is the subject of a construction whose site is not homogenous, empty time, but time filled full by now-time [Jetztzeit]. Thus, to Robespierre ancient Rome was a past charged with now-time, a past which he blasted out of the continuum of history. The French Revolution viewed itself as Rome incarnate. It cited ancient Rome exactly the way fashion cites a by-gone mode of dress. Fashion has a nose for the topical; no matter where it stirs in the thickets of long ago; it is the tiger's leap into the past. Such a leap, however, takes place in an arena where the ruling class gives the commands. The same

\footnotetext{
${ }^{140}$ For more detail on air force and police power see (Neocleous 2011; Neocleous 2013a; Neocleous 2013b).

${ }^{141}$ In On the Concept of History (1940), he writes: "The concept of mankind's historical progress cannot be sundered from the concept of its progression through a homogeneous, empty time. A critique of the concept of such a progression must underlie any criticism of the concept of progress itself”' (W. Benjamin 2006d, 394-395).
} 
leap in the open air of history is the dialectical leap Marx understood as revolution (W. Benjamin 2006d, 395). ${ }^{142}$

In this passage, Benjamin presents a re-interpretation of the images of the collective imaginary - such as Rome. This re-interpretation differs significantly from the one presented by Marx in The Eighteenth Brumaire of Louis Bonaparte (1852). ${ }^{143}$ In this essay, Marx refers to the figures and images from past historical events (e.g., the French Revolution) that were used by actors in politics and identifies such use as deceptive and mystifying. Benjamin, on the other hand, presents a rather different reading of the same constellation. Here, he depicts Robespierre's use of the collective imagery as a 'tiger's leap into the past" (W. Benjamin 2006d, 395) which overleaps the continuum of history by invoking image(s) from the archive of historical memory. Benjamin's notion of the "tiger's leap into the past" thus derives from a concept of history which "understands the construction of history as work in and with the images of recollection, and which founds the [re]cognizibility of the past in a model of memory" (Weigel 1996, 13). The "nowtime' [Jetztzeit] is thus the actualization of the blasting out of the historical object from the continuum of history. ${ }^{144}$

\footnotetext{
142 The theological name of the time "filled full by now-time" (W. Benjamin 2006d, 395) is messianic time. Benjamin's use of the messianic should not be read as a deployment of a theological concept within the profane field of history; rather, what he does here is the displacement of the messianic actuality to the field of revolutionary politics (Khatib 2013b).

${ }^{143}$ Marx writes: "The tradition of all the dead generations weighs like a nightmare on the brain of the living. [...] Thus Luther donned the mask of the Apostle Paul, the Revolution of 1789 to 1814 draped itself alternately as the Roman [R]epublic and the Roman [E]mpire, and the Revolution of 1848 knew nothing better to do than parody, now 1789, now the tradition of 1793 to 1795 . [...] Camille Desmoulins, Danton, Robespierre, Saint-Just, Napoleon, the heroes as well as the parties and the masses of the old French Revolution, performed the task of their time in Roman costume and with Roman phrases, the task of unchaining and setting up modern bourgeois society" (Marx 1977, 300-301).

${ }^{144}$ Benjamin's concept of now-time [Jetztzeit] is a profane model of (fulfilled) messianic time. It is fulfilled because of the actualization of the blasting out of the historical object from the historical continuum. For more information on Benjamin's notion of the messianic see (Hamacher 2005; Gibbs 2005; Caygill 2005).
} 
Thus, history, for Benjamin, is based on a disruptive constellation of the past and the present rather than on the continuum of "homogenous, empty time" (W. Benjamin 2006, 395), called 'progress.' In this context, historical cognition concerns the cognition of that "which has not yet become history, that which yet can become history" (Benjamin qt. in Hamacher 2005, 39). For, "its possibilities [...] have not yet been actualized" (Hamacher 2005, 39). Benjamin writes:

The past carries with it a secret index by which it is referred to redemption. Doesn't a breath of the air that pervaded earlier days caress us as well? In the voices we hear, isn't there an echo of now silent ones? Don't the women we court have sisters they no longer recognize? If so, then there is a secret agreement between past generations and the present one. Then our coming was expected on earth. Then, like every generation that preceded us, we have been endowed with a weak messianic power, a power on which the past has a claim (W. Benjamin 2006d, 390) (emphasis in the original).

As demonstrated in this passage, Benjamin associates the un-actualized possibilities of the past with the Messianic. Similar to Kafka, who claims that "[t]he messiah will only come when he is no longer necessary; he will come only on the day after his arrival" (Kafka 1984, 182), Benjamin's notion of the Messiah is grounded on the understanding that the Messiah is not coming in time. Thus, there is no messianic type of politics within Benjamin's theoretical framework.

To explain this further, Benjamin makes a clear distinction between the order of the profane and the order of the messianic. In Theological-Political Fragment (1938), he writes: "[t]he secular order cannot be built on the idea of the Divine Kingdom, and theocracy has no political but only religious meaning" (W. Benjamin 2006c, 305) Accordingly, the role of the messianic for the order of the profane is to bear witness to an incompleteness, which prevents the order of the profane from being a closed, selftotalizing sphere. In other words, the role of the Messianic in Benjamin's understanding 
of politics is to render profane politics open to the past that can give rise to a future, which is not the mere continuation of the past.

Moreover, Benjamin's articulation of the messianic regarding the possibility of redemption does not point towards a messianic expectation but towards a profane one. He writes:

If one arrow points to the goal toward which the secular dynamic acts, and another marks the direction of the messianic intensity, then certainly the quest of free humanity for happiness runs counter to the messianic direction. But just as a force, by virtue of the path it is moving along, can augment another force on the opposite path, so the secular order - because of its nature as secular - promotes the coming of the Messianic Kingdom (W. Benjamin 2006c, 305).

In other words, the messianic tendency of history is not found in a messianic direction. The hope for redemption has no messianic horizon of expectation; in fact, it orients itself towards the opposite direction, that is, the direction of the profane. Thus, Benjamin argues, "[o]nly for the sake of the hopeless ones have we been given hope" (W. Benjamin 1996, 356). Here, hope is not depicted as an individual attitude directed to the future but as something "we have been given" by those who lived before us. It is this hope of the hopeless, the openness to the past, the possibility of cognizingly seizing and actualizing the missed possibility that gives rise to a future.

But, what is it that makes this messianic power weak? Two reasons could be identified by way of explanation. First, the messianic power, according to Benjamin, does not derive from ourselves, which also means that it is not at our disposal; rather, we namely, the present generation - are given this power by the previous generations in every possibility missed by them and these missed possibilities' demand for fulfillment. Second, as Hamacher argues (2005), the messianic power "has to become extinguished in 
each future by which it is not perceived and actualized" (42). "For it is an irretrievable image of the past which threatens to disappear in any present that does not recognize itself as intended in that image" (W. Benjamin 2006d, 391).

Thus, history, according to Benjamin, is possible because of the possibilities that were missed, which means that redemption is about the redeeming of these missed possibilities of the past. These possibilities become possibilities for the future precisely because they are not fulfilled. Since the possibilities of the past have not yet been fulfilled, they continue to have "an effect as intentions and demand their realization from those who feel addressed by them" (Hamacher 2005, 41). Yet, the possibility that is stored in the 'un-actualized' is not an ideal possibility for everyone and for all times; rather, it is a possibility for a particular future that recognizes itself in it as 'missed.' To put it differently, the 'unactualized' possibility "leaps beyond its particular Now and demands from another Now its settlement, correction and fulfillment" (Hamacher 2005, 41).

In this context, time becomes the dimension of the possible that claims to be actualized. Yet, these possibilities do not consist of abstract categories, conditions, objects and actions, meaning that any claim of past possibilities to fulfillment does not address a specific "constituted subject" who is to perceive this claim. Rather, they are possibilities only for those who could seize them (W. Benjamin 2002). Therefore, those who seize these missed possibilities construct themselves as political subjects in and through political action. As Hamacher (2005) most eloquently puts it, "[t]he claim's addressee is rather fundamentally a function of this claim, 'thoroughly colored by the 
time,' and of the possibilities that assert their demands towards this claim, not only in its time but as its time" (41) (emphasis in the original).

\subsubsection{Profane Illumination}

Benjamin relates the symptoms of modernity to dreams and the unconscious while associating the flashlike visibility of this world with a new gaze. Thus, he writes: "[S]o long as they [the individual and the collective] preserve this unconscious, amorphous dream configuration $[\ldots]$ they stand in the cycle of the eternally selfsame, until the collective seizes upon them in politics and history emerges" (W. Benjamin 2002d, 390, $\mathrm{K} 1,5)$. This new mode of seeing, according to Benjamin, resides in "[t]he realization of dream elements in the course of waking up," that is, "the canon of dialectics" (W. Benjamin 2002d, 464, N4,4). This new gaze marks a certain state of consciousness in which "the temporal structure of the political affect" (Hamacher 2005, 38) is taken as the starting point. In doing so, Benjamin demonstrates the force of political affects in the cognition of reality by means of which rational individuality can be overcome.

In this context, Benjamin articulates his notion of politics through three new conceptualizations: a) profane illumination [profane Erleuchtung], b) "image-space" [Bildraum], and c) "body-space" [Leibraum]. All of these conceptualizations are designed to overcome the dualistic oppositions between form and content, philosophy and literature, politics and art, theory and practice, sobriety and ecstasy, individuality and collectivity, corporeal immediacy and figurative representation, and in turn, relate cognition immediately to the prospects of revolution and revolutionary experience. In his Surrealism (1929) essay, Benjamin writes:

[A]s we know, an ecstatic component lives in every revolutionary act. This component is identical with the anarchic. But to place the accent exclusively 
on it would be to subordinate the methodical and disciplinary preparation for revolution entirely to a praxis oscillating between fitness exercises and celebration in advance (W. Benjamin 2005d, 215-216).

In this passage, Benjamin draws attention to the classical distinction between "mere anarchic revolt and mere submission to the coming of the real revolution" (Hanssen 2006, 5), the distinction between libertarian anarchism and the hierarchical Leninist party structure. To overcome this duality, he develops a dialectical concept of intoxication, by means of which "political materialism and physical creatureliness" (W. Benjamin 2005d, 217) would dialectically interpenetrate each other.

Benjamin found an inspiration for this dialectical concept of intoxication in Surrealism. The Surrealists, Benjamin argues, are concerned with experiences and these experiences "are by no means limited to dreams, hours of hashish eating, or opium smoking" (W. Benjamin 2005d, 208), and thus, cannot be simply related to "religious ecstasies or ecstasies of drugs" (W. Benjamin 2005d, 209). Benjamin describes the Surrealist intoxication as a profane illumination, which is a "materialist, anthropological inspiration" (W. Benjamin 2005d, 209), a type of materialist epiphany or a sudden inspiration, in and through which "enlightened consciousness and mythical or religious experience is suspended" (Khatib 2014, 2), and in which a historical view of the past is substituted by a political one (W. Benjamin 2005d). ${ }^{145}$ In this configuration, profane illumination blurs the distinction between reality and sur-reality, individuality and collectivity, ecstasy and sobriety, sleeping and awakening. This indicates the inaccessibility of profane illumination to (private) contemplation, (subjective) intention, and (moralistic) metaphors as well as to the total absorption of the self in a collective

\footnotetext{
${ }^{145}$ Benjamin finds the embodiment of profane illumination in the types of "the thinker, the reader, the loiterer, the flâneur" (W. Benjamin 2005d, 216).
} 
state of ecstasy, which makes it possible to transgress the limitations of individualism and lived experience [Erlebnis]. Benjamin writes:

In the world's structure dream loosens individuality like a bad tooth. This loosening of the self by intoxication is, at the same time, precisely the fruitful, living experience that allows these people to step outside the charmed space of intoxication. [...] But, the true, creative overcoming of religious illumination certainly does not lie in narcotics. It resides in profane illumination, a materialist, anthropological inspiration, to which hashish, opium, or whatever else can give an introductory lesson (W. Benjamin 2005d, 209).

To put it differently, the dreamlike threshold experiences brought forth by profane illumination - the "light of the image" (Breton 1969, 37) - create a crack in the kitsch condition, which renders synaesthetic ${ }^{146}$ experience possible, in which "sound and image, image and sound interpenetrate[s] with automatic precision and such felicity that no chink was left for the penny-in-the-slot called 'meaning'” (W. Benjamin 2005d, 208). That is to say, profane illumination disrupts the order of meanings through tearing the bubble of the 'private.'

The spontaneity, unpredictability, explosiveness and shocking force of profane illumination plays a part in the unsettling and "[o]vercomig [of] the private" (W. Benjamin 1977, 1024) ${ }^{147}$ and the entrance into the image-space of politics (W. Benjamin 2005d). This space however does not emerge magically; rather, it arises within and through political action. Thus, the collective subjectivity that occupies this image-space

\footnotetext{
${ }^{146}$ Synaesthetia is an Ancient Greek word, composed of syn, "together," and aeisthèsis, "sensation." In modern Latin, it means "joint perception." As a neurological phenomenon, synaesthetia is understood as a stimulation of one sensory or cognitive pathway leading to involuntary experiences in a second sensory or cognitive pathway - such as perceiving letters and numbers as inherently colored. In the arts, the concept of synaesthesia is also used in reference to artistic and poetic devices that attempt to create a link between the senses - such as "a sharp tone" or "loud color" (The Oxford English Dictionary 2015).

${ }^{147}$ Benjamin refers to the "overcoming of the private" as a "revolutionary virtue" (W. Benjamin 1977) within the constellation of modernity.
} 
cannot be represented by any (pre-existing) political imaginary - whether it is bourgeois moralism, social democratic futurism or traditional Marxist politics. That is to say, there is no collective subjectivity that precedes this image-space. For, the image-space and political action presuppose each other. Here, once again, Benjamin emphasizes the indeterminate character of the collective subjectivity and revolutionary politics. Although the image-space could lead to a rise of new political imaginaries, such imaginaries do not precede the "political community-to-come" (Khatib 2015, 1). Thus, "[t]he site of a revolutionary community-to-come, the space where this community comes into being, is the interpenetration of a collective body-space [Leibraum] and the image-space [Bildraum] of political action" (Khatib 2015, 1-2).

\subsubsection{Image-Space and Body-Space}

Against "poetic politics" (W. Benjamin 2005d, 216) where images as well as politics become means to an (higher) end, Benjamin identifies the task of materialist politics as the "organization of pessimism" (W. Benjamin 2005d, 216), pessimism toward the idea that politics can stand for something else - such as a means for a superior end, whether a means to the realization of higher moral principles (e.g., human rights, justice, equality); the achievement of ideological goals (e.g., neoliberalism's claim to selfresponsibility to become more secure, efficient, prosperous), or the embodiment of a teleological process towards communism. ${ }^{148}$ Benjamin's stance against representation

\footnotetext{
${ }^{148}$ Recently, Jon Simons (2016) questioned whether Benjamin's notion of politics could lend itself to a different kind of politics. In Benjamin's writings, Simons argues, communism emerges as a "society that will be "mature enough to make technology its organ"" (48). Although Benjamin's sympathy toward communism cannot be ignored, it should be remembered that he had never become a member of the communist party, and perhaps more importantly, he unceasingly criticized any form of "idealization" in politics, especially in reference to preconfigured, progressive and optimistic notions of the future (W. Benjamin 2006d). Furthermore, Simons' (2016) reliance on expressions such as "progressive reconception of
} 
and moralism in politics makes it possible to free political action from all forms of political belief, dogma and/or ideology that restricts (political) action and imagination. In this configuration, political action becomes an opening, an image-space where liberal moralism and individualism become "inoperative [and] all external meanings are extinguished" (Khatib 2015, 7). That is to say, despite, and perhaps more importantly, because of, the intertwinement of metaphorical political language and the immediate perceptible presence of dream images in kitsch politics, profane illumination disrupts the 'beautified ghostly reality' by short-circuiting the unceasing interaction between firstand second-order phantasmagorias, thereby paving the way for the entrance into the image-space.

Since the image-space of politics is devoid of any moral and trans-historical meaning, it is embodied only by political action itself. The entrance of the subject into the image-space, which "can no longer be measured out by contemplation" (W. Benjamin 2005d, 217), indicates the fact that the distance between subject and image is liquidated. Benjamin states:

[W]here an action puts forth its own image and exists, absorbing and consuming it, where nearness looks with its own eyes, the long-sought imagespace $[$ Bildraum] is opened, the world of universal and integral actuality, where the "best room" is missing - the space, in a word, in which political

technology" (46), and "a progressive channeling of the effects of technology" (48) to describe Benjamin's notion of politics in relation to communism, disregards Benjamin's critique of the "progressive" notion of history (W. Benjamin 2006d). Indeed, in Simons' article, communism appears to be articulated in and through a social evolutionist perspective, which ignores the evanescent and explosive elements of Benjamin's alternative politics, where, as I have argued, politics attains primacy over history" (W. Benjamin 2002d, 389, K1,2) in the sense that "whathas-been" is seen as "something that just first happened to us" (W. Benjamin 2002d, 389, K1,2), thereby engendering a dialectical relationship between the "what-has-been" and the "now." Therefore, even if Benjamin might have found similarities between his alternative politics and communism, imposing communism as a political form that Benjamin had envisioned for the future, as Simons does, only serves to pull Benjamin into kitsch politics. For, in my view, the significance of Benjamin as a theorist, as a literary critic, as an activist is his place as non-place in radical thought. 
materialism and physical creatureliness share the inner man, the psyche, the individual, or whatever else we wish to throw them, with dialectical justice, so that no limb remains untorn. Nevertheless - indeed, precisely after such dialectical annihilation - this will still be an image-space and, more concretely, a body-space [Leibraum] (W. Benjamin 2005d, 217).

In the image-space, Benjamin argues, the "best room" - the room of the individual, the private, the space of contemplation - "is missing" (W. Benjamin 2005d, 217). That is to say that the subject and image collide, which also marks the collision of the image- and body-space. For, "the subject has entered into this image-space by becoming part of it, literally with his body" (Weigel 1996, 16). The collision of image- and body-space which Benjamin depicts as a process of absorption and consumption - a process in which "no limb remains untorn" (W. Benjamin 2005d, 217), a process in which "the inner experience is turned inside out" (Khatib 2014, 6) - marks the blasting of the duality between closeness and distance (i.e., the duality of kitsch perception and auratic perception), as a result of which the interpreter of the image and the creator of the image become inseparable. In Weigel's words, "the one who deciphers an image [becomes indistinguishable] from the one who represents or in actuality is an image" (Weigel 1996, 16).

Benjamin applies the collision of the image- and body-space later on in his Surrealism (1929) essay to the collective. He writes:

The collective is a body, too. And the physis that is being organized for it in technology can, through all its political and factual reality, be produced only in that image-space to which profane illumination initiates us. Only when in technology body- and image-space so interpenetrate that all revolutionary tension becomes bodily collective innervation, and all the bodily innervations of the collective become revolutionary discharge (W. Benjamin 2005d, 217).

In this configuration, Benjamin's use of the term innervation is important. This concept "refers, broadly, to a neurophysiological process that mediates between internal and 
external, psychic and motoric, human and mechanical registers" (Hansen 1999, 313). It "is frequently used in a structural sense, to mean the anatomical distribution of nerves in some organism or bodily region. Freud uses it $[\ldots]$ to mean the transmission of energy into a system of nerves [...] a process tending towards discharge" (Freud 2010, 539, fn.2). In the context of Benjamin's writings, innervation functions as a dialectical opposite to the technologically mediated, shock-absorbing mimetic reception, which protects the organism at the price of paralyzing it, and robbing it of its capacity for imagination. In contrast to this deflective mimetic reception and its anaesthetizing effects, innervation refers to a mimetic reception of stimuli by means of which the external world is incorporated into perception "as form of empowerment" (Buck-Morss 1992, 17).

Thus, the concept of innervation, in Benjamin's writing, functions in a two-way process: (1) an "individual corporeality and a collective spirit," and (2) a "collective body and an individual psyche" (Khatib 2014, 7). In this configuration, the bodily collective innervation and bodily innervations of the collective refer to a new form of technology where a collective spirit becomes corporeal. To put it differently, "the reality of the [body-space] is produced in an image-space which in turn refers to the corporeal materiality of the collective as its matrix" (Weigel 1996, 16).

In this sense, the image- and body-space is similar to a dream-image, which is materialized in objects, space, and practices (e.g., dream houses and dream agora), or is a materialized fantasy (e.g., commodity). In both cases, the individual "participates in the scene that he imagines" (Weigel 1996, 18). What is different in the interpenetration of image- and body space is it being "both the matrix and material expression" (Weigel 1996, 18) of the collective at once. It is this collision of the matrix and corporeal 
materiality that transforms the collective into a "detonating mechanism: a truly 'dialectical fairyland"” (Weigel 1996, 19). Thus, it is not surprising to see that at the end of his Surrealism (1929) essay Benjamin inserts the image of the alarm clock: "[t]he play of human features for the face of an alarm clock that in each minute rings for sixty seconds" (W. Benjamin 2005d, 218). The strikes of the alarm clock are the strikes of the 'now-time' [Jetztzeit] against the continuous, measured, progressive time.

Thus, according to Benjamin, alternative politics and/or revolutionary action is spontaneous, unpredictable and disruptive. The outcomes of this revolutionary discharge are unknown and indeterminate; yet, two generalizable outcomes could be expected. First, revolutionary discharge could lead to a overstretching of kitsch politics' ability to contain, maintain and reproduce itself, and its associated form of sur-reality, and in turn, could pave a way to a new alignment of technology and humanity in which the capitalist exploitative relations are overcome, and a new configuration between nature and man emerges. In the One-Way Street Benjamin writes: "[T]echnology is not the mastery of nature but of the relation between nature and man" (W. Benjamin 1996, 487). Second, despite the pulling of the "emergency break" (W. Benjamin 2006d, 402) ${ }^{149}$, the 'abstractreal' - 'real-abstract' reality of the sur-real world, kitsch perception and kitsch politics could restore themselves while producing an image of the revolutionary discharge in accordance with, and within the bounds of, the order of posited norms and meanings,

\footnotetext{
${ }^{149}$ Benjamin writes: "Marx says that revolutions are the locomotive of world history. But perhaps it is quite otherwise. Perhaps revolutions are an attempt by the passengers on this train - namely, the human race - to activate the emergency brake" (W. Benjamin 2006d, 402).
} 
integrating the image of this revolutionary discharge into kitsch politics, and the progression of time. ${ }^{150}$

\subsection{Conclusion:}

In this chapter I first discussed the relationship between the public and the private spheres and the consequent blurring of the distinction between these spheres with the rise of the social, in order to set the backdrop against which the implications of the transformation of the collective organization of human perception and the fabric of experience on "the political" could be explored. Benjamin discusses public and private life in reference to the 'interior,' which was demarcated as a space that was separate from work. In other words, within bourgeois society, the interior arose as a response to the alienating processes of the capitalist social relations of production, the unfamiliar city and its shock-ridden, momentary and instantaneous experiences [Erlebnisse]. The space of dwelling therefore was a place of refuge for the private individual, a closeted dreamspace, which created the "phantasmagoria of the interior." In this space, things as commodities were transformed into things beautified, and as such, things of experience, thereby enabling the individual to "feel at home, at ease, comfortable and comforted" (W. Benjamin 2005e, 621). In the twentieth century however, the emulation of the interior by

${ }^{150}$ Benjamin's alternative politics could be illustrated by the "Arab Spring" (2011), the "Occupy Movement" (2011), and the Gezi Park Protests (2013). All of these movements became sites of the "detonating mechanism" where an image- and body-space sprang up, leading to the ringing of alarm clocks in various cities, communities, and countries. Despite their failure to generate a new configuration of nature, technology, and humanity, all of these movements contributed to the archive of revolutionary image-space (e.g., the wide use of social media, performative acts, the diversity of the people involved, the dissolution of fixed identities, and the integration of symbols, humor, satire and graffiti). For instance, in Gezi Park Protests, a photograph of a woman in red dress became a symbol of resistance internationally; a silent, standing protest of performative artist Erdem Gunduz - known as "standing man" - was taken up by many as a form of protests in various cities in Turkey. Therefore, I argue, all these movements have been the embodiments of the possibility of local, international, and global collectivity, solidarity, and action in the world of individualism, alienation and isolation. 
the exterior served to stimulate economic activity and to transform the city into "prosceniums for collective representation" (Solibakke 2009, 158). In other words, as the domestic interior stimulated intoxication and dream (for the private individual), the arcades (as dream houses) generated "religious intoxication [for] great cities" (W. Benjamin 2002d, 61, A13). Therefore, Benjamin's reading of the 'exterior as interior' reflects the dream-like nature of the collective organization of human perception. In this constellation, the "exterior as interior" has become the expression of the dreaming collective, similar to the arrangement, décor, and furnishing of the domestic interior, which is the expression of the dreaming subject.

This led me to conclude that the political imaginary is conditioned by the interaction between the first- and second-order phantasmagoria and the resulting shift from auratic perception to kitsch perception. Thus, by traversing the confines of the dwelling kitsch saturates the dream houses with the appropriation of a beautified ghostly reality, thereby leading the collective "deeper into sleep" (Benjamin 1999, 389, K1,4). In turn, this dream-filled sleep precludes the formation of new political imaginaries void of the conflation between metaphor and image, which, for Benjamin, is crucial for the rise of an alternative politics beyond capitalism.

The transformation of the collective organization of human perception manifests in "the political" as the conflation between metaphor and image. Thus, in the metaphorical political language of liberal and/or social democracy, images lose their temporal and immediate mediacy and turn into a stock of imagery, whose boundaries are carefully and strictly marked by the practical language and existing reality. Therefore, the resulting political imaginaries are nothing more than optimistic images of a future, 
professing the "liberal moral-humanistic ideal of freedom" (W. Benjamin 2005d, 215) or, the social democratic conception of a future where "everyone lives 'as if they were free"" (W. Benjamin 2005d, 216). It is thusly that politics engenders "reconciliation" [Verständigung] "between classes, between nations, [and] between individuals" (W. Benjamin 2005d, 217), thereby perpetuating the "homogeneous, empty time" (W. Benjamin 2006d, 395) of the history of the victors.

The effectiveness and efficiency of liberal and/or social democratic politics however, does not only derive from the conflation between the metaphor and image. Rather, and more importantly perhaps, the images of the metaphorical political language materialize in "space, objects and practices" (Wohlfarth 1996, 199), thereby acquiring an immediate perceptible presence in the capitalist everyday, giving rise to, what I call, the "dream agora". What this means is that as the "dream houses" render the relation of the capitalist social relations of production to liberal and/or social democratic politics imperceptible by the senses, the "dream agora" becomes the manifestation of the collective desires, wishes, and feelings - which are strictly bound to the order of posited norms - thereby rendering the phantasmagoric reality of commonality, collectivity, and totality, perceptible. On this basis, I argued that this politics - where the metaphorical political language intertwines with the immediate perceptible presence of images - is truly "kitsch politics."

In this kitsch politics, the "dream agora" and "dream houses" transform the arrangement and operation of the public sphere. Thus, as collective desires, wishes, and feelings (e.g., equality, freedom, security, human rights, etc.) are acted out through the sensory consumption of images, the resulting sense of collectivity and commonality 
render the relationship between the capitalist mode of production and liberal and/or social democratic politics imperceptible to the senses. In other words, Arendt's allegorical table - which provides the necessary distance for the operationalization of inclusive identities is dissolved, thereby heralding the (re)arrangement of the public sphere on the basis of sameness rather than human distinctiveness. Thus, the operating principle of the public sphere becomes rooted in the fixed, static and exclusionary identities, which provide a sense of belonging through the demonization of the other(s). This is the outcome of the "dream-filled sleep [that] came over Europe" (W. Benjamin 2002d, 391, K1a,8) with capitalism.

The operationalization of kitsch politics, therefore, renders the creation of new political imaginaries mute. For, if the collective "preserve this unconscious, amorphous dream configuration, $[\ldots]$ they stand in the cycle of the eternally selfsame" (W. Benjamin 2002 d, 389-390, K1,5). Yet, this is not to say that kitsch is the immutable, permanently unavoidable characteristic of modernity. For every sleep is followed by a waking hour. Drawing on the work of the Surrealists, Benjamin argues that the fixed imagery of the metaphor needs to be destroyed by bringing forth the image, which becomes legible within the text while simultaneously dissolving it. This destruction facilitates the "organization of pessimism" (W. Benjamin 2005d, 216), which should prompt us "to discover in the space of political action the one hundred percent image space [Bildraum]" (W. Benjamin 2005d, 217). Thus, Benjamin's alternative politics rises against the optimistic metaphorical political language of kitsch politics. For, the sudden, evanescent - flash-like - coming together of the image at the intersection of "what-has-been" [das 
Gewesene] and the "now" also reflects the nature of cognition, which is bound to the 'now of a particular recognizibility' (W. Benjamin 2002d, 463, N3,1)

Here, Benjamin criticizes the progressive notion of history and chronological time. In contra-distinction to linear time and progressive history, Benjamin proposes that we understand "the construction of history as work in and with the images of recollection and which founds the [re]cognizibility of the past in a model of memory" (Weigel 1996, 13). In this configuration, the 'now-time' [Jetztzeit $]$ overleaps the continuum of history by invoking image(s) from the archive of historical memory. This conception of history in turn, has some important implications for the future of alternative politics. Namely: 1) it leads Benjamin to conclude that the present is shot-through with the possibilities of the past that have not yet been fulfilled, and thereby "demand their realization from those who feel addressed by them" (Hamacher 2005, 41); and 2) 'now-time' [Jetztzeit], for Benjamin, embodies the dimension of the possible that claims to be actualized.

In this context, Benjamin articulates his vision for an alternative politics through three new conceptualizations: a) profane illumination [profane Erleuchtung], b) "imagespace" [Bildraum], and c) "body-space" [Leibraum]. These conceptualizations are thus designed to overcome the dualistic oppositions (e.g., form and content, politics and art, theory and practice, individuality and collectivity, etc.) which are an integral part of kitsch politics. Thus, profane illumination shatters the kitsch condition rendering synaesthetic experience possible, thereby disrupting the order of meanings through tearing apart the bubble of the 'private.' In turn, the spontaneous, unpredictable and explosive force of the flash-like profane illumination ushers in the image-space of politics (W. Benjamin 2005d). Arising within and through political action, this image-space 
resides outside of the preceding political imaginary of the collective subjectivity. As the image-space disrupts the duality between closeness and distance - the duality of kitsch perception and auratic perception - the body-space "is produced in an image-space which in turn refers to the corporeal materiality of the collective as its matrix" (Weigel 1996, $16)$.

On this basis, I concluded this chapter by arguing that only in this matrix can the alarm-clock strike the 'now-time' [Jetztzeit $]$ - effectively suspending the continuous, measured, progressive time - discharging the revolutionary power, where the "emergency break" (W. Benjamin 2006d, 402) is pulled, and thus, the missed possibilities of the past are actualized. Yet, the outcomes of the revolutionary discharge are unknown and indeterminate, which means that such discharge could either lead to an overcoming of the capitalist exploitative relations, and in turn, a new configuration between nature, technology and humanity, or to restoration of the sur-real world of kitsch, kitsch perception, and kitsch politics.

In this dissertation, by constructing kitsch as a theoretical tool, where Benjamin's "dialectical optic" is put to work, a new perspective into modernity is developed. This perspective reveals the dialectical relation between the real and sur-real, intoxication and cognition, innervation and consciousness, closeness and distance, metaphor and image, corporeal immediacy and figurative representation. As such, I demonstrate the ways in which the occult and phantasmagoric phenomena are an integral part of reality. Moreover, as the concept of kitsch cuts through objects (i.e., commodity), culture (i.e., "debased"), sensibilities (i.e., aesthetic attitude), and ideology (i.e., "false" aesthetic consciousness), it lends itself to the articulation of the material, the cultural, the aesthetic 
(i.e., perception, experience, memory) and "the political." Thus, kitsch emerges as the dialectical image, the historical object where dream and awakening, organic and inorganic, real and sur-real crystalize. Accordingly, the conceptualization of kitsch perception serves to explore both the mode of "seeing" and the form of experience [Erlebnis] that have become predominant under the commodity form and technological reproduction while also assisting in the articulation of an alternative mode of "seeing" and potential revolutionary experience. The conceptualization of kitsch politics, on the other hand, provides the ground on the basis of which the intertwinement of the metaphorical political language and the immediate perceptible presence of images is investigated and criticized, and but perhaps more importantly, a Benjaminian alternative politics is imagined.

The dialectical image of kitsch renders it possible to overcome the dichotomy between reality and mystification, infrastructure and superstructure, consciousness and false consciousness, autonomous art and the culture industry that has been an acute problem not only of traditional Marxism but also the Frankfurt School. Such overcoming makes it possible to view the sur-real world of fetishized images - that is, kitsch - not as the enemy, which leads to false (aesthetic) consciousness, but as the source of both dream and awakening. Benjamin neither conceives of this sur-real world of fetishized images as a world in which revolutionary action is unlikely to occur - like Adorno and Horkheimer (T. Adorno and Horkheimer 2002) - nor as a world in which Habermas' progressive quasi-transcendental communicative rationality (1990) would unfold. Rather, this sur-real world is conceived as a world from which a new configuration of nature, technology, and humanity could spring forth. For, the training of human sensory organs by technology 
(i.e., consciousness as a protective shield) also creates its dialectical opposite, that is, innervation. In One-Way Street, Benjamin writes:

[B]ecause the lust for profit of the ruling class sought satisfaction through it, technology betrayed man and turned the bridal bed into a bloodbath. The mastery of nature, so the imperialists teach, is the purpose of all technology. But who would trust a cane wielder who proclaimed the mastery of children by adults to be the purpose of education? Is not education above all the indispensable ordering of the relationship between generations and therefore mastery, if we are to use this term, of that relationship and not of children? And likewise technology is not the mastery of nature but of the relation between nature and man. Men as a species completed their development thousands of years ago; but mankind as a species is just beginning his (W. Benjamin 1996, 487).

As clearly articulated in this passage, rather than blaming technology per se, Benjamin criticizes the capitalist-imperialist notions of technology for the purposes of mastering nature, and argues that there is a possibility of an alternative relationship with technology, "predicated on pedagogy (as a discipline ordering intergenerational relations rather than one of mastering children)" (Hansen 1999) which points to the politics of innervation. The revolutionary discharge, in which by creating the intertwinement of individual and collective innervation within the image- and body-space, by means of which individual bodies literally become nerves of the collective and vice versa, is what Benjamin calls the "second technology" (W. Benjamin 2006c, 109). It is a liberated and emancipatory technology whose goal is not the "mastery over nature" like capitalistexploitative "first technology" but an "interplay between nature and humanity" (W. Benjamin 2006c, 109).

It is at the intertwinement of the individual and collective innervation within the image- and body-space that Benjamin inserts the allegory of the alarm clock to describe the character of the revolutionary discharge: "The play of human features for the face of 
an alarm clock that in each minute rings for sixty seconds" (W. Benjamin 2005d, 218). In this allegory, Benjamin points out the taking over of the body of both the individual and the collective by the image of the alarm clock. Here, the strikes of the alarm clock refer to the strikes of the 'now-time' [Jetztzeit] against the continuous, measured time adopted not only by the bourgeoisie but also social democrats (W. Benjamin 2006d). ${ }^{151}$ As Weigel (1996) puts it, "the strike against time is thus spontaneously a strike against the notion of the opposition between the organic and the mechanical, between the human being and the mechanical device. The boundary between the two here is eliminated" (15), which indicates an actualization of a possibility that not-yet-has-been, but might-cometo-be.

In this configuration, radical and/or revolutionary politics is understood to be spontaneous, unpredictable, and disruptive whose outcomes are indeterminate and unknown. In the Thesis XVIIa of the Paralipomena to "On the Concept of History (1940), Benjamin states:

[w] hoever wishes to know what the situation of a "redeemed humanity" might actually be, what conditions are required for the development of such a situation, and when this development can be expected to occur, poses questions to which there are no answers. He might just as well seek to know the color of ultraviolent rays (W. Benjamin 2006d, 402) (emphasis added).

In other words, the "redeemed humanity" is the claim of the past generations on the present ones, and the actualization of such a claim is bound to the "now of a particular

${ }^{151}$ Challenging the social democratic reading of Marx where revolution becomes an indispensible and necessary outcome of progressive history. He writes: "Through a series of class struggles, humanity attains to a classless society in the course of historical development. $=$ But classless society is not to be conceived as the endpoint of historical development. = From this erroneous conception of Marx's epigones have derived (among other things) the notion of the 'revolutionary situation,' which, as we know, has always refused to arrive. = A genuinely messianic face must be restored to the concept of classless society and, to be sure, in the interest of furthering the revolutionary politics of the proletariat itself" (W. Benjamin 2006d, 402-403). 
recognizibility' (W. Benjamin 2002d, 463, N3,1). Therefore, the revolutionary discharge, even if it does not lead to the reconfiguration of nature and technology, technology and humanity, would expand the archive of revolutionary image-space, thereby generating new claims by the "what-has-been" on the "now." In other words, the revolutionary discharge, by pulling the "emergency break," paves a path for new political imaginaries that could transgress the boundaries of kitsch politics, and in turn, re-charges the possibility of the actualization of the claims of the past.

At this point, it is necessary to address the importance of Benjamin's thought for understanding the world of the twentieth and twenty-first centuries. My attempt to address the significance of Benjamin's thought however is not an attempt to identify the contemporaneity of his thought, because such an attempt would require an assumption of a linear historical chronology, which, by definition, would contradict the methodology I adopted in this dissertation. To put it more clearly, any attempt to place Benjamin within a theoretical tradition through which the heritage of that school of thought could be genealogically articulated would be a betrayal of Benjamin's intentional intellectual homelessness. In reference to Benjamin's notes on the concept of history, Weigel (1996) argues that, for Benjamin, "the manner in which something from the past is honored as heritage is more calamitous than its loss could be" (4). Benjamin's actuality therefore does not derive from the historical appropriateness of his theoretical formulations, but from his way of thinking, writing, and investigating which is adopted towards the material of history and culture, by means of which the material of the past is re-read while being constructed as an image. 
Benjamin's diagnosis of the abandonment of the epic element of history under the commodity form and technological reproduction, and his recognition of the breaking down of history into images rather than stories led him to integrate the newly emergent fragmentary and discontinuous dimension of (sur-)reality into his methodology in order to blast an object of history out of the historical continuum rather than condemning the process of fragmentation as "decadence." In a sense, he mimicked the character of (sur)reality in his thinking and writing to mirror the disjointed and fragmented character of everyday life. This methodological mimesis is the other reason for the actuality of Benjamin's thought. For, by mimicking everyday life he awakens the involuntary memory of the reader by means of which the similarities of the fragmentary sur-real world become legible. 


\section{Conclusion:}

\subsection{The Concept of Kitsch:}

In the $1930 \mathrm{~s}$, the concept of kitsch became an object of contemplation in the discussions concerning the rise of mass society and the commecialization of art. Refering to judgements of taste in general, and aesthetic inadequacy in particular, the term kitsch at various points - was assoicated with 'bad art' (Macdonald 1957; Kulka 1996; Eco 1989), 'a category of falsehood' (Greenberg 1961; Dorfles 1969; Ćelebonović 1969) and 'bad taste' (Broch 2002; Kundera 1999; Giesz 1969). In my review of the literature on kitsch, I employed a thematic approach in order to reveal the analytical connections between, rather than within, the different disciplines. The themes which I identify in my analysis of the literature reflect the debates surrounding the implications of the emerging technological reproducability on culture in general, and art, in particular. I presented five thematic categories; Kitsch as: 1) an ersatz culture, 2) a philosophical and existential phenomenon, 3) a "travestied aesthetic consciousness," 4) a technique of political manipulation, or 5) an aesthetic category.

In the first category, I focused on the rise of mass society and mass culture. Here, kitsch is seen as a by-product of the Industrial Revolution, which unlocked the aristocratic privileges without offering leisure and comfort by means of which a genuine culture could be cultivated. Thus, kitsch objects are depicted as cultural commodities, which in turn reflect vulgar taste in an attempt to imitate the life of a dominant class (Greenberg 1961, Ćelebonović 1969, Macdonald 1983).

In the second category, kitsch moves beyond the confines of capitalist production and/or bad taste in reflecting a particular historical sensibility, originating from the 
Romantic cult of beauty - which substituted the transcendental aesthetic ideal with the ideal in which beauty became the immediate and tangible goal for any work of art. Thus, the Kitschmensch, who inhabits this category, enjoys himself while consuming the object, and is stimulated by the very fact of being moved by the object (Diaconu 2010). In other words, the lover of kitsch substitutes the 'real' with what is wished to be seen, felt, and/or experienced. Rejecting all that is undesirable, in the words of Kundera, kitsch sensibility is a "categorical agreement with being" (Kundera 1999, 248).

The third category concentrates on the socio-economic conditions of capitalism, which produce and re-produce the culture industry, and is associated "sensual immediacy" (Adorno 1997, 13). By the imposition of an instrumental rationality on art and culture, they are both reified, thereby transforming culture and art to a source of pleasure (T. W. Adorno 1997; T. W. Adorno 2001; Horkheimer 1982). In this context, kitsch is conceptualized as an ideology, which conceals and alters the contradictions of the capitalist socio-economic system - by producing objects that become the mechanism for escaping the boredom and toil of daily life.

The fourth category is based on a specific form of sensibility that concerns the need to reconcile with the social environment that surrounds people. Friedländer (1984) identifies this as a common sensibility for "the order of things" (26). Therefore, kitsch, according to Friedländer, facilitates the fabrication and maintenance of submission and consensus within society through the instrumentalization of culture for political propaganda. Consequently, it (kitsch) serves to (re)formulate unacceptable, unforgivable, terrifying actions, and attitudes into a familiar, identifiable, bearable, and universally acceptable course of things, and in turn, casts a lasting and convincing spell on the people 
(Friedländer 1984). This is the point where the relationship between (political) kitsch and mass sentiment becomes manifest, and where kitsch emerges as a technique for political manipulation (Montgomery 1991; Kundera 1999).

The fifth thematic category addresses the debates surrounding kitsch as an aesthetic category. These debates oscillate between the condemnation of kitsch as aesthetically deficient and artistically inferior (Kulka 1996), and the celebration of its dialectical potential (Eco 1989). Here, on the one hand, it is argued that kitsch functions to "trigger an unreflective emotional response" (Kukla 1996, 26) through the use of effortlessly discernible images and objects. On the other hand, and despite - or rather, because of - its lack of associative potential (between the observer and the work of art), kitsch manifests the possibility for the emergence of a dialectical relationship between art and kitsch (Eco 1989). Thus, kitsch is more than just a falsehood, or a lie; but rather, an insight that necessitates the abandonment of the hierarchical distinction between original and copy in the face of simulation (Gumpert 1999).

In this chapter, I also argued that the studies of kitsch within each of the five thematic categories offer restrictive, and in turn, incomplete analyses of the concept. For limiting kitsch to the social, cultural, or aesthetic spheres leads to a disregard of the fact that the commodity form and technological reproduction irreversibly alter the fabric of everyday life, and in turn, the forms of communication, human perception, and experience. Similarly, viewing kitsch solely as a particular historical sensibility originating in the Romantic cult of beauty re-produces the subject-oriented analysis of the Enlightenment, and in turn, demands a return to the unattainable, transcendental notion of beauty. The conceptualization of kitsch as "false aesthetic consciousness" criticizes the 
penetration of exchange relations into all aspects of life, which leads to the reification of culture and art, thereby transforming the relationship between the observer and the artwork. This transformation results in the reconstruction of culture as a source of pleasure. Such analysis however, reproduces Marx's assumption that the superstructure is the reflection of the infrastructure. On the contrary, Benjamin convincingly argues that the relationship between the infrastructure and superstructure is considerably more nuanced, and as such it is better characterized as expressive (allowing for mutual conditioning) rather than reflective (limited to uni-directional hierarchy).

In his examination of kitsch as a technique of political manipulation, Friedländer importantly points out the political dimensions of kitsch, yet he unexpectedly cripples his analysis by restricting it to fascist and communist regimes only. Lastly, while the analysis of kitsch as an aesthetic category hints at the dialectic potential of the concept, studies within this theme neuter their analytic potential by relegating kitsch to the value system of aesthetics. In other words, individually, each of these thematic categories is fraught with incomplete theoretical conceptualization, and often-contradictory analytical conclusions.

Collectively, however, these thematic categories point to a rather important observation, that is: the emergence of kitsch, its endurance, and unceasing proliferation are all reflective of the possibility that kitsch as a concept is quite a bit more than simply the sum of its - here to analyzed - parts. Indeed, it is not a coincidence that kitsch emerged in the nineteenth century where both the commodity form and technological development expanded beyond the sphere of production, and penetrated into other spheres of life. Therefore, I argued that kitsch finds its expressions in the different 
spheres (e.g., social, political, economic, cultural, historical) of life by (re)producing particular: patterns of behavior, ways of engaging with reality, and forms of attitudes toward oneself, others and the external world. In other words, kitsch is truly a defining characteristic of modernity. In the following three chapters, therefore, I demonstrated how the examination of kitsch as such can lead us to a better understanding of the modern condition, culminating in Chapter IV, where I explored how such a study of kitsch enables us to question whether this condition could be resisted, and altered.

\subsection{Capitalism, Culture and Technology:}

In the 1930s the debate surrounding the state of art was a way to explore the transformation of human perception and the experience of reality that were ushered in by the penetration of the commodity form into the cultural sphere, and the alteration of the production and consumption of cultural goods through technological reproduction. For Marx, artistic activities were an "active affirmation of [one's] own nature" (Marx qt. in Markus 2011, 554) (emphasis in the original) and therefore, could not be absorbed under capitalism. Building on this, Lukács argued that 'authentic' art embodies the potential for the existence of a non-reified relation to reality (Lukács 1971a). Following Lukács, Adorno claimed that the process of commodification is paradoxically the precondition for both the possibility that art could be subsumed under capitalism (i.e., culture industry), and its autonomy (i.e., emancipation) (T. W. Adorno 1997). Thus, while on the one hand, the culture industry transforms art in order to expand and reproduce the interests of capital, on the other hand, it enables art to be freed from its cultic function, thereby becoming valuable in its own terms. In contrast, Brecht dismissed the possibility of art being autonomous under the conditions of the commodity form as an illusion (Brecht 
2007). For, according to him, “....art as a whole becomes commodity or it does not become it at all" (Brecht qt. in Markus 2001, 6). In offering a more nuanced account of the state of art Benjamin challenges both Adorno and Brecht, and claims that cultural objects are neither entirely autonomous from the material conditions nor are products entirely determined by exchange value. Benjamin sees cultural objects as a form of collective expression conditioned by both technological reproduction and the social relations of production (W. Benjamin 2002d).

By emphasizing the fact that cultural objects are an expression rather than a reflection of the social relations of production, Benjamin offers an important critique of the Marxist tradition in its depiction of the relationship between the infrastructure and superstructure. While Marx conceptualizes the reality created by the capitalist mode of production as a reflection of the infrastructure structure on the superstructure - which then leads to false consciousness (Marx \& Engels 1998), Benjamin views this relation as a form of expression, which is akin to the forms of expression between the unconscious and the conscious. This view leads Benjamin to conclude that the commodity form combined with technological reproduction condition the new materials and forms of life of the historically situated individuals and collectivities in an immediate and sensuous way rather than through their ideological transposition. In this configuration, Benjamin portrays cultural forms as the expressions of a collective unconscious under the conditions of "a new dream-filled sleep that fell over Europe" (W. Benjamin 2002d, 391, $\mathrm{K} 1 \mathrm{a}, 8)$ - that is, capitalism.

The work of art, Benjamin argued, in classical capitalism was characterized by an autonomous existence, which was substantiated and expressed in the "aura" (W. 
Benjamin 2006c). The aura, for Benjamin, conditions the production of the works of art and regulates their perception, and is thus an objective aspect of the collective experience of art. But more importantly perhaps, the aura of the artwork is reflective of the singular existence and authenticity, historical testimony and authority, of the work of art. Consequently, "[t]he uniqueness of the work of art is identical to its embeddedness in the context of tradition" (W. Benjamin 2006c, 105).

However, technological reproduction significantly alters both the production and perception of artworks (e.g., reproducibility versus uniqueness, closeness versus distance, up-to-dateness versus authenticity), signaling the "shattering of tradition" which symptomatically manifests itself in the "decay of aura" (W. Benjamin 2006c). To put it differently, technological reproducibility and the rise of the masses heralds the alteration of the medium in which sense perception occurs - where auratic perception is replaced by a new form of perception characterized by a dissolution of the "borders of objects by bringing them 'closer' spatially and humanly" and thus overcoming "the uniqueness of every reality" (Caygill 1998, 103). This is where we find the fundamental feature of human perception in the age of technological reproducibility: the desire to extract "sameness even from what is unique" (W. Benjamin 2006c, 105). As such it is the locus where the "alignment of reality with the masses and of the masses with reality" (W. Benjamin 2006c, 105) resides. Indeed, it is where a new reality emerges.

Benjamin examines this new reality by means of the concept of phantasmagoria. Both Marx and Benjamin use the term phantasmagoria in order to describe the nature of reality that emerged under the conditions of capitalism. For Marx, things as commodities materialize a social relation between people, yet in the eyes of people these things (as 
commodities) assume "the phantasmagorical form of a relation between things" (Marx 1967, 76-77), producing a ghostly reality in which "the qualities of social things are at the same time perceptible and imperceptible by the senses" (Marx 1887, 47) (emphasis added).

Conversely, Benjamin focuses his analysis on the exploration of the ways in which Marx's phantasmagorical reality is perceived. For, if the relation between the infrastructure and the superstructure is one of expression - and not of reflection - then only through the examination of human perception can the phantasmagoric nature of reality be comprehended. Thus, radicalizing Marx's concept of phantasmagoria, in the Arcades Project (2002) Benjamin argues that the equivalence constructed between the product and its price elicits "empathy" with the exchange value. Consequently, the empathetic relation that emerges between the consumer and the object of consumption reveals the implications of the commodity form on the collective organization of human perception.

Reading Marx's conceptualization of phantasmagoria against that of Benjamin leads to two important conclusions: 1) the empathetic relation is not among people; but rather, it is between the consumer and the value of the object in the market, namely, money; and 2) the collective organization of human perception is the expression of the commodity form and technological reproduction. In other words, while the exchange value of the commodity is the location where the specter first appears, in the empathetic relation - where the wishes, desires and feelings of the consumer are given a corporeal form - the specter appears once again. What this means is that in the operation of the 
commodity form there are two forms of phantasmagoria at play. I call these phantasmagorias: first-order and second-order phantasmagoria.

The first-order phantasmagoria refers to the mysterious character of the commodity, which gives rise to a "sensuous-supra-sensuous" relation, a relation that is "perceptible and imperceptible by the senses" (Marx 1887, 47), thereby creating a 'realabstract' reality where things as commodities act out social relations. The 'real-abstract' reality here refers to the shift from use-value (i.e., sensuous, real) to exchange value (i.e., supra-sensuous, abstract). In this context, things as commodities become the sensuous medium of social relations while at the same time being the supra-sensuous expression of a purely social relation. The second-order phantasmagoria, on the other hand, is about the processes through which the empathetic relation to the commodity conditions the collective organization of human perception, thereby creating a 'abstract-real' reality where things as commodities and their exchange value act out human wishes, desires, and feelings, thereby precipitating a sense of realization and fulfillment. Here, the 'abstractreal' reality refers to the transposition of human wishes, desires, and feelings, which are socially constructed) onto the commodity and/or the exchange value of the commodity. For, the act of consumption presupposes the use of the commodity, thereby giving a corporeal form to the wishes, desires and feelings of human beings.

In the second chapter of this dissertation, I argued that kitsch emerges as the defining characteristic of modernity at the point where the first and second order phantasmagorias converge. This convergence manifests as the doubling of the phantasmagoria in modern society, which is the expression of the complex, nuanced, and reciprocal conditioning relation between the two orders of phantasmagoria. In turn, I 
defined kitsch as the apparition of a beautified ghostly ('real-abstract' / 'abstract-real' and/or 'abstract-real' / 'real-abstract') reality. This apparition occurs at the point where the commodity form and technological reproduction engender the accessibility of the world of objects, and in turn, collide with the rise of the masses and their "desire to get closer to things" (W. Benjamin 2006c, 105). For, the closer the world of objects (as commodities) is to the masses, the more attainable the dreams of the masses appear to them.

At the point of this collision the collective organization of human perception finds its expression in a "sur-real" world, a world in which fetishized images are alienated from the people, but also constituting and shaping them. At the intersection of the 'realabstract' and 'abstract-real' reality, employing Benjamin's dialectical optic, I explored this sur-real world of kitsch in order to reveal the fact that occult and phantasmagoric phenomena are an integral part of modern reality. In this analysis, kitsch as a theoretical construct rendered it possible to demonstrate how the objects as commodities are transformed into entities of narcissistic adoration, where, by identification with the commodity and/or its exchange value, the consumer and the collective become an embodiment of the image reflected back on her/him and itself. This reflection is beautified through the intoxicating reassurance of familiarity and closeness of the inhabited world thereby generating feelings of security, comfort, reaffirmation, and contentment.

\subsection{The Crisis of Experience:}

For Benjamin, the sur-real world of modernity is characterized by the changes to the mode of human perception, which is brought forth by the adaptation to the material 
and social conditions of capitalism (e.g., commodification, technological reproduction, urbanization, alienation, etc.). The radical restructuring of the mode of human perception manifests itself in spatial and temporal registers (i.e., such as proximity and distance, permanence and transitoriness). As the mode of perception changes, so does the fabric of experience. For, the restructuring of the human sensory apparatus and the historical shifts that occurred within the forms of communication - namely, a shift from unmediated to mediated communication, storytelling to information - are intimately connected to the replacement of the continuity and unity of experience by discontinuity and fragmentation, leading to the incommunicability of experience.

The decline of storytelling plays a central role in Benjamin's analysis of modernity because he treats the different forms of communication as a prism through which the changes that occurred in the collective organization of human perception and the fabric of experience can be investigated. For instance, according to Benjamin, the rise of the novel - in the face of the decline of storytelling - is an expression of the transformations taking place in the infrastructure, thereby substantiating a radical restructuring of human perception, manifesting itself in a shift from the shared collective experience [Erfahrung] to privatized and individualized experiences [Erlebnisse]. These changes, Benjamin argues, found their expression in a new form of communication: textual narration, that is, the novel. For while the production and reception of storytelling was a collective process, both the production and reception of the novel is an isolated one. In other words, Benjamin found the earliest symptom of a process that ended with the decline of storytelling in the rise of the novel. Consequently, in the crisis of the novel he recognized the emergence of a new form of communication, that is, information. For 
Benjamin, the proliferation of information as the dominant form in which experience is stored was a primary symptom of the crisis of experience. Therefore, in distinguishing between storytelling and information, he identifies three major differences (W. Benjamin 1968, 159).

Firstly, with the advent of information as a dominant mode of communication the spatial and temporal category of distance - which was the hallmark of storytelling - is eroded, thereby altering the spatial and temporal organization of human perception. Secondly, the instantaneous verifiability of information replaces the authority of the story, for as Agamben (1993) has convincingly argued, the measurable certainty of experience prompts the immediate loss of its authority. These changes occurring in the fabric of experience prompted a shift in experience toward a "desultory and isolated, overwhelmingly private character" (Wolin 1982, 22), thereby forfeiting the collective and continuous aspects of experience [Erfahrung]. While the constant production of fresh news leads to an increase in the breadth of knowledge, it also leads to a decline in its depth. For, the riddling through of information with explanation eliminates the space for interpretation. Thirdly, the temporality of information replaces the timelessness of the story, which in turn impacts the relationship between experience and memory. Thus, while storytelling prompts the integration of that which is told into memory, through relaxation and self-forgetfulness, the transitoriness of information impacts memory and the mimetic faculty through the advent of shock.

In distinguishing between experience [Erfahrung] (continuous and collective) and immediate experience [Erlebnis] (instantaneous and private) as distinct temporalities of experience, Benjamin investigates the relationship between experience, memory, and the 
mimetic faculty in modern society. For experience [Erfahrung] and immediate experience $[$ Erlebnis $]$ are intimately connected to memory and the mimetic faculty. In order to explore this relationship, Benjamin associates Proust's notion of the involuntary memory [mémoire involuntaire] to Freud's assumption, hypothesizing a correlation between memory and consciousness. In this configuration, the involuntary memory is associated with experience [Erfahrung] while the immediate experience [Erlebnis] is associated with the absorptive function of consciousness, which translates the shocks of the incidents of daily life into isolated experiences (W. Benjamin 2006a).

More importantly perhaps is the function that memory plays in experience. Here, Benjamin draws on Reik's distinction between memory as Gedächtnis (long-term memory) and memory as Erinnerung (reminiscence/recollection), where the former serves to conserve and protect impressions while the latter serves to dissolve them in consciousness (Reik 1936). According to Benjamin, the epic component of storytelling brings Gedächtnis and Erinnerung together. While the former marks the specific character of the tradition of experiences, which creates the community of listeners through repetition, the latter indicates the creative element of the storytelling, which renders the creation of stories afresh each time they are told, thereby maintaining the (re)formation of the tradition.

The present conditions (modernity) however, Benjamin argues, do not result in the absorption of the course of events and their repetition in narration. For, although there appears to be a chain of events and activities in modern everyday life, which should result in a continuity and unity of experience [Erfahrung], they are neither connected to the previous events or activities of the same day nor to the ones of the previous 
day/week/month/year. More precisely, these events, activities, or occurrences are in fact the exact repetition of the previous ones, and are therefore "new" at each instance. Thus, they neither create a tradition nor maintain a previous tradition, meaning that what seems to be tradition is nothing more than a phantasmagoria of tradition. It is this fragmentary, unrepeatable, individualized and isolated nature of the experiences of modern man that characterizes the crisis of experience. In this observation, Benjamin does not call for the restoration of the experience [Erfahrung]; rather, he calls for the understanding and acknowledgement of the state of experience [Erfahrung] in order to pave a way for new beginnings.

This crisis of experience also marks the decline of the mimetic faculty, which, for Benjamin, is "one of the quintessential modes of human cultural production" (Hanssen 2004, 56). Benjamin identifies the condition of a possible experience as an appearance on the surface that is readable. Therefore, experience is defined not as what is received as impressions but the reading of appearances within a configuration, which eliminates the distinction between the subject and the object of experience. The configuration, in this context, emerges not only as the condition of legibility - which is, in turn, the condition of a possible experience - but also as the discovery of "non-sensuous similarities" between configured patterns. Therefore, for Benjamin, the mimetic faculty is concerned with the configurations of similarities or correspondences in nature. It (the mimetic faculty) thus is the capacity to both recognize and produce such similarities and correspondences.

According to Benjamin, however, our capacity to perceive, and to reproduce similarities, has diminished in the modern world; "[f]or clearly the perceptual world 
[Merkwelt] of modern human beings seems to contain far fewer of those magical correspondences than did that of ancient or even that of primitive peoples" (W. Benjamin 2005e, 695). Although, Benjamin argues, "our existence no longer includes what once made it possible to speak of this kind of [non-sensuous] similarity [...] we, too, possess a canon according to which the meaning of non-sensuous similarity can be clarified. And this canon is language" (W. Benjamin 2005e, 721). ${ }^{152}$

However, in the present, the function of the mimetic faculty, that is, its indexical function - or rather the function which depends on the relationship between the material contiguity and temporality of the object of perception - has been fused with the operationalization of "a perceptual likeness between sign and reality" (M. Hansen 1987, 195) in semiotic terms - a process, which is enhanced by the growing speed of writing and reading. This is particularly problematic however, as the outcome of this process renders the semiotic aspect dominant and the mimetic aspect indiscernible. Thus, in the context of language for example, the treatment of language only as a medium of communication detaches it from its task of configuring the relationship between experience and mimesis. In other words, as experience [Erfahrung] shifts towards immediate experience [Erlebnis], and as long-term memory [Gedächtnis] shifts into reminiscence [Erinnerung] the perceptual world [Merkwelt] shrinks, only to be replaced by the semiotic, thereby leading the collective organization of human perception away

\footnotetext{
152 The transition from reading 'what was never written' to writing affects the complexity of the configuration. While in the former, configurations were read against each other in a space where there was neither foreground nor background, in the latter configurations are read "according to their relative position on a given uniform extended surface. Configuration thus transformed into inscription, reducing speculative reading of the similarity between patterns into the transcendental reading of graphically inscribed marks upon an infinite but bounded surface" (Caygill 1998, 5).
} 
from auratic perception and towards, what I identified in the third chapter as kitsch perception.

Benjamin defines the aura as "a strange tissue of space and time: the unique apparition of a distance, however near it may be" (W. Benjamin 2006c, 104-105). The aura is thus a form of perception that "invests" a phenomenon with "the ability to look at us in return" (W. Benjamin 1968, 188). In other words, the aura in its "anthropological, perceptual-mnenomic, and visionary dimensions" is not an essential property of persons or objects; rather, it is the medium of perception, which indicates a particular mode of looking. Benjamin depicts an intimate relation between involuntary memory and the aura. Benjamin finds this relation in: a) the data of involuntary memory - which is "incidentally, unique: [that is] they are lost to the memory that seeks to retain them" (W. Benjamin 2006d, 338); and b) the definitive aspect of the aura - that is, "a unique apparition of a distance" - which expresses unapproachability and unattainability. Therefore, the connection between the aura and involuntary memory signifies not only the fact that the "unique apparition of a distance" has a temporal dimension, but also the intertwinement of distance with the unconscious.

Yet, under the conditions of the commodity form and technological reproduction, the aura - just like experience [Erfahrung] - begins to decline, signaling the transformation of the relations of looking in modern society. The new mode of perception - which here I call kitsch perception - is a manifestation of perception that is mediated by technology. Thus, while auratic perception indicates the return of the gaze of the beholder by the object, kitsch perception tears apart this "strange tissue of space and time" (W. Benjamin 2006c, 104), thereby dislodging the possibility of returning of 
the gaze. Therefore, in contrast to auratic perception and its relationship to involuntary memory, kitsch perception originates in the "perpetual readiness of voluntary, discursive memory, encouraged by technological reproduction" (W. Benjamin 2006d, 337) including haptic and optic experiences. While haptic experiences consist of experiences in which the associations or correspondences are substituted by techniques, which serve to retain an event through the apparatus (e.g., taking a photograph, recording an event, setting up digital reminders of special dates), optic experiences include experiences are supplied by, for instance, the advertising pages of a newspaper or the traffic of a big city. Thus, kitsch perception designates the mode of perception which emerged as a result of the subjection of "human sensorium to a complex kind of training" (W. Benjamin 2006d, 328) by technology.

The technological mediation of perception has some serious consequences for the collective organization of human perception regarding: a) spatial and temporal categories; and b) the object's mode of being in relation to others (Hansen 2012). For, as the spatial and temporal categories of auratic perception (i.e., closeness versus distance, transitoriness versus permanence) are liquidated, the de-spatialization and detemporalization become prominent, resulting in the subject being uprooted from a human range of perception. Thus, as kitsch perception replaces auratic perception, the distance is dissolved and closeness is crystalized. Yet, this is not a singular process, indeed, this process is conditioned by: 1) a growing urge of the masses to get closer to things both in time and space; and 2) the rise of commodity production and technological reproduction which enable the fulfillment of this urge. Thus, the interaction between these two aspects results in the decreasing perceptivity of the masses. Consequently, while the possibility 
for the discovery of non-sensuous similarities is reduced, the absorption of the intended meanings inscribed in a particular configuration increases. Thus, I argued that kitsch perception is in fact a quasi-perception.

This becomes even more problematic when one considers that the shift from auratic perception to kitsch perception also precipitates a shift towards a different form of perceptual mode of similitude, that is, sameness qua identity. Here, the mimetic faculty, and therefore the non-sensuous similarity, which is its perceptual condition, submerge[s] into the "iconicity of photographic representation" (Hansen 2012, 94), thereby giving rise to a form of perception characterized by seriality and repeatability. Thus, kitsch perception leads to the identification of 'what appears' with 'what is.' In other words, the phantasmagorias - by means of which dream images are materialized - are being experienced [Erlebnis] as wish fulfillments rather than as the distorted similarities of the collective unconscious that needs to be investigated.

\subsection{Politics of Phantasmagoria: Kitsch Politics:}

The rise of capitalism, technological advancement and the alterations to the socioeconomic and political conditions have radically restructured our patterns of representation, apprehension, and experience. Thus, the pressures generated by the technological configurations of the urban environment, the acceleration of the speed of communication, and the overabundance of discontinuous stimuli are mitigated by the preoccupation with "looking" and "seeing." In this context, "scopophilic exhilaration and distraction" (Koepnick 1999, 142) serve to preserve the political community, and reinvent individual and collective identities against the grain of technological progress, alienation and isolation. Both political action and political imaginary are affected by the 
radical restructuring of human perception and the transformation of the fabric of experience. Therefore, it is important to investigate the implications of the kitsch condition - the interaction between the first-and second-order phantasmagorias - and the resulting shift from auratic perception to kitsch perception.

The rise of the capitalist mode of production and the formation of the nation-state created the conditions of life that transformed the relationship between the public and the private spheres. In this configuration, a new sphere arose: the sphere of the social, which signaled the shift of the economic reproduction processes and activities from the private to the public sphere. Thus, the private sphere of society has become publicly relevant (Arendt 1998; Habermas 1991). In this context, innumerable rules are imposed on members of society, resulting in pushing issues of distinction and difference, which were the matters of the public realm, to the private sphere. In this process, the occupational sphere "gained independence as a quasi-public realm in relation to a private sphere" (Habermas 1991, 154) and the private sphere is reduced to the realm of intimacy. Thus, in contemporary society, the sphere of the intimate emerges as a domain of leisure, a domain of the purely personal, where all the socially controlled roles are left behind.

Benjamin discusses public and private life within bourgeois society in reference to the 'interior,' the place of dwelling, which was demarcated as a space that was separated from work. That is to say, the interior arose as a response to the alienating processes of the capitalist social relations of production as well as the unfamiliar city, and its shock-ridden, momentary and instantaneous experiences [Erlebnisse]. Thus, the living space of the nineteenth century became a place of refuge for the private individual. It was a closeted dream-space, or more precisely, a space characterized by the "phantasmagoria 
of the interior." By encasing oneself in the comforts of the interior the bourgeois individual created a "real-abstract"-"abstract-real" reality where things as commodities were transformed into things beautified and as such, things of experience, thereby enabling the individual to "feel at home, at ease, comfortable and comforted" (W. Benjamin 2005e, 621).

Yet, the unceasing growth of the social led to the liquidation of the interior. In the twentieth century, as the distinction between inside and outside is liquidated, the emulation of the interior by the exterior served not only to stimulate economic activity (i.e., consumption) but also, and perhaps more importantly, to transform the city into "prosceniums for collective representation" (Solibakke 2009, 158). Thus, while the domestic interior created "stimulus to intoxication and dream" (W. Benjamin 2002d, 216, I2,6) for the private individual, the arcades became the source of "religious intoxication of great cities" (W. Benjamin 2002d, 61, A13), where the promise of happiness for the masses was to be materialized. These dream houses - that is the privately owned and publicly accessible spaces of intoxication - however, quickly burst out of the narrow confines of the arcades to be replicated wherever the urban crowd congregated, thereby transforming the faces of the cities. A transformation which converted the landscape of the cities into "techno-aesthetics, dazzling, crowd-pleasing dreamworld[s] that provided total environments to envelop the crowd" (Buck-Morss 1995, 6). In this constellation, the "exterior as interior" has become the expression of the dreaming collective, similar to the arrangement, décor, and furnishing of the domestic interior, which is the expression of the dreaming subject. 
Consequently, as the reality of commodities saturates the capitalist reality with kitsch, the appropriation of a beautified ghostly reality traverses the confines of the dwelling, and manifests within and through the dream houses of the collective - where what is "common among men" becomes the realization of the personalized, immediate, temporal fantasy world of the individuals. This transformation also reveals the process through which capitalism leads to the re-enchantment of the world via its disenchantment - where the ghostly reality is "beautified." Thus, the collective - "unconscious of itself, composed of atomized individuals, consumers who imagined their commodity dream world to be uniquely personal [...], and who experienced their membership in the collectivity only in an isolated, alienating sense" (Buck-Morss 1991, 260) - falls "deeper into sleep" (Benjamin 1999, 389, K1,4).

In the fourth chapter of this dissertation, I argued that it is precisely this dreamfilled sleep that precludes the formation of new political imaginaries void of the conflation between metaphor and image, which is crucial for the emergence of an alternative politics beyond capitalism. Drawing on the work of the Surrealists, Benjamin's analysis of the relationship between metaphor and politics challenges us to witness the collision of the metaphor and the image. In exploring Freud's notion of dream and the relationship between the unconscious and lived reality, the Surrealists were attempting to untether themselves from the confines of the habituated rational thought processes in order to release the unbridled imagination of the unconscious. In this context - unlike the conventional conceptualization of the image, where the metaphor is a purely referential "copy" or "duplicate" portraying an external reality - the creative drive of words is unbridled by stretching the components of the metaphor to a point where the 
logical resemblances are transgressed, thereby igniting the emotive power of the image. As such, the Surrealists destroy the fixed imagery of the metaphor by bringing forth the image, which becomes legible within the text while simultaneously dissolving it. This process of destruction, I argued, can aid in the understanding of politics. For, as Benjamin argues, "nowhere do these two - metaphor and image - collide so drastically and so irreconcilably as in politics" (W. Benjamin 2005d, 217).

Within the conventional metaphor, images are instrumentalized to designate something else other than their immediate and temporal signification. Thus, in the metaphorical political language of liberal and/or social democracy, images become means to a fixed and predetermined end(s), losing their temporal and immediate mediacy, thereby turning into a stock of imagery, whose boundaries are carefully and strictly marked by practical language and existing reality. It is precisely here where the power of Benjamin's critique, of the collision of the metaphor and the image, resides. For, with the loss of the immediate mediacy of the image(s), the historically posited politics of meansends arises, whose mediacy is masked by metaphorical political language, and as such, serve to maintain the ways of life imbued with the positive forms of law. As the immediate mediacy of the image is sacrificed at the alter of the moral and/or political program of liberal and/or social democratic politics, the resulting political imaginaries are nothing more than optimistic images of a future; professing the "liberal moral-humanistic ideal of freedom" (W. Benjamin 2005d, 215) or, the social democratic conception of a future where "everyone lives 'as if they were free" (W. Benjamin 2005d, 216). The outcome of this, then, is the "reconciliation" [Verständigung] "between classes, between nations, [and] between individuals" (W. Benjamin 2005d, 217), which only serves to 
perpetuate the continuum, the homogeneous, empty time" (W. Benjamin 2006d, 395) of the history of the victors.

The effectiveness and efficiency of liberal and/or social democratic politics however, does not only derive from the use of metaphors where images become the bearers of liberal and/or social democratic values, which claim to be eternal, universal and timeless; yet are reflective of political imaginaries bound by the established order of meanings, and therefore, delimited by the order of posited norms. Rather, and more importantly perhaps, the materialization of these images in "space, objects and practices" (Wohlfarth 1996, 199) generates an immediate perceptible presence - that is, the phantasmagoric character of reality - in the capitalist everyday. Thus, arises the "dream agora," which constitutes the space of commonality, collectivity, and totality in a world of individualized, alienated, and isolated individuals - where the collective desires, wishes, and feelings are bound to the order of posited norms.

This "dream agora" along with the "dream houses" render the relation of the capitalist social relations of production to liberal politics imperceptible by the senses while making the phantasmagoric reality of commonality, collectivity, and totality perceptible. It is precisely this politics - within which metaphorical political language intertwines with the immediate perceptible presence of images - that I identify as "kitsch politics." In kitsch politics, the phantasmagoric reality doubles through the interaction of the first- and second-order phantasmagorias. Here collective desires, wishes, and feelings (e.g., equality, freedom, security, human rights, etc.) are acted out through the sensory consumption of images, thereby giving rise to a sense of collectivity, commonality, and wholeness, and thus, rendering it possible for the individual(s) to feel at home, 
comfortable and comforted while simultaneously making the relationship between the capitalist mode of production and liberal and/or social democratic politics imperceptible to the senses.

In this constellation, the assembly of things creates the phantasmagoria of tradition, which gives rise to a sense of continuity in a world of discontinuity and fragmentation through the appropriation and assimilation of the various components of tradition by the commodity form, and the material graphicness of liberal and/or social democratic metaphors. Here, the "dream agora" and "dream houses" transform the arrangement and operation of the public sphere by manifesting the conditions of kitsch perception. Consequently, as the distance (which makes the perception of difference and commonality possible) is dissolved through the material presence and closeness of things as commodities (which promise happiness and prosperity to the masses) as well as the immediate perceptible presence of the images in which the metaphors of liberal politics are materialized, Arendt's allegorical table is also dissolved. This signals the rearrangement of the public sphere on the basis of sameness rather than human distinctiveness.

Yet, this sameness operates as a "highly considerate mirror" (Broch 1969a, 49) in which the image of the individual is reflected as part of a collective. In this collective however - organized on the basis of individuality and functioning on the basis of ever increasing alienating division of labour - lived, immediate, and in turn, quickly forgotten experience [Erlebnis] has replaced experience [Erfahrung]. But more importantly perhaps, through this rearrangement of the public sphere, the modus operandi shifts from "whoness" to "whatness" of being - that is: fixed, static and exclusionary identities, 
identities that provide a sense of belonging through the demonization of the other(s). Thus, identities become the sensuous mediums of social relations while simultaneously being the non-sensuous expressions of a social relation - the commodity form. In other words, just like commodities, identities become the mediums onto which human desires, wishes, and feelings are transposed, creating a sense of collectivity and totality. These manufactured identities however - constructed by "othering," yet, simultaneously venerating the ideal of humanity and human rights - that are to be worn as a mask in the public sphere, permeate through the body and soon, become a part of the human physiognomy. This is the unavoidable outcome of kitsch politics.

Kitsch politics then, is the expression of capitalism, for "[c]apitalism was a natural phenomenon with which a new dream-filled sleep came over Europe, and, through it, a reactivation of mythical forces" (W. Benjamin 2002d, 391, K1a,8). Therefore, if the collective "preserve this unconscious, amorphous dream configuration, [...] they stand in the cycle of the eternally selfsame" (W. Benjamin 2002d, 389-390, $\mathrm{K} 1,5)$. Yet, every sleep is followed by a waking hour. As the sur-real world of fetishized images arose to replace tradition, the explanation of dreams was replaced with distraction. Yet, despite the elimination "all bodily and natural aids to remembrance" (W. Benjamin 2002d, 388, K1,1) this distraction also paved a path for a new mode of remembering. In this configuration, the act of remembrance is no longer about the gaze from the present into the past; rather, the gaze of the past at the present, thereby establishing a "relation of immediacy to the material of the social" (Weigel 1996, 3), which allows for a re-reading of the material. In and through this re-reading, Benjamin re-configures "the political" in relation to the image. 
Benjamin's alternative politics is based in the "organization of pessimism" against the optimistic metaphorical political language, which intertwines with the immediate perceptible presence of images - that is, kitsch politics. According to Benjamin, the organization of pessimism will prompt us "to discover in the space of political action the one hundred percent image space [Bildraum]" (W. Benjamin 2005d, 217), which originates in the "distinction between metaphor and image" (W. Benjamin 2005d, 217). In this configuration, the image reflects a different modality of thought, one that is based on simultaneity and constellation rather than continuity, similarity rather than representation, fragment rather than the whole (Weigel 1996). As such, the image is a constellation of the "what-has-been" [das Gewesene $]$ and the "now" which "come together in a flash" (W. Benjamin 2002d, 462, N2a,3). This sudden, evanescent - flashlike - coming together of the image at the intersection of "what-has-been" [das Gewesene] and the "now" also reflects the nature of cognition, which is bound to the 'now of a particular recognizibility' (W. Benjamin 2002d, 463, N3,1). In this context, Benjamin criticizes the progressive notion of history and chronological time. For, the truly historical concept of history cannot be based on a linear, successive time, but, on a non-linear time.

In contra-distinction to linear time and progressive history, Benjamin "understands the construction of history as work in and with the images of recollection and which founds the [re]cognizibility of the past in a model of memory" (Weigel 1996, 13). In this configuration, the 'now-time' [Jetztzeit] overleaps the continuum of history by invoking image(s) from the archive of historical memory, thereby blasting out of the continuum of history. This has some important implications for the future of alternative 
politics. For, only if history is understood as a disruptive constellation of the past and the present, can historical cognition reflect the not yet actualized possibilities of that "which has not yet become history, that which yet can become history" (Benjamin qt. in Hamacher 2005, 39). In other words, the possibilities of the past that have not yet been fulfilled continue to have "an effect as intentions and demand their realization from those who feel addressed by them" (Hamacher 2005, 41). Thus, 'now-time' [Jetztzeit] embodies the dimension of the possible that claims to be actualized. In this configuration, the possible does not consist of abstract categories, conditions, objects and actions; its fulfillment therefore does not address a specific constituted subject.

In this configuration, Benjamin articulates alternative politics through three new conceptualizations: a) profane illumination [profane Erleuchtung], b) "image-space" [Bildraum], and c) "body-space" [Leibraum]. These conceptualizations relate cognition to revolutionary experience by overcoming the dualistic oppositions between the form and content, philosophy and literature, politics and art, theory and practice, sobriety and ecstasy, individuality and collectivity, corporeal immediacy and figurative representation. In order to do so, finding inspiration in Surrealism, Benjamin develops a dialectical concept of intoxication through which the "political materialism and physical creatureliness" (W. Benjamin 2005d, 217) would dialectically interpenetrate each other. Thus, profane illumination reflects a type of materialist epiphany or a sudden inspiration, in and through which a historical view of the past is substituted by a political one (W. Benjamin 2005d), thereby blurring the distinction between reality and sur-reality, individuality and collectivity, ecstasy and sobriety, sleeping and awakening. 
The experience of profane illumination therefore suspends the kitsch condition by rendering synaesthetic experience possible, thereby disrupting the order of meanings through tearing apart the bubble of the 'private.' In this configuration, the spontaneity, unpredictability, explosiveness, and shocking force of the profane illumination ushers in the image-space of politics (W. Benjamin 2005d). Arising within and through political action, this image-space resides outside of the preceding political imaginary of the collective subjectivity. For, alternative politics is spontaneous, and thus, indeterminate.

The "organization of pessimism" (W. Benjamin 2005d, 216) - as a counterdistinction to "poetic politics" (W. Benjamin 2005d, 216) - therefore engenders the freeing of political action from all forms of political belief, dogma and/or ideology that restricts (political) action and imagination. For, since the image-space of politics is devoid of any moral and trans-historical meaning, it is embodied only in political action itself. And as subject and image collide "the subject [...] enter[s] into this image-space by becoming part of it, literally with his body" (Weigel 1996, 16). This is where the imagespace and body-space interpenetrate - a process in which "the inner experience is turned inside out" (Khatib 2014, 6) - thereby disrupting the duality between closeness and distance - i.e., the duality of kitsch perception and auratic perception. To put it differently, the body-space "is produced in an image-space which in turn refers to the corporeal materiality of the collective as its matrix" (Weigel 1996, 16).

Only in this matrix can the alarm-clock strike the 'now-time' [Jetztzeit], effectively suspending the continuous, measured, progressive time - manifesting the revolutionary discharge, where the "emergency break" (W. Benjamin 2006d, 402) is pulled, thereby actualizing the missed possibilities of the past. The outcomes of this 
revolutionary discharge are unknown and indeterminate; yet, two generalizable outcomes could be expected. First, revolutionary discharge could lead to a overstretching of kitsch politics' ability to contain, maintain, and reproduce itself, and its associated form of surreality, and in turn, could pave a way to a new alignment of technology and humanity in which the capitalist exploitative relations are overcome, and a new configuration between nature and man emerges. Second, despite the pulling of the "emergency break" (W. Benjamin 2006d, 402), the 'abstract-real' - 'real-abstract' reality of the sur-real world, kitsch perception, and kitsch politics could restore themselves while producing an image of the revolutionary discharge in accordance with, and within the bounds of, the order of posited norms and meanings, integrating the image of this revolutionary discharge into kitsch politics, and the progression of time. 


\section{Bibliography:}

Ackerman, James S. 1962. "A Theory of Style." The Journal of Aesthetics and Art Criticism 20 (3): 227-37.

Adorno, Theodor, and Max Horkheimer. 2002. Dialectic of Enlightenment: Philosophical Fragments. Edited by Gunzelin Schmid Noerr. Translated by Edmund Jephcott. California: Standford University Press.

Adorno, Theodor W. 1941. "On Popular Music." Studies in Philosophy and Social Sciences 9: 17-48.

- 1997. Aesthetic Theory. Edited by Rolf Tiedemann and Gretel Adorno. Translated by Robert Hullot-Kentor. London: Continuum.

—. 2001. The Culture Industry: Selected Essays on Mass Culture. Edited by J. M. Bernstein. Second. London: Routledge Classics.

Adorno, Theodor W., and Max Horkheimer. 2002a. "The Concept of Enlightenment: Philosophical Fragments." In Dialectic of Enlightenment, edited by Gunzelin Schmid Noerr, translated by Edmund Jephcott, 1-34. Stanford: Standford University Press.

_ 2002b. The Culture Industry: Enlightenment as Mass Deception. Edited by Gunzelin Schmid Noerr. Translated by Edmund Jephcott. Dialectic of

Enlightenment: Philosophical Fragments. Stanford: Standford University Press.

Agamben, Giorgio. 1993. "Infancy and History: An Essay on the Destruction of Experience." In Infancy and History: The Destruction of Experience, translated by Liz Heron, 11-65. London: Verso.

Arendt, Hannah. 1993. "The Crisis in Culture: Its Social and Its Political Significance." In Between Past and Future: Eight Exercises in Political Thought, 197-227. New York: Penguin Books.

. 1998. The Human Condition. Chicago: The University of chicago Press.

Aristotle. 1898. The Poetics of Aristotle. Translated by S. H. Butcher. London: MacMillan and Co., Limited.

Augustine, St. 1997. On Christian Doctrine. Translated by D. W. Jr. Robertson. New Jersey: Pearson Education.

Baudrillard, Jean. 1993. Symbolic Exchange and Death. Translated by Iain Hamilton Grant. London: SAGE Publications Ltd.

- 1994. Simulacra and Simulation. Translated by Shelia Faria Glaser. Michigan: University of Michigan Press.

Benjamin, Andrew. 1991. "Tradition and Experience: Walter Benjamin 'S 'On Some Motifs in Baudelaire."” In The Problems of Modernity: Adorno and Benjamin, edited by Andrew Benjamin, 122-40. London: Routledge.

Benjamin, Walter. 1968. Illuminations: Walter Benjamin Essays and Reflections. Edited by Hannah Arendt. Translated by Harry Zohn. New York: Schocken Books. . 1977. Gesammelte Schriften II. Edited by Rolf Tiedemann and Hermann Schweppenhäuser. Frankfurt: Suhrkamp.

- 1996. Walter Benjamin: Selected Writings, Volume 1:1913-1926. Edited by Marcus Bullock and Micheal W. Jennings. Cambridge: The Belknap Press of Harvard University Press.

- 1998. The Origin of German Tragic Drama. Translated by John Osborne. 
London: Verso.

—. 2002a. "Convolutes." In The Arcades Project, edited by Rolf Tiedemann, translated by Kevin Eiland, Howard, and McLaughlin. Cambridge: The Belknap Press of Harvard University Press.

_ 2002b. "Paris, Capital of the Nineteenth Century [Expose of 1939]." In The Arcades Project, translated by Howard Eiland and Kevin McLaughlin, 14-27.

Cambridge: The Belknap Press of Harvard University Press.

- 2002c. "Paris, the Capital of the Nineteenth Century [Expose of 1935]." In The Arcades Project, edited by Rolf Tiedemann, translated by Howard Eiland and Kevin McLaughlin, 3-14. Cambridge: The Belknap Press of Harvard University Press. - 2002d. The Arcades Project. Translated by Howard Eiland and Kevin McLaughlin. Cambridge: The Belknap Press of Harvard University Press.

- 2002e. "The Work of Art in the Age of Its Technological Reproducibility." In Walter Benjamin: Selected Writings, Volume 3, 1935-1938, translated by and others Jephcott, E., Eiland, H. Cambridge: Harvard University Press.

- 2005a. "Doctrine of the Similar." In Walter Benjamin: Selected Writings, Volume 2, Part 2, 1931-1934, edited by Michael W. Jennings, Howard Eiland, and Gary Smith, translated by Michael W. Jennings, 694-98. Cambridge: The Belknap Press of Harvard University Press.

_. 2005b. "Experience and Poverty." In Walter Benjamin: Selected Writings, Volume 2, Part 2: 1931-1934, edited by Michael W. Jennings, Gary Smith, and Howard Eiland, translated by Rodney Livingstone, 731-36. New York: The Belknap Press of Harvard University Press.

-2005c. On the Mimetic Faculty. Edited by Michael W. Jennings, Howard Eiland, and Gary Smith. Translated by Edmund Jephcott. Walter Benjamin: Selected Writings, Volume 2, Part 2, 1931-1934. Cambridge: The Belknap Press of Harvard University Press.

_. 2005d. Walter Benjamin: Selected Writings, Volume 2, Part 1: 1927-1930. Edited by Michael W. Jennings, Howard Eiland, and Gary Smith. Translated by Rodney Livingstone and Others. Cambridge: The Belknap Press of Harvard University Press.

- 2005e. Walter Benjamin: Selected Writings, Volume 2, Part 2, 1931-1934. Edited by Michael W. Jennings, Howard Eiland, and Gary Smith. Translated by Rodney Livingstone. Cambridge: The Belknap Press of Harvard University Press.

—. 2006a. "On Some Motifs in Baudelaire." In Walter Benjamin: Selected Writings, Volume 4, 1938-1940, edited by Howard Eiland and Michael W. Jennings, translated by Harry Zohn, 313-54. Cambridge: The Belknap Press of Harvard University Press.

— 2006b. "Problems in the Sociology of Language." In Walter Benjamin: Selected Writings, Volume 3, 1935-1938, edited by Michael W. Jennings and Howard Eiland, translated by Edmund jephcott, 68-93. Cambridge: The Belknap Press of Harvard University Press.

-2006c. Walter Benjamin: Selected Writings, Volume 3: 1935-1938. Edited by Howard Eiland and Michael W. Jennings. Translated by Edmund Jephcott, Howard Eiland, and Others. Cambridge: The Belknap Press of Harvard University Press. .2006d. Walter Benjamin: Selected Writings, Volume 4: 1938-1940. Edited by 
Howard Eiland and Michael W. Jennings. Translated by Edmund Jephcott and Others. Cambridge: The Belknap Press of Harvard University Press.

- 2007. "The Author as Producer." In Reflections: Essays, Aphorisms,

Autobiographical Writings, edited by Peter Demetz, translated by Edmund Jephcott, 220-39. New York: Schocken Books.

- 2011. Walter Benjamin: Early Writings 1910-1917. Translated by Howard et.

all. Eiland. London: The Belknap Press of Harvard University Press.

Bohn, Williard. 2002. The Rise of Surrealism: Cubism, Dada and the Pursuit of the Marvelous. New York: State University of New York Press.

Brecht, Bertolt. 2007. “Against Georg Lukács.” In Aesthetics and Politics, 68-86. New York: Verso.

Breton, André. 1969. Manifestoes of Surrealism. Translated by Richard Seaver and Helen R. Lane. Michigan: The University of Michigan Press.

Broch, Hermann. 1969a. "Kitsch and 'Art-with-a-Message."” In Kitsch: An Anthology of Bad Taste, 68-76. London: Studio Vista.

- 1969b. "Notes on the Problem of Kitsch." In Kitsch: An Anthology of Bad Taste, 49-77. London: Studio Vista.

- 2002. "Evil in the Value-System of Art." In Geist and Zeitgeist: The Spirit in an Unspirited Age, edited by John Hargraves, 3-65. New York: Counterpoint.

Buck-Morss, Susan. 1991. The Dialectics of Seeing: Walter Benjamin and the Arcades Project. Cambridge: The MIT Press.

- 1992. "Aesthetics and Anasthetics: Walter Benjamin's Artwork Essay Reconsidered." October 62: 3-41.

—. 1995. "The City as Dreamworld and Catastrophe." October 73 (Summer): 3-26.

Calinescu, Matei. 1987. Five Faces of Modernity: Modernism, Avant-Garde, Decadence, Kitsch, Postmodernism. Durham: Duke University Press.

Castle, Terry. 1988. "Phantasmagoria: Spectral Technology and the Metaphorics of Modern Reverie." Critical Inquiry 15 (1): 26-61.

Caygill, Howard. 1998. Walter Benjamin: The Colour of Experience. New York: Routledge.

_. 2004. "Walter Benjamin's Concept of Cultural History." In The Cambridge Companion to Walter Benjamin, edited by David S. Ferris, 73-96. Cambridge: The Cambridge University Press.

- 2005. "Non-Messianic Political Theology in Benjamin's 'On the Concept of History." In Walter Benjamin and History, edited by Andrew Benjamin, 215-26. London: Continuum.

Ćelebonović, Aleksa. 1969. "Notes on Traditional Kitsch." In Kitsch: An Anthology of Bad Taste, 280-91. London: Studio Vista.

Cohen, Margaret. 2006. “Benjamin's Phantasmagoria: The Arcades Project.” In The Cambridge Companion to Walter Benjamin, edited by David S. Ferris, 199-220. Cambridge: Cambridge University Press.

Coleman, Roy. 2005. "Surveillance in the City: Primary Definition and Urban Spatial Order." Crime, Media, Culture 1 (2): 131-48.

Connerton, Paul. 1974. "The Collective Historical Subject: Reflections on Lukács' History and Class Consciousness." The British Journal of Sociology 25 (2).

Coplan, Amy, and Peter Goldie, eds. 2011. "Introduction.” In Empathy: Philosophical 
and Psychological Perspectives, ix - xlvii. Oxford: Oxford University Press.

Debord, Guy. 2005. Society of the Spectacle. Translated by Ken Knabb. London: Rebel Press.

Diaconu, Mădălina. 2010. “Enjoyment.” In The Handbook of Phenomenological Aesthetics, edited by Lester Sepp, Hans Rainer \& Embree, 99-105. New York: Springer.

Doane, Mary A. 1985. “The Moving Image.” Wide Angle 7 (1\&2): 42-57.

Donzelot, Jacques. 1979. The Policing of the Families. New York: Pantheon Books. - 1991. "The Mobilization of Society." In The Foucault Effect: Studies in Governmentality, edited by Graham Burchell, Colin Gordon, and Peter Miller, 16980. Chicago: University of Chicago Press.

Dorfles, Gillo. 1969. "Kitsch.” In Kitsch: An Anthology of Bad Taste, 13-37. London: Studio Vista.

Eco, Umberto. 1989. “The Structure of Bad Taste." In The Open Work, translated by Anna Cancogni, 180-116. Cambridge: The Hardvard University Press.

Eisenberg, Nancy, and Janet Strayer. 1987. Empathy and Its Development. Cambridge: Cambridge University Press.

Foucault, Michel. 1988. Madness and Civilization: A History of Insanity in the Age of Reason. Translated by Richard Howard. New York: Vintage Books.

- 1995. Discipline and Punish: The Birth of Prison. Translated by Alan Sheridan. New York: Vintage Books.

- 2008. The Birth of Biopolitics: Lectures at the Collegè de France 1978-1979. Edited by Michel Senellart. Translated by Graham Burchell. New York: Palgrave MacMillan.

Freud, Sigmund. 1961. Beyond the Pleasure Priniple. Translated by James Strachey. New York: W. W. Norton \& Company.

- 2010. The Interpretation of Dreams. Translated by James Strachey. New York: Basic Books.

Friedländer, Saul. 1984. Reflections of Nazisim: An Essay on Kitsch and Death. Translated by Thomas Wyer. New York: Harper and Row Publishers.

- 1990. "Preface to Symposium: Kitsch and the Apocalyptic Imagination." Salmagundi: Quarterly of the Humanities and Social Sciences 85-86: 201-6.

Gasset, Ortega y. 1994. The Revolt of the Masses. New York: W. W. Norton \& Company. Germain, Gil. 2009. Spirits in the Material World: The Challenge of Technology. New York: Lexington Books.

Gibbs, Robert. 2005. "Messianic Epistemology: Thesis XV." In Walter Benjamin and History, edited by Andrew Benjamin, 197-214. London: Continuum.

Giesz, Ludwig. 1969. "Kitsch-Man as Tourist." In Kitsch: An Anthology of Bad Taste, 156-75. London: Studio Vista.

Greenberg, Clement. 1961. "Avant-Garde and Kitsch.” In Art and Culture: Critical Essays, 3-22. Boston: Beacon Press.

Gumpert, Matthew. 1999. "Venus de Kitsch: Or, The Passion of the Venus de Milo." Criticism 41 (2): 155-85.

Gunning, Tom. 2003. “The Exterior as Interieur: Benjamin's Optical Detective.” Boundary 230 (1): 105-30.

Habermas, Jurgen. 1988. "Walter Benjamin: Conscious-Raising or Rescuing Critique.” In 
On Walter Benjamin: Critical Essays and Reflections, edited by Gary Smith, 90129. Cambridge: The MIT Press.

- 1990. Moral Consciousness and Communicative Action. Translated by Christian Lenhardt and Shierry Weber Nicholsen. Cambridge: The MIT Press.

- 1991. The Structural Transformation of the Public Sphere. Translated by Thomas Burger. Cambridge: The MIT Press.

Hamacher, Werner. 1994. "Afformative, Strike: Benjamin's 'Critique of Violence.” In Walter Benjamin's Philosophy: Destruction and Experience, edited by Andrew Benjamin and Peter Osborne, translated by Dana Hollander, 110-38. New York: Routledge.

- 2005. "Now': Walter Benjamin on Historical Time." In Walter Benjamin and History, edited by Andrew Benjamin, 38-68. New York: Continuum.

Hansen, Mirriam Bratu. 1987. "Benjamin, Cinema and Experience: 'The Blue Flower in the Land of Technology." "New German Critique 40 (Special Issue on Wiemer Film Theory): 179-224.

— 1993. "Foreward." In Public Sphere and Experience: Toward an Analysis of the Bourgeois and Proletarian Public Sphere, translated by Peter Labanyi, Jamie Owen Daniel, and Assenka Oksiloff, ix - xlii. Minneapolis: University of Minnesota Press.

_ 1999. "Benjamin and Cinema: Not a One-Way Street." Critical Inquiry 25 (2): $306-43$.

-2012. Cinema and Experience: Siegfried Kracauer, Walter Benjamin and Theodor W. Adorno. Berkeley: University of California Press.

Hanssen, Beatrice. 2004. "Language and Mimesis in Walter Benjamin's Work." In The Cambridge Companion to Walter Benjamin, 54-72. Cambridge: Cambridge University Press.

—. 2006. "Introduction: Physiognomy of a Flâneur: Walter Benjamin's Peregrinations Through Paris in Search of a New Imaginary." In Walter Benjamin and the Arcades Project, edited by Beatrice Hanssen, 1-11. New York: Continuum. Harvey, David. 2008. "The Right to the City." New Left Review 53: 23-40.

- 2010. A Companion to Marx's Capital. London: Verso.

Heidegger, Martin. 1991. Nietzsche, Volumes One and Two. Translated by David Farrell Krell. New York.

- 2001. "The Origin of the Work of Art." In Poetry, Language, Thought, translated by Albert Hofstadter, Perennial, 15-87. New York: Harper Perennial Modern Classics.

Hillach, Ansgar. 1979. "The Aesthetics of Politics: Walter Benjamin's 'Theories of German Fascism." Translated by Jerold Wikoff and Ulf Zimmerman. New German Critique Special Wa (17): 99-119.

Horkheimer, Max. 1982. "Art and Mass Culture." In Critical Theory: Selected Essays Max Horkheimer, translated by M. J. and others O'Connell, 273-90. New York: Continuum.

Hull, Margaret Betz. 2002. The Hidden Philosophy of Hannah Arendt. London: Routledge.

Jameson, Fredric. 1979. "Reification and Utopia in Mass Culture." Social Text Winter (1): 130-48.

Jameson, Friedrich. 2007. Signatures of the Visible. New York: Routledge Classics. 
Jay, Martin. 1986. "Georg Lukács and the Origins of the Western Marxist Paradigm." In Marxism and Totality: The Adventures of a Concept from Lukács to Habermas, 81128. Los Angeles: University of California Press.

— 1992. “'The Aesthetic Ideology' as Ideology: Or, What Does It Mean to Aestheticize Politics?" Cultural Critique 21 (Spring): 41-61.

- 2005. Songs of Experience: Modern American and European Variations on a Universal Theme. Los Angeles: University of California Press.

Kafka, Franz. 1984. "The Coming of the Messiah.” In The Basic Kafka, 182. New York: Pocket Books.

Kang, Jaeho. 2011. "The Spectacle of Modernity: Walter Benjamin and a Critique of Culture (Kulturkritik)." Constelleations 18 (1): 74-90.

. 2014. Walter Benjamin and the Media. Cambridge: Polity Press.

Khatib, Sami. 2013a. "Fantasy, Phantasmagoria, and Image-Space. Walter Benjamin's Politics of Pure Means." In Die Politik Des Phantasmas. Vol. 5. Berlin.

- 2013b. "The Messianic Without Messianism: Walter Benjamin's Materialist Theology." Anthropology \& Materialism 1: 2-15.

- 2014. "'To Win the Energies of Intoxication for the Revolution': Body Politics, Community, and Profane Illumination." Anthropology \& Materialism 2: 2-11.

- 2015. “'Action Puts Forth Its Own Image': Notes on Walter Benjamin's Essay on Surrealism." In Zürcher Hochschule Der Künste (ZHdK). Zurich.

Koepnick, Lutz Peter. 1999. Walter Benjamin and the Aesthetics of Power. London: University of Nebraska Press.

Kulka, Tomas. 1996. Kitsch and Art. Pennsylvania: The Pennsylvania State University. Kundera, Milan. 1988. The Art of Novel. Translated by Linda Asher. New York: Grove Press.

- 1999. The Unbearable Lightness of Being. Translated by Michael Henry Heim. New York: Harper Perennial Modern Classics.

Lindroos, Kia. 1998. Now-Time/Image-Space: Temporalization of Politics in Walter Benjamin's Philosophy of History and Art. Jyvāskylā: SoPhi: University of Jyvāskylā.

- 2001. "Scattering Community: Benjamin on Experience, Narrative and History." Philosophy and Social Criticism 27 (6): 19-41.

Lukács, Georg. 1971a. "Reification and the Consciousness of the Proleteriat." In History and Class Consciousness: Studies in Marxist Dialectics, translated by Rodney Livingstone, 83-223. Cambridge: The Mit Press.

-1971b. The Theory of the Novel. Translated by Anna Bostock. Cambridge: The MIT Press.

Macdonald, Dwight. 1957. “A Theory of Mass Culture.” In Mass Culture: The Popular Arts in America, edited by Bernard Rosenberg and David Manning White, 59-74. New York: The Free Press.

_. 1983. "Masscult and Midcult." In Against the American Grain, 3-76. New Tork: Da Capo Press.

Markus, Gyorgy. 2001. "Walter Benjamin or: The Commodity as Phantasmagoria." New German Critique 83: 3-42.

_ 2007. "Walter Benjamin and the German 'Reproduction Debate." In Moderne Begreifen: Zur Paradoxie Eines Sozio-äesthetischen Deutungsmusters, edited by 
Christine Magerski, Robert Savage, and Christiane Weller, 351-64. Weisbaden: Deutscher Universtäts-Verlag.

- 2011. Culture, Science, Society: The Constitution of Cultural Modernity.

Culture, Science, Society: The Constitution of Cultural Modernity. Boston: Brill.

Martin, Stewart. 2007. "The Absolute Artwork Meets the Absolute Commodity." Radical Philosophy November/D: 15-25.

Marx, Karl. 1887. Capital Volume 1. Edited by Friedrich Engels. Translated by Samuel Moore and Edward Aveling. Moscow: Progress Publishers.

- 1967. Capital: A Critique of Political Economy. Edited by Friedrich Engels. Vol. I. New York: International Publishers.

- 1977. Karl Marx: Selected Writings. Edited by David McLellan. Oxford: Oxford University Press.

Marx, Karl, and Friedrich Engels. 1998a. The Communist Manifesto. Edited by David McLellan. New York: The Oxford University Press.

. 1998b. The German Ideology. New York: Prometheus Books.

McMullan, John L. 1998. "Social Surveillance and the Rise of the "Police Machine."," Theoretical Criminology 2 (1): 93-117.

Menninghaus, Winfried. 2009. 'On the 'Vital Significance' of Kitsch: Walter Benjamin's Politics of Bad Taste." In Walter Benjamin and the Architecture of Modernity, edited by Charles Benjamin, Andrew, and Rice, 39-57. Melbourne.

Miller, Peter, and Nikolas Rose. 2008. Governing the Present: Administering Economic, Social and Personal Life. Cambridge: Polity Press.

Mitchell, W. J. T. 1986. Iconology: Image, Text, Ideology. Chicago: University of Chicago Press.

Montgomery, Scott. 1991. "Science as Kitsch: The Dinasour and the Other Icons." Science as Culture 2 (1): 7-58.

Neocleous, Mark. 2007. "Security, Commodity, Fetishism.” Critique: Journal of Socialist Theory 35 (3): 339-55.

- 2011. "The Police of Civilization: The War on Terror as Civilizing Offensive." Political Sociology 5: 144-59.

_. 2013a. "Air Power as Police Power." Environment and Planning D: Society and Space 31 (4): 578-93.

. 2013b. "Police Power, All the Way to Heaven:Cujus Est Solum and the No-Fly Zone.” Radical Philosophy 182 (November/December): 5-14.

O’Malley, Pat. 1996. "Post-Keynesian Policing." Economy and Society 25 (2): 137-55.

Olalquiaga, Celeste. 2002. The Artificial Kingdom: On the Kitsch Experience. Minnesota: University of Minnesota Press.

Osborne, Thomas. 1996. "Security and Vitality: Drains, Liberalism and Power in the Nineteenth Century." In Foucault and Political Reason: Liberalism, Neo-Liberalism and Rationalities of Governments, edited by Andrew Barry, Thomas Osborne, and Nikolas Rose, 99-122. London: The Uniiversity of Chicago Press.

Pasquino, Pasquale. 1991. "Theatrum Politicum: The Genelogy of Capital - Police and the State Prosperity." In The Foucault Effect: Studies in Governmentality, edited by Graham Burchell, Colin Gordon, and Peter Miller, 105-18. Chicago: University of Chicago Press.

Peck, James, and Adam Tickell. 2002. "Neoliberalizing Space.” Antipode 34 (3): 380- 
404.

Pensky, Max. 2004a. "Method and Time: Benjamin's Dialectical Images.” In Cambridge Companion to Walter Benjamin, edited by David S. Ferris, 177-98. Cambridge: The Cambridge University Press.

_. 2004b. "Method and Time: Benjamin's Dialectical Images." In The Cambridge Companion to Walter Benjamin, edited by David S. Ferris, 177-98. Cambridge: The Cambridge University Press.

Purcell, Mark. 2013. "Possible Worlds: Henri Lefebvre and the Right to the City." Journal of Urban Affairs 36 (1): 141-54.

Rattray, Jacqueline. 2001. "The Metamorphisis of Vision in the Surrealist Text: José María Hinojasa's 'Granadas de Fuego.'” In Sensual Reading: New Approaches to Reading in Its Relation to Senses, edited by Michael Syrotinski and Ian MacLachlan, 166-76. London: Buckness University Press.

Reik, Theodor. 1936. "The Distinction between Memory and Reminiscence." In Surprise and The Psycho-Analyst: On the Conjecture and Comprehension of Unconscious Processes, 126-40. London: Kegan Paul, Trench, Trubner and Co. Ltd.

Rice, Charles. 2004. "Rethinking Histories of the Inteiror." The Journal of Architecture 9 (3): 275-87.

- 2007. The Emergence of the Interior: Architecture, Modernity, Domesticity. London: Routledge.

Richards, I. A. 1965. The Philosophy of Rhetoric. New York: Oxford University Press.

Rosenberg, Harold. 1994. "Pop Culture: Kitsch Criticism." In The Tradition of the New, 259-69. New York: Da Capo Press.

Salzani, Carlo. 2008. Constellations of Reading: Walter Benjamin in Figures of Actuality. Berlin: Peter Lang AG, Internationaler Verlag der Wissenschaften.

Schmiedgen, Peter. 2009. "Interiority, Exteriority and Spatial Politics in Benjamin's Cityscapes." In Walter Benjamin and the Architecture of Modernity, edited by Andrew Benjamin and Charles Rice, 147-59. Melbourne: re.press.

Scholem, Gershom, and Theodor W. Adorno, eds. 1994. The Correspondances of Walter Benjamin: 1910-1940. Translated by Manfred R. Jacobson and Evenly M. Jacobson. Chicago: The Uniiversity of Chicago Press.

Simons, Jon. 2016. “Benjamin's Communist Idea: Aestheticized Politics, Technology, and the Rehearsal of Revolution." European Journal of Political Theory 15 (1): 4360.

Smith, Adam. 1958. The Wealth of Nations. London: Dent.

Solibakke, Karl Ivan. 2009. "The Passagen-Werk Revisited: The Dialectics of Fragmentation and Reconfiguration in Urban Modernity." In A Companion to the Works of Walter Benjamin, edited by Rolf J. Goebel, 153-76. New York: Camden House.

Spitzer, S. 1995. "Security and Control in Capitalist Societies: The Fetishism of Security and the Secret Thereof." In Crime and the Media, edited by Richard V. Ericson, 4358. Dartmouth Pub Co.

The Oxford English Dictionary. 2005. Third. Oxford: Oxford University Press. Uno, Kōzō. 1980. Principles of Political Economy: The Theory of a Purely Capitalist Society. Translated by Thomas T. Sekine. Sussex: Harvester Press.

Vandenberghe, Frédéric. 2013. "Reification: History of the Concept." Logos 12 (3). 
Vattimo, Gianni. 1988. The End of Modernity. Translated by Jon R. Snyder. Cambridge: Polity Press.

. 1992. The Transparent Society. Translated by David Webb. Cambridge: Polity Press.

Volker, Eick. 2006. "Preventive Urban Discipline: Rent-a-Cops and Neoliberal Glocalization in Germany." Social Justice 33 (1): 1-19.

Weigel, Sigrid. 1996. Body-and Image-Space: Re-Reading Walter Benjamin. Translated by Paul Georgina, Rachel McNicholl, and Jeremy Gaines. New York: Routledge.

- 2015. "The Flash of Knowledge and the Temporality of Images: Walter Benjamin's Image-Based Epistemology and Its Preconditions in Visual Arts and Media History." Translated by Chadwick Truscott Smith and Christine Kutschbach. Critical Inquiry 41 (2): 344-66.

Wind, Edgar. 1963. Art and Anarchy. London: Faber \& Faber.

Winton, Alexa Griffith. 2013. "Inhabitated Space: Critical Theories and the Domestic Interior." In The Handbook of Interior Architecture and Design, edited by Lois Weinthal and Graeme Brooker, 40-49. London: Bloomsbury Press.

Wohlfarth, Irving. 1996. "Smashing the Kaleidoscope: Walter Benjamin's Critique of Cultural History." In Walter Benjamin and the Demands of History, edited by Michael P. Steinberg, 190-205. London: Cornell University Press.

—. 2006. "Et Cetera? The Historian as Chiffonnier." In Walter Benjamin and the Arcades Project, edited by Beatrice Hanssen, 12-32. London: Continuum.

Wolin, Richard. 1982. "Benjamin's Materialist Theory of Experience." Theory and Society 11 (1): 17-42. 